Andrews University

Digital Commons @ Andrews University

\title{
An Investigation of the Knowledge and Beliefs Held by Teachers and Parents in a Parochial School System Regarding Attention- Deficit/Hyperactivity Disorder and the Variables that Predict their Knowledge
}

Kendra-Lee Yvonne Pearman

Andrews University

Follow this and additional works at: https://digitalcommons.andrews.edu/dissertations

Part of the Behavior and Behavior Mechanisms Commons, Education Commons, and the School Psychology Commons

\section{Recommended Citation}

Pearman, Kendra-Lee Yvonne, "An Investigation of the Knowledge and Beliefs Held by Teachers and Parents in a Parochial School System Regarding Attention-Deficit/Hyperactivity Disorder and the Variables that Predict their Knowledge" (2009). Dissertations. 626.

https://digitalcommons.andrews.edu/dissertations/626

https://dx.doi.org/10.32597/dissertations/626

This Dissertation is brought to you for free and open access by the Graduate Research at Digital Commons @ Andrews University. It has been accepted for inclusion in Dissertations by an authorized administrator of Digital Commons@ Andrews University. For more information, please contact repository@andrews.edu. 


\begin{abstract}
AN INVESTIGATION OF THE KNOWLEDGE AND BELIEFS HELD BY TEACHERS AND PARENTS IN A PAROCHIAL SCHOOL SYSTEM REGARDING ATTENTION-DEFICIT/HYPERACTIVITY DISORDER AND THE VARIABLES THAT PREDICT THEIR KNOWLEDGE
\end{abstract}

by

Kendra-Lee Yvonne Pearman

Chair: Rudolph Bailey 


\title{
ABSTRACT OF GRADUATE STUDENT RESEARCH
}

Dissertation

\author{
Andrews University \\ School of Education
}

Title: AN INVESTIGATION OF THE KNOWLEDGE AND BELIEFS HELD BY TEACHERS AND PARENTS IN A PAROCHIAL SCHOOL SYSTEM REGARDING ATTENTION-DEFICIT/HYPERACTIVITY DISORDER AND THE VARIABLES THAT PREDICT THEIR KNOWLEDGE

Name of researcher: Kendra-Lee Yvonne Pearman

Name and degree of faculty chair: Rudolph Bailey, Ph.D.

Date completed: July 2009

\section{Problem}

Attention-Deficit/Hyperactivity Disorder (ADHD) is one of the most prevalent childhood disorders affecting 3 to $5 \%$ of school populations in the United States and other countries. Due to the behavioral and/or academic challenges of children with ADHD, they are at risk for grade retention, dropping out of high school, and teenage delinquency, which can lead to negative consequences in society. Children with ADHD are found in every school setting, including parochial schools. Past studies have found teachers and parents have inadequate knowledge about ADHD, which can negatively affect these children. This 
study investigated what teachers and parents of children in a parochial school system know and believe about ADHD and what predicts their knowledge.

\section{Method}

A four-section questionnaire was compiled for this study to investigate the knowledge and beliefs of a convenience sample of 76 regular education teachers and 373 parents in a parochial school system. Questionnaires consisted of knowledge and belief statements, demographic questions, and experience with/exposure to ADHD questions. Descriptive statistics assessed knowledge and belief scores; one-way ANOVA and chisquare analyzed differences between teachers' and parents' knowledge and beliefs, and Categorical Regression investigated important contributors to knowledge of ADHD.

\section{Results}

Teachers and parents of children in a parochial school system have inadequate knowledge regarding ADHD, but they have positive beliefs in many areas of ADHD. They also believe some of the myths associated with ADHD. Demographic variables and experience with ADHD contributed to teachers' knowledge regarding ADHD, while exposure to information about ADHD possibly contributed to teachers' knowledge. Exposure to information about ADHD and experience with an ADHD variable contributed to parents' knowledge regarding ADHD. Both groups believe they would benefit from additional training and information about ADHD.

\section{Conclusion}

Teachers and parents have inadequate knowledge of ADHD. Nonetheless, they have positive beliefs in many areas, but they have negative beliefs about stimulant 
medication. Experience with ADHD and exposure to information about ADHD can increase teachers' and parents' knowledge regarding ADHD. Adequate knowledge and positive beliefs can ensure children with ADHD in a parochial school system can have a positive outlook at school, at home, and in society. 
Andrews University

School of Education

\title{
AN INVESTIGATION OF THE KNOWLEDGE AND BELIEFS HELD BY TEACHERS AND PARENTS IN A PAROCHIAL SCHOOL SYSTEM REGARDING ATTENTION-DEFICIT/HYPERACTIVITY DISORDER AND THE VARIABLES THAT PREDICT THEIR KNOWLEDGE
}

\author{
A Dissertation \\ Presented in Partial Fulfillment \\ of the Requirements for the Degree \\ Doctor of Philosophy
}

by

Kendra-Lee Yvonne Pearman

July 2009 
(C) Copyright by Kendra-Lee Yvonne Pearman 2009 All Rights Reserved 


\title{
AN INVESTIGATION OF THE KNOWLEDGE AND BELIEFS HELD BY TEACHERS AND PARENTS IN A PAROCHIAL SCHOOL SYSTEM REGARDING ATTENTION-DEFICIT/HYPERACTIVITY DISORDER AND THE VARIABLES THAT PREDICT THEIR KNOWLEDGE
}

\author{
A dissertation \\ presented in partial fulfillment \\ of the requirements for the degree \\ Doctor of Philosophy
}

by

Kendra-Lee Yvonne Pearman

APPROVAL BY THE COMMITTEE:

Chair: Rudolph Bailey

Member: Lena Caesar

Member: Ron Coffen

External: Harold Smith
Dean, School of Education

James R. Jeffery 
I dedicate this work to my three children, Mikaela Ian Pearman, Samaela Cannonier, and

Trae Cannonier; my grandson, Amari Ian Pearman Smith; and to my mother, Yvonne Pearman. The journey has been long, but the rewards are worth it. I love you all.

Trae, your diagnosis of ADHD-PI put us all on this ADHD journey, and because of you I embarked on this research project. Therefore, I especially dedicate the completion of this dissertation to you. Remember, you can be anything that you want to be. You are the wind beneath my wings. 


\section{TABLE OF CONTENTS}

LIST OF TABLES $\ldots \ldots \ldots \ldots \ldots \ldots \ldots \ldots \ldots \ldots \ldots \ldots \ldots \ldots \ldots \ldots \ldots \ldots \ldots$

ACKNOWLEDGMENTS $\ldots \ldots \ldots \ldots \ldots \ldots \ldots \ldots \ldots \ldots \ldots \ldots \ldots \ldots \ldots \ldots$

Chapter

I. INTRODUCTION $\ldots \ldots \ldots \ldots \ldots \ldots \ldots \ldots \ldots \ldots \ldots \ldots \ldots \ldots$

Background of the Problem . . . . . . . . . . . . . . . . 1

Consequences of Inadequate Knowledge Regarding ADHD . . . . . . . . 3

Consequences of Adequate Knowledge Regarding ADHD . . . . . . . . 6

Consequences of Beliefs Regarding ADHD . . . . . . . . . . . . . . . 7

Possible Solutions for Teachers and Parents . . . . . . . . . . . 9

Statement of the Problem . . . . . . . . . . . . . . . . . . . . . 10

Rationale for the Study . . . . . . . . . . . . . . . . . . . 12

Purpose of the Study . . . . . . . . . . . . . . . . . . . . . . 14

Research Questions and Hypotheses ................. 16

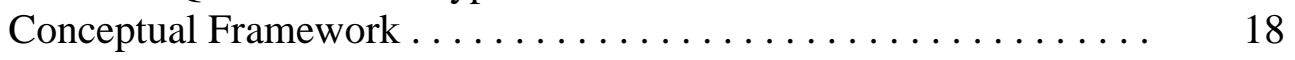

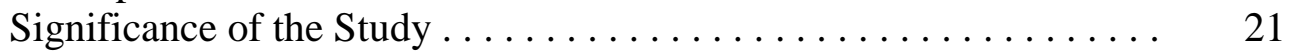

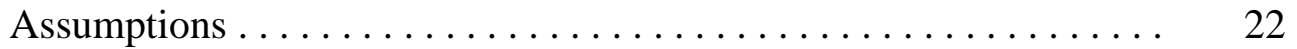

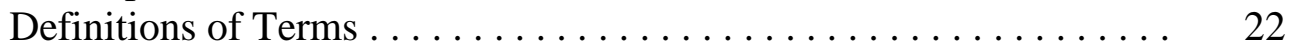

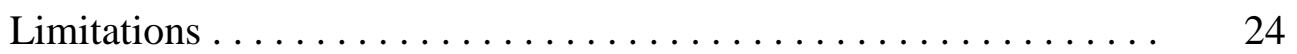

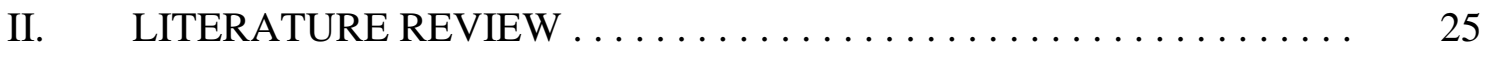

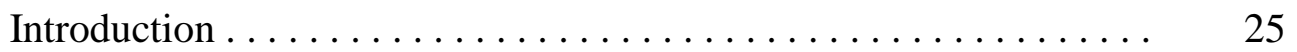

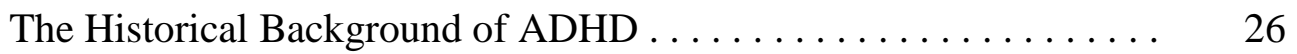

Empirical Evidence or Diagnostic Criteria Regarding ADHD . . . . . 29

Symptoms and Characteristics of ADHD . . . . . . . . . . . 29

Primary Symptoms . . . . . . . . . . . . . . . . . . . . . . . . . . 29

Inattention ........................... 30

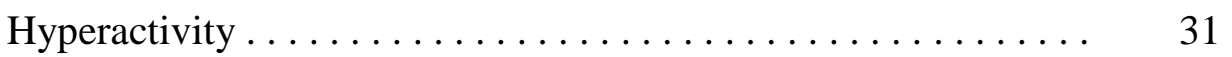

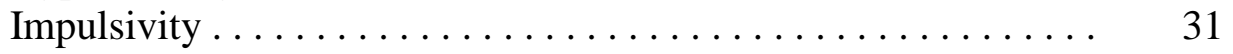

Associated Characteristics ................... 33

General Information Regarding ADHD . . . . . . . . . . . . . 34

Prevalence ............................... 34

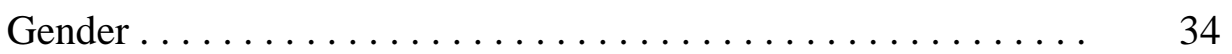

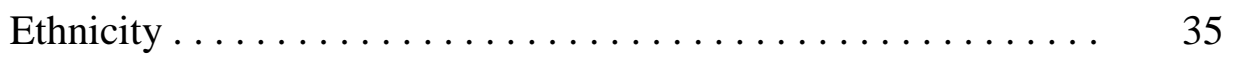

Risk for Delinquency .................... 36

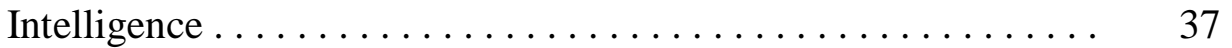




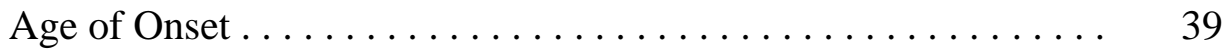

Expression ......................... 40

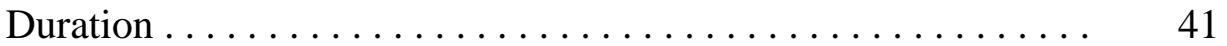

Causes of ADHD ....................... 43

Genetic or Biological Factors . . . . . . . . . . . . . . . . 44

Environmental Factors . . . . . . . . . . . . . . . . . . . . . . 49

Unsubstantiated Causes of ADHD . . . . . . . . . . . . . . 57

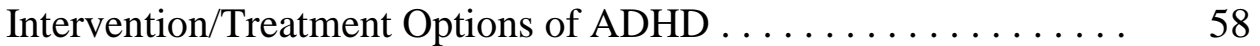

Pharmacological Treatment .................. 58

Behavioral and Educational Interventions . . . . . . . . . . 60

Combined or Multimodal Interventions . . . . . . . . . . . 62

Diet as Treatment .......................... 63

Knowledge-based Versus Belief-based Items Regarding ADHD ..... 65

Studies Conducted on Knowledge and Beliefs Regarding ADHD ..... 67

Adequacies and Inadequacies of Studies . . . . . . . . . . . . . 69

The Knowledge and Beliefs of Teachers, Parents and Others

Regarding ADHD . . . . . . . . . . . . . . . . . . . . . . 71

Symptoms and Characteristics of ADHD ............. 71

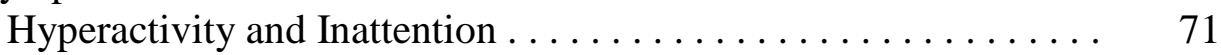

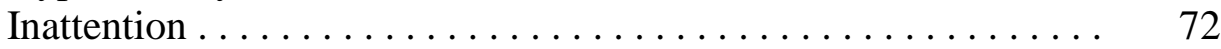

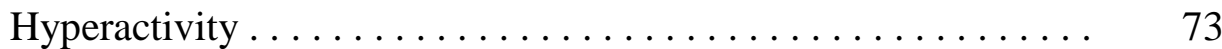

Other Possible Symptoms or Characteristics . . . . . . . . . . 74

General Information Regarding ADHD . . . . . . . . . . . . . . . 78

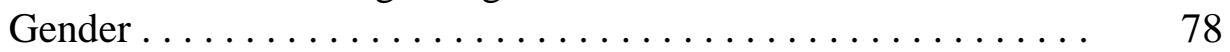

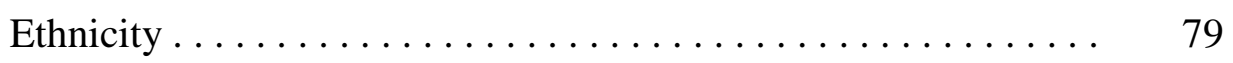

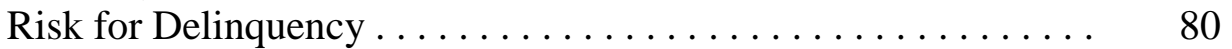

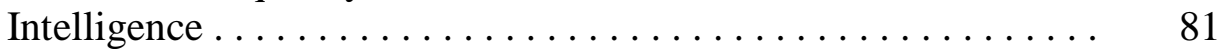

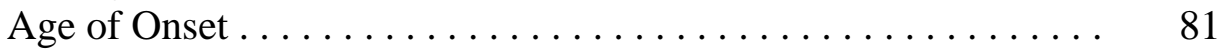

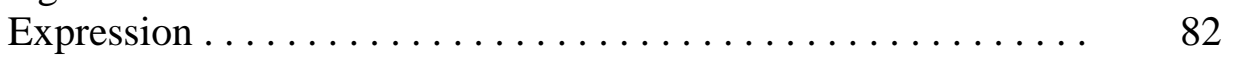

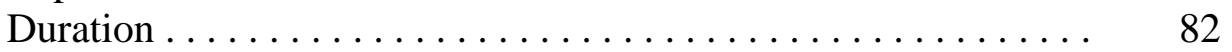

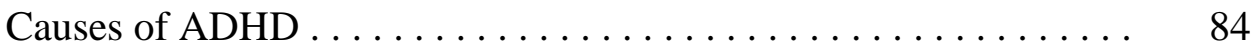

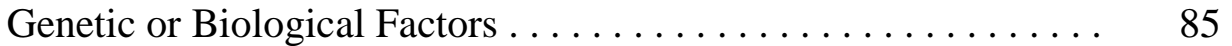

Environmental Factors . . . . . . . . . . . . . . . . . . . . . . 89

Unsubstantiated Causes of ADHD . . . . . . . . . . . . . . . 95

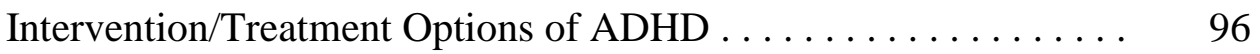

Pharmacological Treatment . . . . . . . . . . . . . . . . . 96

Educational and Behavioral Interventions . . . . . . . . . . . . 98

Combined or Multimodal Interventions . . . . . . . . . . . . . . . . 100

Diet Treatment . . . . . . . . . . . . . . . . . . . . . 102

Overall Knowledge Regarding ADHD . . . . . . . . . . . . . . . . . . 104

Recommended Knowledge Regarding ADHD for Teachers and

Parents . . . . . . . . . . . . . . . . . . . . . . . . . . . . . . 105

Knowledge Predictors of ADHD . . . . . . . . . . . . . . 108

Summary ........................... 113 


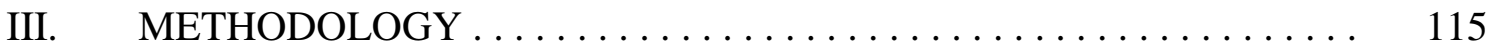

Introduction . . . . . . . . . . . . . . . . . . . . . . 115

Conference Permission . . . . . . . . . . . . . . . . . . . . . . 116

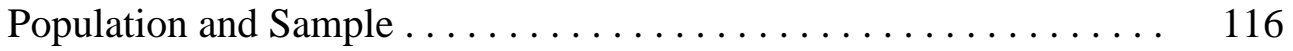

Instrumentation . . . . . . . . . . . . . . . . . . . . . . . 120

Knowledge and Belief Section: True, False, and Don't Know

Format . . . . . . . . . . . . . . . . . . . . . . . . . . . . 120

Belief Section: Likert Item Format . . . . . . . . . . . . . . . . 123

Demographic Information . . . . . . . . . . . . . . . . . 125

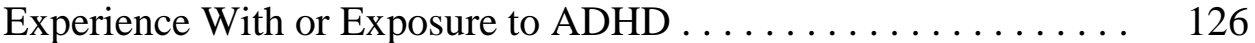

The Variables . . . . . . . . . . . . . . . . . . . . . . . . . . . . 126

Survey Format . . . . . . . . . . . . . . . . . . . . . . 138

Procedure . . . . . . . . . . . . . . . . . . . . . . . . . . 138

Preparation for Distribution of the Surveys . . . . . . . . . . . 138

Distribution of the Surveys . . . . . . . . . . . . . . . . . . . . . . . . . . 139

Return of the Surveys . . . . . . . . . . . . . . . . . . . . . . . . . . . 140

Handling of Returned Surveys . . . . . . . . . . . . . . . . . 141

Research Design ... . . . . . . . . . . . . . . . . . . 141

Research Questions, Hypotheses, Null Hypotheses and Design Analysis . . . . . . . . . . . . . . . . . . . . . . . . . . . . . . . . . 141

Data Analysis . . . . . . . . . . . . . . . . . . . . . . . . . . . . 145

Knowledge and Beliefs About ADHD Section: True, False and Don't Know . . . . . . . . . . . . . . . . . . . . . . . . . 145

Beliefs About ADHD Section: Likert Item Format . . . . . . . . . . . 146

Demographics Section . . . . . . . . . . . . . . . . . . . . 146

Experience With and Exposure to ADHD Section . . . . . . . . . . . 147

Summary . . . . . . . . . . . . . . . . . . . 151

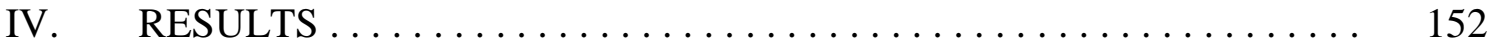

Introduction . . . . . . . . . . . . . . . . . . . . 152

Recoding of Variables . . . . . . . . . . . . . . . . . . . . 152

Item Analysis . . . . . . . . . . . . . . . . . . . . 154

Characteristics of the Sample . . . . . . . . . . . . . . . . . . . 157

Teachers' Demographic Variables . . . . . . . . . . . . . . . . . 158

Gender . . . . . . . . . . . . . . . . . . . . . . . . 158

Race ................................. 159

Conference (School District) . . . . . . . . . . . . . . . . 159

Education Level . . . . . . . . . . . . . . . . . . . . . . . . . . . . 160

Teachers' Certification . . . . . . . . . . . . . . . . . . . . 160

Grade/s Taught .......................... 160

Years of Teaching Experience . . . . . . . . . . . . . . 161

Teachers' Exposure to Information About ADHD Variables ........ 162

Articles Read About ADHD ... . . . . . . . . . . . . . . . . 162 
Books Read About ADHD . . . . . . . . . . . . . . . . . . . . 162

Videos Viewed About ADHD ..................... 163

Graduate Courses Taken Pertaining to ADHD . . . . . . . . . . . . 163

Instruction About ADHD in Teacher Training . . . . . . . . . . 164

Training About ADHD Since Beginning Teaching . . . . . . . . 165

Teachers' Experience With ADHD Variables . . . . . . . . . . . . 165

Current and Former Students With ADHD . . . . . . . . . . . . . 165

Current and Former Students Thought to Have ADHD . . . . . . . 166

Acquaintances Outside of School With ADHD . . . . . . . . . . 166

Parents' Demographic Variables . . . . . . . . . . . . . . . . . 167

Gender ............................. 167

Race................................ 167

Conference (School District) . . . . . . . . . . . . . . . . . . 168

Education Level . . . . . . . . . . . . . . . . . . . . . . . . . . . . . 168

Marital Status . . . . . . . . . . . . . . . . . . . . . . . . . . . 169

Parents' Exposure to Information About ADHD Variables . . . . . . 169

Lectures Attended About ADHD . . . . . . . . . . . . . . . . . . . . . . . 169

Articles Read About ADHD . . . . . . . . . . . . . . . . . . . . . . . 170

Books Read About ADHD . . . . . . . . . . . . . . . . . . . 170

Videos Viewed About ADHD . . . . . . . . . . . . . . . 171

Belonged to Support Group for ADHD . . . . . . . . . . . 171

Parents' Experience With ADHD Variables . . . . . . . . . . . . . . 172

Acquaintances Outside of Home with ADHD . . . . . . . . . . . . 172

Family Member Evaluated for ADHD . . . . . . . . . . . . . . . 172

Family Member Identified With ADHD . . . . . . . . . . . . 173

Family Member Treated for ADHD . . . . . . . . . . . . . . . 173

Results by Question/Null Hypothesis . . . . . . . . . . . . . . . . . 174

Analysis of Research Questions 1-4 . . . . . . . . . . . . . . . . . 174

Knowledge and Beliefs About Symptoms and Characteristics

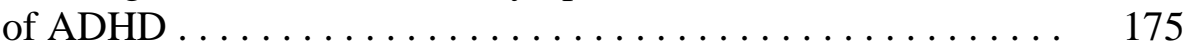

Knowledge and Beliefs About General Information Regarding

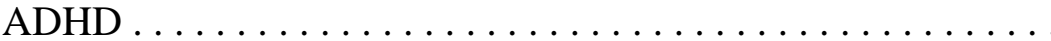

Knowledge and Beliefs About Causes of ADHD

Knowledge and Beliefs About ADHD Intervention/Treatment Options . . . . . . . . . . . . . . . . . . . . . . . . 192

Beliefs About Medication, Behavioral and Educational 208

Interventions: Likert Items . . . . . . . . . . . . . . .

Other Beliefs About ADHD Issues: Likert Items of Agreement and Disagreement ...................... 214

Analysis of Research Question 5 . . . . . . . . . . . . . . . . . . 219

Overall Knowledge of ADHD Between Teachers and Parents 220

Analysis of Research Questions 6 and 7. . . . . . . . . . . . 221

Research Question 6...................... 222

Exploratory Analysis . . . . . . . . . . . . . . . . . . 224

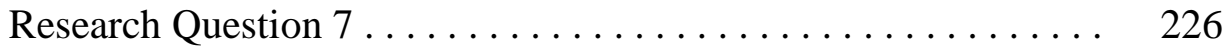

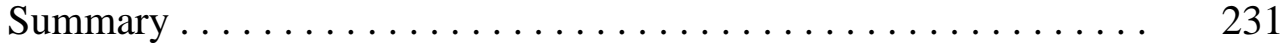




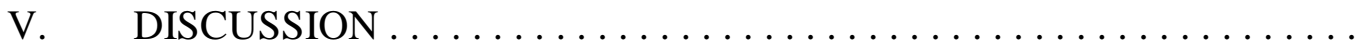

Introduction . . . . . . . . . . . . . . . . . . . . . 233

Summary of Purpose and Methodology . . . . . . . . . . . . 233

Summary of Major Findings .................... 235

Demographic Information. . . . . . . . . . . . . . . . 235

Exposure to Information About ADHD . . . . . . . . . . . 235

Experience With ADHD ...................... 235

Questions and Null Hypotheses . . . . . . . . . . . . . 236

Discussion of Major Findings ..................... 237

Adequate Knowledge Versus Inadequate Knowledge Regarding

ADHD ..................................... 237

Implications of Inadequate Knowledge . . . . . . . . . . . . 239

Teachers of Children in Parochial Schools .............. 242

Knowledge Regarding ADHD of Teachers of Children in Parochial Schools ..................................... 242

Consequences of Teachers' Inadequate Knowledge Versus Adequate Knowledge for the Children They Teach ......... 246

Parents of Children in Parochial Schools . . . . . . . . . . . . 248

Knowledge Regarding ADHD of Parents of Children in Parochial Schools .................................... 248

Consequences of Parents' Inadequate Knowledge Versus Adequate Knowledge for the Children With Whom They Come in Contact

Predictors of the Knowledge of Regular Education Teachers and

Parents . . . . . . . . . . . . . . . . . . . . . . . . 251

Demographic Implication . . . . . . . . . . . . . . . . . 252

Exposure to Information About ADHD . . . . . . . . . . . . . . . 253

Experience With ADHD Implications . . . . . . . . . . . . . . 255

Beliefs Regarding ADHD ...................... 256

Beliefs of Regular Education Teachers of Children in Parochial

Schools ................................. 258

Consequences of Teachers' Beliefs for the Children They Teach 262

Beliefs of Parents of Children in Parochial Schools . . . . . . . . . . 262

Consequences of Parents' Beliefs for the Children With Whom

They Come in Contact .......................... 264

Comparison and Discussion of Findings of the Current Study to Past

Studies ....................................... 264

Importance of the Study . . . . . . . . . . . . . . . . . 266

Limitations of the Study ....................... 268

Delimitations of the Study . . . . . . . . . . . . . . . . . . . . . . . 269

Implications for Practice ......................... 270

Directions for Future Research . . . . . . . . . . . . . . . . . . 273

Conclusions .................................... 274

Summary .............................. 275 
Appendix

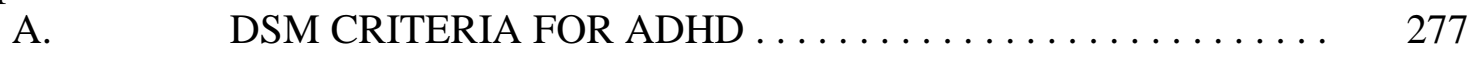

B. STUDIES REGARDING KNOWLEDGE, BELIEFS AND/OR

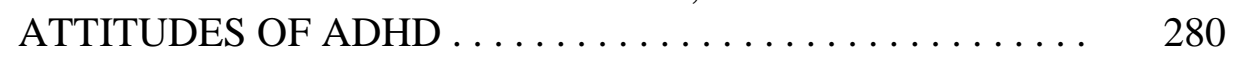

C. KNOWLEDGE STATEMENTS ANSWER KEY . . . . . . . . 286

D. TEACHERS' AND PARENTS' QUESTIONNAIRE . . . . . . . . 288

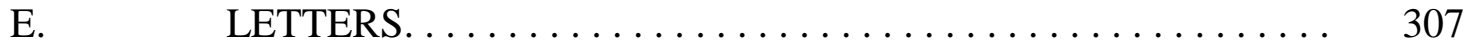

F. WEBSITES LISTING “MYTHS” OF ADHD . . . . . . . 321

REFERENCE LIST ................................... 323

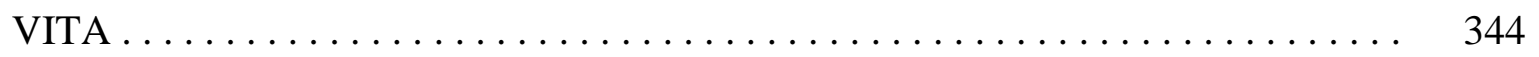




\section{LIST OF TABLES}

1. Number of Schools, Teachers, Students and Families by Conference (School 117 District) ........

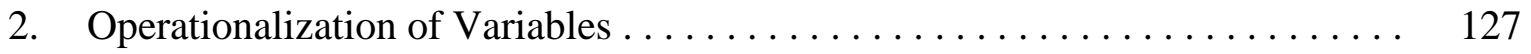

3. Item-Discrimination and Item-Difficulty Indices of Knowledge Statements for Teachers and Parents . . . . . . . . . . . . . . . . . . . . . . . . . 155

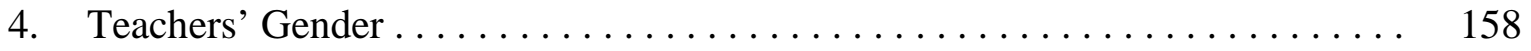

5. Teachers' Race ... . . . . . . . . . . . . . . . . . . . . . . . . . . . . . 159

6. Teachers' Conference (School District) . . . . . . . . . . . . . . . . . 159

7. Teachers' Educational Level . . . . . . . . . . . . . . . . . . . . . . . 160

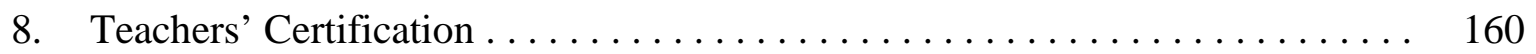

9. Teachers' Grade Level Taught . . . . . . . . . . . . . . . . . 161

10. Years of Teaching Experience $\ldots \ldots \ldots \ldots \ldots \ldots \ldots \ldots \ldots \ldots \ldots \ldots \ldots \ldots \ldots \ldots$

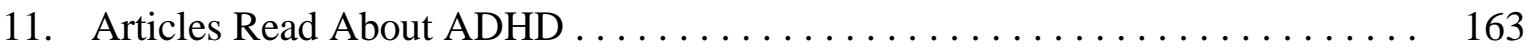

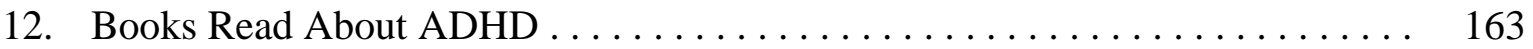

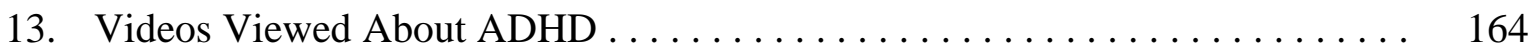

14. Graduate Courses Taken Pertaining to ADHD . . . . . . . . . . . . . . . . . 164

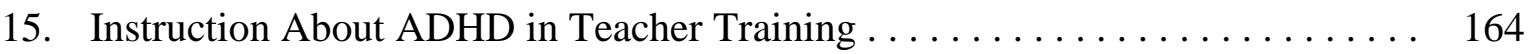

16. Training About ADHD Since Beginning Teaching $\ldots \ldots \ldots \ldots \ldots \ldots \ldots$

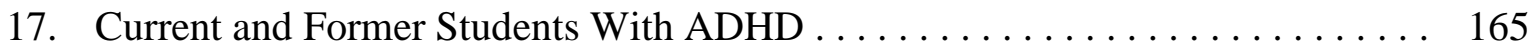

18. Current and Former Children Thought to Have ADHD . . . . . . . . . 166

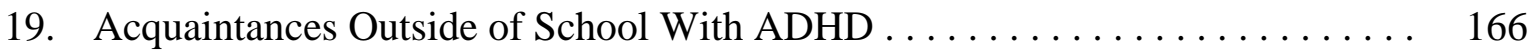




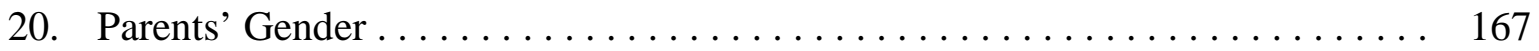

21. Parents' Race ..................................... 167

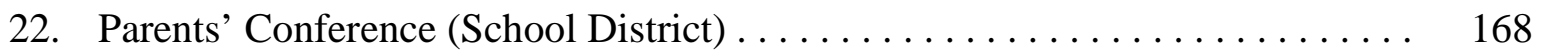

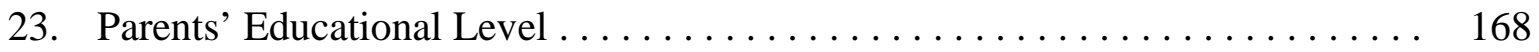

24. Parents' Marital Status . . . . . . . . . . . . . . . . . . . . . . . . . . 169

25. Lectures Attended About ADHD . . . . . . . . . . . . . . . . . . . . . . . . 169

26. Articles Read About ADHD . . . . . . . . . . . . . . . . . . . . 170

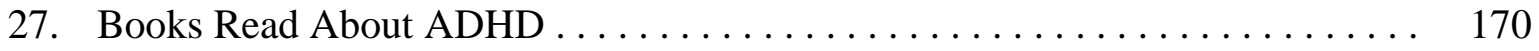

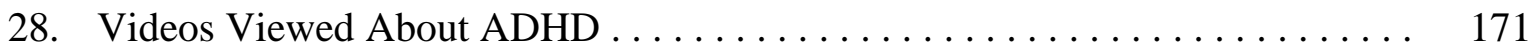

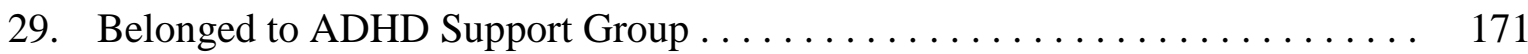

30. Acquaintances Outside of Home With ADHD . . . . . . . . . . . . . . 172

31. Family Member Evaluated for ADHD . . . . . . . . . . . . . . . . . 172

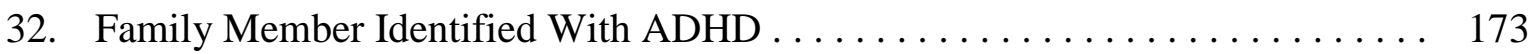

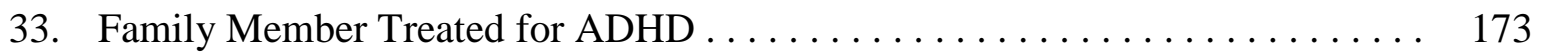

34. Teachers' and Parents' True, False and Don't Know Responses to Knowledge 176 About Symptoms and Characteristics About ADHD ...............

35. Teachers' and Parents' True, False and Don't Know Responses to Knowledge and Beliefs About General Information About ADHD . . . . . . . . . . . . . . . . 182

36. Teachers' and Parents' True, False and Don't Know Responses to Knowledge and Beliefs About ADHD Causes . . . . . . . . . . . . . . . . . . . . . .

37. Teachers' and Parents' Likert Item Responses to Beliefs About Possible Causes

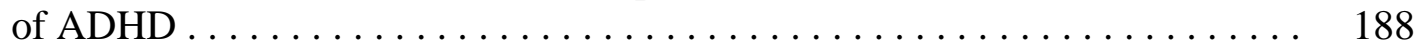

38. Teachers' and Parents' Beliefs About Possible Causes of ADHD by Mean and Standard Deviation . . . . . . . . . . . . . . . . . . . . . . 190

39. ANOVA Summary Table for Mean Scores . . . . . . . . . . . . . . . . 191 
40. Teachers' and Parents' True, False and Don't Know Responses to Knowledge

About ADHD Intervention/Treatment Options . . . . . . . . . . . . . . . . . . 194

41. Teachers' and Parents' Beliefs About Stimulant Medication . . . . . . . . . . . . 196

42. Teachers' and Parents' Beliefs About Stimulant Medication by Mean and

Standard Deviation . . . . . . . . . . . . . . . . . . . . . . . . . . . . . 198

43. ANOVA Summary Table for Mean Score . . . . . . . . . . . . . . . . . . . . . . . 199

44. Teachers' and Parents' Beliefs About Interventions . . . . . . . . . . . . . . . . 204

45. Teachers' and Parents' Beliefs towards ADHD Interventions by Mean and Standard Deviation . . . . . . . . . . . . . . . . . . . . . . . . . 206

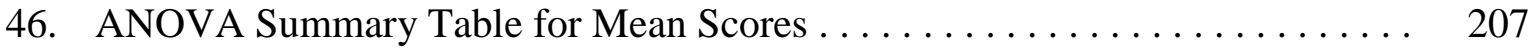

47. Teachers' and Parents' Beliefs About Medication, Behavioral and Educational Interventions by Percentages . . . . . . . . . . . . . . . . . . . . . 209

48. Teachers' and Parents' Beliefs About Medication, Behavioral and Educational Interventions by Mean and Standard Deviation . . . . . . . . . . . . . . . . 210

49. ANOVA Summary Table for Mean Scores . . . . . . . . . . . . . . . . . . . 214

50. Teachers' and Parents' Other Beliefs About ADHD Issues . . . . . . . . . . . 215

51. Teachers' and Parents' Other Beliefs About ADHD by Mean and Standard Deviation ...................................... 217

52. ANOVA Summary Table for Mean Scores . . . . . . . . . . . . . . . . . . . . . . . 219

53. Teachers' and Parents' Overall ADHD Knowledge . . . . . . . . . . . . . . . 221

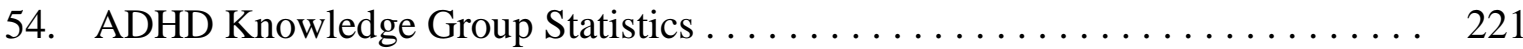

55. Correlations, Coefficients, and Importance of Demographic Variable Contributors to Teachers' Overall Knowledge Regarding ADHD (CATREG)

56. Correlations, Coefficients, and Importance of Exposure to Information About ADHD Variable Contributors to Teachers' Overall Knowledge Regarding

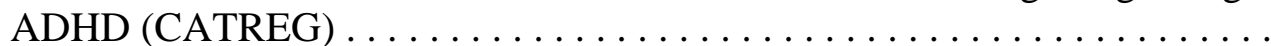

57. Correlations, Coefficients, and Importance of 3 Exposure to Information About ADHD Variable Contributors to Teachers' Overall Knowledge Regarding

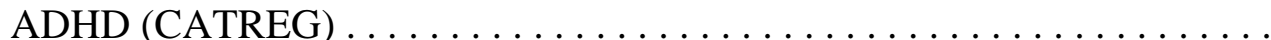


58. Correlations, Coefficients, and Importance of Experience With ADHD Variable

Contributors to Teachers' Overall Knowledge Regarding ADHD (CATREG) 227

59. Correlations, Coefficients, and Importance of Demographic Variable Contributors to Parents' Overall Knowledge Regarding ADHD (CATREG) . 228

60. Correlations, Coefficients, and Importance of Exposure to Information About ADHD Variable Contributors to Parents' Overall Knowledge Regarding

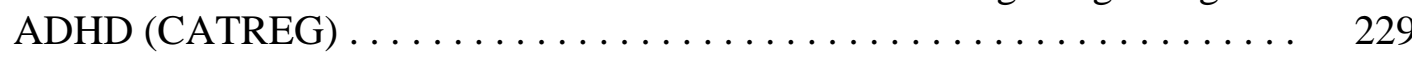

61. Correlations, Coefficients, and Importance of Experience With ADHD Variable Contributors to Parents' Overall Knowledge Regarding ADHD

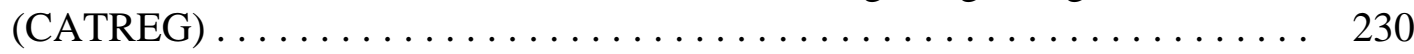




\section{ACKNOWLEDGMENTS}

First I would like to thank my Lord and Savior, Jesus Christ, who has been my ultimate source of strength during this academic pursuit.

I would like to thank Astrid Thomassian and Millie Felt from the Atlantic Union Conference for making it possible for me to photocopy the surveys at the union office; and Marie Bakerlis from the Atlantic Union College for completing the photocopying of the surveys for me. Thanks to Sandra Hinds, Marilyn Simmons, Sharai Brunson, Kim Burgess, Milita Williams, and Tamara Bean for helping to prepare the surveys for distribution, along with Samaela and Trae. Thanks to the superintendents of the Atlantic Union Conference for their support in this research project, especially David Cadavero and Sheila Holder for going the extra mile in this endeavor. I would like to thank my dissertation committee, Dr. Rudolph Bailey, Dr. Lena Caesar, and Dr. Ron Coffen. Rudi, thanks for being there, especially through the difficult times when I did not think that I would make it. Your encouragement saw me through. You are a true gem. Thanks to Jean Hannant for proofreading the document, Bonnie Proctor for meticulously editing the document, and Karen Benjamin for printing and photocopying the document for me. Thanks to my family and friends, who are too numerous to mention by name, for their encouragement, prayers, and support. Last but not least, I would like to thank my children, Mikaela Ian, Samaela, and Trae; and my mother, Yvonne Pearman for their loving support and understanding during this arduous time in my life. To Amari Ian, my loving grandson, thanks for being a wonderful diversion when NaLee needed a break from her writing.

May God bless you all now and forevermore.

Kendra-Lee Yvonne Pearman 


\section{CHAPTER 1}

\section{INTRODUCTION}

\section{Background of the Problem}

Attention-Deficit/Hyperactivity Disorder (ADHD) is a common developmental disorder affecting children, adolescents, and adults as documented in many countries around the world. ADHD is considered to be one of the most prevalent psychiatric disorders of childhood (Olfson, 1992) and has primary symptoms of hyperactivity, impulsivity, and/or inattention (APA, DSM-IV-TR, 2000). The disorder is considered to be "a developmental disorder of self-control. It consists of problems with attention span, impulse control, and activity level" (Barkley, 2000, p. 19). ADHD affects about $3-7 \%$ of the child population in the United States (APA, 2000). It has received much interest in recent years and "has become a household word, yet it remains poorly understood" (Nigg, 2006, p. 3).

Due to the primary symptoms of hyperactivity, impulsivity, and inattention, children and adolescents with ADHD often face many challenges both at home and at school. These challenges can include constant movement, excessive talking, high distractibility, difficulty with organization, failure to complete chores or school work, losing toys or other things, forgetfulness and intruding on others, difficulty interacting with peers and teachers, difficulty attending and following directions, difficulty staying seated, difficulty working independently, difficulty starting and completing tasks 
(Barkley, 1998; see Appendix A). In addition, children with ADHD can exhibit secondary symptoms such as disruptive behaviors, inattention, distractibility, academic underachievement and/or academic performance deficits in the classroom (Barkley, 1998; DuPaul \& Stoner, 2003). ADHD can negatively affect the academic performance of children for their entire school experience (Fischer, Barkley, Fletcher, \& Smallish, 1993), thus many of these children may not benefit maximally from their educational opportunities. As a result, many children with ADHD may be placed in special education classes or retained in a grade, which can eventually lead to dropping out of high school (Barkley, 1998; Barkley, Fischer, Edelbrock, \& Smallish, 1990). In addition, children with ADHD are at risk for becoming delinquent as teenagers (Woodward \& Ferguson, 1999), which can result in them becoming a menace to society. Coupled together, these possible outcomes for children with ADHD can lead to significant vocational and social difficulties in adulthood, which can result in a daunting outlook for children who present with this disorder.

Since ADHD affects children both at home and at school, parents and regular education teachers represent two groups who would benefit from accurate and adequate knowledge about the disorder. By having adequate knowledge about the disorder, parents and regular education teachers would be able to structure their homes and classrooms in a supportive and nurturing way to give a child with ADHD the best possible chance for success in both environments. Children with ADHD who have homes and classrooms geared to their success can have positive academic, social, and emotional experiences to prepare them for successful futures. 


\section{Consequences of Inadequate Knowledge Regarding ADHD}

The problems that children with ADHD can experience in the classroom can be compounded in many ways when regular education teachers do not have accurate and adequate knowledge about ADHD. When there is a lack of knowledge regarding ADHD, these teachers are unable to provide parents with accurate information about the effects of stimulant medication when asked (Kasten, Coury, \& Heron, 1992). They are limited in the implementation of intervention strategies to manage the children in their classrooms, which can lead to over-identification of children with ADHD (Glass \& Wegar, 2001). They do not value the feasibility of using behavioral techniques that target specific ADHD behaviors; they do not use classroom management options and they tend to be reactive rather than proactive (Arcia, Frank, Sánchez-LaCay, \& Fernández, 2000). Reactive techniques tend to be punitive in nature (DuPaul \& Stoner, 2003), which can cause these children to retaliate, thus causing more problems socially and academically. A lack of knowledge precludes teachers from effectively dealing with students with ADHD in the classroom, and these students need to have teachers who can provide an environment that promotes both academic and social skill development (DuPaul \& Stoner, 2003; A.L. Robin, 1998). Regular education teachers who do not have adequate knowledge of the disorder can inadvertently contribute to acting-out behaviors of their students (Schoun, 1993a) especially when they do not know how to adequately handle the primary and/or secondary symptoms of ADHD. In addition, a lack of training can be a top barrier to effective teaching of children with ADHD (Bussing, Gary, Leon, Garvan, \& Reid, 2002; Reid, Vasa, Maag, \& Wright, 1994). 
When teachers lack adequate knowledge about ADHD, they are more likely to have negative attitudes towards the students and are less likely to make efforts to accommodate these students (Kiffer, 1996). Both regular education teachers and preservice teachers tend to have negative attitudes towards children with disabilities and it is difficult to modify these attitudes (Alexander \& Strain, 1978; Alghazo, Dodeen, \& Algaryouti, 2003; Beare, 1985). When regular education teachers are bothered by disturbing behaviors, their attitudes may be biased against these particular students (Algozzine, 1980). Teachers who do not understand the behavioral profile of ADHD are hampered in their ability to make necessary referrals, which may result in the underidentification of inattentive children and the overidentification of disruptive children who do not have ADHD (Arcia et al., 2000) or they are reluctant to refer (Holst, 2008). Teachers are more likely to refer boys than girls for ADHD regardless of consistent symptoms in both groups, which suggests that they may view the behaviors of boys and girls differently and consider the behaviors of boys as problematic (Sciutto, Nolfi, \& Bluhm, 2004). A lack of knowledge can lead to many problems academically and socially for those children with ADHD and exacerbate their difficulties.

Many of the problems that children with ADHD experience in the home can be compounded by a lack of knowledge of parents. Parents who do not have adequate knowledge about ADHD are more inclined to believe misconceptions and minimize the benefits of treatments, while they may also be unaware of school services available to children with ADHD (Bussing, Gary, Mills, \& Garvan, 2007; Stief, 2003). Parents who do not have positive relationships with their children with ADHD may have children who withdraw from parental interactions, which can lead to negative interactions with their 
peers and in the long run unhealthy relationships throughout their lives (Hurt, Hoza, \& Pelham, 2007).

Therefore, the impact of limited knowledge regarding ADHD of regular education teachers on children with ADHD can be disastrous. Children who are erroneously referred for ADHD may be incorrectly labeled, which may impact their lives in a negative way both academically and socially, while those who are not referred but have ADHD may not receive the necessary interventions to help them succeed academically and socially. Those children who are in either camp may experience difficulties in their lives that can affect them emotionally, academically, and socially into adulthood. For those who are not managed effectively in the classroom, academic failure and social rejection can be their experience due to disruptive behaviors and academic deficits. These children will have difficulty developing strategies to help them function normally in an academic setting, which can limit their achievements or impede their aspirations for the future (Gilbert, 2005). The impact of parents' lack of knowledge regarding ADHD means they may not make good decisions about interventions and special services and may not be supportive or responsive to their children, especially those who exhibit disruptive behaviors. These children will possibly have difficulties throughout their lives, socially and emotionally, which may impact their present and future relationships with peers and significant others.

\section{Consequences of Adequate Knowledge Regarding ADHD}

Adequate knowledge about ADHD precludes regular education teachers from making unnecessary special education referral, gives them more confidence in managing children with ADHD, allows them to provide accurate information to parents, and can 
lessen their stress levels (Barbaresi \& Olsen, 1998; Glass \& Wegar, 2001; Kasten et al., 1992; Ohan, Cormier, Hepp, Visser, \& Strain, 2008; Reid et al., 1994; Snider, Busch, \& Arrowood, 2003; Tsai, 2003). Those who have adequate knowledge of the disorder can make accommodations, use classroom and intervention strategies, and manage behaviors (Barkley, 1998; DuPaul \& Stoner, 2003). Regular education teachers with adequate knowledge of ADHD are able to create the structured educational setting that provides the best outcome for children with the disorder (Arcia et al., 2000). Adequate knowledge of ADHD consistently impacted how teachers report ADHD behaviors and their perception of children with the disorder (Ohan et al., 2008).

Parents who had greater knowledge of ADHD were able to enroll their children in ADHD intervention programs that included pharmacological and nonpharmcological interventions (Corkum, Rimer, \& Schachar, 1999). Parents who are well-informed about ADHD are cautious about their willingness to accept medication as treatment for their child with ADHD (Rostain, Power, \& Atkins, 1992). Those who have adequate knowledge regarding ADHD are able to make informed decisions for their child with ADHD and work better with those in the school system (Davidson \& Ford, 2002). Parents who understand ADHD tend to have positive relationships and are warm towards their children with ADHD, which provides them with both a model of positive social interactions and positive social orientation towards peer relationships. Positive parents are more supportive and responsive to their children's need, thus having good relationships with them (Hurt et al., 2007), which can help these children have healthy relationships throughout their lives. 
The impact of having adequate knowledge on children with ADHD can be the difference between success and failure for these children academically, socially, and emotionally. Children with ADHD who are educated by regular education teachers who understand their disorder and who are willing to make the necessary accommodations and interventions will have the opportunity to succeed academically and socially. When disruptive behaviors are managed in the classroom, children with ADHD have a better chance of being accepted by their peers and they will have the opportunity to complete their work with their peers. A positive school experience for children with ADHD can lead to the desires and aspirations that can be attained by these children.

In order to successfully manage and educate children with ADHD, a collaborative effort between teachers and parents is necessary (Rief, 2003) and this begins with understanding the disorder. If lack of knowledge contributes to negative beliefs, this further negatively impacts children with ADHD. Therefore, teachers and parents need to have adequate knowledge regarding ADHD for the benefit of the children with the disorder.

\section{Consequences of Beliefs Regarding ADHD}

There are more than 10 websites listing myths regarding ADHD (see Appendix G). It is possible that many of these myths have been inculcated, accepted, and believed as factual knowledge regarding ADHD among teacher and parent populations. Beliefs can actually be more influential than knowledge in determining how people define problems, and they strongly predict behavior (Nespor, 1987). Teachers with inadequate knowledge about ADHD can have negative beliefs and are less likely to accommodate children with the disorder (Kiffer, 1996). Regular education teachers tend to have 
negative attitudes towards children with special needs and it is difficult to modify these beliefs (Alexander \& Strain, 1978; Beare, 1985). Successful teachers who have positive attitudes usually believe that every child can be successful at something; they also believe devaluing a child's differences does them injustice (Love \& Kruger, 2005).

DiBattista and Shepherd (1993) found teachers overwhelmingly believed sugar consumption affects the behavior of hyperactive and normal children, thus they suggested to parents that they needed to reduce sugar intake in order to control their child's activity level. Parents tend to believe what teachers tell them about ADHD issues and follow their advice without checking to see if it is valid (DiBattista \& Shepherd, 1993). They also get information from the media, friends, and family (Ghanizadeh, 2007), thus they possibly believe myths about ADHD. Parents who exhibit positive attitudes towards their children with ADHD are satisfied with stimulant medication and improvements in their child's self-esteem, school grades, and school behavior (dosReis et al., 2003).

When teachers and parents believe they are knowledgeable about ADHD, they are less likely to seek information about the disorder (Kos, Richdale, \& Hay, 2006), thus tending to believe whatever information they have, regardless of whether it is accurate or inaccurate. Therefore, beliefs held by teachers and parents can have an impact on how they relate to children with the disorder.

\section{Possible Solutions for Teachers and Parents}

A possible solution that can help regular education teachers provide a supportive and nurturing classroom environment for children with ADHD is teacher training regarding the disorder. Teachers who have training about ADHD are more confident in their decisions to accommodate children with ADHD (Destefano, Shriner, \& Lloyd, 
2001) and those who implement intervention strategies help improve their students' success in school (Webb \& Myrick, 2003). A specially tailored environment can foster academic and social success in children with ADHD.

A possible solution that can help parents provide a supportive environment in the home for their children with ADHD is parent training (Anastopoulos, Smith, \& Wien, 1998; Barkley, 2000). Parents would benefit from being informed about ADHD in the event their child was unnecessarily referred for an evaluation due to a teacher's erroneous belief. When children with ADHD have teachers and parents who understand their disorder and are supportive and responsive, they will be empowered to do their best academically, socially, and emotionally. Children benefit from teachers and parents who have positive attitudes who are often satisfied with their academic and behavioral progress in school. Positive experiences at school coupled with positive experiences at home can help children with ADHD lead productive, responsible, and successful lives in every dimension.

\section{Statement of the Problem}

Due to the prevalence of ADHD, every school setting, including parochial schools, will encounter children with the disorder at some point (DuPaul \& Stoner, 2003). The symptoms and characteristics of the disorder can affect children academically, which can prevent them from maximizing their educational opportunities and lead to grade retention or placement in special education classes. Children with ADHD are at risk for delinquent behaviors and coupled with academic failure, they can drop out of high school and become a menace to society. Public schools are mandated by law to address the special needs of children who are covered under IDEA and Section 504 (Council of 
Educators for Students with Disabilities, n.d.); therefore, they have the resources to meet these special needs. However, parochial schools may not have the resources to meet these special needs of children who present with disabilities or other health impairments, such as ADHD.

Regular education teachers of children in public schools need to have adequate knowledge about ADHD in order to use the resources to provide services to children with the disorder in school. Their beliefs about the disorder can also influence how they interact with children with ADHD. The literature suggests the impact of adequate knowledge of ADHD of teachers in public schools is positive towards students with the disorder. These teachers are willing to accommodate and use strategies for their students with the disorder. Public school teachers who have positive attitudes towards children with ADHD are more supportive and believe these children can be successful academically. To date, much research has been conducted in the U.S. and other parts of the world examining the knowledge regarding ADHD and/or beliefs of regular education teachers in public schools, with findings suggesting public school teachers have limited knowledge and/or gaps in their knowledge about ADHD (Bekle, 2004; Brook, Watemberg, \& Geva, 2000; Ghanizadeh, Bahredar, \& Moeini, 2006; Holst, 2008; Jerome, Gordon, \& Hustler, 1994; Ohan et al., 2008; Sciutto, Teriesen, \& Frank, 2000; West, Taylor, Houghton, \& Hudyma, 2005) and many believe misconceptions about the disorder (Bekle, 2004; Jerome et al., 1994; Sciutto et al., 2000; Tsai, 2003). Many of these studies found that teachers in public schools have not received specific training regarding ADHD, thus they were possibly hindered from providing the necessary accommodations and/or modifications for children with ADHD in the classroom. 
Little study has been conducted on regular education teachers in parochial schools. One study found Catholic and private school teachers also had limited knowledge about ADHD (Kos, Richdale, \& Jackson, 2004). Of the limited research that has been conducted on parents, findings suggest parents of a child with ADHD have limited knowledge about ADHD (Ghanizadeh, 2007; West et al., 2005). Of the studies examining parents' knowledge, none have been conducted on those who send their children to Seventh-day Adventist (SDA) schools, the second largest parochial school system in North America.

Since limited research has been conducted on teachers and/or parents of children in parochial schools, this issue has not been adequately addressed and needs to be further studied in parochial schools and in particular the SDA school system. One of the possible solutions to helping and supporting children with ADHD is to provide teachers and parents with training and intervention strategies regarding the disorder. However, before training and interventions can be implemented in parochial schools, it is imperative to have information from this population concerning their knowledge and beliefs about ADHD. Therefore, a study which included a sample of teachers and parents of children in SDA parochial schools would add to the existing literature and provide an insight into what is known and believed about ADHD in this population. It would be beneficial to discover what sources are able to predict the knowledge of general education teachers and parents of children in these parochial schools. Regular education teachers and parents of children in these parochial schools should have adequate knowledge and beliefs about ADHD. However, we do not know the knowledge or beliefs regarding ADHD of regular education teachers and parents of children in these schools nor do we know what predicts 
their knowledge. Therefore, it is important to establish what regular education teachers and parents of children in the Seventh-day Adventist parochial schools know and believe about ADHD and what sources predict their knowledge. This information can be used to implement training regarding ADHD for teachers in this school system, which can help children with the disorder maximize their educational opportunities. This can possibly thwart the risk for delinquency and provide positive outcomes for these children.

\section{Rationale for the Study}

Teachers who have adequate knowledge about ADHD use interventions to help children with ADHD have positive academic and social outcomes, whereas teachers who do not have adequate knowledge of ADHD do not have the skills to help children with ADHD, which negatively impacts these children. Negative beliefs are associated with inadequate knowledge. Parents who have adequate knowledge about ADHD are supportive of children with the disorder, while parents who do not have adequate knowledge of ADHD do not know how to support these children. The possible negative outcomes for children with ADHD are daunting; therefore, it is imperative that teachers and parents have adequate knowledge regarding ADHD so they can provide these children with the interventions and support necessary to help them have a positive outlook for their futures.

A PSYCinfo database search was conducted which revealed that many studies have been conducted pertaining to knowledge, beliefs, opinions, and/or attitudes of ADHD of professionals who deal with children with ADHD such as school psychologists, nurses, school social workers, general practitioners, psychiatrists, pediatricians, principals, and teachers (see Appendix B). Studies that examined the 
knowledge and/or beliefs of parents' of children with ADHD are few in number. Most of the studies examining teachers' and/or parents' knowledge and/or attitudes have focused on public school teachers and parents of a child with ADHD or at risk for ADHD who send their children to public schools. However, there is only one study to date that has examined and compared both groups at the same time (West et al., 2005), whereas another study included parents of children with and without ADHD, teachers, and other professionals in their study (Dryer, Kiernan, \& Tyson, 2006). Therefore, this issue has not been addressed adequately in parochial schools nor has it been adequately addressed with both regular education teachers and parents simultaneously. Since children with ADHD can be found in every school setting and since there are negative outcomes associated with the disorder, it would be beneficial to find out what teachers and parents of children in a parochial school setting know and believe about the disorder. This information is necessary before training can be suggested and implemented in this population, which can give teachers and parents the necessary tools to provide effective interventions to help children with ADHD become successful in school and in society.

Consequently, the rationale for conducting this research project was to find out what regular education teachers and parents of children in SDA parochial schools know and believe about ADHD. Research suggests that teachers and parents with adequate knowledge of ADHD are able to provide the necessary interventions and support for children with ADHD. In addition, there is a dearth in the literature pertaining to this matter in parochial schools and few studies exist that have examined both teachers' and parents' knowledge and beliefs of ADHD concurrently. 


\section{Purpose of the Study}

The Seventh-day Adventist Church educates 1,437,000 students globally (Department of Education, 2008) and employs 75,000 teachers in a Christian education system. The purpose of this study was to examine the knowledge and beliefs currently held by regular education teachers and parents in SDA parochial schools, the second largest parochial school system in North America, concerning ADHD. Children with special needs are not always accepted into these parochial schools. The main reasons for not accepting students with special needs in this school system include the following: "1). the cost is prohibitive; 2). educating students with disabilities detracts from the needs of the other students; and 3). teachers aren't trained to handle the special needs of students with disabilities" (Tucker, 2001, p. 316). However, Tucker believes cost is not a valid reason because a partnership with a public school system could provide the necessary services to any student with disabilities without denial of a Christian education.

Additionally, students with special needs can receive a better education when taught in an inclusive setting with trained teachers who have sufficient support. Finally, teachers need to receive the necessary training to obtain the specialized skills necessary to teach students with special needs.

Tucker (2001) recommends that pre-service teachers and practicing teachers need to be trained with the necessary skills to meet the challenge of providing for the individual needs of every student, including special needs students, in this parochial school system. Therefore, this investigation would reveal the knowledge and beliefs teachers in these schools have regarding ADHD. 
My intention was to examine the knowledge base and belief systems regarding ADHD of regular education teachers in a SDA parochial school system. Therefore, this study could advance the field by contributing to the literature findings from this population. Additionally, I sought to examine the knowledge and beliefs regarding ADHD of parents of children who attend SDA parochial schools since few studies have examined parents with even fewer examining parents of children attending parochial schools. I used a convenience sample of teachers and parents from the Atlantic Union Conference (AU)

Results of this study can be used to formulate recommendations that can foster positive academic and home environments for children who present with ADHD in the Seventh-day Adventist school system and other parochial school systems.

\section{Research Questions and Hypotheses}

This research project attempted to answer the following questions and test the following hypotheses:

1. What do regular education teachers and parents of children in parochial schools know about ADHD?

2. What do regular education teachers and parents of children in parochial schools believe about ADHD?

3. Are there differences in the knowledge about ADHD on individual items between regular education teachers and parents of children in parochial schools?

Hypothesis 1: There are significant differences in the knowledge about ADHD on individual items between regular education teachers and parents of children in parochial schools. 
4. Are there differences in the beliefs about ADHD between regular education teachers and parents of children in parochial schools on individual items?

Hypothesis 2: There are significant differences in the beliefs about ADHD between regular education teachers and parents of children in parochial schools on individual items.

5. Is there a difference in the overall knowledge regarding ADHD between regular education teachers and parents of children in parochial schools?

Hypothesis 3: There is a significant difference in the overall knowledge regarding ADHD between regular education teachers and parents of children in parochial schools?

6. Do demographic variables (gender, race, conference (school district), grade level taught, teaching experience, and education level), exposure to information about ADHD variables (books read about ADHD, articles read about ADHD, videos viewed about ADHD, instruction about ADHD in teacher training, training about ADHD after beginning teaching, graduate courses pertaining to ADHD) and experience with ADHD variables (former and current students with ADHD, former and current students thought to have ADHD, acquaintances outside of school with ADHD) predict the overall knowledge regarding ADHD of regular education teachers of children in parochial schools?

Hypothesis 4a: One or more of the following demographic variables predicts the overall knowledge regarding ADHD of regular education teachers of children in parochial schools: gender, race, teaching experience, education level, conference (school district), grade level taught, and teacher certification. 
Hypothesis 4b: Exposure to information about ADHD by one or more of the following variables predicts the overall knowledge regarding ADHD of regular education teachers of children in parochial schools: books read about ADHD, articles read about ADHD, videos viewed about ADHD, instruction about ADHD in teacher training, training about ADHD after beginning teaching, and graduate courses pertaining to ADHD.

Hypothesis 4c: Experience with ADHD by one or more of the following variables predicts the overall knowledge regarding ADHD of regular education teachers of children in parochial schools: former and current students with ADHD, former and current students thought to have ADHD, acquaintances outside of school with ADHD.

7. Do demographic variables (gender, race, education level, conference (school district), marital status), exposure to information about ADHD variables (books read about ADHD, articles read about ADHD, videos viewed about ADHD, lectures attended about ADHD and belonged to support group for ADHD) and experience with ADHD variables (family member with ADHD, family member evaluated for ADHD, family member treated for ADHD, acquaintances outside of home with ADHD) predict the overall knowledge regarding ADHD of parents of children in parochial schools?

Hypothesis 5a: One or more of the following demographic variables predicts the overall knowledge regarding ADHD of parents of children in parochial schools: gender, race, education level, marital status, and conference (school district).

Hypothesis 5b: Exposure to information about ADHD by one or more of the following variables predicts the overall knowledge regarding ADHD of parents of children in parochial schools: books read about ADHD, articles read about ADHD, 
videos viewed about $\mathrm{ADHD}$, lectures attended about ADHD, and belonged to support group for ADHD.

Hypothesis 5c: Experience with ADHD by one or more of the following variables predicts the overall knowledge regarding ADHD of parents of children in parochial schools: family member with ADHD, family member evaluated for ADHD, family member treated for ADHD, and acquaintances outside of home with ADHD.

\section{Conceptual Framework}

Attention-Deficit/Hyperactivity Disorder is one of the most prevalent developmental disorders affecting children in the United States and other countries (Barkley, 1998). Those spending substantial amounts of time nurturing and teaching children in this population include parents and regular education teachers. Consequently, it is beneficial for both groups to have adequate knowledge and beliefs about the disorder in order to effectively interact with children who present with ADHD.

Knowledge can come from various sources such as through revelation, our senses, intuition, authority, or reason; however, all of these sources complement each other to aid humans in their knowing. Knowledge is the cognitive outcome of education and consists of concepts, theories, empirical results, and other information that is acquired from the

educational experience (Ernest, 1989). Knowledge requires general or group consensus to ensure validity and appropriateness and is open to evaluation and critical examination (Nespor, 1987). Knowledge is based on what can be verified empirically, thus judged as true or false (Knight, 1997). Pajares (1992) stated: "Knowledge is based on objective fact" (p. 313). Based on these definitions, knowledge is factual evidence that derives 
from various sources, can be judged as true or false, and requires general consensus to ensure validity and appropriateness.

Beliefs cannot be directly observed but are inferred as a result of things the believer says or does (Rokeach, 1968); therefore, they are not based on empirical evidence. People generally have a belief system that has grown and developed over many years which can be influenced by membership in an organization such as a religion. There are different types of beliefs: beliefs that virtually everyone believes, beliefs that are true only to individuals, beliefs about which people differ, and beliefs that are random matters of one's taste. Beliefs can be learned from direct encounters or can be derived indirectly from others (Rokeach, 1968). Pajares (1992) stated, "Belief is based on evaluation and judgment" (p. 313). He suggested that beliefs derive from a person's judgment of the truth or falsity of a proposition; a belief system is disputable, inflexible, and less dynamic than a knowledge system. Nespor (1987) suggested that beliefs are more influential than knowledge and are stronger predictors of behavior. Unlike knowledge, beliefs are not subject to general or group consensus and do not require critical evaluation to be validated (Nespor, 1987). Because beliefs are based on a person's evaluation and judgment and not on empirical evidence, they are therefore subjective and cannot be considered correct or incorrect.

For the purposes of this study, knowledge consisted of statements about ADHD that were supported by empirical evidence and have been accepted by general consensus of the scientific community concerned with ADHD. These statements were considered to be true or false, correct or incorrect. Knowledge was considered to be adequate and to meet mastery level if $80 \%$ or higher of respondents correctly answered the individual 
knowledge items. An average score of $80 \%$ or higher was considered adequate for the overall knowledge of respondents. This criterion was set based on the mastery learning criteria of $80 \%$, which showed persons had adequate knowledge about some specific information (Davis \& Sorrell, 1995). Knowledge was considered to be inadequate if less than $80 \%$ of respondents correctly answered the individual items correctly or received an overall knowledge score below $80 \%$. Beliefs consisted of statements about ADHD that were evaluated and judged by teachers and parents as true or false or with which they agreed or disagreed, but they cannot be considered correct or incorrect. These statements were not supported by empirical evidence.

\section{Significance of the Study}

This study was the first to be conducted regarding ADHD in SDA parochial schools. A similar study that examined knowledge and attitudes of teachers in Catholic and private schools in Australia was conducted by Kos et al. (2004). Atlantic Union Conference represents a unique population living in the northeastern part of the United States and Bermuda. This study is significant because it adds information to the literature about regular education teachers working in the parochial school sector. There are few studies conducted on parents' knowledge and beliefs about ADHD and even fewer have been conducted on parents of children in parochial schools.

One of the aims of this study was to find out what regular education teachers and parents of children attending these parochial schools know and believe about ADHD. This information is necessary in order to provide these teachers and parents with the necessary training to help these children with ADHD be successful in school and in society. Knowing this information will help determine if teachers and parents of this 
school system have adequate knowledge regarding ADHD and if they believe possible myths regarding the disorder. A second aim was to find out what variables predict knowledge regarding ADHD. This information could be invaluable for parochial school districts and parent support groups by helping them streamline their efforts in knowing how best to provide necessary information about ADHD to these two groups.

This study examined the knowledge and beliefs regarding ADHD of regular education teachers working in parochial schools and parents who send their children to these schools. The study also examined sources that could possibly predict knowledge regarding ADHD in regular education teachers and parents. I intended to extend the existing research regarding the knowledge and beliefs regarding ADHD of teachers and parents of children in parochial schools.

\section{Assumptions}

Several assumptions were made regarding the current study. They are as follows:

1. The Likert items are measured as interval data.

2. Respondents answered the questionnaire honestly.

3. Overall knowledge is measured as continuous data and is normally distributed.

4. Individual items of true, false, and don't know are nominal data and when summed together for a knowledge total, they are continuous data.

5. Respondents were regular education teachers or parents of children in parochial schools in the Atlantic Union Conference. 


\section{Definitions of Terms}

The following terms are defined as used in this study:

Attention-Deficit/Hyperactivity Disorder (ADHD): A persistent pattern of inattention and/or hyperactivity-impulsivity that is more frequently displayed and more severe than is typically observed in individuals at a comparable level of development. Some hyperactive-impulsive or inattentive symptoms that cause impairment must have been present before age 7 . Some impairment from the symptoms must be present in at least two settings. There must be clear evidence of interference with developmentally appropriate social, academic, or occupational functioning. The different types of ADHD include the following: ADHD-PI-Predominately inattentive type of ADHD; ADHD$\mathrm{HI}-$ Hyperactive and impulsive type of ADHD; and ADHD-C - Combined type of ADHD which includes PI and HI (DSM-IV-TR, 2000, p. 85).

Knowledge Statement: Facts, truths, or principles about ADHD that are supported by empirical evidence and accepted by general consensus of the scientific community concerned with ADHD as true or false, correct or incorrect. Diagnostic criteria for ADHD that have been clinically established in the DSM-IV-TR (2000) also constitute knowledge in this study because at this time it is the accepted diagnostic criteria for ADHD.

Adequate Knowledge: The group is considered to have adequate knowledge if $80 \%$ or higher answered the knowledge statement correctly. An average score of $80 \%$ or higher was considered adequate for the overall knowledge of respondents. 
Inadequate Knowledge: The group is considered to have inadequate knowledge if less than $80 \%$ answered the knowledge statement correctly. An average score of less than $80 \%$ was considered inadequate for the overall knowledge of respondents.

Belief Statement: Information about ADHD that has not yet been supported by empirical evidence or clinical criteria from the DSM-IV-TR (2000). Belief was also defined as a value or attitude toward ADHD that was expressed in terms of agreement or disagreement.

Myth: A myth can be defined as a popular idea or belief that is considered to be true by a large amount of people. Second, a myth is an inaccurate or untrue belief. Therefore, a statement was considered to be a myth if it was believed by a simple majority $(51 \%)$ and was empirically false.

\section{Limitations}

This study was limited for the following reasons:

1. The teacher and parent participants in the study were not randomly selected and the sample consisted of those who chose to participate in the study, which may not be truly representative of the knowledge and beliefs of the population.

2. Because the sample was not randomly selected, it is possible that it is not free from sampling error and bias.

3. The sample of teachers was small, thus findings may not be generalized to teachers in other parochial school systems.

4. The sixth school district did not participate in the study, thus data from this district may have affected findings.

5. The true/false format may have inflated the scores for many participants may 
have guessed the correct response without really knowing the answer. The 'don't know' option might have caused more participants to be cautious in their responding. 


\section{CHAPTER 2}

\section{LITERATURE REVIEW}

\section{Introduction}

In order to review knowledge and beliefs concerning ADHD, it was necessary to take two main approaches: (a) look at what has been established empirically by research regarding the salient areas of $\mathrm{ADHD}$ and (b) review the literature in regard to what different groups know and believe regarding ADHD. However, it was impossible to examine every empirical research study conducted about the important areas of ADHD and every study conducted about what people know and believe about ADHD. Thus, some type of criteria must be used to decide which studies to examine. One way to do this was to examine the statements that typically appear in research studies that assessed the knowledge and beliefs of teachers and parents, which are the two groups currently of interest. Once these statements were identified, it was necessary to examine the empirical evidence concerning these statements to determine if the statements are based on evidence or not. In addition, it was deemed prudent to examine the following: (a) the samples that have been included in these studies to see which samples still need to be included in further research; (b) the knowledge researchers suggest is important for teachers and parents to know regarding ADHD; and (c) the variables that possibly predict this knowledge. 
Therefore, this review begins with the short historical background section regarding ADHD to set the context of the issue for the reader. It then discusses the empirical evidence or diagnostic criteria pertaining to the salient areas regarding ADHD which include symptoms and characteristics of ADHD, general information regarding ADHD, causes of ADHD, and intervention/treatment options for ADHD from which the most popular statements derived. A discussion regarding knowledge-based versus beliefbased statements follows. Next, studies that have examined the knowledge and/or beliefs regarding ADHD of teachers, parents, and others are reviewed followed by a review of the findings from these studies. Then a discussion of what researchers recommend teachers and parents should know regarding ADHD follows. Finally, a review of knowledge predictors of ADHD completes the review.

\section{The Historical Background of ADHD}

Evidence of ADHD symptoms has existed since the early 1900s as noted by the pediatrician Still in 1902, yet the label has undergone several modifications before it maintained its current term of Attention-Deficit/Hyperactivity Disorder (DSM IV-TR, 2000). The first person credited for describing the precursor to ADHD was Still who stated in a series of lecturers that the behaviors of children he observed in his practice included "passionateness, spitefulness and cruelty, jealousy, lawlessness, dishonesty, wanton mischievousness and destructiveness, shamelessness" (Still, 1902, p. 1009). He noted these children had difficulty with inhibitory volition and had in general difficulty sustaining attention. The description of these symptoms would set the stage for all subsequent observations of children displaying atypical behaviors. 
Subsequently, during 1917-1928 an epidemic of encephalitis swept around the world resulting in behavior and character changes in children affected by the attack (Ebaugh, 2007; Hohman, 1922). In school, teachers found those affected to be "impudent, disrespectful, disobedient, or no longer amenable to discipline. This same disrespectful attitude was also displayed at home; they would curse their parents, or even strike at them" (Hohman, 1922, p. 372). Symptoms evidenced by Holman and Ebaugh included total change in character, insomnia, tics, hyperkinesis, mental deficiency, affective disorder, and over-talkativeness. Strecker and Ebaugh (1924) found children suffering from cerebral trauma also displayed symptoms consistent with those with encephalitis such as change in general character and disposition, hyperkinesis, and affective disorder. In the 1940s, children with these symptoms were considered to be brain injured even though they had insufficient or no evidence of brain pathology. Subsequently, the term was changed to minimal brain damage and then minimal brain dysfunction (Barkley, 1998). In 1957, Laufer, Denhoff, and Solomons described the disorder as "hyperkinetic impulse disorder" with characteristics such as "hyperactivity, short attention span and poor powers of concentration, irritability, impulsivity, variability; and poor school work" (p. 48). The authors assert that of all the symptoms "hyperactivity is the most striking item" (p. 38). Laufer et al. (1957) included explosiveness and inability to delay gratification to the list of symptoms.

The conceptualization of ADHD continued to evolve, and during the 1960s hyperactivity was identified as "one of the most common manifestations of disturbed child behavior" (Chess, 1959, p. 2379). According to Chess, "the hyperactive child is one who carries out activities at a higher rate of speed than the average child, or who is 
constantly in motion, or both" (p. 2379). In order to make a diagnosis, behavioral data observed by parents or teachers had to be supplemented by a clinician's personal observations, psychological tests, and physicians' reports. The emphasis of the disorder, Hyperactive Child Syndrome, had moved away from brain damage. By 1968, the DSMII identified this evolving disorder as Hyperkinetic Reaction of Childhood (APA, 1968). Interest in the disorder continued to grow, and during the 1970s hyperactivity continued to be one of the salient characteristics of the disorder, yet inattention and impulsivity seemed to even be more imperative signs (Douglas, 1972).

By 1980, DSM-III identified the disorder as Attention-Deficit Disorder with hyperactivity $(\mathrm{ADD} / \mathrm{H})$ and Attention-Deficit Disorder without hyperactivity (ADD/WO) (APA, 1980) indicating the main characteristics were hyperactivity, impulsivity, and inattention. However, in the 1987 release of DSM-III-R, ADD/WO was completely removed and $\mathrm{ADD} / \mathrm{H}$ was changed to $\mathrm{ADHD}$ and a minimal disorder labeled Undifferentiated Attention-Deficit Disorder (UADD) replaced ADD. It was in this publication of the DSM that the disorder was officially renamed as Attention-Deficit Hyperactivity Disorder (ADHD). The criteria stated the disorder had to have an onset before the age of 7 and 8 of the 14 symptoms needed to be present for at least 6 months (DSM-III-R, 1987). The next publication, DSM-IV, came out in 1994 and identified ADHD as having three subtypes: ADHD, Predominately Inattentive Type (ADHD-PI); ADHD, Hyperactive/Impulsive Type (ADHD-HI); and ADHD, Combined Type (ADHDC). In this publication, the criteria for the onset and presence remained the same; however, the diagnostic criteria were modified to differentiate the symptoms between ADHD-PI subtype and ADHD-HI subtype. In order to be diagnosed with either the 
inattentive or hyperactive-impulsive subtype, six of the nine symptoms had to be present, but to be diagnosed with the combined subtype, six of the nine symptoms had to be present in both of the preceding subtypes (DSM-IV,1994). In 2000, the DSM-IV-TR was published, but there were no changes to the criteria for ADHD. See Appendix A. In summary, the hyperactive and inattention symptoms of ADHD have remained static throughout the years with impulsivity added later. Much research has been conducted throughout the years on these symptoms as well as other characteristics, general information, causes, and intervention/treatment options of the disorder. The following section discusses the empirical evidence or diagnostic criteria regarding the areas of ADHD.

\section{Empirical Evidence or Diagnostic Criteria Regarding ADHD}

Symptoms and Characteristics of ADHD

\section{Primary Symptoms}

Primary symptoms of ADHD have been identified as inattention, hyperactivity, and impulsivity; however, children who are identified as having ADHD must exhibit these characteristics in an intensity that is developmentally inappropriate in contrast to their peers. These symptoms must be evident before the age of 7 , must be consistent in at least two different environments (home and school), and must be present for at least 6 months (DSM-IV-TR, 2000). The three subtypes of ADHD have been identified as ADHD-PI, ADHD-HI, and ADHD-C (DSM-IV-TR, 2000). Children with ADHD may exhibit any characteristics of inattention and hyperactivity/impulsivity at any time, but they must display at least six or more of the symptoms of one type and fewer than six in the other type in order to receive a diagnosis of either the inattentive subtype or the 
hyperactivity/impulsivity subtype. Those who exhibit six or more symptoms in both subtypes are diagnosed as having combined subtype of ADHD. Therefore, children can be diagnosed with ADHD-PI, ADHD-HI, or ADHD-C.

\section{Inattention}

Inattention is generally associated with lack of concentration, carelessness, distraction, daydreaming, or negligence and can be easily observed in children. In the context of ADHD, inattention encompasses all of these and more. According to the DSMIV-TR (2000), characteristics of inattention include the following: doesn't give close attention to details or makes careless mistakes, has difficulty sustaining attention, doesn't seem to listen when directly spoken to, does not follow through on instructions and fails to finish all types of tasks, has difficulty organizing tasks and activities, is reluctant to engage in tasks that require sustained mental effort, especially schoolwork or homework, loses things necessary for tasks or activities, is easily distracted by extraneous stimuli, and is forgetful in daily activities (see Appendix A). Parents and teachers observed that children with this subtype tended to daydream or get lost in thought, were often confused or as if lost in a fog, apathetic, or unmotivated; they had difficulty completing work and/or tasks, concentrating, following through on instructions, were impaired in academic learning, and were underachievers in school (Barkley, DuPaul, \& McMurray, 1990). According to Spencer, Biederman, and Mick (2007), "Children, adolescents, and adults with the inattentive subtype of ADHD are more likely to be female and have fewer other emotional or behavioral problems compared with other subtypes" (p. 632). 


\section{Hyperactivity}

A hyperactive child can be described as one who is wired, restless, agitated, or energetic. In the context of ADHD, hyperactivity is described in the following ways according to the $D S M-I V-T R$ (2000): fidgets with hands or feet or squirms in seat, leaves seat in classroom or in other situations when supposed to remain seated, runs about or climbs excessively in situations in which it is inappropriate, has difficulty playing or engaging in leisure activities quietly, is "on the go" or often acts as if "driven by a motor," and talks excessively (see Appendix A). Parents and teachers described these children as acting immaturely for their age, producing odd noises and messy school work, fidgety, disruptive towards others, and displaying irresponsible conduct; they also had difficulty completing work and/or tasks, concentrating, following through on instructions, were impaired in academic learning, and were underachievers in school (Barkley, DuPaul, et al., 1990).

\section{Impulsivity}

Impulsivity is the final primary characteristic of ADHD and children who are described as impulsive are considered to be impetuous, spontaneous, reckless, irresponsible, or hasty. In the context of ADHD, the DSM-IV-TR (2000), describes impulsivity in the following way: blurts out answers before questions have been completed, has difficulty awaiting turn, and interrupts or intrudes on others (see Appendix A). Children who display these characteristics are often accident-prone and often do things haphazardly. Barkley (1998) purported:

Clinically, these children are often noted to respond quickly to situations without waiting for instructions to be completed or adequately appreciating what is required in the setting. Heedless or careless errors are often the result. These children may 
also fail to consider the potentially negative, destructive, or even dangerous consequences that may be associated with particular situations or behaviors. (p. 59)

Overall, impulsivity can be a great cause of concern to both teachers and parents, for children who exhibit these characteristics may often get hurt or hurt others.

DuPaul, Anastopoulos, et al. (1998) developed a rating scale containing DSM-IV ADHD criteria to determine if parent's rating of ADHD symptoms aligned with the two subscales of the DSM-IV model. Using both exploratory and confirmatory factor analysis, results indicated items designated as hyperactive-impulsive loaded together on factor 1 , whereas the items designated as inattentive loaded together on factor 2 . These findings support the two subscale models in the DSM-IV which allow for the identification of clinical subtypes of ADHD—predominantly inattentive type, predominantly hyperactiveimpulsive type, and combined type.

Neuman et al. (1999) conducted a study to identify subtypes of ADHD. Latent class analysis was used to investigate associations among the ADHD items. Results of the study indicated there are two subtypes, an inattentive subtype and a combined inattentive and hyperactive-impulsive subtype, which is consistent with the DSM-IV subtypes. Various studies have examined the three subtypes of ADHD in children for different reasons; however, the presence of the subtypes in the samples studied verifies their validity as subtypes of ADHD. Several studies have identified the inattentive, hyperactive-impulsive, and/or combined subtypes in their samples (Counts, Nigg, Stawicki, Rappley, \& Von Eye, 2005; Faraone \& Biederman, 2000; Goodman \& Stevenson, 1989a; Klorman et al., 1999; Nigg, Blaskey, Huang-Pollack, \& Rappley, 2002). The scientific community regarding ADHD accepts the inattentive, hyperactive- 
impulsive, and combined subtypes in the construct of the ADHD model (Barkley, 1998;

Biederman \& Faraone, 2002; Nigg, 2006; Thapar, Holmes, Poulton, \& Harrington, 1999).

\section{Associated Characteristics}

Several websites list "myths" pertaining to video game playing and ADHD. The website, Psychiatry $24 X 7$ (2009) sponsored by Janseen-Cilag, posts the following: "There is absolutely no way she has ADHD! She has no trouble focusing on the things she wants to do, like playing computer games." A website called New Ideas (2008) posts the following: "Children who can concentrate on things that they enjoy, like video games or TV, cannot possibly have ADHD.” BipolarCentral.com (2009) posts the following: "He can't have ADHD if he has no trouble focusing on things he wants to do, like playing computer games." On the other hand, a website sponsored by the Learning Disabilities Association of Kentucky (2005) included this statement on their list of "myths" and realities: "You can have ADHD and still have no trouble focusing on things you want to do, like playing computer games."

Some research has been conducted in this area. Bioulac, Arfi, and Bouvard (2008) compared the behavior of hyperactive and control children playing video games. Results did not find significant differences between the ADHD group and controls on the frequency and duration of play. Houghton et al. (2004) found boys with ADHD completed computer video game trials in less time than their non-ADHD peers when no working memory load and no distracters were evident. Shaw, Grayson, and Lewis (2005) used a computer game, a video game, and computerized tasks to examine whether the inhibitory abilities of children with ADHD are unimpaired when playing the games. There were no differences between the inhibitory performance of children with ADHD 
and their non-ADHD peers on the computer and video games. Therefore, children with ADHD play video games like their non-ADHD counterparts.

In summary, clinical evidence supports the inattentive, hyperactive, and impulsive symptoms of ADHD. Children can be diagnosed with ADHD with the presence of only inattentive or hyperactive/impulsive symptoms. Empirical evidence shows that being able to attend to video games does not preclude a diagnosis of ADHD.

\section{General Information Regarding ADHD}

\section{Prevalence}

ADHD affects about $3-7 \%$ of school-age children in the United States (DSM-IVTR, 2000, p. 90); other sources indicate it affects 3-5\% (Encyclopedia of Psychology, 2000, p. 300; Encyclopedia of Cognitive Science, 2003, p. 227). According to Nigg (2006),

The median estimates of prevalence for all types of ADHD is 6.8\%, 2.9\% for ADHDCombined type, $3.2 \%$ for ADHD-Predominately Inattentive type, and $0.6 \%$ for ADHD_Predominately Hyperactive-Impulsive type with these estimates being consistent in North and South America, Western Europe and Australia; however, these estimates are based on limited research evidence and are somewhat higher for boys. (p. 16)

\section{Gender}

The ADHD Library website (2004) lists the following "myth": "AD/HD occurs less in girls." The National Resource Center on AD/HD (2009) included the following "myth" on their website: "Girls have lower rates and less severe AD/HD than boys." The prevalence of ADHD by gender varies significantly across studies, but boys are three times more likely than girls to have ADHD (Barkley, 2000); however, one study found that the ratio was 2:1 (Martin, Levy, Pieka, \& Hay, 2006). In a sample of more than 
10,000 participants with ADHD, 51\% were male and 49\% were female; the overall prevalence of ADHD in males was 4.19\% and in females was 1.77\% (Cuffe, Moore, \& McKeown, 2005). Girls have been identified as having ADHD, and studies have been conducted including them in samples (DuPaul, Anastopoulos, et al., 1998; Faraone et al., 2000; Weiler, Belinger, Marmor, Rancier, \& Weber, 1999). However, the majority of the literature available on ADHD is preponderantly about boys (Biederman et al., 2002).

Girls with ADHD were more likely to present with the inattentive subtype (Biederman et al., 2002; Spencer et al., 2007; Weiler, Bellinger, Marmor, Rancier, \& Weber, 1999) and were less likely to experience problems in school as were boys with ADHD (Biederman et al., 2002). It is plausible to deduce that since the inattentive characteristics are more covert in comparison to hyperactivity and impulsivity, this could partially clarify why more boys than girls are clinically referred for ADHD (Biederman et al., 2002). Empirical evidence shows that ADHD is not diagnosed as frequently in girls as boys.

\section{Ethnicity}

Overall, ADHD is one of the most prevalent childhood disorders affecting schoolage children worldwide including the United States, Britain, and many other countries (Faraone, Sergeant, Gillberg, \& Biederman, 2003). However, from a cultural perspective, "most of the etiological research available pertains to largely white samples in the United States, Canada, Australia, Great Britain, the Netherlands, and Germany” (Nigg, 2006, p. 25). Consequently, it is not known whether these conclusions are generalizable to other ethnic groups that exist in other nations or within the countries that have been wellstudied (Nigg, 2006). Cuffe et al. (2005) studied the prevalence of ADHD symptoms in 
Hispanic, White, Black, and other (Asian, American Indian, and Pacific Islander)

ethnicities in the National Health Interview Survey (NHIS). The sample of over 10,000 participants was predominantly White (64\%) with fewer Hispanic (16\%) and Black (15\%) participants. Black males were most prevalent $(5.65 \%)$ followed by White males (4.33\%) and Hispanic males (3.06).

Faraone et al. (2003) investigated the worldwide prevalence of ADHD by conducting a MEDLINE search with terms such as ADHD, ADD, HKD, or ADHD and prevalence. ADHD criteria were based on DSM-III, DSM-III-R, or DSM-IV. The authors found that studies were conducted worldwide in the following countries: Australia, Brazil, Canada, China, Columbia, Finland, Germany, Hong Kong, Iceland, India, Israel, Italy, Japan, New Zealand, Spain, Sweden, Taiwan, The Netherlands, Ukraine, UK, and United States. The highest prevalence of ADHD is diagnosed when using the DSM-IV in both U.S. and non-U.S. studies. Prevalence in non-U.S. countries ranged from 2.4-19.8\% and 7.1-16.1\% in the U.S. across the three criteria. Thus, it is evident that ADHD occurs in U.S. and non-U.S. countries, thus affecting children in minority and majority racial groups.

\section{Risk for Delinquency}

Because of their difficulties in school and ADHD symptoms, some children with ADHD have a high risk for becoming delinquent as teenagers (Woodward \& Fergusson, 1999). According to Boyles and Contadino (1999), there are two types of juvenile delinquent offenses: criminal offenses and status offenses. Criminal offenses involve adult crimes such as substance use and abuse, theft, vandalism, physical assault, robbery, shoplifting, etc. Status offenses are illegal because perpetrators are underage and include 
offenses such as truancy, underage drinking, and drug use, etc. (Boyles \& Contadino, 1999). Many of these behaviors are typically associated with conduct disorder (CD) which can be comorbid with ADHD. Nonetheless, not every child with ADHD will develop these types of abhorrent behaviors, but under certain circumstances they could be at high risk for them (Hann \& Borek, 2001). Children with ADHD who have not had their ADHD managed and who enter adolescence with major life difficulties are especially at risk for delinquency (Boyles \& Contadino, 1999).

Lee and Hinshaw (2004) investigated the severity of adolescent delinquency in a group of boys with and without ADHD. ADHD probands were rated as being much more delinquent than non-ADHD peers. Young and Gudjonsson (2006) investigated the relationship between ADHD symptoms and comorbid problems including delinquency. ADHD is associated with a number of comorbid problems such as poor socialization, anxiety, and antisocial problems. Molina et al. (2007) compared delinquent behavior and substance use between children in the Multimodal Treatment Study of Children with ADHD (MTA) and those in a local normative comparison group (LNCG). Those in the MTA group who engaged in delinquency committed mostly minor delinquencies in the home and outside of the home. Similarly, the LNCG group committed more minor delinquencies at home and outside of the home. Those in the MTA group who engaged in moderate to serious delinquency had a comorbid diagnosis of CD. These studies show that children with ADHD are at risk for becoming delinquent as teenagers.

\section{Intelligence}

Several websites list "myths" regarding the intelligence of children with ADHD. BipolarCentral.com (2009) lists the following: "People with ADHD aren't as smart as 
their peers, and ADHD children need to be put in special classes." A website sponsored by the Learning Disabilities Association of Kentucky (2005) lists the following: "Kids with ADHD aren't as smart as their peers, that is why they are in 'special' classes." Janssen-Cilag sponsors the Psychiatry $24 X 7$ (2009) website which includes the following: "Since people with ADHD aren't as smart as their peers, they usually have to be put in special classes." This issue has been studied and some studies have found children with ADHD have lower IQs than their peers (Barkley, 1998), although children with ADHD have normal or average IQs consistent with their non-ADHD peers (MTA Cooperative Group, 1999). Frick et al. (1991) assessed the intelligence of the boys using the WISC-R Full Scale intelligence test. The ADHD group did not differ from the control group on intelligence. The MTA Cooperative Group (1999) found that children with ADHD had IQs in the normal or average range of intelligence. According to Schuck and Crinella (2005),

Because this is the largest and most carefully screened population of children with ADHD yet studied, these results would support the conclusion that the FSIQ levels of children with ADHD, as a group do not differ appreciably from those of the general population. (p. 262)

On the other hand, Biederman et al. (2002), Lee and Hinshaw (2004), Nigg et al. (2002), and Williams, Weiss, and Rolfhus (2003) used a form of the Wechsler to compare IQ and found children with ADHD had average IQs but their IQ scores were lower than the scores of their non-ADHD counterparts.

As the evidence shows, several studies have found that although children with ADHD have average IQs comparable to their peers, many have IQ scores about 6 to 11 points lower. Nevertheless, there are some studies that have shown children with ADHD have above average IQs; therefore, it cannot be said that all children with ADHD have 
lower IQs than their peers. Because of the inattentive and/or impulsive symptoms of ADHD, children may have problems taking and completing items on tests, which may lower their scores. Therefore, it is not known if lower IQ really means differences in intelligence or poor test-taking behaviors (Barkley, 1998). Overall, children with ADHD may or may not have IQ scores that are lower than their peers, thus the empirical evidence is contradictory. Since the empirical evidence is contradictory, a definitive statement about the IQs of all children with ADHD cannot be made at this time.

\section{Age of Onset}

According to DSM-IV-TR (2000) clinical criteria for ADHD, the onset of ADHD must be before the age of 7. Applegate et al. (1997) examined the validity of this requirement and found almost all children diagnosed with ADHD-HI met the age of onset; however, less than half diagnosed with ADHD-I and less than $20 \%$ of those diagnosed with ADHD-C did not manifest ADHD symptoms before age 7. The authors question the validity of the age of onset stipulated by the DSM. They state, "Impairment may not become evident until children enter school or other situations in which ADHD symptoms interfere with their ability to meet social and academic demands" (p. 1218). In regard to the inattentive subtype, symptoms usually exhibit when youths have difficulties with the demands of the independent academic work placed on them. Barkley and Biederman (1997) argued that there is no justification for the 7-year age of onset and suggest the age of onset criterion (AOC) should be either abandoned or broadened to include an onset during the childhood years. According to the authors, "We can see no positive benefits of the recommended AOC except that it would 
certainly limit the number of children (and probably adults) with diagnosed ADHD” (p. 1208).

Waschbusch, King, and Gregus (2007) examined the age of onset of elementary school children using parent ratings. Similar to findings of Applegate et al. (1997), they found that children diagnosed with ADHD-HI met the age of onset, but some of those diagnosed with ADHD-I and ADHD-C failed to meet the age of onset and were diagnosed after the age of 7 . They believe this is possible because inattention problems tend to be identified as children get older, whereas hyperactive-impulsive behaviors can be detected earlier in children. These authors also question the validity of the DSM age of onset for ADHD. Nonetheless, even though there is some controversy concerning the age of onset for ADHD, the DSM criterion is the present acceptable diagnostic criterion for ADHD. Therefore, the diagnostic criterion supports the knowledge that ADHD begins in childhood by age 7 .

\section{Expression}

According to the DSM-IV-TR (2000), in order for ADHD to be diagnosed, relevant symptoms must be exhibited in two or more settings, either at home and school or work. The limitation to this requirement relies on agreement between teachers and parents on the behaviors of a child; if disagreement occurs, this could reflect differences in attitudes and judgment between different people based on what they think is atypical or typical behaviors (Barkley, 1998). Nevertheless, the current diagnostic criterion of the $D S M-I V-T R$ for the expression of ADHD is that it must be evident in two or more settings. 


\section{Duration}

ADHD has been identified as a childhood disorder; however, adolescents and adults also have the disorder as studies have been conducted on these populations (Biederman et al., 1995; Eaves et al., 2000). According to DSM IV-TR, "In most individuals, symptoms (particularly motor hyperactivity) attenuate during late adolescence and adulthood, although a minority experience the full complement of symptoms of Attention-Deficit/Hyperactivity Disorder into mid-adulthood" (2000, p. 90). Faraone et al. (2003) state that, "in approximately $80 \%$ of children with ADHD, symptoms persist into adolescence and may even continue into adulthood" (p. 104). Resnick (2005) reported that ADHD symptoms and concerns continue into adulthood but typically look different in adults.

Several "myths" have been posted on websites in regard to the duration of ADHD. The website run by CHADD, National Resource Center (2009), has the following statement: “ADHD is a disorder of childhood." The ADDA (2006) website has the following listed: "Children outgrow ADD or ADHD." The websites run by Novartis (2009) and the Learning Disabilities Association of Kentucky (2005) posts the following: “Children naturally outgrow ADHD." The BipolarCentral.com (2009) posts the following: "ADHD is just a phase. Children grow out of it." A website called Momference: A Meeting Place of the Moms (2008) the following: "People outgrow ADHD." Finally, the website called About Kids Health (2008) posts the following: "Children outgrow ADHD."

In a 12-year follow-up study conducted by Claude and Firestone (1995), the authors found core deficits of ADHD persisted in more than half of males who were 
diagnosed with ADHD as children. Barkley, Fischer, Smallish, and Fletcher (2002) examined the persistence of ADHD into young adulthood in a follow-up study at age 21 . Young adults were not likely to report ADHD symptoms, whereas their parents had higher reporting of the symptoms. Therefore, this was evidence to suggest ADHD persists into adulthood. In a study in South Africa, 22 out of 58 adults had childhood ADHD and less than half continued to have ADHD symptoms into adulthood (Mahomedy, van de Westhuizen, van der Linde, \& Coetsee, 2007).

On the other hand, Mannuzza, Klein, Bessler, Malloy, and LaPadula (1998) conducted a study to understand the natural course of ADHD into adulthood. Only 5\% of the sample met the DSM-III-R criteria for full ADHD in adulthood at age 25, which shows that ADHD continued into adulthood only for a few boys. Based on the literature it cannot be conclusively stated that ADHD is not outgrown nor can it be stated it is outgrown. Mannuzza, Klein and Moulton (2003) cite several reasons for discrepant findings: (a) how the assessment is conducted (self-rating, observation ratings, current status, persistence since childhood required), (b) attrition rate, (c) person interviewed (subject or parent), (d) type of criteria used (DSM-III-R or DSM-IV, etc.), and (e) whether the evaluator is blind to childhood status. They found persistence into adulthood ranged from 5\% to $49 \%$ in the studies they evaluated. Because there are adults with ADHD, it supports the assertion that the disorder can persist into adulthood. Spencer et al. (2007) state, "Adults must have childhood-onset, persistent, and current symptoms of ADHD to be diagnosed with the disorder" (p. 632). Nonetheless, the contradictory evidence suggests some children with ADHD will have the persistence of the disorder into 
adulthood, while others do not. Because of the contradictory evidence, a definitive statement about whether or not children outgrow ADHD cannot be made at this time

In summary, ADHD does not occur equally the same in girls as it does in boys, and it occurs in minority and majority racial groups. Children with ADHD are at risk for delinquency as teenagers. The disorder begins in childhood and must be expressed in more than one environment. Knowledge items pertaining to occurrence by gender and racial group, risk for teenage delinquency, the age of onset, and the expression in more than one setting are supported by empirical evidence or diagnostic criteria. There is contradictory evidence concerning the duration of ADHD and the intelligence of children with ADHD. Therefore, items pertaining to this issue are not based on conclusive knowledge.

\section{Causes of ADHD}

When a disorder such as ADHD affects so many children and has received a plethora of interest in many countries of the world, it is natural to endeavor to discover the cause of the disorder. However, many agree there is not a single cause and "the exact causes of AD/HD remain elusive" (CHADD, 2006, para. 26). Much of the literature, both primary and secondary, indicates possible etiologies of ADHD include genetic and environmental factors (Barkley, 1998; Biederman \& Faraone, 2002; Durston, 2003; Levy, Hay, \& Bennett, 2006; Nigg, 2006; Thapar et al., 1999). ADHD is not caused by any single factor, but its etiology is likely multifactorial and its heritability is likely polygenetic (LaHoste et al., 1996). Researchers have used twin, adoption, and family studies to investigate a genetic basis for ADHD. In addition, environmental factors such as ingestion of food additives and sugar, parenting issues, and chaotic families have been 
investigated as possible influences in the etiology of ADHD. DuPaul and Stoner (2003) suggest that "most of the research examining the etiology of ADHD is correlational. Thus, caution is warranted in attributing causal status to identified variables" (p. 13). The literature to date has provided contradictory evidence concerning the possible etiologies of ADHD, thus much controversy exists.

\section{Genetic or Biological Factors}

Twin studies

Twin studies are one method used to study hereditary influences in the genetic theory of ADHD. According to Khan and Faraone (2005):

Twin studies show perhaps the most compelling data for understanding heritability. Monozygotic twins share $100 \%$ of the genes, whereas fraternal twins and other siblings share $50 \%$ of their genes. Therefore, heritability can be computed by determining the extent to which monozygotic twins are more concordant for ADHD compared with fraternal twins. (p. 393)

Goodman and Stevenson (1989b) studied inattentiveness and hyperactivity and the role of genes with a sample of identical (MZ) and same-sexed fraternal (DZ) twins. Identical twins were more similar in these symptoms than fraternal twins. Levy, Hay, McStephen, Wood, and Waldman (1997) researched the heritability of ADHD in a large-scale twin study using $\mathrm{MZ}$ and $\mathrm{DZ}$ twins. Identical twins were twice as concordant on the symptoms of ADHD as fraternal twins. Martin et al. (2006) investigated shared genetic heritability in a large sample of twins. They found heritability accounts mostly for ADHD-PI and ADHD-HI but less for ADHD-C. Identical twins' correlations were almost twice that of fraternal twins. McLoughlin, Ronald, Kuntsi, Asheron, and Plomin (2007) investigated the genetic component of a large sample of $\mathrm{MZ}$ and $\mathrm{DZ}$ twins on the inattentive and hyperactive-impulsive subtypes of ADHD. Identical twins had correlation scores of 78\%- 
$88 \%$ while DZ twins had correlation scores of $37 \%-53 \%$. All of these studies concluded there is a hereditary component to the cause of ADHD. On the other hand, Heiser et al. (2006) assessed heritability of activity, attention, and impulsivity by comparing a small sample of MZ and DZ twins. No significant heritabilities were found; therefore, the authors concluded there were no significant influences of genetic factors on these symptoms of ADHD.

Joseph (2000) criticized twin studies because they have investigated pairs reared together with no studies investigating those reared apart. As expected, MZ twins are more concordant than DZ twins and this fact is also true for the occurrence of ADHD; identical twins correlate higher for ADHD-related behaviors than do fraternal twins. His next criticism involves the equal environment assumption (EEA) in which he postulates the twin study method is based on the assumption that both $\mathrm{MZ}$ and $\mathrm{DZ}$ twins share equal environments. If EEA is violated "the twin method could be measuring nothing else than the more similar environment and greater emotional bond experienced by MZ twins" (p. 543). Joseph claims that

ADHD twin studies are based on an unsupported theoretical assumption and therefore offer, like family studies, only a "hint" about the possible genetic basis of ADHD. It is quite possible, and even likely, that these studies have recorded nothing more than the greater psychological bond and environmental similarity experienced by identical twins. (p. 551)

Faraone and Biederman (2000) refute Joseph's (2000) claims about the EEA for they purport that even though MZ twins share equal environments, this environment sharing does not "predict twin similarity of ADHD scores" (p. 570). However, this is an area requiring further testing since those who are biased towards the genetic basis for ADHD may have ignored the problems of EEA in twin studies. 
Adoption studies

Few adoption studies have been conducted by researchers to investigate the genetic component in the etiology of ADHD. Morrison and Stewart (1973) compared adoptive parents' psychiatric diagnoses with biological and control parents. Biological parents, not adoptive parents, had higher prevalence of psychiatric disorders associated with ADHD. Alberts-Corush, Firestone, and Goodman (1986) investigated attention and impulsivity characteristics of 176 biological and adoptive parents of hyperactive and normal control children. The biological parents of hyperactive children performed significantly poorer than other parents on attention measures and intellectual functioning. Van den Oord, Boomsma, and Verhulst (1994) studied genetic and environmental influences on problem behaviors in international adopted children. Biological sibling adoptees were significantly more alike on attention problems and externalize behaviors than non-biological siblings, suggesting a genetic component. Sprich, Biederman, Crawford, Mundy, and Faraone (2000) investigated the issue of genetics in ADHD using adopted and biological children with ADHD. Biological parents and siblings had higher rates of ADHD than adoptive and control parents and siblings of teenagers with ADHD. These authors concluded there is a genetic component in the cause of ADHD.

However, most of these studies suffer from methodological problems due to using the Adoptive Family Method and unblinded diagnoses, thus limiting their interpretation (Faraone \& Biederman, 2000; Joseph, 2000; Sprich et al., 2000; Thapar et al., 1999). There are two main problems with the adoptive family method: (a) adoptive parents have undergone psychological screening during the adoptive process, thus limiting or 
excluding psychopathology and (b) biological and adoptive relatives of the same child are not studied (Joseph, 2002).

Family studies

Family studies have also been conducted to investigate hereditary influences in the etiology of ADHD. Biederman et al. (1992) conducted a study to examine familial risk factors for ADHD in Caucasian families. A similar study was replicated in African American families by Samuel et al. (1999). Both studies found ADHD is transmitted in families with first-degree relatives of ADHD probands in comparison to controls. Faraone et al. (1993) investigated the familial transmission of ADHD and learning disabilities (LD) with a sample of 140 ADHD probands. Relatives of probands with ADHD with and without LD had a significantly higher risk of ADHD than normal children. Faraone et al. (2000) assessed the familial transmission of ADHD in families through girls with ADHD. Relatives of girls with ADHD had significantly higher rates of ADHD than comparisons.

Biederman et al. (1995) investigated children at risk for ADHD from parents who had clinical diagnoses of childhood onset of the disorder. Parents with a diagnosis of ADHD had children who were at a high risk for also meeting ADHD criteria. Wilens et al. (2005) evaluated the influence of parental ADHD and substance use disorders (SUD) on the risk for ADHD in their children. Children of parents with ADHD had 11 times the risk for developing ADHD, whereas children of parents with ADHD and SUD had 23 times the risk for developing ADHD in comparison to children of parents with neither diagnosis. Biederman et al. (2008) examined the familial risks in first-degree relatives for ADHD and SUD. Relatives were significantly at risk for ADHD when ADHD was 
consistent in the proband regardless of comorbidity with SUD. These studies conclude ADHD is transmitted in families.

Nonetheless, Joseph (2000) postulates family studies do not truly conclude a genetic component in the etiology of ADHD, but suggests they "might be able to demonstrate the familiarity of ADHD” (p. 560). He also suggests the disorder can be transmitted in families via environmental factors and/or genetic factors. Faraone and Biederman (2000) disagreed with Joseph's assertions of the irrelevant use of family studies to support the theory that genes influence the etiology of ADHD. According to the authors, "the theory provides the testable prediction that ADHD should run in families, which has yet to be proven wrong" (p. 570).

In summary, twin studies show MZ twins have a greater concordance for ADHD than DZ twins; however, identical twins are more likely to share equal environments than DZ twins, which could inflate results. Most twin studies are based on subjective measures where parents rate their children's ADHD behaviors, thus results may overestimate the heritability of ADHD symptoms. Adoption studies are plagued by methodological problems, thus they are weak in the assertion that genetic factors play an important role in the etiology of ADHD. Due to these problems, inferences drawn from the results are limited. Family studies suggest ADHD is transmitted in families, for first-degree relatives of ADHD probands have a higher prevalence for the disorder than comparison probands. Because rates of prevalence are higher for children of parents with ADHD, it seems children are more at risk for developing ADHD from their parents who have ADHD. Although results indicate ADHD runs in families, the findings do not indicate this disorder affects the majority of first-degree relatives of ADHD probands. Nonetheless, 
there is enough empirical evidence to support the notion that ADHD does have a genetic or biological component in its etiology.

\section{Environmental Factors}

Many researchers in the scientific community surrounding ADHD favor genetic or neuropsychological factors in the etiology of ADHD; however, alternative or precipitating factors in the etiology should not be excluded from consideration. Several non-genetic or environmental factors, considered risk factors, are associated with the etiology of ADHD. These include but are not limited to postnatal exposure to food additives, sugar, poor parenting, and chaotic/dysfunctional families (Banerjee, Middleton, \& Faraone, 2007; Barkley, 1998; Durston, 2003; Nigg, 2006).

Food additives and sugar

Food additives and sugar consumption have been considered to be among the alternative factors in the etiology of ADHD. Dietary hypotheses have been promoted mainly by parents reporting restlessness, irritation, and intractableness in the children in reaction to certain foods or additives (Kinsbourne, 1994). Consequently, many studies have been conducted to ascertain if the diet hypotheses hold true or false. Many websites have listed "myths" regarding sugar and/or food additives on their websites. The website operated by Novartis Pharmaceuticals Corporation (ADHD info.com, 2009) lists the following: "ADHD is caused by too much white sugar, preservatives, and other artificial food additives. Removing these things from a child's diet can cure the disorder." ChangeYourThinking.com (Morelli, 2009, para. 5) lists the following: “ADHD symptoms, especially hyperactivity, can be explained by a diet rich in sugars. In other 
words, these kids are on a sugar high. Just cut out the sugar and the hyperactivity goes away." BipolarCentral.com (2009) lists the following: "ADHD comes from eating too much junk food, sodas, and sugar." Lastly, the Learning Disabilities Association of Kentucky (2005) website posts the following: "ADHD is caused by too much sugar, preservatives, and other food additives."

Food additives. Feingold (1975) postulated there was a link between hyperactivity in children and synthetic food colors, flavors and naturally occurring salicylates. He claimed an elimination diet was the answer. Harley, Ray, et al. (1978) conducted a double-blind crossover study to test Feingold's hypothesis. There were no significant changes in hyperactivity attributable to the diet, thus the authors do not support the efficacy of the elimination diet for school-aged boys. Harley, Matthews, and Eichman (1978) also conducted a double-blind challenge experiment involving candy bars and cookies on 9 children with hyperactivity for 21 days. The hyperactive group was not found to be adversely affected by the consumption of artificial color food products. Weiss et al. (1980) conducted another double-blind study that examined behavioral responses to artificial food colors in children between the ages of 2.5 and 7 years old and found the majority in the study, 20 out of 22 , did not exhibit sensitivity to the color challenge.

On the other hand, Conners, Goyette, Southwick, Lees, and Andrulonis (1976) conducted a double-blind crossover trial study utilizing a diet eliminating artificial flavors, colors, and natural salicylates for a group of children with hyperkinesis. There was a reduction in hyperactive symptoms for children on the elimination diet free from food additives. Harley, Ray, et al. (1978) found there was evidence to suggest only 
younger children had an improvement in their behavior while on the Feingold diet. Weiss et al. (1980) found a 3-year-old boy exhibited significant elevations in two aversive behaviors while a 34-month-old girl had a significant increase in aversive behaviors after the color challenge in their study.

Bateman et al. (2004) investigated the effects of artificial colorings and benzoate preservatives on hyperactive behavior of 3-year-old children. There was an increase in hyperactive behaviors while the children received the food additives and the preservatives and a decrease in hyperactive behaviors during the withdrawal from these substances. Schab and Trinh (2004) conducted a meta-analysis of double-blind placebocontrolled trials to determine if artificial food colorings (AFC) contribute to the behavioral changes in children diagnosed with hyperactivity. After examining 15 studies, "results strongly suggest an association between ingestion of AFCs and hyperactivity" (p. 430).

Sugar. Soon after the appearance of food additives as a causation of ADHD, it was claimed sugar consumption causes problems in hyperactive children. However, a review of many studies found there is no scientific evidence to support a relationship between sugar and ADHD behaviors (Milich, Wolraich, \& Lindgren, 1986). Gross (1984) investigated the effect of sucrose on children with hyperkinesis. None of the 50 children in the study showed any consistent response to sucrose. Kaplan, Wamboldt, and Barnhart (1986) conducted a study on 9 disturbed children with most parents reporting adverse behavioral effects of sugar on their children. However, these children did not have any adverse effects to the sugar. Wolraich, Lindgren, Stumbo, Stegink, et al. (1994) conducted a double-blind controlled trial on normal preschool children and school-age 
children described as having sensitivity to sugar. Children thought to have sensitivity to sugar did not show any differences in their behaviors when ingesting the sugar substances.

Wolraich, Wilson, and White (1995) conducted a meta-analysis on 23 studies to examine the effect of sugar on the behavior or cognition of children. They concluded sugar does not affect the behavior or cognition of children. Kinsbourne (1994) reviewed several studies and stated, "There is no evidence that sugar alone can turn a child with normal attention into a hyperactive child" (p. 355). He continued to state, "Sugar clearly does not induce psychopathology where there was none before, but it may on occasion aggravate an existing behavior disorder" (p. 356). Schnoll, Burshteyn, and Cea-Aravena (2003) also found there was no solid basis to support the contention that sugar consumption causes hyperactive symptoms in children.

In summary, findings from the research are conflicting on food additives, thus this is an area of controversy. Some researchers believe the theory of food additives as a causation of ADHD has been studied and rejected (Faraone \& Biederman, 2000); however, this view cannot be supported by the existing empirical data. The research findings showed food additives can promote hyperactivity in some children, while they do not have an adverse effect on the behaviors of most children. Because there is conflicting scientific evidence, this issue needs further scrutiny. On the other hand, the evidence clearly shows sugar does not cause adverse behavioral effects in all children. In spite of the empirical evidence, teachers and parents continue to believe sugar causes ADHD (DiBattista \& Shepherd, 1993; Furukawa \& Mahan, 1994). 
Poor parenting and chaotic, dysfunctional families

The issue of whether or not poor parenting causes ADHD is another area causing much controversy. According to Barkley (1998), "theories of causation of AD/HD can no longer be based solely or even primarily on social factors, such as parental characteristics, caregiving abilities, child management, or other family environmental factors" (p. 176). Several websites list "myths" regarding environmental factors surrounding families. The National Resource Center (2009) website, the Play Attention Solution (2009) website and ADHDLibrary.org (2004) list the following: "Poor parenting causes ADHD." The Attention-Deficit Disorder Association (2006) website lists the following: "ADHD is basically due to bad parenting and lack of discipline, and all that ADHD children really need is old-fashioned discipline, not any of these phony therapies." The Novartis (2009) and the Learning Disabilities Association (2005) websites list the following: "Poor parenting is responsible for ADHD behaviors in children." Lastly, the Momference: A Meeting of the Moms (2008) website lists the following: "ADHD is caused by bad parenting and lack of discipline."

Poor parenting. Parents of children with ADHD tend to have higher rates of aversive, controlling, and negative behaviors in comparison to parents of children without ADHD (Wells et al., 2000). Factor analysis of both the Parent-Child Relationship Questionnaire (PCRQ) and the Alabama Parenting Questionnaire (APQ) revealed a factor measuring negative/ineffective discipline, which included the following items: disagree/quarrel, yell, hit, make child feel ashamed, spank, slap, threaten to punish but don't, don't check return of child from school, don't tell child where you are going, punishment depends on mood, etc. (Hinshaw et al., 2000; Wells et al., 2000). These 
scales present a base for what poor parenting looks like, while other studies included negative behaviors such as high maternal and paternal criticism and low maternal and paternal warmth (Goodman \& Stevenson, 1989b), negative affect, negative parenting styles, disciplinary aggression, poor parental coping, lack of sensitivity (Woodward, Taylor, \& Dowdney, 1998), negative parenting styles, parenting satisfaction, family functioning (Lange et al., 2005), and inconsistent discipline and poor monitoring/supervision (Rielly, Craig, \& Parker, 2006).

Goodman and Stevenson (1989b) conducted a study examining associations between adverse family factors and hyperactivity. High maternal and paternal criticism and low maternal and paternal warmth were significantly associated with hyperactivity. Woodward et al. (1998) conducted a study to identify associations between parenting and family life with childhood hyperactivity. Parents of the hyperactive group had significantly higher scores on negative affect (feelings of anger and disappointment; parent-child conflict), disciplinary aggression (shouts, loses temper with, physically punishes child) and poor parent coping, but significantly lower scores on authoritative parenting, sensitivity (responds to child's worries and concerns, etc.) in comparison to control parents. These results indicated a direct association between negative or poor parenting behaviors and hyperactivity.

Lange et al. (2005) conducted a study comparing mothers and fathers of boys with ADHD on the following areas: stress, support and quality of life, current family functioning, parenting style and satisfaction in the family of origin, and current family and current and past parental functioning. Parents in the ADHD group reported higher levels of authoritarian parenting, less parenting satisfaction, and greater problems in 
family functioning (communication, problem solving, roles, affective responsiveness, and affective involvement) than control parents. Rielly et al. (2006) examined parenting characteristics of boys and girls with and without subclinical attention problems. Parents in the attention-problem group scored lower on positive parenting and parental involvement, yet they scored higher on inconsistent discipline and poor monitoring/supervision than the comparison group.

Chaotic, dysfunctional families. Family dynamics have also been studied to ascertain if there is an association between adverse family factors and ADHD or ADHD symptomology. Several studies used various characteristics to support the idea of these types of families such as chaotic family style, poverty, overcrowding, exposure to harmful toxins, parental malaise (Goodman \& Stevenson, 1989b), clinically disturbed parents, less support from family and friends (Woodward et al., 1998), lack of cohesion, expressiveness, conflict, lower achievement and organization (Pressman et al., 2006), marital conflict, parental lifetime psychiatric disorders, socioeconomic status, stressful life events (Counts et al., 2005), stress, less social support, lower quality of life, and parental functioning difficulties (Lange et al., 2005).

Goodman and Stevenson (1989b) found that common environmental factors such as a chaotic family style can explain some of the variance in ADHD symptoms of inattentiveness and hyperactivity. Woodward et al. (1998) examined parenting and family life factors and their association with childhood hyperactivity with a sample of children with pervasive hyperactivity and control children. Parents of children with hyperactivity had difficulty coping effectively, were aggressive when using discipline, displayed negative affect towards their children, did not use authoritative parenting, and were less 
sensitive to their children than the control parents. Counts et al. (2005) evaluated the associations between family adversity and ADHD. ADHD symptoms, both inattention and hyperactivity, were related to children's perception of marital conflict. Results found by Lange et al. (2005) indicated parents of ADHD children reported more stress, less total social support and social support from family and friends, lower quality of life, and greater difficulties in parental functioning (psychological health, childhood ADHD, and parental ADHD symptomology) than control parents.

Pressman et al. (2006) examined links between family environment, parental psychiatric diagnosis, and child impairment with parents and children affected by ADHD. Parents of ADHD-affected sibling pairs reported significantly more problems with cohesiveness, expressiveness, achievement orientation, organization, and conflict than normal parents. Kepley and Ostrander (2007) investigated the family environments of children with ADHD. ADHD families had higher conflict and lower cohesiveness, expressiveness, and organization than controls. These findings are consistent with findings from Pressman et al. (2006). Dryer et al. (2006) found participants in their study believed home environment accounted for $18.77 \%$ of the variance in causal factors. Home environment included parenting styles (lack of discipline, lack of attention, lack of tolerance for the child), maladaptive behaviors of the child (inappropriate behavior that has been learned, watching too much TV, lack of self-discipline/control, child seeking attention) and unstable family environment.

Consequently, the literature shows parents of children with attentional problems, hyperactivity, or ADHD exhibit negative or poor parenting behaviors towards their children in comparison to control parents. In addition, correlations between negative 
parenting and hyperactivity were evident in the findings. Therefore, it is plausible to suggest poor parenting can exacerbate and maintain ADHD characteristics in children (Barkley, 1998, Nigg, 2006; Woodward et al., 1998). In addition, there is a possibility that ADHD behaviors in children can lead to poor parenting, which in turn exacerbates the condition (Barkley, 1998); therefore, it is a reciprocal cycle. Similarly, research evidence supports the idea that dysfunctional family factors are associated with ADHD and can adversely affect children who present with the disorder. It is possible a diagnosis of ADHD can cause dysfunction in the family which perpetuates ADHD symptomology. Further study needs to be conducted in this area. Nonetheless, there is a relationship between chaotic family environments and ADHD symptomology, but to date there is no study that clarifies their role, if any, in the etiology of ADHD. There is evidence to suggest negative parenting behaviors and dysfunctional families are related to ADHD, but there is not sufficient evidence to suggest that they cause or do not cause ADHD.

\section{Unsubstantiated Causes of ADHD}

Some studies have included statements eliciting knowledge or attitudes about unsubstantiated causes of ADHD such as emotional imbalance, immaturity, active personality, unclear expectations in the classroom, and incongruence between classroom expectations and developmental abilities (Carlson, Frankenbergrer, Hall, Totten, \& House, 2006; Õim, 2004). Emotions can affect attention as evidenced by children who are fixated on what has made them angry, frightened, or excited (Nigg, 2006); however, this does not support the idea that ADHD is caused by emotional imbalance. Children with ADHD often act silly and immature in comparison to their peers, thus they tend to play with younger children (Papalia, Olds, \& Feldman, 2004), but this does not suggest 
the disorder is caused by immaturity. These children may have active personalities or characteristics since they are constantly on the go or actively involved in many things (DSM-IV-TR, 2000); however, this is a symptom of the disorder. Children with ADHD may experience difficulties with classroom expectations due to inattention problems or hyperactivity/impulsivity, but these may be byproducts of ADHD symptoms ( $D S M-I V$ $T R, 2000)$. Therefore, emotional unbalance, immaturity, active personality, and difficulties with classroom expectations may be experienced by children with ADHD; however, the literature has not established either of them as contributing to the cause of ADHD.

\section{Intervention/Treatment Options of ADHD}

Interventions for treating ADHD are not limited to medication only, even though stimulant medication has been used for decades to treat the disorder (Barkley, 1998). Types of intervention services that have been used to treat children with ADHD include the following: medication management; mental health counseling; other counseling; and psychotherapy (Hoagwood, Kelleher, \& Feil, 2000). A meta-analysis of the literature on interventions for ADHD found the following types of interventions are used to treat ADHD: pharmacological, behavioral, and cognitive behavioral, parental, educational, and multimodal (Purdie, Hattie, \& Carroll, 2002).

\section{Pharmacological Treatment}

Hundreds of studies have been conducted on the use of pharmacological drugs as a treatment for ADHD, thus there is an enormous amount of scientific literature that can attest to the effectiveness of this type of treatment (Swanson et al., 1993). Of all the 
research conducted on interventions, pharmacological treatments and their effectiveness have been studied the most (Purdie et al., 2002). In addition, stimulant medication prescriptions have become the norm for children with ADHD with an increase over the years (Hoagwood et al., 2000).

In the 1950s, the types of medication used to treat hyperkinetic impulse disorder included amphetamines, chlorpromazinc, Ritalin, Benadryl, Phenergan, Desoxyn, Miltown, Meratran, Dramamine and Bonamine, and Atrax (Laufer et al., 1957). The types of medication currently used to treat ADHD include stimulants (Ritalin, Adderall, Dexedrine, \& Cylert), antidepressants (Tofranil, Imipramine, Prozac, Zoloft, Effexor, Wellbutrin) and antihypertensives (Carapres \& Tenex) (Doggett, 2004; Kollins, Barkley, \& DuPaul, 2001). Several side-effects are associated with the drugs used to treat ADHD: insomnia, decreased appetite, headache, dizziness, crying, irritability, anxiousness, nightmares, constipation, drowsiness, severe nausea, blurred vision, stomach aches, etc. (Doggett, 2004).

The MTA Cooperative Group conducted a study examining treatment strategies for ADHD over a 14-month period which included medication management behavioral treatment, combined treatment, and community care (MTA Cooperative Group, 1999). Children treated with medication management showed significantly greater improvement in ADHD symptoms than those receiving behavioral treatment and community care. Swanson et al. (1993) conducted a "review of reviews" on the effect of stimulant medication on children with ADD. The authors compared traditional reviews, metaanalyses, general audience reviews, and recent reviews in their review. Overall, the conclusion of the reviews was the agreement that treatment with stimulant medication is 
effective in the improvement of ADHD symptoms such as performance and behavior, but they are not as effective in academic achievement.

Crenshaw (1997) conducted a meta-analysis on 115 studies from 1981 to 1995 concerning the efficacy of stimulant medication in the treatment of children with ADHD, specifically in the area of academic achievement, social/peer relations, and aggressive/noncompliant behavior. Overall results indicated stimulant medications continue to have positive effects on behavior but are not as effective in the improvement of academic achievement. Purdie et al. (2002) found even though medication treatment is beneficial in helping with ADHD symptoms, it does not appear to improve emotional well-being or school-based achievement.

\section{Behavioral and Educational Interventions}

Behavioral interventions comprise parent training, child-focused treatment, school-based or classroom interventions, academic or educational interventions, and peer interventions (Daly, Creed, Xanthopoulos, \& Brown, 2007; MTA Cooperative Group, 1999). According to Frazier and Merrell (1997), "behavioral interventions are set apart from other techniques in their focus on changing observable and measurable behaviors through the manipulation of the environment" (p. 446). In the MTA Cooperative Group (1999) study, behavior treatment was comprised of, child-focused treatment, and schoolbased interventions. Behavioral interventions were not as effective on ADHD symptoms as combined treatments and medication management. However, more than three-fourths of the children were successfully maintained by behavioral interventions without medication throughout the study. 
DuPaul and Eckert (1997) conducted a meta-analysis which examined the effects of school-based interventions for both children and adolescents with ADHD and found academic intervention and contingency management strategies were most effective in improving classroom behavior in children with ADHD than were cognitive-behavioral strategies. They found cognitive-behavioral procedures were most effective in enhancing the academic performance of children with ADHD than academic intervention and contingency management. Purdie et al. (2002) suggested educational interventions are necessary in order to enhance educational outcomes. Academic (educational) interventions have been shown to help in the academic achievement of children with ADHD (Jitendra et al., 2007).

One-to-one interactions

Often children with ADHD have difficulty working in school due to inattention and/or disruptive behaviors (DSM-IV-TR, 2000); therefore, working one-on-one with them can prove to be advantageous in improving academic and behavioral difficulties. DuPaul, Ervin, Hook, and McGoey (1998) examined classwide peer tutoring (CWPT) and found children with ADHD involved in tutoring peers with non-ADHD children for 15 minutes, three times a week, had an increase in active engaged time and a reduction in disruptive off-task behaviors. These increases in on-task behaviors were comparable to those found in children who were treated with medication.

Plumer and Stoner (2005) investigated the effects of CWPT and peer coaching on the social behaviors of children with ADHD with three students in Grades 3 and 4. From an academic perspective, all three participants experienced a marked increase in positive social behaviors when interacting with their peers and were actively and positively 
engaged in working the CWPT program. Hook and DuPaul (1999) examined the effects of parent tutoring on the reading performance of four students with ADHD in Grades 2 and 3. All children increased in words read per minute (wcpm) at home and at school in the tutoring phase, with one child maintaining the highest level of wcpm at home and at school during follow-up.

\section{Combined or Multimodal Interventions}

Combined interventions typically involve both medication and behavior management. DuPaul and Weyandt (2006) found that a multimodal approach, including psychostimulant medication and behavioral strategies, is the most effective treatment for ADHD. In the MTA study, medication management was combined with parent training, school-based treatment, and child-focused treatment (MTA Cooperative Group, 1999). Results indicated combined treatment was found to be most effective clinically and statistically in treating ADHD symptoms in comparison to behavioral intervention and community care. Majewicz-Hefley and Carlson (2007) conducted a meta-analysis of combined treatments for children with ADHD using eight studies. Results indicated combined (multimodal) treatment is most effective for core symptoms of inattention and hyperactivity and least effective for peripheral features of academics. For children with ADHD who have academic difficulties, an integrated plan including educational, behavioral, psychological, and pharmacological interventions could prove to be beneficial (Frankenberger \& Cannon, 1999). 


\section{Diet as Treatment}

As previously mentioned, food additives were thought to cause ADHD (Feingold, 1975), resulting in the establishment of the Feingold diet to treat ADHD symptoms. This resulted in parents changing their children's diets to treat the disorder. Diet supplementation has also been used as a treatment option for ADHD symptoms. In one study, $37 \%$ of parents tried elimination diet and $31 \%$ tried fatty acid supplementation as treatment options for their child with ADHD with low satisfaction rates of $45 \%$ for elimination diet and 34\% for fatty acid supplementation (Concannon \& Tang, 2005). Similarly in another study, $26 \%$ of parents tried dietary supplements and $66 \%$ tried a modified diet, with low satisfaction rates of $7.6 \%$ for dietary supplements and $42.4 \%$ for modified diet (Sinha \& Efron, 2005). As previously discussed, a “myth" has been listed on websites in regard to diet as a cure for ADHD, thus many parents may believe their child with ADHD can be cured if their diet is modified.

Harley, Matthews, et al. (1978) examined hyperactive children and their consumption of artificial colors over a 21-day period with results indicating these children did not display any adverse behaviors, thus not supporting Feingold's claims. Kavale and Forness (2001) reviewed 23 research studies investigating the Feingold hypothesis. Findings from the meta-analysis did not support the Feingold hypothesis. The authors assert, "By using scientific standards for accumulating evidence not found in less formal reviews, it was possible to draw reliable and reproducible conclusions suggesting that the Feingold K-P diet is not an effective intervention approach for hyperactive children" (p. 329). After reviewing various studies investigating the effects of the Feingold diet, Schnoll et al. (2003) state, "Examination of the data from these studies 
indicated that the effects of the Feingold diet are less dramatic and predictable than would be expected on the basis of Feingold's claims" (p. 66).

On the other hand, Conners et al. (1976) found a diet eliminating artificial flavors, colors, and natural salicylates reduced hyperactive symptoms in children with hyperactivity. Harley, Ray, et al. (1978) also found younger children had an improvement in their behavior while on an elimination diet thus suggesting there may be a small group of younger children who might experience adverse behaviors; however, further study was necessary. Arnold (1999) suggested a few-foods diet had convincing evidence for a selected subgroup of children. Schnoll et al. (2003) found in their review of literature a small subset of children demonstrated a dramatic reduction in hyperactivity when on the Feingold diet. A recent study found hyperactive behaviors were reduced in preschool children with the removal of artificial colorings and sodium benzoate from their diets (Bateman et al., 2004).

Richardson and Puri (2002) found that highly unsaturated fatty acids (HUFAs) supplementation was able to reduce ADHD-related symptoms in children who had specific learning difficulties. Arnold (1999) suggested essential fatty acid supplementation has promising effects, but the clinical trials have produced equivocal results. He also suggested that single-vitamin megadoses, Chinese herbals, iron and magnesium supplementation have some promising results, but zinc and amino acid supplementation and megadose multivitamin combinations are probably ineffective. Schnoll et al. (2003) assert that "diet modification plays a major role in the management of ADHD and should be considered as part of the treatment protocol" (p. 63). 
In summary, empirical evidence supports the use of stimulant medications and behavioral and educational interventions to treat ADHD behaviors. Stimulant medications are undoubtedly effective in improving behavioral symptoms of ADHD but are not as effective in improving academic achievement. Behavioral and educational interventions are viable treatment options for children with ADHD. Either used alone or in combination with medication, they are effective in improving academic, behavioral, and social difficulties faced by children with ADHD. Educational interventions such as one-to-one interactions allow children with ADHD to work with another person to help them academically, behaviorally, and socially. Empirical evidence is contradictory regarding diet as a treatment option for the hyperactivity component of the disorder. Some subsets of children with hyperactivity benefit from diet treatment, while others do not benefit at all. In addition, there is no evidence to suggest diets are helpful in treating the inattentive symptoms of ADHD. Therefore, this suggests that diet treatment is beneficial to some children with ADHD but not most children. Even though the empirical research has provided conflicting evidence, there is sufficient research to indicate that diet treatments do not cure ADHD.

\section{Knowledge-based Versus Belief-based Items Regarding ADHD}

Many studies have assessed the knowledge and/or beliefs or attitudes of ADHD (Barbaresi \& Olsen, 1998; Bekle, 2004; Jerome et al., 1994; Kos et al., 2004; Ohan et al., 2008; Sciutto et al., 2000; West et al., 2005;). However, these studies did not differentiate between knowledge and belief items, thus all items were treated as knowledge items (Kos et al., 2006). This poses a problem for the existing research findings, for in order for items to be considered as knowledge they must be based on empirical evidence and 
accepted by general or group consensus (Ernest, 1989; Nespor, 1987) or supported by diagnostic criteria. Additionally, if knowledge is to be properly assessed, then the items used to assess this knowledge must be supported by empirical evidence or diagnostic criteria. West et al. (2005) stated, "In constructing the KADD-Q, care was taken to only include items that were arguably well supported by empirical research" (p. 196). However, all of the items used in this study were not published so verification that all items were in fact well supported by empirical evidence must be taken at face value. As previously mentioned, the authors did not differentiate between knowledge and belief items even though claiming to assess both types. Nonetheless, I set a criterion to distinguish between knowledge-based statements and non-knowledge-based statements. A statement or item considered to be knowledge-based must be supported by empirical evidence or diagnostic criteria which can be evaluated as correct or incorrect, true or false. Items not supported by empirical evidence or diagnostic criteria cannot be considered knowledge-based and cannot be evaluated as correct or incorrect. Therefore, these items must be considered and assessed as belief items.

As previously reviewed above, genetic factors play a part in the etiology of ADHD, although they do not directly cause the disorder; therefore, items pertaining to their role in the etiology are supported by empirical evidence as correct or incorrect, thus they are knowledge-based. Any other suggested causes that do not have empirical support must be treated as beliefs. The DSM has clearly established the symptoms and the clinical diagnostic criteria of ADHD; therefore, items pertaining to these issues are clinically supported, thus they are knowledge-based. Empirical evidence supports the occurrence by gender and race, the risk for delinquency, video game playing, and 
intervention/treatment options for ADHD. Empirical evidence pertaining to

environmental factors such as poor parenting, family dynamics, and sugar and food additives has not conclusively supported their definite role in the etiology of ADHD. In addition, there is contradictory empirical evidence pertaining to the duration of ADHD and IQ.

The following section examines the studies that have assessed knowledge and/or beliefs regarding ADHD.

\section{Studies Conducted on Knowledge or Beliefs Regarding ADHD}

Due to the high profile of ADHD, there have been many studies published examining the knowledge and beliefs or attitudes relating to ADHD using samples of professionals and parents. However, not all of the literature actually measures the same knowledge base. In fact, many studies utilized different instruments with heterogeneous items to elicit their information, thus creating a diverse pool of results pertaining to the knowledge, beliefs, and/or attitudes of ADHD.

As shown in Appendix B, 27 of the 45 studies investigated knowledge, beliefs, or opinions or attitudes of teachers working in public school settings. One study conducted by Kos et al. (2004) examined teachers from Catholic and private schools while the study by Dryer et al. (2006) collected data from teachers recruited from government and private primary schools. Seven of the eight studies using parent samples were obtained from public schools and all were from parents of children who were diagnosed with ADHD or were at high risk for ADHD; however, Dryer et al. (2006) recruited 79 parents of children with and 87 parents of children without ADHD from both government and private 
primary schools. To date, only one study has examined and compared both teacher and parent groups (West et al., 2005).

All of the studies shown in Appendix B were not included for discussion in this review. The studies included in this review used the same or similar statements regarding the knowledge and/or beliefs of ADHD and were a source of valid data. They also used the same methodological formats, which are discussed in more detail below. On the other hand, studies excluded from this review used statements that were not the same as other studies regarding the knowledge and/or beliefs of ADHD. In addition, studies that used different response formats such as multiple choice or fill-in-the-blank were not included in this review.

Many of the studies assessing teachers' knowledge and/or beliefs regarding ADHD (Barbaresi \& Olsen, 1998; Jerome, Washington, Laine, \& Segal, 1999; Bekle, 2004; Ohan et al., 2008) used the same true-and-false format designed by Jerome et al. (1994). Õim (2004) and Stormont and Stebbins (2005) used eclectic questionnaires compiled from various studies and the literature regarding ADHD. Ghanizadeh et al. (2006) and Ghanizadeh (2007) used a self-report, true/false questionnaire prepared by the authors.

Several studies also used the true-and-false format; however, a third option of Don't Know incorporated by Sciutto et al. (2000) was included in their knowledge statements (Kos et al., 2004; Liesveld, 2007; Sciutto et al., 2000; Tsai, 2003; West et al., 2005). Kos et al. (2004) used items from both Jerome's and Sciutto's instruments.

Carlson et al. (2006) assessed teachers' attitudes towards ADHD and intervention/treatment options using a Likert scale. 


\section{Adequacies and Inadequacies of Studies}

There are some positive aspects of the studies that have examined knowledge and/or attitudes regarding ADHD including the use of the same survey items in the majority of the studies (Barbaresi \& Olsen, 1998; Bekle, 2004; Jerome et al., 1994, 1999;

Ohan et al., 2008), which provides a base of consistent items for evaluative purposes. Other studies used a few of the same or similar items in their surveys, thus these items add to the existing knowledge base (Ghanizadeh et al., 2006; Ghanizadeh, 2007; Kos et al., 2004; Liesveld, 2007; Õim, 2004; Sciutto et al., 2000; Stormont \& Stebbins, 2005; Tsai, 2003; West et al., 2005).

However, many inadequacies are evident in these studies examining knowledge and/or beliefs, attitudes, or opinions. First, many of these past studies used nonrandom small samples which can limit their findings and generalizability (Barbaresi \& Olsen, 1998; Bekle, 2004; Jerome et al., 1999; Kos et al., 2004; West et al., 2005). Second, a true-and-false format allows for participants to guess the answer, giving them a $50 \%$ chance of guessing correct even if they don't know the correct answer, thus possibly resulting in artificially inflated results which may not truly reflect what they know (Kos et al., 2006; Sciutto et al., 2000) or lower results if participants guessed wrong. Third, none of these studies explicitly discussed what they considered to be adequate or appropriate knowledge for individual items; however, it is assumed by the wording used that Jerome et al. (1994) considered individual percentages of $76 \%$ and higher to indicate teachers were well informed about specific items. Kos et al. (2004) calculated an overall knowledge score of $60.7 \%$ for their teachers and considered their "knowledge about ADHD was adequate" (p. 525), although this percentage is low. Ohan et al. (2008) 
indicated teachers with high knowledge had a total score of about $80 \%$ correct or better, teachers with average knowledge had a total score of about $70 \%$ to $80 \%$ correct, and teachers with low knowledge had total scores less than $69 \%$ or lower correct. Therefore, there is no criterion set for what is considered to be adequate or appropriate knowledge for individual items and some guidelines for what could be considered adequate overall knowledge.

Fourth, a few studies published only some of their findings while others omitted some findings or didn't include an answer sheet to verify correct answers (Kos et al., 2004; Õim, 2004; Liesveld, 2007; Sciutto et al., 2000; Tsai, 2003). Carlson et al. (2006) used the terms attitude and beliefs interchangeably without clarifying a conceptual difference, if any. Snider et al. (2003) referred to their statements as opinions, while Frankenberger, Farmer, Parker, and Cermak (2001) called the same or similar statements attitudes and opinions. Both studies referred to these concepts as beliefs in the discussion section. Therefore, these concepts were not carefully conceptualized in these studies, which can cause confusion in the literature.

Finally, some studies claiming to assess teachers' knowledge and beliefs or attitudes (Jerome et al., 1994, 1999; West et al., 2005) actually only assessed knowledge (Kos et al., 2006). Even though these inadequacies exist, other problems may exist with the existing knowledge base regarding ADHD. In order to be evaluated as a knowledge item, each item must be supported by empirical evidence or diagnostic critiera. Knowledge items can be correct or incorrect, true or false. However, as mentioned, many of the studies evaluated items as knowledge items even though claiming to have evaluated beliefs or attitudes. If any of these statements are not supported by empirical 
evidence, they were incorrectly evaluated as knowledge items, thus providing a false knowledge base. Any items not supported by empirical evidence or diagnostic criteria must be evaluated as beliefs. Therefore, items used in the aforementioned studies will be critically analyzed using the empirical evidence presented in the previous section or the clinical criteria of the $D S M-I V-T R$ to determine if they are in fact knowledge-based or belief-based.

\section{The Knowledge and Beliefs of Teachers, Parents, and Others Regarding ADHD}

Symptoms and Characteristics of ADHD

\section{Hyperactivity and Inattention}

Hyperactivity and inattention are both subtypes and symptoms of ADHD;

however, children do not have to present with both in order to be diagnosed with ADHD. According to the DSM IV-TR (2000) there is a combined subtype of ADHD including both hyperactivity and inattention characteristics, but children can be diagnosed with either subtype. Õim (2004) included the following statement in his study; however, he did not publish the 'correct' answer: In order to have the diagnosis of ADHD, both hyperactivity and inattentiveness must be present. Based on the literature, this statement is knowledge-based with a definitive answer of false. Õim reported $66.7 \%$ of Estonian and $58.3 \%$ of Norwegian teachers responded correctly to the statement; however, these results cannot be compared with other studies due to the omission of a published correct answer. Ohan et al. (2008) included a similar statement in their study: A girl/boy can be appropriately labeled as ADHD and not necessarily be over-active. Findings showed that $79.8 \%$ of teachers responded with true to the statement. Stormont and Stebbins (2005) 
included a similar statement in their survey, keying the answer as true, and found $66 \%$ of pre-school teachers understood children with ADHD can have problems with attention but not be overactive.

\section{Inattention}

Inattention is one of the subtypes of ADHD which is characterized by difficulty sustaining attention, difficulty with organization, difficulty following through on instructions, and failure to listen attentively and complete tasks. Associated features of ADHD include inadequate self-application to tasks or activities requiring sustained mental effort, which can be interpreted by others as laziness, lack of responsibility, oppositionality or an unwillingness to conform to what others have demanded (DSM-IV$T R, 2000)$. Defiance and oppositionality are not characteristics of the inattention subtype of ADHD but are characteristics of Oppositional Defiant Disorder (ODD). The DSM-IV$T R$ (2000) states, "Oppositional behaviors must also be distinguished from the disruptive behavior resulting from inattention and impulsivity in ADHD” (p. 102). Therefore, inattention is not primarily a consequence of defiance or oppositional behavior. Few studies included the following statement in their surveys: The inattention of children with ADHD is not primarily a consequence of defiance, oppositionality, and an unwillingness to please others. The DSM-IV-TR criteria support this statement as knowledge based; therefore, it supports the keyed answer of true as correct.

Results from Jerome et al. $(1994,1999)$ indicated the majority of practicing teachers $(88 \%)$ and teachers in training $(93 \%)$ answered the following statement as true: The inattention of children with ADHD is not primarily a consequence of defiance, oppositionality, and an unwillingness to please others. Bekle (2004) found 93\% of 
teachers and $85 \%$ of education students answered the statement as true. Ohan et al. (2008) found $78.5 \%$ of their teacher sample responded with true to the statement. These results show that most teachers know the inattention of children with ADHD is not associated with defiance, oppositionality, or an unwillingness to please others.

Dryer et al. (2006) found participants, including teachers and parents, rated the concentration/attention factor significantly higher than other four ADHD characteristic factors, indicating they believed concentration and attention issues are characteristics of ADHD. This factor included the following characteristics: short attention span, difficulty finishing tasks, concentration problems, easily distracted, and difficulty planning. West et al. (2005) included a statement about inattention in their study and found $93 \%$ of teachers and $92 \%$ of parents know that children with ADHD tend to be inattentive. This result shows that most participants know inattention is a bona fide characteristic of ADHD.

\section{Hyperactivity}

Hyperactivity is another subscale of ADHD and those children diagnosed with this type of ADHD have the characteristic of being on the go constantly according to the $D S M-I V-T R$. In one study, Dryer et al. (2006) found participants endorsed overactive, poor self-control, and fidgeting as 3 of 10 most highly endorsed characteristics of ADHD. These 3 and 11 other characteristics made up the behavior control factor in this study, which contained symptoms found in the ADHD hyperactive-impulsive subtype. Participants, including teachers and parents, endorsed this factor as highly characteristic of ADHD. In another study, Pentecost and Wood (2002) found 69\% of social workers believed children with ADHD are on the go at all times. 


\section{Other Possible Symptoms or Characteristics}

The DSM-IV-TR (2000) describes the diagnostic features and associated features of ADHD (pp. 85-88), and hallucinations are not included in these sections, thus they have not been associated with ADHD. In addition, the DSM-IV-TR includes a section under substance-related disorders entitled Hallucinogen Use Disorders, HallucinogenInduced Disorders, and Other Hallucinogen-Induced Disorders, with none referencing ADHD. Incidentally, haptic hallucinations have been associated with low doses of the treatment methylphenidate (MPH) for ADHD in some cases (Gross-Tsur, Joseph, \& Shaley, 2004). Õim (2004) exclusively included the following knowledge statement in his study: Hallucinations are associated with ADHD. Based on the clinical criteria of the $D S M-I V-T R$, the correct answer is false. Õim reported the majority of Estonian teachers, $84.5 \%$, and Norwegian teachers, $94.5 \%$, correctly responded to the statement; however, the results cannot be compared with other studies due to the researcher's omission of a correct answer.

The following statement was included in three studies: Children with ADHD generally display an inflexible adherence to specific routines and rituals. However, the clinical criteria of the $D S M-I V-T R$ do not include a characteristic of ADHD that suggests children with ADHD display an inflexible adherence to specific routines and rituals. Therefore, this knowledge statement was keyed as false. Kos et al. (2004) found only $22.5 \%$ of in-service teachers and $11.1 \%$ of pre-service teachers responded with false to the statement. However, these results did not show how many participants answered 'don't know' to this statement; therefore, it is unknown as to how many believed the statement. Sciutto et al. (2000) and Tsai (2003) included this statement in their studies; 
however, Sciutto et al. (2000) did not publish results and Tsai (2003) found the majority of teachers $(87 \%)$ most frequently answered this question with 'don't know'. Since this symptom is not in the DSM-IV-TR and has not been established in the literature, the keyed answer of false is the accepted answer.

Children with ADHD often do not follow through on instructions and fail to complete assignments (DSM-IV-TR, 2000). Reeve and Schandler (2001) found children with ADHD did not complete all categories on standardized assessments and had more perserverative responses and perserverative errors than controls, which supports the assertion that they do not complete assignments. A few studies included the following statement in their studies: Children with ADHD misbehave primarily because they don't want to follow rules or complete assignments. The DSM-IV-TR (2000) does not suggest misbehavior is the reason children with ADHD have difficulty with following rules or completing assignments. Since this is the diagnostic criteria for ADHD at this time, this knowledge statement was correctly keyed as false. Jerome et al. (1999) found the majority of teachers $(96 \%)$ and teachers in training (100\%) responded with false. Bekle's (2004) results were consistent for $100 \%$ of teachers and $93 \%$ of education students responded with false. Similarly, more than $90 \%$ of teachers responded with false before receiving ADHD training (Barbaresi \& Olsen, 1998). A recent study reported $91.9 \%$ of teachers responded with false (Ohan et al., 2008). These results indicate participants believed children with ADHD do not misbehave volitionally.

Jerome et al. (1994, 1999) included the following statement in their survey: If a child can get excellent grades one day and awful grades the next, then he must not be ADHD. This statement was keyed as false, but there is no empirical evidence to support 
or negate the statement. There is also no clinical criterion in the DSM-IV-TR to support the statement. Therefore, it is not based on knowledge, so it is best considered a belief. Results from Jerome et al. (1994, 1999) showed $98 \%$ of teachers and 95\% of teachers in training believed the statement to be false which was consistent with Bekle's (2004) $100 \%$ of teachers and $90 \%$ of student teachers. Similar results from Barbaresi and Olsen (1998) indicated more than $90 \%$ of teachers in pre-training believed the statement to be false. Ohan et al. (2008) found $93.6 \%$ of teachers answered the statement with false. For a child with ADHD, concentration and remaining on task is an issue (DSM IV-TR, 2000); therefore, depending on the lesson content, he/she might master work one day and completely flounder the next day, but this does not negate the disorder. Participants in the studies above seem to realize inconsistent grades do not negate the disorder.

Children with ADHD have difficulty engaging in tasks requiring mental effort, they have difficulty sustaining attention, they do not follow through on instructions or they make careless mistakes in schoolwork (DSM-IV-TR, 2000). However, there is nothing in the $D S M-I V$-TR that refers to children doing better if they try harder. Therefore, it is not known if children with ADHD could do better if only they would try harder. Nonetheless, Jerome et al. (1994) included the following statement in their study, which has been used in subsequent studies: Children with ADHD could do better if only they would try harder. The answer was keyed as false although it is not known if the answer is true or false. Since the statement is not empirically supported or found in the $D S M-I V-T R$, it is not knowledge-based; therefore, it is based on a belief. Nonetheless, $92 \%$ of Canadian and $89 \%$ of American teachers believed the statement to be false 
(Jerome et al., 1994). Subsequently, 95\% of teachers in training believed the statement to be false (Jerome et al., 1999).

Bekle's (2004) replication of the study reported $93 \%$ of teachers and $90 \%$ of education students responded consistently with results from Jerome et al. $(1994,1999)$. Barbaresi and Olsen (1998) also published consistent results with more than 90\% of teachers believing the statement to be false even before receiving ADHD training. Ohan et al. (2008) reported consistent results for $91.2 \%$ of teachers who believed the statement to be false. This statement yielded consistent results for all studies that used it. In a similar statement, fewer pre-service teachers (78.2\%) believed students with ADHD just need to try harder (S. Robin, 1998). These results indicated most of the participants did not believe children with ADHD could do better if they only tried harder in school.

Jerome et al. (1999) included the following statement in their study and labeled it a "myth": If a child can play Nintendo for hours, he or she probably isn't ADHD. The answer was keyed as false, and based on the research literature (Biolac et al., 2008; Shaw et al., 2005) the statement is knowledge-based; therefore, a false answer is correct. The literature showed the majority of participants did not believe this statement and the empirical evidence found the statement to be false, thus the statement is not a "myth". In fact, Jerome et al. (1994) found 92\% of both groups of teachers responded with false as did $90 \%$ of teachers in training (Jerome et al., 1999). In the replicated study by Bekle (2004), $100 \%$ of teachers and $88 \%$ of student teachers responded with false, which is consistent with the teachers $(88.1 \%)$ in the study by Ohan et al. (2008). Similarly, $96 \%$ of school psychologists (Smith, 1999) and 90\% of teachers in pre-training (Barbaresi \& Olsen, 1998) responded with false to the statement. Kos et al. (2004) reported slightly 
lower results: $77.5 \%$ of in-service teachers and $82.2 \%$ of pre-service teachers responded with false to the statement.

In summary, more than two-thirds of participants knew children can be diagnosed with ADHD with either inattention or hyperactivity and that children with ADHD are on the go all the time. Most teachers believed the inattention of children with ADHD has nothing to do with defiance, oppositionality, and an unwillingness to please others and that children with ADHD can play video games for hours. Most participants were unsure whether the displaying of an inflexible adherence to specific routines and rituals is a characteristic of ADHD, while most teachers disbelieved children with ADHD misbehave because they do not want to be compliant, inconsistent grades negate ADHD and trying harder in school means doing better.

\section{General Information Regarding ADHD}

\section{Gender}

The following statement appeared in several studies: ADHD occurs equally as often in girls as boys. The answer for this statement was keyed as false and can be supported by the empirical evidence. Jerome et al. (1994) found about $80 \%$ of both groups of teachers responded with false to the statement. In comparison with teachers, fewer teachers in training (64\%) responded with false to the statement. Bekle (2004) found more teachers (90\%) and more education students (78\%) believed ADHD does not occur equally in girls and boys. Similarly, more than $90 \%$ of teachers chose false to the statement before receiving ADHD training (Barbaresi \& Olsen, 1998); however, post-training results were not supplied. 
Most nurses from Kansas believed boys and girls do not have similar rates of ADHD; however, the authors did not publish specific results (Frisch, Moser, Hawley, Johnston, \& Romereim, 2003). The majority of pre-school teachers (95\%) believed girls are not more likely to be hyperactive than boys (Stormont \& Stebbins, 2005). Tsai (2003) found the majority of teachers (91\%) did not know if the prevalence of ADHD in boys and girls is equivalent in school. Sciutto et al. (2000) and Liesveld (2007) did not publish their findings to this question. Based on the literature discussed above, girls are more likely to be inattentive than hyperactive, thus fewer girls are diagnosed with the hyperactive subtype and overall fewer girls are diagnosed with ADHD.

Several websites listed statements about ADHD occurring less in girls than in boys as "myths." However, empirical evidence shows that, in fact, ADHD does not occur as frequently in girls as it does in boys. Additionally, the majority of participants studied do not believe it occurs equally in boys and girls. Therefore, there is no "myth" because a majority of people know the correct, empirically based answer.

\section{Ethnicity}

The following statement was included in several studies: ADHD occurs more in minority groups than in Caucasian groups. The answer to this statement was keyed as false, which is supported by the research literature. One study found $97 \%$ of Canadian teachers, $92 \%$ of American teachers, and $90 \%$ of teachers in training knew the statement to be false (Jerome et al., 1994, 1999). Similarly, 100\% of teachers and $98 \%$ of education students in Bekle's (2004) study also chose 'false' as did more than $90 \%$ of the teachers in pre-training (Barbaresi \& Olsen, 1998). Overall, the majority of teachers indicated that they knew ADHD does not occur more in minority groups than in Caucasian groups. 


\section{Risk for Delinquency}

Several studies included the following statement and correctly keyed the answer as true: Children with ADHD have a high risk for becoming delinquent as teenagers. Based on the empirical evidence, children with ADHD are at risk for becoming delinquent (Lee \& Hinshaw, 2004; Molina et al., 2007; Young \& Gudjonsson, 2006). Therefore, this statement is knowledge-based. In response to the statement, Jerome et al. (1994) found $70 \%$ of Canadian and $71 \%$ of American teachers correctly responded with true to the statement, whereas $60 \%$ of teachers-in-training agreed (Jerome et al., 1999). Similarly, $73 \%$ of teachers and $60 \%$ of education students responded with true to the statement (Bekle, 2004). Fewer teachers $(64.8 \%)$ and parents $(54.4 \%)$ in Iran believed the statement (Ghanizadeh, 2007; Ghanizadeh et al., 2006). In a recent study, Ohan et al. (2008) found $50.4 \%$ of teachers agreed with the statement, which shows that these participants were divided in their response to this statement. Brook et al. (2000) asked the following question but did not report results: Are ADHD pupils at risk to become: delinquent, alcoholics, drug addicts and sufferers of depression? Due to the various types of delinquent behaviors that exist, it is not known as to what the participants in these studies understood was meant by "high risk for becoming delinquent as teenagers." Jerome et al. (1994, 1999) listed this statement as a "myth"; however, the empirical evidence found the statement to be true. In addition, more than half of the participants in all studies believed the statement to be true. Therefore, this statement that children with ADHD have a high risk for becoming delinquent as teenagers should not be considered a "myth" but is an empirically based true statement. 


\section{Intelligence}

Õim (2004) included the following statement in his study: A pupil with ADHD has lower IQ than his peers. There was no published 'correct' answer key for this item in the study; therefore, it is not known whether true or false was the 'correct' answer. Even so, the literature does not support an absolute true or false answer, thus the statement is not based on knowledge and cannot be correct or incorrect. Therefore, the statement is best considered to be belief based. Õim (2004) found 59.6\% of Estonian teachers and $98.2 \%$ of Norwegians 'correctly' responded to the statement, although these results cannot be compared with other studies. The following statement was included in two studies: ADHD children's IQ is more than that of non-ADHD children. Ghanizadeh et al. (2006) found only $13 \%$ of teachers and $14.4 \%$ of parents (Ghanizadeh, 2007) believed children with ADHD have a lower IQ than their peers, $44.4 \%$ of teachers and $45.9 \%$ of parents believed their IQ is similar to peers, and $38.3 \%$ of teachers and $39.6 \%$ of parents believed children with ADHD have a higher IQ than their peers. Most participants in these two studies believed children with ADHD have an IQ that is the same as their peers. Since fewer than $50 \%$ of participants actually believed the idea that children with ADHD have lower IQs than their peers, it cannot be labeled a "myth" at this time.

\section{Age of Onset}

Õim (2004) included the following statement in his study and labeled it a misconception: ADHD may begin in adolescence. According to the diagnostic criteria in the $D S M-I V-T R$, the answer for this statement is false, although this criterion is debated by several researchers (Barkley \& Biederman, 1997; Washbusch et al., 2007). Õim (2004) found more than half of Estonian teachers (52.8\%) and 23\% of Norwegian 
teachers incorrectly responded that it could begin in adolescence. More Norwegian teachers correctly understood ADHD begins before adolescence. Tsai (2003) and Liesveld (2007) included the following statement in their studies: In order to be diagnosed with ADHD, the child's symptoms must have been present before age 7 . This answer is true, but $56 \%$ of teachers in Liesveld's study answered false to the statement, while 68\% in Tsai's study answered with 'don't know'. Sciutto et al. (2000) also used the same statement but did not publish findings.

\section{Expression}

To address this specific criterion, Õim (2004) included this statement in his survey: ADHD may express itself in only one environment. However, he did not indicate whether the correct answer was keyed as true or false. Based on the DSM-IV-TR, false is the correct answer. Õim (2004) reported that $82.5 \%$ of Estonian and $91.3 \%$ of Norwegian teachers correctly answered the statement, although these results cannot be compared with other results. Sciutto et al. (2000) and Tsai (2003) included a question pertaining to this issue in their studies; however, neither one of them furnished the results, thus it is not known how their teachers responded to this statement.

\section{Duration}

Several studies addressed the following statement with the answer key indicating the answer was false: Most children with ADHD outgrow their disorder and are normal as adults. However, based on the empirical evidence there is no correct answer to this particular statement (Barkley et al., 2003; Claude \& Firestone, 1995; Mahomedy et al., 2007; Mannuzza et al., 1998). Therefore, the statement must be considered a belief. This 
statement was also considered to be a "myth" by Jerome et al. (1999) and subsequent studies. Results from the study conducted by Jerome et al. (1994) indicated 59\% of Canadian teachers and about $50 \%$ of American teachers believed ADHD cannot be outgrown by most children; however, only $31 \%$ of teachers in training believed it cannot be outgrown. Ohan et al. (2008) reported consistent results from their teacher sample (57.3\%). Bekle (2004) replicated the study by Jerome et al. (1999) and found higher results than the previous study: $70 \%$ of teachers and $58 \%$ of student teachers believed ADHD cannot be outgrown by most children. Results of these studies indicated participants are not sure if ADHD can be outgrown or not, which is consistent with the contradictory evidence in the research.

S. Robin (1998) found $32.8 \%$ of pre-service teachers in her study believed children do not outgrow the disorder, with $54.7 \%$ remaining unsure. More than half of the participants were unsure, thus supporting the uncertainty of whether it is outgrown or not. Brook et al. (2000) found $28.3 \%$ of teachers in their sample believed ADHD-related difficulties continue for life. Only a few teachers $(8.7 \%)$ and parents $(6.1 \%)$ in the two studies in Iran believed ADHD-related difficulties continued for life (Ghanizadeh et al., 2006; Ghanizadeh, 2007). Higher results were found by Stormont and Stebbins (2005) who found $77 \%$ of pre-school teachers believed ADHD is not a condition children will outgrow, while Smith (1999) found the majority of school psychologists (92.6\%) believed children with ADHD will not outgrow the disorder by adulthood.

Õim (2004) found $73.3 \%$ of Estonian teachers and 32.7\% of Norwegian teachers believed it is possible to outgrow ADHD. The inconsistencies in the literature are indicative of these mixed results. Symptoms may attenuate, but for the most part continue 
for the lifetime (DSM IV-TR, 2000). Both Sciutto et al. (2000) and Tsai (2003) included a statement in their surveys pertaining to children outgrowing ADHD to function as normal adults; however, neither one published the results of this statement, thus limiting the ability to discuss these results. Since the statement is not empirically false and the research findings are conflicting, it cannot be determined at this time whether the idea that children outgrow ADHD is a myth or not.

In summary, most participants knew that girls are not diagnosed with ADHD as much as boys and that ADHD does not occur more in minority groups, while many teachers knew that children with ADHD are at risk for delinquency as teenagers. Some teachers erroneously believed ADHD can begin in adolescence. Also, some teachers believed ADHD can be outgrown, while others believed it cannot be outgrown. Few participants believed children with ADHD have lower IQs than their peers. Findings pertaining to the expression of ADHD were not published adequately to evaluate.

\section{Causes of ADHD}

Many researchers believe there is a hereditary influence in the development of ADHD; however the evidence is controversial. Nonetheless, many studies have included a statement pertaining to whether people believe ADHD is inherited. There is a technical difference between inherited and heritability. The term heritable means heredity or genes contribute to or influence a specific trait and is expressed on a continuum ranging from 0.0 to 1.0 , with 1.0 indicating genes are $100 \%$ responsible for the trait. Observable traits are often a combination of both genetic and environmental factors, which is called multifactorial transmission. On the other hand, inherited means genes are exclusively responsible for a specific observable trait, such as the ability to tongue curl, which is 
transmitted directly from parent to child. Traits are exclusively transmitted via dominant, recessive, or polygenic inheritance (Papalia et al., 2004). On considering the question: “Is ADHD inherited?" Nigg (2006) provided this answer, "The propensity to develop ADHD is partially influenced by heredity" (p. 220). This answer supports the notion that genetic factors influence ADHD, but only partially. Therefore, ADHD is highly heritable, but it is not inherited.

\section{Genetic or Biological Factors}

Jerome et al. (1994) included a statement on their survey suggesting that ADHD is inherited and coded the statement as true; however, the literature supports the idea ADHD may have hereditary influences but does not support the idea it is solely inherited. It is unknown how the participants interpreted "inherited," nonetheless, the answer should be coded as false since there is no gene or genes absolutely responsible for transmitting ADHD from parent to child. Jerome et al. (1994) found $67 \%$ of all the teachers in their study believed ADHD is inherited. Subsequently, Jerome et al. (1999) found consistent results with their teachers in training (69\%), while Ohan et al. (2008) found slightly lower results (62\%) from their teacher sample. Bekle (2004) published results indicating more teachers $(83 \%)$ in her study believed ADHD can be inherited; however, student teachers (43\%) in her study were skeptical. The in-service teachers (42.5\%) in the study by Kos et al. (2004) were as skeptical about whether ADHD was inherited as were the student teachers in Bekle's study; however, the pre-service teachers (16.6\%) in their study were even more skeptical. Because Kos et al. (2004) included a 'don't know' option in their survey, it is safe to assume their results are lower than the other studies due to this option, although they did not include these results. 
It is plausible to assume that those in these studies who believed ADHD is inherited might have agreed with the statement because they believed heredity and inherited are synonymous terms. If this assumption is correct, then the confusion around these two technical terms continues. Those who believed ADHD is not inherited might have disagreed with the statement because they understood the influence of heredity or they might have disagreed because they just did not know at all. It is difficult to ascertain which stand is the correct stand. By including the 'don't know' option, Kos et al. (2004) gave their participants the option to choose it if they didn't know the answer, although they did not publish the results. In order to clarify the research, this statement should be included in future research with all options being explored and discussed.

S. Robin (1998) found 65.6\% of pre-service teachers in Saskatchewan believed genetics are the primary cause of ADHD, whereas Stief (2003) found 68.4\% of parents, African American and White, in her study conducted in Virginia Beach believed genetics or biology causes ADHD. More than three-fourths of the parents $(77 \%)$ in the study conducted by Pugh (2002) across the United States believed ADHD derives from a parent who had ADHD as a child. Bussing, Schoenberg, and Perwien (1998) found a higher percentage of the parents (84\%), African American and White, in their study in Florida believed ADHD is caused by genetics. In the study conducted by Venter, Van der Linde, du Plessis, and Joubert (2004), South African psychiatrists (81.9\%) and pediatricians (79.5\%) believed ADHD is influenced by genetics. From an attitudes perspective, Carlson et al. (2006) found U.S. and Swedish teachers agreed with the following statement: ADHD behaviors are probably caused by a genetic predisposition towards hyperactivity and poor self-control. They used a Likert format. 
Jerome et al. (1994) and subsequent studies included a statement pertaining to biological vulnerabilities and keyed the answer as true. Since the literature supports a genetic or biological influence on ADHD the statement is true. They found $83 \%$ of Canadian teachers and $87 \%$ of American teachers knew children with ADHD are born with biological vulnerabilities towards inattention and self-control. Using the same instrument as Jerome et al. (1994), a subsequent study by Jerome et al. (1999) compared the original Canadian teachers with a sample of Canadian teachers in training, which yielded consistent results (86\%). Bekle (2004) compared practicing teachers and education students in Australia and found $93 \%$ of teachers and $83 \%$ of education students knew the connection between biological vulnerabilities and ADHD symptoms. Barbaresi and Olsen (1998) found more than $90 \%$ of U.S. teachers also agreed with the statement, while Ohan et al. (2008) found $79.5 \%$ of teachers knew the statement to be true. However, Kos et al. (2004), also using this same statement, found only $48.3 \%$ of their inservice teachers and $48.9 \%$ of their pre-service teachers, agreed with the statement. The majority of the participants in all four studies agreed that the statement was 'true'.

Similar to Kos et al. (2004), teachers (46\%) in the study by Ghanizadeh et al. (2006) knew ADHD is due to biological and genetic vulnerabilities, which is similar to the statement posed by Jerome et al. (1994). Ghanizadeh (2007) replicated the original study with a group of Iranian parents (47.7\%) and found consistent results. Kos et al. (2004) did not publish the 'don't know' responses, but it is plausible to assume that the 'don't know' option affected the scores since they are much lower than the other four studies. Any future study utilizing this statement should include a 'don't know' option and report the results. 
Pre-school teachers in the U.S. participated in a study conducted by Stormont and Stebbins (2005) and Estonian and Norwegian teachers in a study conducted by Õim (2004) with both studies yielding consistent results with those of Jerome et al. (1994). Pre-school teachers (81\%) knew ADHD has a biological basis, whereas Estonian teachers $(81.2 \%)$ and Norwegian teachers $(88.8 \%)$ believed ADHD is a neurobiological disorder. Even though these results are similar, the questions are quite dissimilar. In the former study, the pre-school teachers were asked if ADHD has a biological basis; however, it is unknown as to what the teachers truly understand about this biological basis. In the latter study, the teachers were asked if ADHD is a neurobiological disorder, which means that it stems from the nervous system. This question is quite vague and really does not tell us anything, since all behaviors stem from the brain. It is not known as to how much the teachers truly understood what the statements were asking, but the majority in both studies chose the correct answer, whether by guessing or by truly knowing the answer. By using the true and false format, there was no option for those who did not know if the statement was true or false.

In summary, in the majority of studies discussed, two-thirds and higher of participants have incorrect knowledge that ADHD is inherited, while others have correct knowledge that hereditary, genetic, or biological influences contribute to the development of ADHD in children. However, there still remain groups of people who either do not believe this to be true or are unsure whether this is true. 


\section{Environmental Factors}

Food additives and sugar

Jerome et al. (1994) and all those who used this instrument accepted the statement, ADHD can often be caused by food additives, as a "myth" and keyed the answer as false. As previously discussed, the evidence on food additives is inconclusive, and the evidence on sugar does not support the causation of adverse behaviors in children. Thus this statement, although considered knowledge-based by Jerome and subsequent studies, is not supported by the literature. Therefore, it is a belief statement which cannot be considered true or false. Nonetheless, Jerome et al. (1994) found about $66 \%$ of all of the teachers in this study indicated ADHD can be caused by sugar or food additives.

In a subsequent study by Jerome et al. (1999), $65 \%$ of the Canadian teachers and $52 \%$ of the teachers in training also agreed with the statement. Bekle (2004) found about half of the teachers (52\%) and student teachers (47\%) agreed ADHD can be caused by sugar and food additives. Barbaresi and Olsen (1998) found $41 \%$ of teachers in pretraining believed ADHD is caused by sugar or food additives; however, only $5 \%$ believed the statement after training. Ohan et al. (2008) found $73 \%$ of teachers believed the statement to be true. The results from the initial study by Jerome et al. (1994) indicated the older teachers believed the statement, but the subsequent study showed teachers in training were more inclined to disagree (Jerome et al., 1999). A more recent study by Bekle (2004) indicated fewer teachers and student teachers believed the statement, suggesting that it is possible these participants were exposed to correct information about 
these two issues. Further research using Jerome et al.'s 1994 survey should evaluate the statement as belief-based rather than knowledge-based.

The following studies examined the issue of sugar or food additives independently as a causation of ADHD. One third of the teachers in the study by Ghanizadeh et al. (2006) believed ADHD may be caused by excessive sugar intake, while a lesser percentage of parents (11.3\%) believed the statement (Ghanizadeh, 2007).

Stormont and Stebbins (2005) found 25\% of pre-school teachers believed excessive sugar intake has been found to be a major contributor to ADHD symptoms, while $20 \%$ believed food additives cause ADHD. In-service teachers (75\%) and pre-service teachers (71\%) in the study conducted by Kos et al. (2004) believed ADHD is not caused by too much sugar. More than half of groups, $57 \%$ in-service teachers and $51 \%$ pre-service teachers, believed ADHD is not caused by food additives.

One study incorporated the option of 'don't know' in their survey (Kos et al., 2004) but they did not publish those results, so it is not known how many teachers responded with 'don't know'. In addition, Kos et al. (2004) and Stormont and Stebbins (2005) separated the two issues and had two statements instead of one, which is consistent with the literature. By using two statements instead of one, Kos et al. (2004) and Stormont and Stebbins (2005) allowed their participants to consider the statements separately rather than together, which resulted in very different results. More teachers believed sugar does not cause ADHD, which is consistent with the evidence in the literature; however, teachers were more accepting of food additives as being a causal agent of ADHD. Again, the literature is inconclusive on this issue, thus it is possible 
teachers may have received information suggesting food additives are involved in the etiology of ADHD.

In a study of Kansas nurses (Frisch et al., 2003), most believed ADHD is not caused by too much sugar in the diet, which was consistent with psychiatrists $(73.6 \%)$ and pediatricians (69.9\%) in South Africa (Venter et al., 2004). When considering parents' knowledge about this issue, Pugh (2002) found $48 \%$ of parents believed ADHD is caused by sugar or food additives. Similarly, Bussing et al. (1998) reported 44\% of their caregivers believed ADHD is caused by sugar. In contrast, $68.6 \%$ of parents in the study by Stief (2003) believed too much sugar in the diet does not cause ADHD.

In summary, many participants believe sugar and/or food additives cause ADHD; however, there are greater numbers who believe they do not cause the disorder. Empirical evidence shows that sugar does not cause adverse behaviors in children, whereas food additives may cause hyperactivity in some children. Adverse behaviors and hyperactivity are symptoms of ADHD, but they are not the only components necessary for a diagnosis of the disorder. Therefore, the point can be made that sugar or food additives do not cause ADHD. Nonetheless, the statement actually contains two separate factors and should be separated in future studies. Therefore, the statement, ADHD can often be caused by sugar or food additives, should not be evaluated as a whole.

Poor parenting and chaotic, dysfunctional families

Poor parenting. Several websites listed "myth" statements pertaining to poor parenting. However, these statements were not considered to be "myths" in the following studies. Jerome et al. (1994) and subsequent studies keyed the following statement as false: ADHD can be caused by poor parenting. This statement is considered to be 
knowledge-based by the studies using it, but it is not supported as definitively true or false in the literature. Therefore, the statement must be belief-based and cannot be keyed as correct or incorrect. Jerome et al. (1994) found 74\% of Canadian teachers and 78\% of American teachers believed ADHD is not caused by poor parenting practices, which is consistent with the teachers $(78.8 \%)$ in the study by Ohan et al. (2008). In the subsequent study, $98 \%$ of teachers in training also believed this is not a cause of ADHD (Jerome et al., 1999). Bekle's (2004) study furnished consistent, yet lower results, for $70 \%$ of teachers and $73 \%$ of student teachers also believed the statement was false.

Kos et al. (2004) found a higher percentage of in-service teachers (80\%) and preservice teachers $(91 \%)$ believed ADHD does not result from poor parenting skills. Similarly, $80 \%$ of teachers in the study by Sciutto et al. (2000) and $90 \%$ of teachers in the study by Liesveld (2007) believed ineffective parenting skills does not result in ADHD. Tsai (2003) used the same statement but did not publish results. Stormont and Stebbins (2005) found that $92 \%$ of pre-school teachers believed parental upbringing is not responsible for ADHD in children. Conversely, Venter et al. (2004) found $55.6 \%$ of psychiatrists and $63.3 \%$ of pediatricians believed ADHD may be caused by poor parenting. Similarly, about $54 \%$ of teachers and $52.2 \%$ of parents in the studies conducted by Ghanizadeh et al. (2006) and Ghanizadeh (2007) believed it is caused by poor parenting practices and parental spoiling. Similarly, one study showed $41 \%$ of the teachers before training believed ADHD may be caused by poor parenting, but after training, the numbers decreased to 7\% (Barbaresi \& Olsen, 1998).

Williams (1996) found the majority of principals (82.7\%) believed ADHD is not caused by poor parenting skills. Smith (1999) found $85.4 \%$ of school psychologists 
believed the majority of children referred for ADHD do not behave the way they do because of poor parenting. Similarly, 65\% of parents in Stief's (2003) study also believed parenting behaviors do not cause ADHD. Empirical evidence shows that parenting behaviors are not a cause of ADHD and coupled with the findings that show the majority of participants do not believe that parenting behaviors cause ADHD, statements pertaining to this issue cannot be considered "myths."

From an attitudes perspective, Carlson et al. (2006) found U.S. teachers tended to agree whereas Swedish teachers were neutral concerning response to this statement: Behaviors like Christopher's can result from certain parenting methods, such as little positive reinforcement for good behavior and attention for bad behavior. This statement is worded differently from the other statements; however, the idea is the same-ADHD behaviors can come from parenting practices. U.S. teachers believed this to be true, whereas Swedish teachers exercised more caution.

Chaotic, dysfunctional families. Jerome et al. (1999) and others who utilized their survey included the following statement and keyed the answer as false: ADHD often results from a chaotic, dysfunctional family life. However, the literature does not support a definitive true or false answer to this statement or similar statements. Therefore, the statement cannot be knowledge-based but must be based on beliefs. Consistent results were found in four studies: Jerome et al. (1994) found 76\% of Canadian teachers and $78 \%$ of American teachers believed the statement to be false; Jerome et al. (1999) found $83 \%$ of teachers in training also believed the statement to be false; Bekle (2004) found $73 \%$ of teachers and $80 \%$ of education students believed it to be false; and Ohan et al. (2008) found $85.5 \%$ of teachers also believed the statement to be false. Õim (2004) 
included the following statement in his study and labeled it a misconception: Above all ADHD is a result of bad upbringing and difficulties in everyday life (problems in family, stress, etc). He published results which indicated about half of Estonian teachers (49\%) and $94.8 \%$ of Norwegian teachers agreed the statement was false. A lesser percentage of in-service teachers (35\%) and pre-service teachers $(26.7 \%)$ in the study by Kos et al. (2004) believed family dysfunction may not increase the likelihood that a child will be diagnosed with ADHD. The majority of teachers in the study by Barbaresi and Olsen (1998) agreed with Jerome's statement before receiving ADHD training; however, the authors did not publish the post-training results, which limits discussion, for it is not known if teachers had a change of thought.

Sciutto et al. (2000) and Tsai (2003) included a statement on their questionnaires pertaining to inadequate, chaotic home environments and ADHD symptoms in nonADHD children, but Sciutto et al. (2000) did not publish results. Tsai (2003) found most teachers $(89 \%)$ in her study believed inadequate, chaotic home environments produce ADHD symptoms in non-ADHD children. Stormont and Stebbins (2005) found $42 \%$ of pre-school teachers believed children can develop ADHD after extreme family stress such as the loss of a parent or parental divorce.

A different, yet similar attitudes statement was posed by Carlson et al. (2006) who found both U.S. and Swedish teachers tended to agree that environmental factors such as stress and conflict in the student's home life can cause ADHD behaviors. These results were consistent with a previous study by Frankenberger et al. (2001) which found that the school psychologists in their study also agreed with the statement. Snider et al. (2003) 
reported that $71 \%$ of teachers in their study also believed stress and conflict in the students' home life can cause ADHD symptoms.

In summary, most studies published results indicating participants believed ADHD is not caused by poor parenting or family dynamics, while few studies show participants believed these environmental factors cause ADHD. Future studies addressing these environmental factors need to evaluate them as beliefs rather than knowledge.

\section{Unsubstantiated Causes of ADHD}

Carlson et al. (2006) found both groups of teachers disagreed regarding the following: ADHD behaviors are the result of an active personality rather than a disorder, children with ADHD behaviors learned to be that way; and ADHD behaviors are more likely the result of immaturity rather than ADHD. An active personality or children learning to be ADHD has not been associated with the etiology of ADHD. It is unknown as to what type of immaturity this latter statement refers to; however, there is research that supports a delay in cortical maturation for children with ADHD (Shaw et al., 2007), which disappears as children get older. Another found "no support for the theory of a general biological immaturity, where the child shows signs of biological immaturity of the kind a normal younger child would show, as an important etiologic factor for ADHD symptomology" (Gustafsson et al., 2008, p. 237). Some children with ADHD show signs of emotional immaturity compared to their peers and interact more effectively with younger children (Papalia et al., 2004). Nonetheless, the idea that ADHD is the result of immaturity has not been conclusively established in the literature as a cause of ADHD.

There were discrepancies between the two groups of teachers for the following items: U.S. teachers disagreed that ADHD behaviors are often the result of unclear 
expectations in the classroom, whereas Swedish teachers were neutral. U.S. teachers believed ADHD behaviors can result when classroom expectations are incongruent with the developmental abilities of the child, whereas Swedish teachers were neutral.

Research has not established a link between cause of ADHD and classroom problems, although classroom problems are characteristic of children with ADHD (DSM IV-TR, 2000; DuPaul \& Stoner, 2003).

Õim (2004) included the following statement in his survey, considered it to be a misconception, and keyed the answer as false: ADHD derives from emotional imbalance. The majority of Estonian teachers, $81.1 \%$, believed this to be true; however, $72 \%$ of Norwegian teachers believed the statement to be false.

Intervention/Treatment Options of ADHD

\section{Pharmacological Treatment}

Pharmacological treatments, such as stimulant medications, have been used for years to treat ADHD. Few studies addressed this in their surveys with the following statement: ADHD is a medical disorder that can only be treated with medication. The answer to this statement was keyed as false and since it is supported by the research literature, the answer is accepted as correct. Jerome et al. (1994) found $82 \%$ of Canadian and $76 \%$ of American teachers knew the statement to be false, with fewer teachers in training (69\%) responding with false (Jerome et al., 1999). Bekle's (2004) results were similar with $73 \%$ of teachers and $78 \%$ of education students choosing false for the statement. Ohan et al. (2008) also reported similar results with their sample of teachers (76.2\%). The operative word in this statement is 'only', which makes the statement false. It is surprising results were not higher for this statement because the word 'only' implies 
no other treatments are effective in treating ADHD. Nonetheless, almost three-fourths of participants recognized medication is not the only intervention for ADHD, thus other treatment options are viable.

In reference to the eight statements pertaining specifically to attitudes related to stimulant medication in the study by Carlson et al. (2006), Swedish teachers were mostly in disagreement, whereas U.S. teachers were in agreement. Swedish teachers disagreed, but U.S. teachers agreed with the following statement: If children like Christopher do not receive stimulant treatment to treat their hyperactivity, impulsivity, and inattention, they will probably be worse off in the long run. Swedish teachers disagreed, but U.S. teachers had significantly higher agreement with the following statement: Christopher may benefit from a trial dosage of stimulant medication. Swedish teachers disagreed, whereas U.S. teachers had significantly higher agreement: If his behavior markedly improves after taking the stimulant mediation, it would seem to indicate that he has an attentional disorder (ADHD or DAMP). In response to the statement, Stimulant medication is a safe way to improve behaviors like Christopher's, Swedish teachers disagreed, whereas U.S. teachers had significantly higher agreement.

When considering the statement, too many U.S. children like Christopher receive stimulant medication, both groups of teachers were in agreement, which was also agreed to by school psychologists in the study by Frankenberger et al. (2001) and the teachers in the study by Snider et al. (2003). U.S. teachers had neutral attitudes, whereas Swedish teachers had significantly lower scores of disagreement to the following: Before his behavior can be improved, Christopher needs to be evaluated by a pediatrician or child psychiatrist, so he can be treated with stimulant medication. Swedish teachers particularly 
disagreed with the statement: It is a disservice to children with behaviors like Christopher's when they do not receive stimulant medication, whereas U.S. teachers were more in the neutral range.

Both groups of teachers had similar neutral attitudes towards the following statement: There are more children like Christopher who are in need of stimulant treatment for their behaviors but do not presently receive it. One article discussed the reality that prescriptions for stimulant medication had increased to the point that children with ADHD "are now less likely to be seen without a psychotropic prescription being made. Prescriptions are more the rule than the exception" (Hoagwood et al., 2000). Bearing this information in mind, it could appear too many children are receiving stimulant medication.

\section{Educational and Behavioral Interventions}

Õim (2004) included the following statement in his survey: A therapy that focuses on obedience is used in treatment of ADHD. However, a correct answer was not published in the study. Since the literature supports behavioral interventions that focus on obedience, a true answer can be accepted as correct. Results indicated $50.2 \%$ of Estonian teachers and $77.8 \%$ of Norwegian teachers responded correctly to the statement, although the results cannot be compared with other studies. This statement was exclusive to his study. A database search did not yield any literature specific to obedience therapy and ADHD. It is not known as to why Õim included this particular statement in his survey; however, it is possible he could have been referring to behavior modification or behavior therapy. 
When examining the attitudes of teachers concerning intervention methods for ADHD, Carlson et al. (2006) furnished results indicating that U.S. teachers had significantly higher rates of agreement than Swedish teachers to the following: Classroom teachers should first try classroom interventions to improve ADHD behaviors before referral to a doctor and classroom teachers should try classroom interventions to improve academic achievement before referral for a special education evaluation. Swedish teachers agreed to the first statement but were neutral in the second statement. As previously mentioned, peer tutoring as a classroom intervention can be effective for children with ADHD (DuPaul, Ervin, et al., 1998), thus the agreement of both groups of teachers is consistent with this research. Both U.S. teachers and Swedish teachers disagreed, although Swedish teachers more strongly, with the following statement: Behavioral interventions with children with ADHD often will not work unless they are treated with stimulant medication first.

Three statements that addressed the effectiveness of medication, behavioral, and educational interventions in the improvement of hyperactive and impulsive behaviors, academic achievement, and attention in the classroom produced mixed results. Swedish teachers rated educational interventions as most effective for children with ADHD but did not believe medication and behavioral interventions were as effective. U.S. teachers rated medication and educational interventions as more favorable than behavioral interventions to help a child with ADHD. Overall, the literature shows each of these interventions have merit in the treatment of ADHD. 
One-to-one interactions

Empirical evidence supports the fact that one-to-one interactions are effective for children with ADHD. Jerome et al. (1994) found 97\% of Canadian teachers and $88 \%$ of American teachers responded with true that children with ADHD are typically better behaved in one-to-one interactions. Subsequently, $83 \%$ of teachers-in-training also knew the statement to be true (Jerome et al., 1999). Consistent results were published by Bekle (2004) who found $93 \%$ of teachers and $80 \%$ of education students also agreed with the statement. A recent study reported consistent results with $85 \%$ of teachers responded with true to the statement (Ohan et al., 2008). It is possible that participants in these studies had the experience of witnessing the beneficial effects of one-on-one interactions with children in the classroom in general or they might have experienced children with ADHD. Nevertheless, most of the participants understood one-to-one interactions are beneficial for children with ADHD.

\section{Combined or Multimodal Interventions}

The following statement was included in several studies with a keyed answer of false: If medication is prescribed, educational interventions are often unnecessary. The research literature supports the keyed answer. Jerome et al. (1994) reported $80 \%$ of Canadians and $78 \%$ of American teachers chose false. Similarly, $83 \%$ of teachers- intraining (Jerome et al., 1999), 83\% of teachers, and $85 \%$ of education students (Bekle, 2004) chose false for the statement. Ohan et al. (2008) reported slightly higher results with $90.6 \%$ of teachers responding with false to the statement. Similarly, $75 \%$ of inservice teachers and fewer pre-service teachers $(44.4 \%)$ chose false for the statement 
(Kos et al., 2004); however, these results do not reflect 'don't know' responses, which makes it impossible to know how many participants chose that option.

These results show that participants realize that even though medication may be prescribed, educational interventions can also be necessary to help children with ADHD in the classroom. As previously mentioned, the use of stimulant medication to treat ADHD symptoms can be beneficial; however, it does not appear to help in the area of school achievement (Purdie et al., 2002). West et al. (2005) included the following similar statement in their study: Currently, a combination of medication and behavior management is a highly recommended form of treatment for Attention-Deficit Disorder. They found $89 \%$ of teachers believed this statement, but they did not publish parents' results. These results are consistent with the research mentioned above that showed a multimodal approach with medication and behavior modification is the most effective treatment for ADHD (The MTA Cooperative Group, 1999).

In one study examining attitudes, both U.S. and Swedish teachers disagreed with the following statement: Behavioral interventions with children like Christopher often will not work unless they are treated with stimulant medication first (Carlson et al., 2006). These results indicated both groups of teachers understood behavioral interventions can work without stimulant medication treatments, although they might not be as effective (The MTA Cooperative Group, 1999). Frankenberger et al. (2001) found school psychologists and Snider et al. (2003) found teachers disagreed to the following statement: If a student is receiving stimulant medication, other methods of intervention are unnecessary. As previously mentioned, research supports a combined intervention method of both medication and behavioral interventions; however, evidence shows 
behavior modification interventions are widely used alone to treat ADHD symptoms (DuPaul, 2007) suggesting medication does not have to be included as an intervention.

\section{Diet Treatment}

The following statement was included in several studies and labeled as a "myth": Diets are usually not helpful in treating most children with ADHD. The research literature suggests that diet may be helpful in treating some children with ADHD, but not most children. Therefore, the keyed answer of true is correct. Jerome et al. (1994) found $77 \%$ of Canadian and $81 \%$ of American teachers believed diets are helpful in treating most children with ADHD, whereas $68 \%$ of teachers-in-training also believed the statement (Jerome et al., 1999). Bekle (2004) found 77\% of teachers and $78 \%$ of student teachers also believed diets are helpful in treating most children with ADHD. A higher percentage of in-service teachers $(85.8 \%)$ yet comparable percentage of pre-service teachers $(73.3 \%)$ believed diets are helpful in treating children with ADHD as found by Kos et al. (2004). Similarly, 87\% of teachers in a recent study believed diets are helpful (Ohan et al., 2008). These previous studies all used the original statement from Jerome et al. (1994) and results consistently showed that participants believed diets are helpful in treating most children with ADHD.

Venter et al. (2004) found contrasting results with only $23.9 \%$ of psychiatrists and $25.5 \%$ of pediatricians also agreeing diets are helpful in treating ADHD, whereas the remaining participants were either unsure or disagreed. West et al. (2005) found $38 \%$ of teachers in their study agreed that special diets (e.g., reduced sugar, wheat-free, milk-free, additive-free) are effective treatments for ADD). It is not known as to what percentage of parents agreed with the statement nor did the authors report the 
percentage of teachers and parents who responded with 'don't know' for the statement, thus limiting discussion of the results. Sciutto et al. (2000) found $42.3 \%$ of teachers believed if sugar or food additives intake was reduced, ADHD symptoms would also be reduced, which was similar to the findings (44\%) by Liesveld (2007). Tsai (2003), using this same statement, found the majority of teachers, $92 \%$, believed the statement. When considering the results from these studies, there are obvious discrepancies, which are indicative of the inconsistent information found in the empirical research. Empirical evidence shows that diets are not helpful for most children with ADHD; however, research findings show that more than $50 \%$ of participants believe that diets do help in treating ADHD. Thus, a myth exists because the majority of people believe the inaccurate idea that diets are helpful for most children with ADHD.

In summary, most teachers correctly believed ADHD is not only treated with medication, one-to-one interactions are effective for children with ADHD, and educational interventions can be used with stimulant medication to treat ADHD. Swedish teachers mostly disagreed with stimulant medication, whereas U.S. mostly agreed, and they were neutral on a few issues. Both groups of teachers disagreed that multimodal interventions can be effective in treating ADHD. Teachers agreed that classroom interventions should be tried before referrals are made. U.S. teachers believed medication and behavioral interventions are more effective in treating ADHD behaviors, whereas Swedish teachers believed educational interventions are more effective than the other two. Findings referring to obedience therapy cannot be summarized due to the omission of the correct answer. Most teachers erroneously believed diets are helpful in treating most children with ADHD. 


\section{Overall Knowledge Regarding ADHD}

Many of the researchers chose to provide an overall or total score for knowledge of ADHD. Jerome et al. (1994) found teachers had a total ADHD knowledge score of $78 \%(m=15.5)$ for Canadian teachers and $77 \%(m=15.4)$ for American teachers. Bekle (2004) reported teachers in her study had a knowledge score of $82.8 \%(m=16.57)$, whereas education students had a knowledge score of $75.1 \%(m=15.03)$. Barbaresi and Olsen (1998) reported teachers in their study collectively scored 77\% on knowledge of ADHD before receiving ADHD training and $85 \%$ post-training. Similarly, Lewis (2000) found teachers in their study increased their ADHD knowledge scores from a pre-test score of $63.7 \%(m=19.120)$ to a post-test score of $91.9 \%(m=27.580)$.

West et al. (2005) published a total knowledge score of 62.09\% $(m=41.60)$ for parents and an overall knowledge score of $53.8 \%(m=36.08)$ for teachers on the KADDQ. Sciutto et al. (2000) reported a total knowledge score of $47.8 \%(m=17.21)$ on the KADDS for the teachers in their study, whereas Tsai (2003) reported a total score of $43 \%$ and Liesveld (2007) reported a total score of 59\%. Ghanizadeh et al. (2006) furnished a knowledge score of $47.3 \%(m=3.79)$ for the teachers in their survey. Kos et al. (2004) reported a total knowledge score of $60.7 \%(m=16.38)$ whereas Frisch et al. (2003) reported a median number of 15 out of 20 correct responses for the nurses in their study.

Due to the different instruments and questions used to collect data about the knowledge of ADHD, the results show inconsistencies. Some participants seem to have a good knowledge base of ADHD while others seem not to. Because the studies conducted by Jerome et al. (1994), Barbaresi and Olsen (1998), Bekle (2004), and Ohan et al. (2008) used the same instrument for their studies, these results can be compared, although the 
knowledge score is not a true score. Similarly, the total scores of the KADDS can also be compared (Liesveld, 2007; Sciutto et al., 2000; Tsai, 2004). Nevertheless, data suggest participants in these three studies had similar knowledge about ADHD. Kos et al. (2004) used some of the same statements in their study, but they incorporated additional items with results showing participants seem to have less knowledge about ADHD than other studies. The remaining studies all used different instruments; therefore, total scores cannot be compared even though individual statement results can. Results show total knowledge is inconsistent across the studies with some participants having more knowledge about ADHD than others. However, the main problem with these overall or total scores from these studies is that the knowledge score is not a true knowledge score since belief statements were included in the score.

The knowledge or beliefs regarding ADHD held by teachers, parents, and others have been discussed above; however, there is specific knowledge that teachers and parents should have regarding ADHD. Therefore, the following section reviews what these two groups should know about the disorder.

\section{Recommended Knowledge Regarding ADHD for Teachers and Parents}

It is recommended that all teachers should have a good grasp of the nature, course, causes, outcomes, and appropriate therapies regarding ADHD, which may improve academic and social functioning for those with the disorder (Pfiffner \& Barkley, 1998). They must be provided with information about the characteristics of children with ADHD, effective methods of identifying students, and procedures for school-based interventions (Shapiro, DuPaul, Bradley, \& Bailey, 1996). This knowledge should 
"extend beyond the primary symptoms specified in the DSM-IV" (Sciutto et al., 2000, p. 121). It is unequivocally necessary for teachers to have adequate knowledge concerning the primary symptoms of ADHD so they can make necessary referrals and avoid the negative impact of the underidentification of inattentive children and the overidentification of children who may not have the disorder (Arcia et al., 2000; Sciutto et al., 2000). Girls are often underidentified because they do not typically exhibit hyperactive and/or impulsive behaviors or teachers view their behaviors differently than in boys (Sciutto et al., 2004), thus when teachers have adequate knowledge about the symptoms, they should be able to refer girls if they exhibit these primary symptoms.

Teachers should have adequate knowledge about intervention strategies so they are able to effectively manage children with ADHD by providing accommodations and/or modifications and offer parents accurate information about stimulant medication (Glass \& Wegar, 2001; Kasten et al., 1992; Snider et al., 2003). Teachers who have adequate and accurate knowledge of ADHD will less likely believe "myths" that exist about the disorder (Bekle, 2004) because they will be able to dispel and reject this erroneous information.

Parents need to know accurate facts about ADHD, which includes information about the etiology, symptoms, duration, its manifestation, diagnostic criteria, strategies, treatment options, general information, and home-based interventions; this knowledge can reject "myths" and false beliefs about the disorder (Barkley, 2000; Bussing et al., 2007; A.L. Robin, 1998). They need to know about the secondary characteristics of the disorder and the problems associated with ADHD that are evidenced at home and at 
school (Barkley, 2000). It is imperative that parents have adequate and accurate knowledge about treatment options, including both pharmacological and nonpharmocological (Barkley, 2000; Corkum et al., 1999; Rostain et al., 1992) in the event that their child or an acquainted child is being treated or needs to be treated for ADHD.

Findings from the studies previously discussed indicate that teachers have some knowledge about the symptoms, causes, diagnostic criteria, general information, and intervention/treatment options of ADHD. Researchers of these studies indicated teachers have gaps in their knowledge base and do not have adequate overall knowledge of the disorder (Bekle, 2004; Ghanizadeh et al., 2006; Jerome et al., 1994; Ohan et al., 2008; Sciutto et al., 2000; West et al., 2005). Few studies have examined parents' knowledge about ADHD, but existing studies found parents do not have adequate knowledge about ADHD (Ghanizadeh et al., 2006; West et al., 2005). In addition, several statements included in the studies were considered to be "myths" by the researchers and/or were listed as "myths" on several websites. However, most of the participants did not believe the "myths" and/or the empirical research dispelled the "myths." The fact that the researchers (Jerome et al., 1999) labeled such statements as "myths," incorrectly keyed the answer to some statements, and considered all statements to be knowledge-based suggests that they themselves do not have adequate knowledge in some areas pertaining to ADHD. Subsequent studies accepted Jerome's handling of these statements without questioning their correctness (Barbaresi \& Olsen, 1998; Bekle, 2004; Kos et al., 2004; Ohan et al., 2008). 


\section{Knowledge Predictors of ADHD}

Demographic information was most often elicited from the majority of the studies pertaining to knowledge and/or attitudes of ADHD. Data were collected on variables to determine if there was a relationship with knowledge of ADHD that include but are not limited to the following: gender, race, years of teaching experience, education level, marital status, geographical location, ADHD in-service training or workshops, preservice training, special education courses, teaching students with ADHD, reading ADHD book or articles, viewing ADHD videos or programs, grade level taught, teacher certification, knowing someone with ADHD, or belonging to a support group (Barbaresi \& Olsen, 1998; Bekle, 2004; Blume-D’Ausilio, 2005; Brook et al., 2000; Frisch et al., 2003; Ghanizadeh, 2007; Ghanizadeh et al., 2006; Gunderson, 1994; Jerome et al., 1994, 1999; Kos et al., 2004; Lewis, 2000; Liesvald, 2007; Õim, 2004; S. Robin, 1998; Scuitto et al., 2000; Stormont \& Stebbins, 2005; Tsai, 2003; Vereb \& DiPerna, 2004; West et al., 2005).

Vereb and DiPerna (2004) found training about ADHD was significantly $(r=.49$; $p=.01)$ related to greater ADHD knowledge. Kos et al. (2004) indicated additional ADHD training is significantly related to ADHD knowledge $(r=.24 ; p<.05)$, although this represents a small relationship. Liesveld's (2007) study found past ADHD training was related to higher knowledge $(p<.01)$. Another study by West et al. $(2005)$ confirmed these findings, for teachers who had participated in professional development in the past 12 months had significantly higher ADHD knowledge scores $(m=40.52)$ than those who had not $(m=34.43) ;\left(F(1,248)=14.66, p<.001, n^{2}=.06\right)$. Partial eta squared of .02 indicates an unimportant relationship between professional development and ADHD 
knowledge scores. Conversely, Bekle (2004) found there was no significant relationship between undergraduate ADHD training and knowledge scores for practicing teachers $\chi^{2}$ $(2)=.08, p>.05)$ and education students $\left(\chi^{2}(1)=.04, p>.05\right)$. She also found there was no significant relationship between in-service training and knowledge scores $\left(\chi^{2}(2)=\right.$ $.08, p>.05$ ) for practicing teachers, which supports the findings of Blume-D'Ausilio (2005). Liesveld (2007) also found that attending a workshop or conference pertaining to ADHD did not mean higher scores on the KADDS $(p>.05)$.

Unlike Bekle's findings, Barbaresi and Olsen (1998) found ADHD in-service training significantly improved teachers' overall knowledge pre-test of $77.7 \%$ to post-test of $85.2 \%$ after 1 month, which yielded significantly higher results $(p<.001)$ indicating a relationship between in-service training and ADHD knowledge. Tsai (2003) also found teachers who have participated in in-service training $(p<.0001)$ attained much higher scores on the KADDS than those who have not participated. Lewis (2000) found a relationship between taking an ADHD workshop and ADHD knowledge as evidenced by a significant difference between pre-test scores $(m=19.120)$ and post-test scores $(m=$ $27.580 ; p<.001)$. Teachers and prospective teachers unanimously agreed they would want or benefit from additional information about ADHD (Barbaresi \& Olsen, 1998; Bekle, 2004; Brook et al., 2000; Jerome et al., 1994; Vereb \& DiPerna, 2004).

Jerome et al. (1994) found that Canadian teachers' years of teaching experience predicted higher knowledge scores, although results were not published to show this relationship. Similarly, Sciutto et al. (2000) found a small, significant relationship between total knowledge score and years of teaching experience $(r(145)=.29, p<.001)$ and Frisch et al. (2003) found years of working as a school nurse was significantly 
correlated with total knowledge scores $(p<.02)$. Õim (2004) found length of teaching experience influenced Estonian teachers' knowledge of ADHD

$(p=.01)$. Liesveld (2007) found the number of years taught was associated with a decrease in knowledge about ADHD $(p<.05)$. In contrast, Kos et al. (2004) and Brook et al. (2000) did not find years of teaching experience was significantly related to actual ADHD, although authors did not publish the specific results to support this claim. Stormont and Stebbins (2005) found that years of teaching experience did not reflect significant differences on ADHD knowledge scores for teachers $(F(2,135)=2.09 ; p=$ $.13)$.

Bekle (2004) and Sciutto et al. (2000) found a significant relationship ( $r(128)=$ $.22, p=.011)$ between the number of children with ADHD taught and knowledge of ADHD, although Bekle did not publish results. Liesveld (2007) found the number of current and former children taught with ADHD was associated with higher knowledge about $\operatorname{ADHD}(p<.05)$. In contrast, Kos et al. (2004) did not find a significant relationship between number of students with ADHD taught and actual ADHD knowledge. Blume-D'Ausilio (2005) and Vereb and DiPerna (2004) did not find a significant relationship $(p>.05)$ between experience teaching children with ADHD and ADHD knowledge. However, Sciutto et al. (2000), Tsai (2003), Õim (2004), and Kos et al. (2004) found teachers who had taught at least one child with ADHD were more knowledgeable about the disorder $(p<.05)$. Blume-D'Ausilio (2005) found a negative significant relationship between teaching position and ADHD knowledge $(r=-.159 ; p=$ .05). As teachers' grade level taught increased, teachers' knowledge about ADHD 
decreased. It is unknown as to why this negative relationship was found, and the author did not expound on it in the discussion.

Jerome et al. (1994), Tsai (2003), Õim (2004), and West et al. (2005) found teachers who had received special education qualifications had more knowledge of $\operatorname{ADHD}(p<.05)$, although Jerome did not publish results. Conversely, Sciutto et al. (2000) and Stormont and Stebbins (2005) found that taking special education courses was unrelated to overall knowledge of $\operatorname{ADHD}(p>.05)$. Liesveld (2007) found that teachers with special education licensure or who had taken college course with information about ADHD did not have higher scores on the KADDS ( $p>.05)$. Blume-D'Ausilio (2005) also did not find a relationship with college courses and knowledge about ADHD ( $p>$ .05). Ghanizadeh et al. (2006) found a significant, yet small, positive correlation between ADHD knowledge and educational level $(r=.0178 ; p<.01)$. However, Gunderson (1994) and Sciutto et al. (2000) did not find a relationship between educational levels with overall knowledge of ADHD ( $p>.05)$.

Jerome et al. (1994) found gender did not affect knowledge; however, Gunderson (1994) and Õim (2004) found women had better knowledge about ADHD than men $(p<$ $.05)$. Liesveld (2007) found that gender $(p<.05)$ was associated with higher ADHD knowledge scores, whereas ethnicity was not $(p>.05)$. Õim (2004) also found school location was related to Estonian teachers' knowledge of ADHD; those from bigger towns were more knowledgeable about ADHD than those from small towns or rural areas $(p<$ $.05)$. Liesveld (2007) $(p<.000)$ and Blume-D' Ausilio (2005) found that teachers who had personal experience with ADHD in the form of relationship with friends or family members had higher knowledge scores $(p<.05)$. 
Stormont and Stebbins (2005) and Blume-D'Ausilio (2005) did not find a relationship between teachers' reading a journal article or reading a professional publication on ADHD and ADHD knowledge scores ( $p>$.05). However, Liesveld (2007) found teachers who had read journals or books about ADHD had higher scores on the KADDS $(p<.02)$. West et al. (2005) found a relationship between parents attending ADHD information seminars or belonging to a support group and higher scores on ADHD knowledge.

In summary, the results from these studies are contradictory for many reasons. For instance, some studies found teachers who have taught children with ADHD have more knowledge about ADHD, whereas other studies found there was no relationship between the variables. Findings suggest years of teaching experience are related to knowledge about ADHD but not for all teachers. Most studies found that teachers who received inservice training about ADHD have higher scores on knowledge about ADHD. Most teachers agreed they need or would benefit from training regarding ADHD. Interestingly, one study found grade level taught was negatively related to knowledge about ADHD.

Most studies found educational qualifications, specifically special education, had a relationship with teachers' knowledge about ADHD. Few studies found female teachers had more knowledge about ADHD than male teachers. One study found teachers of schools in larger towns had more knowledge than those from small or rural towns. Reading journal articles or professional publications about ADHD was not related to teachers' knowledge about ADHD. Parents who attended informational seminars about ADHD or belonged to a support group for ADHD had more knowledge about ADHD. 
These findings must be interpreted with caution because some of the results may not be trusted since total knowledge scores included incorrectly keyed answers and beliefs statements (Bekle, 2004; Barbaresi \& Olsen, 1998; Jerome et al., 1994, 1999).

\section{Summary}

Several studies have been conducted assessing teachers' knowledge and/or beliefs of ADHD. Fewer studies have assessed parents' knowledge regarding ADHD. However, there is a dearth of literature pertaining to the knowledge regarding ADHD of teachers in parochial schools and of parents in general. The existing literature indicates teachers and parents have some knowledge of ADHD, although there are some gaps in their knowledge base. Upon reviewing the empirical data pertaining to salient aspects of ADHD, it is evident that all of the studies reviewed have incorrectly evaluated many items as knowledge-based, although these items are not supported by the empirical evidence. This poses a serious problem for the knowledge base since inaccurate data exist in the literature regarding what teachers and parents actually know about ADHD in comparison to what they believe.

Most studies computed an overall or total score of what teachers and/or parents know about ADHD, but since these scores included items not based on knowledge and incorrectly keyed answers, they do not reflect true knowledge scores. Therefore, what appears to be knowledge is not knowledge. Of all the studies reviewed, few have specifically focused on the knowledge regarding ADHD of parochial school teachers and parents in general. Even fewer have assessed teachers' or parents' beliefs regarding the disorder. Further study is warranted regarding teachers' and parents' true knowledge of 
ADHD and since there is a dearth of research regarding their beliefs about the disorder, this too needs to be studied.

Since there are many inadequacies in the past studies that assessed knowledge and/or beliefs regarding ADHD, future studies should separate and evaluate items as knowledge-based or belief-based. Future studies should consistently use the term beliefs to examine items and adopt a three-option format of true, false, and don't know. Finally, future studies should also set a criterion of what constitutes adequate knowledge for individual items and overall knowledge. 


\section{CHAPTER 3}

\section{METHODOLOGY}

\section{Introduction}

The purpose of this study was to investigate the knowledge and beliefs concerning ADHD held by teachers and parents of children in the SDA parochial school system. The Atlantic Union Conference, a convenience sample in this school system, is comprised of 65 elementary schools, 8 academies, and 1 college. For the purpose of this study, only teachers and parents from elementary schools and academies were studied. Atlantic Union Conference includes six school districts: Greater New York, New York, Northeastern, Northern New England, Southern New England, and Bermuda, although Northeastern Conference did not participate in this study. These six school districts include the northeastern states of Connecticut, Rhode Island, Vermont, New York, Maine, and the island of Bermuda. During the 2006-2007 school year, the Atlantic Union Conference enrolled 4,463 students in Kindergarten (K) to Grade 12 with 403 teachers serving them (Atlantic Union Conference, 2008). This research study was the first of its kind to be conducted in the Seventh-day Adventist parochial school system.

This chapter discusses permission to conduct the study, population and sample, instrumentation, variables, survey format, procedure, research design, and data analysis. 


\section{Conference (School District) Permission}

The six school districts in the Atlantic Union Conference have boards that make decisions for the schools in each school district; therefore, there are six boards. These boards are referred to as K-12 boards and consist of superintendents, principals, pastors, parents, teachers, and other pertinent members. I sent letters to each K-12 board to request permission to conduct the study in their school districts. In addition, I attended the K-12 board meeting for Southern New England Conference and had a conference call with the president and secretary of the K-12 board of the Bermuda Conference when these school districts met to discuss the research project. I had the opportunity to speak directly to members of these two boards to answer any questions that came up. In order to participate in the study, each K-12 board voted to either grant or deny permission for me to conduct the study in its specific school district. Permission to conduct this study was granted by five of the six school districts: Bermuda Conference (BDA), Greater New York Conference (GNYC), New York Conference (NYC), Northern New England Conference (NNEC), and Southern New England Conference (SNEC). The sixth school district, Northeastern Conference, did not respond to several invitations to participate in the research project.

The following section discusses the population and sample for the study.

\section{Population and Sample}

Atlantic Union Conference had 4,463 students enrolled in 65 elementary schools and 8 academies at the time of the study (AU, 2007). Approximately 2,562 students were enrolled in schools within the five school districts that participated in the study (see Table 1); therefore, the sample of parents was taken from this population of students. 
Elementary schools typically educate students from Kindergarten to Grade 8, while academies educate students from Grades 9-12. It is unknown at this time how many parents were represented in the number of students; however, it was estimated that there were approximately 1,800 parents. Teachers in Atlantic Union Conference numbered 403 at the time of the study (AU, 2007), although there were 232 teachers represented in the five school districts that participated (see Table 1). The different ethnicities represented in these populations included but were not limited to Caucasian, African American, Hispanic, Caribbean Black, African, Asian, Bermudian, and other. One school district did not participate in the study. Table 1 presents the numbers for the five school districts that did participate.

Table 1

Number of Schools, Teachers, Students and Families by School District District \# of Schools \# of Teachers Approx. \# of Students Approx. \# of Families

\begin{tabular}{lcccc}
\hline BDA & 1 & 35 & 372 & 256 \\
GNYC & 12 & 67 & 1,050 & 750 \\
NYC & 11 & 39 & 195 & 140 \\
NNEC & 12 & 38 & 350 & 275 \\
SNEC & 16 & 53 & 595 & 420 \\
Total & 52 & 232 & 2,562 & 1,841 \\
\hline $\begin{array}{l}\text { Note. BDA = Bermuda Conference; GNYC = Greater New York Conference; NYC = New York Conference; NNEC = Northern New } \\
\text { England Conference; SNEC = Southern New England Conference }\end{array}$
\end{tabular}


Four of the five conferences operate one academy each, whereas Southern New England operates two. The school in Bermuda Conference enrolls students from K-12. Teachers with special education endorsements were included in the total number of teachers in each conference: Bermuda and Southern New England had four each, Greater New York did not have any, and New York and Northern New England had two each.

In order to protect the confidentiality of the families, I did not have a list with parents' or children's names; therefore, the surveys were not addressed to the parents or to the children by name. The 2,000 surveys were sent to the schools to be distributed to the students, who were requested to take them home to their parents. The surveys were distributed to all of the teachers in the conferences (school districts). The teachers and parents who returned the surveys became the sample. A total of 76 teachers $(31.9 \%$ of the sample) and 373 parents (18.6\% of the number of surveys sent out) returned the surveys to participate in the study.

Teachers who teach in Atlantic Union Conference must be practicing the religion and maintain good and regular standing in a Seventh-day Adventist (SDA) church. Many of these teachers have received their teacher training in SDA colleges and universities; however, many have received their teacher training in non-SDA institutions (my knowledge from teaching in AU). Teachers who teach for this system are often without teachers' assistants and some teach multi-grades, as is the case in small church schools (Atlantic Union Conference of SDA, 2007). It is common for teachers in small schools to teach either Grades K-4 or 5-8, or sometimes Grades 1-8. Because ADHD is prevalent, many teachers in AU have encountered (my knowledge from teaching in AU) or will encounter a student with this disorder at some time in their teaching career. 
There are few or no professional services available in SDA schools to support teachers and students with ADHD. This means that most, if not all, teachers who teach in the SDA school system must deal with children with ADHD without resources or professional support, thus teachers need to have the necessary information about ADHD in order to successfully teach children who present with the disorder (Tucker, 2001). The Journal of Adventist Education, a professional journal for SDA teachers, published two articles in 1993: "Understanding the Student With Attention Deficit Disorder: Part I" and "Helping the Attention-Deficit Student: Part II" (Schoun, 1993a, 1993b). The first article provided an overview of the disorder including descriptions of ADHD, associated academic/social and health problems, causes, definition and incidence of ADHD, usual response to symptoms, and implications for teachers (Schoun, 1993a). Article 2 provided strategies to be used in classrooms, specifically pertaining to environment, instruction and curriculum, and management with an additional section on responsibility for implementation (Schoun, 1993b). This information would be useful for teachers; however, these articles were published over 10 years ago, thus information about ADHD has been updated and improved since then. A search in the journal shows that nothing about ADHD has been published since 1993, and if teachers wanted to obtain these outdated articles, they would have to search the journal online. Therefore, there is limited information available to teachers regarding ADHD that has been published by the SDA school system. Teachers wanting information about ADHD would have to seek this information by their own volition.

Parents who send their children to SDA parochial schools are often very involved in these schools, especially the smaller multi-grade schools. It is common for parents to 
sit on school boards, attend the same churches, volunteer to assist in school activities and in the classroom, prepare hot lunches, and socialize in community affairs. Due to these realities, parents of children in SDA parochial schools need to know about ADHD for many will interact with children with the disorder due to the overlap of school, social, and church settings or they may have a child with the disorder (my knowledge from teaching in and sending my children to schools in AU).

\section{Instrumentation}

The survey was in the form of a questionnaire which was segmented into four different sections: demographic information; experience with ADHD and exposure to information about ADHD; knowledge and beliefs about ADHD; and beliefs about issues regarding ADHD. It contained statements from several surveys that were previously used to examine teachers' and/or parents' knowledge and/or attitudes, beliefs, or opinions of ADHD.

Knowledge and Belief Section: True, False, and Don't Know Format

One section of the survey contained what previous studies called knowledge statements. These statements were in a true/false/don't know format. A true/false format was consistently used in past studies that examined ADHD knowledge and is an appropriate format since it measures factual information that is true or false, correct or incorrect. One disadvantage of this format is the possibility of guessing due to the forced choice. The 'don't know' option was added to the format because it is not known how many people truly don't know the answer and simply guess. In addition, 'don't know' is different from false and the inclusion of this option may reduce guessing and distinguish 
between what teachers and parents don't know and what they believe incorrectly (Sciutto et al., 2000). Even though the addition of the 'don't know' option was intended to reduce or prevent guessing, there was no way to ensure that participants did not guess.

Questions 1-7, 9-11, 13-16, and 18-21 were taken from a study conducted by Jerome et al. (1994) with additional statements taken from studies conducted by Power, Costigan, Leff, Eiraldi, \& Landau (2001), questions 8, 12, and 17, Õim (2004), questions 22-25, 27 29, and Sciutto et al. (2000), question 26, to examine the knowledge and beliefs of teachers and parents concerning ADHD. Each item was phrased with a statement about ADHD, which elicited a response of true $(T)$, false $(F)$, or don't know (DK), which followed the format utilized by Sciutto et al. (2000), Kos et al. (2004), and West et al. (2005). Jerome's survey had also been used by several subsequent studies: Jerome et al. (1999), Barbaresi and Olsen (1998), Pisecco, Huzinec, and Curtis (2001), Bekle (2004), and Ohan et al. (2008). These six studies provided me with sufficient data to compare the results of the current study, although their instrument did not include the 'don't know' option. By adding the 'don't know' option, the literature is incrementally advanced.

I found in the literature review that many of the statements considered to be knowledge-based in Jerome's instrument did not accurately reflect the literature and were not based on empirical evidence or diagnostic criteria. Nonetheless, the instrument was used in this current study with statements recategorized to reflect the literature. Specifically, statements not supported by empirical evidence or diagnostic criteria were categorized as belief statements and those supported by empirical evidence or diagnostic criteria remained categorized as knowledge statements. Belief statements could not be keyed as correct or incorrect. Knowledge statements supported by empirical evidence or 
the DSM criteria for ADHD included items 3-6, 8, 10, 11-14, 16-19, 20, 23-26, and 2729. These statements have a keyed correct answer (see Appendix C). Belief statements unsupported by empirical evidence or the DSM criteria for ADHD included items 1, 2, 7, 9, 15, 21, and 22. Respondents were requested to rate them as true, false, or don't know. In addition, since none of the researchers who used these statements previously conducted an item analysis on each item, I conducted an item discrimination index and an item difficulty index on the 22 knowledge items. The results of the item analysis are discussed in chapter 4.

Jerome et al. (1999) provided subscales for the statements in their study with the following labels, which were also used by Bekle (2004): biological and nonvolitional factors, family influences, causation, medical and educational interventions, and ADHD myths or misconceptions. However, they did not reveal the method used to group the statements into the subscales, thus I chose not to adopt these unsubstantiated subscales. In addition, this study did not compare subscales so there was no justifiable need to group the statements into subscales. For discussion purposes, statements that contained similar ideas were discussed together in the following sections regarding ADHD: symptoms and characteristics, general information, causes, and intervention/treatment options. By grouping the statements in this way, related ideas as evidenced in the literature regarding ADHD could be discussed in the same section, which promotes cohesiveness of ideas for the reader. The following items were discussed in this study under the symptoms and characteristics regarding ADHD section: 4, 5, 7, 8, 12, 15, 17, 18, 23, 24, and 26; the following items were discussed in this study under the general information regarding ADHD section: 9, 11, 13, 19, 22, 25, and 29; the following items were discussed in this 
study under the causes of ADHD section: 1, 2, 3, 10, 21, and 27 and, finally, the following items were discussed under the intervention/treatment options of ADHD section: $6,14,16,20$, and 28 .

None of the past studies explicitly set a criterion for adequate knowledge for the individual items; however, it is assumed by the wording used that Jerome et al. (1994) considered individual percentages of $76 \%$ and higher to indicate teachers were well informed about specific items. Kos et al. (2004) calculated an overall knowledge score of $60.7 \%$ for their teachers and considered their "knowledge about ADHD was adequate" (p. 525). Ohan et al. (2008) indicated teachers with high knowledge had a score of about $80 \%$ correct or better, teachers with average knowledge had a score of about $70 \%$ to $80 \%$ correct, and teachers with low knowledge had scores less than $69 \%$ or lower correct. However, they did not discuss the implications of these knowledge levels in terms of adequate or inadequate knowledge. Therefore, the current study set a criterion based on the mastery learning criterion of $80 \%$, which indicates a person has a good understanding or knowledge about something (Davis \& Sorrell, 1995). Thus, knowledge at the mastery level was considered to be adequate if $80 \%$ or higher of teachers and parents correctly answered the individual knowledge items. An average score of $80 \%$ or higher was considered adequate for the overall knowledge of respondents.

\section{Belief Section: Likert Item Format}

The beliefs about ADHD section had 36 questions with a Likert item format which followed the format used by Carlson et al. (2006). Carlson referred to this section as attitudes; however, these results are discussed mostly in the context of beliefs rather than attitudes. Carlson's study did not differentiate between attitudes and beliefs; 
therefore, the current study referred to the term exclusively as beliefs. Questions 1-33 had a 6-point scale on a continuum of disagree/agree: $1=$ strongly disagree; $2=$ moderately disagree; $3=$ slightly disagree; $4=$ slightly agree $; 5=$ moderately agree; $6=$ strongly agree. Questions 34-36 had a 5-point scale on a continuum of effectiveness: $1=$ not effective; 2 = slightly effective; $3=$ moderately effective; $4=$ effective; $5=$ very effective. Questions 1-20 and 34-36 were taken from a study conducted by Carlson et al. (2006) and I selected questions 21-33 based on the literature in order to elicit information not addressed in the surveys aforementioned. Carlson et al. (2006) adapted their instrument from two other studies conducted by Frankenberger et al. (2001) and Snider et al. (2003). As previously mentioned in chapter 2, Frankenberger et al. (2001) used the terms opinions and attitudes but also discussed results in the context of beliefs, whereas Snider et al. (2003) used the terms knowledge and opinions but also used the term belief in the discussion. Therefore, this current study used the term belief exclusively to avoid any confusion in interpretation.

In the study conducted by Carlson et al. (2006) participants were presented with a vignette of a 9-year-old boy who exhibited ADHD-combined-type symptoms prior to responding to the statements in this section. This vignette was not published with the study; therefore, the current study used a vignette describing the behaviors of a child with ADHD-combined type published in the study by Pisecco et al. (2001). I did not adopt the vignette verbatim, but made modifications to make it appropriate for this study. Specifically, "Both parents and teachers say that" was added to the beginning of sentence 6 to reflect the teachers and parents in this study. The final sentence was added to reflect 
$D S M$ criteria for ADHD-C, which replaced the final sentence in Pisecco's vignette (see Appendix D).

The questions in this section were designed to examine the beliefs of both teachers and parents about specific aspects in relation to ADHD. Carlson et al. (2006) categorized the statements into the following three groups: causes of ADHD, possible intervention methods for ADHD, and attitudes related to stimulants. These categories were maintained in the current study with the addition of statements exclusive to the current study. These added statements were grouped in sections with statements examining similar content. Therefore, the belief sections were examined as follows: causes of ADHD, stimulant medication, intervention methods, and other beliefs. By grouping the statements in this way, related ideas could be discussed together to promote cohesiveness of ideas for the reader. The following items were discussed in this study under the causes of ADHD section: 1-9. The following items were discussed in this study under the stimulant medication section: $12,14-20$. The following items were discussed in this study under the ADHD interventions/treatments section: 10, 13, 21-23, 27, and 3436. Finally, the following items were discussed in this study under the other beliefs section: $24-26$ and $28-33$.

\section{Demographic Information}

Section 3 of the survey elicited demographic information from both teachers and parents such as gender, racial or ethnic background, and conference (school district). In addition, the parental survey asked for marital status and education level (see Appendix D). The teachers' survey asked for highest degree earned, grade level currently taught, certificates/licenses held, and years of teaching experience (see Appendix D). 


\section{Experience With or Exposure to ADHD}

Section 4 of the survey elicited the experience with and exposure to ADHD of both parents and teachers and consisted of nine questions and was adapted from a study conducted by Anastopoulos, Guevremont, Shelton, and DuPaul (1992) and Jerome et al. (1994) both of which examined the knowledge levels of teachers, whereas Anastopoulos et al. (1992) also examined the knowledge levels of parents. The items in this section were in a multiple-choice format.

\section{The Variables}

In order to ensure the validity of the study, the independent and dependent variables were defined conceptually, instrumentally, and operationally. Table 2 shows how independent variables and dependent variables were operationalized to define how each was measured and expressed quantitatively. Independent variables included demographics (gender, educational level, marital status, race, conference (school district), grade taught, teacher certification, and teaching experience), exposure to information about ADHD (instruction about ADHD in teacher training, training about ADHD after beginning teaching, graduate courses taken pertaining to ADHD, lecturer/presentation attended about ADHD, belonging to support group for ADHD, number of articles and books read about ADHD, number of information programs or videos viewed about ADHD), and experience with ADHD (former and current students with ADHD, former and current students thought to have ADHD, acquaintances outside of school/home with ADHD, family member with ADHD, family member evaluated for ADHD, family member treated for ADHD). The dependent variable included knowledge and belief items and overall knowledge. 
Table 2

Operationalization of Variables

\begin{tabular}{|c|c|c|c|c|}
\hline & Variables & $\begin{array}{l}\text { Conceptual } \\
\text { Definition }\end{array}$ & $\begin{array}{l}\text { Instrumental } \\
\text { Definition }\end{array}$ & $\begin{array}{l}\text { Operational } \\
\text { Definition }\end{array}$ \\
\hline 1 & Gender & $\begin{array}{l}\text { Difference between } \\
\text { the sex of the } \\
\text { participants is } \\
\text { gender. }\end{array}$ & $\begin{array}{l}\text { This variable was } \\
\text { determined by } \\
\text { response to the } \\
\text { following question: } \\
\text { What is your gender? } \\
1 \text {. Male; } 2 \text {. Female }\end{array}$ & $\begin{array}{l}\text { Responses were } \\
\text { categorized as a } \\
\text { nominal scale as } \\
\text { follows: } \\
\text { Male }=1 \\
\text { Female }=2\end{array}$ \\
\hline 2 & $\begin{array}{l}\text { Educational } \\
\text { Level of } \\
\text { Parents }\end{array}$ & $\begin{array}{l}\text { Educational level is } \\
\text { the amount of } \\
\text { education that } \\
\text { parents have } \\
\text { attained. }\end{array}$ & $\begin{array}{l}\text { This variable was } \\
\text { determined by } \\
\text { response to the } \\
\text { following question: } \\
\text { What is your education } \\
\text { level? } \\
\text { 1. Below High School } \\
\text { 2. High School } \\
\text { 3. Undergraduate } \\
\text { 4. Graduate }\end{array}$ & $\begin{array}{l}\text { Responses were } \\
\text { categorized as an } \\
\text { ordinal scale as } \\
\text { follows: } \\
\text { Below High School } \\
\quad=1 \\
\text { High School = } 2 \\
\text { Undergraduate = } 3 \\
\text { Graduate }=4\end{array}$ \\
\hline 3 & $\begin{array}{l}\text { Educational } \\
\text { Level of } \\
\text { Teachers }\end{array}$ & $\begin{array}{l}\text { Educational level is } \\
\text { the highest degree } \\
\text { earned by teachers. }\end{array}$ & $\begin{array}{l}\text { This variable was } \\
\text { determined by } \\
\text { response to the } \\
\text { following question: } \\
\text { What is the highest } \\
\text { degree you have } \\
\text { earned? } \\
\text { 1. Bachelor's Degree } \\
\text { 2. Master's Degree } \\
\text { 3. Doctoral Degree } \\
\text { 4. Other Adv. Degree }\end{array}$ & $\begin{array}{l}\text { Responses were } \\
\text { categorized as an } \\
\text { ordinal scale as } \\
\text { follows: } \\
\text { Bachelor's Degree } \\
\quad=1 \\
\text { Master's Degree = } 2 \\
\text { Doctoral Degree =3 } \\
\text { Other Advanced } \\
\text { Degree }=4\end{array}$ \\
\hline 4 & $\begin{array}{l}\text { Parents' } \\
\text { Marital } \\
\text { Status }\end{array}$ & $\begin{array}{l}\text { Marital status is } \\
\text { status of parents in } \\
\text { relation to marriage. }\end{array}$ & $\begin{array}{l}\text { This variable was } \\
\text { determined by } \\
\text { response to the } \\
\text { following question: } \\
\text { What is your marital } \\
\text { status? } \\
\text { 1. Single } \\
\text { 2. Married } \\
\text { 3. Separated } \\
\text { 4. Divorced } \\
\text { 5. Widowed }\end{array}$ & $\begin{array}{l}\text { Responses were } \\
\text { categorized as a } \\
\text { nominal scale as } \\
\text { follows: } \\
\text { Single = } 1 \\
\text { Married = } 2 \\
\text { Separated = } 3 \\
\text { Divorced = } 4 \\
\text { Widowed = 5 }\end{array}$ \\
\hline
\end{tabular}


Table 2-Continued.

\begin{tabular}{|c|c|c|c|c|}
\hline & Variables & $\begin{array}{l}\text { Conceptual } \\
\text { Definition }\end{array}$ & $\begin{array}{l}\text { Instrumental } \\
\text { Definition }\end{array}$ & $\begin{array}{l}\text { Operational } \\
\text { Definition }\end{array}$ \\
\hline 5 & Race & $\begin{array}{l}\text { Race indicates } \\
\text { ethnic group of } \\
\text { participants. }\end{array}$ & $\begin{array}{l}\text { This variable was } \\
\text { determined by response } \\
\text { to the following } \\
\text { question: } \\
\text { What is your racial or } \\
\text { ethnic background? } \\
\text { 1. Asian } \\
\text { 2. Black or African } \\
\text { American } \\
\text { 3. Caucasian or White } \\
\text { 4. Hispanic/Latino } \\
\text { 5. Other }\end{array}$ & $\begin{array}{l}\text { Responses were } \\
\text { categorized as a } \\
\text { nominal scale as } \\
\text { follows: } \\
\text { Asian =1 } \\
\text { Black or African } \\
\text { American = } 2 \\
\text { Caucasian/White = } 3 \\
\text { Hispanic/Latino = } 4 \\
\text { Other = 5 }\end{array}$ \\
\hline 6 & $\begin{array}{l}\text { Conference } \\
\text { (School } \\
\text { District) }\end{array}$ & $\begin{array}{l}\text { Conference } \\
\text { represents union } \\
\text { territory parents } \\
\text { and teachers live or } \\
\text { work in. }\end{array}$ & $\begin{array}{l}\text { This variable was } \\
\text { determined by response } \\
\text { to the following } \\
\text { question: } \\
\text { What conference do you } \\
\text { live/teach in? } \\
\text { 1. Bermuda } \\
\text { 2. Greater New York } \\
\text { 3. New York } \\
\text { 4. Northern New } \\
\text { England } \\
\text { 5. Southern New } \\
\text { England }\end{array}$ & $\begin{array}{l}\text { Responses were } \\
\text { categorized as a } \\
\text { nominal scale as } \\
\text { follows: } \\
\text { Bermuda = } 1 \\
\text { GNY = } 2 \\
\text { New York = } 3 \\
\text { NNE = } 4 \\
\text { SNE = 5 }\end{array}$ \\
\hline 7 & Grade & $\begin{array}{l}\text { Grade indicates } \\
\text { grade that teachers } \\
\text { are currently } \\
\text { teaching. }\end{array}$ & $\begin{array}{l}\text { This variable was } \\
\text { determined by response } \\
\text { to the following } \\
\text { question: } \\
\text { What grade/s level/s are } \\
\text { you currently teaching? } \\
\text { 1. PreK/K } \\
\text { 2. Grades } 1-3 \\
\text { 3. Grades } 4-6 \\
\text { 4. Grades } 7-8 \\
\text { 5. Grades } 9-12 \\
\text { 6. Multigrade } \\
\text { 7. Other }\end{array}$ & $\begin{array}{l}\text { Responses were } \\
\text { categorized as a } \\
\text { nominal scale as } \\
\text { follows: } \\
\text { PreK/K }=1 \\
\text { Grades } 1-3=2 \\
\text { Grades } 4-6=3 \\
\text { Grades } 7-8=4 \\
\text { Grades } 9-12=5 \\
\text { Multigrade = } 6 \\
\text { Other }=7\end{array}$ \\
\hline
\end{tabular}


Table 2-Continued.

\begin{tabular}{|c|c|c|c|c|}
\hline & Variables & $\begin{array}{l}\text { Conceptual } \\
\text { Definition }\end{array}$ & $\begin{array}{l}\text { Instrumental } \\
\text { Definition }\end{array}$ & $\begin{array}{l}\text { Operational } \\
\text { Definition }\end{array}$ \\
\hline 8 & Certification & $\begin{array}{l}\text { Certification } \\
\text { indicated } \\
\text { certificate or } \\
\text { license to teach } \\
\text { that teachers hold. }\end{array}$ & $\begin{array}{l}\text { This variable was } \\
\text { determined by response } \\
\text { to the following } \\
\text { question: } \\
\text { What certificate/s or } \\
\text { license/s do you hold? } \\
\text { 1. Early Childhood } \\
\text { Education } \\
\text { 2. Elementary } \\
\text { Education } \\
\text { 3. Middle School } \\
\text { 4. High School } \\
\text { 5. Special Education } \\
\text { 6. Other }\end{array}$ & $\begin{array}{l}\text { Responses were } \\
\text { categorized as a } \\
\text { nominal scale as } \\
\text { follows: } \\
\text { Early Childhood } \\
\quad=1 \\
\text { Elementary = } 2 \\
\text { Middle School } \\
\quad=3 \\
\text { High School = } 4 \\
\text { Special Ed. = } 5 \\
\text { Other = } 6\end{array}$ \\
\hline 9 & $\begin{array}{l}\text { Teaching } \\
\text { Experience }\end{array}$ & $\begin{array}{l}\text { Teaching } \\
\text { experience is } \\
\text { number of years } \\
\text { that teachers have } \\
\text { been teaching. }\end{array}$ & $\begin{array}{l}\text { This variable was } \\
\text { determined by response } \\
\text { to the following } \\
\text { question: } \\
\text { How many years of } \\
\text { teaching experience do } \\
\text { you have? }\end{array}$ & $\begin{array}{l}\text { Responses were } \\
\text { tabulated as a } \\
\text { continuous scale } \\
\text { ranging from 0- } \\
40\end{array}$ \\
\hline 10 & $\begin{array}{l}\text { Instruction } \\
\text { about ADHD in } \\
\text { teacher training }\end{array}$ & $\begin{array}{l}\text { ADHD instruction } \\
\text { received as part of } \\
\text { teacher training. }\end{array}$ & $\begin{array}{l}\text { This variable was } \\
\text { determined by response } \\
\text { to the following } \\
\text { question: } \\
\text { Did you receive any } \\
\text { instruction about } \\
\text { ADHD as part of your } \\
\text { teacher training? } \\
\text { 1. No Training } \\
\text { 2. Yes, briefly } \\
\text { during } \\
\text { coursework/field } \\
\text { practicum } \\
\text { 3. Yes, extensively } \\
\text { during } \\
\text { coursework/ } \\
\text { field practicum }\end{array}$ & $\begin{array}{l}\text { Responses were } \\
\text { categorized as an } \\
\text { ordinal scale as } \\
\text { follows: } \\
\text { No = } 1 \\
\text { Yes, briefly = } 2 \\
\text { Yes, extensively } \\
=3\end{array}$ \\
\hline
\end{tabular}


Table 2-Continued.

\begin{tabular}{|c|c|c|c|c|}
\hline & Variables & $\begin{array}{l}\text { Conceptual } \\
\text { Definition }\end{array}$ & $\begin{array}{l}\text { Instrumental } \\
\text { Definition }\end{array}$ & $\begin{array}{l}\text { Operational } \\
\text { Definition }\end{array}$ \\
\hline 11 & $\begin{array}{l}\text { Former and } \\
\text { current } \\
\text { students } \\
\text { with } \\
\text { ADHD }\end{array}$ & $\begin{array}{l}\text { Former and } \\
\text { current students } \\
\text { with ADHD. }\end{array}$ & $\begin{array}{l}\text { This variable was } \\
\text { determined by response to } \\
\text { the following question: } \\
\text { How many children have } \\
\text { you taught whom you know } \\
\text { were identified by a medical } \\
\text { doctor or psychologist as } \\
\text { having ADHD? } \\
\text { 1. None } \\
2.1 \text { or } 2 \\
3.3 \text { to } 5 \\
4.6 \text { or more }\end{array}$ & $\begin{array}{l}\text { Responses were } \\
\text { categorized as an } \\
\text { ordinal scale as } \\
\text { follows: } \\
\text { None }=1 \\
1 \text { or } 2=2 \\
3 \text { to } 5=3 \\
6 \text { or more }=4\end{array}$ \\
\hline 12 & $\begin{array}{l}\text { Former and } \\
\text { current } \\
\text { students } \\
\text { thought to } \\
\text { have } \\
\text { ADHD }\end{array}$ & $\begin{array}{l}\text { Former and } \\
\text { current students } \\
\text { thought to have } \\
\text { ADHD. }\end{array}$ & $\begin{array}{l}\text { This variable was } \\
\text { determined by response to } \\
\text { the following question: } \\
\text { How many children have } \\
\text { you taught whom you know } \\
\text { were not identified as } \\
\text { ADHD but you think should } \\
\text { have been? } \\
\text { 1. None } \\
\text { 2. } 1 \text { or } 2 \\
\text { 3. } 3 \text { to } 5 \\
4.6 \text { or more }\end{array}$ & $\begin{array}{l}\text { Responses were } \\
\text { categorized as an } \\
\text { ordinal scale as } \\
\text { follows: } \\
\text { None }=1 \\
1 \text { or } 2=2 \\
3 \text { to } 5=3 \\
6 \text { or more }=4\end{array}$ \\
\hline 13 & $\begin{array}{l}\text { Training } \\
\text { about } \\
\text { ADHD } \\
\text { after } \\
\text { beginning } \\
\text { teaching }\end{array}$ & $\begin{array}{l}\text { Teacher training } \\
\text { about ADHD } \\
\text { since beginning } \\
\text { teaching. }\end{array}$ & $\begin{array}{l}\text { This variable was } \\
\text { determined by response to } \\
\text { the following question: } \\
\text { Have you received any } \\
\text { training about ADHD after } \\
\text { you began teaching? } \\
\text { 1. No } \\
\text { 2. Yes, briefly in-service } \\
\text { training } \\
\text { 3. Yes, comprehensive } \\
\text { workshop }\end{array}$ & $\begin{array}{l}\text { Responses were } \\
\text { categorized as an } \\
\text { ordinal scale as } \\
\text { follows: } \\
\text { No }=1 \\
\text { Yes, briefly }=2 \\
\text { Yes, comprehensive }\end{array}$ \\
\hline
\end{tabular}


Table 2-Continued.

\begin{tabular}{|c|c|c|c|c|}
\hline & Variables & $\begin{array}{l}\text { Conceptual } \\
\text { Definition }\end{array}$ & $\begin{array}{l}\text { Instrumental } \\
\text { Definition }\end{array}$ & $\begin{array}{l}\text { Operational } \\
\text { Definition }\end{array}$ \\
\hline 14 & $\begin{array}{l}\text { Graduate } \\
\text { courses } \\
\text { taken } \\
\text { pertaining } \\
\text { to ADHD }\end{array}$ & $\begin{array}{l}\text { Indicates whether } \\
\text { teachers have taken any } \\
\text { graduate courses about } \\
\text { ADHD. }\end{array}$ & $\begin{array}{l}\text { This variable was } \\
\text { determined by } \\
\text { response to the } \\
\text { following question: } \\
\text { Have you taken any } \\
\text { graduate courses } \\
\text { pertaining to ADHD? } \\
\text { 1. No } \\
\text { 2. Yes }\end{array}$ & $\begin{array}{l}\text { Responses were } \\
\text { categorized as an } \\
\text { ordinal scale as } \\
\text { follows: } \\
\text { No }=1 \\
\text { Yes }=2\end{array}$ \\
\hline 15 & $\begin{array}{l}\text { Family } \\
\text { member } \\
\text { evaluated } \\
\text { for ADHD }\end{array}$ & $\begin{array}{l}\text { Indicated if a family } \\
\text { member had been } \\
\text { evaluated for ADHD. }\end{array}$ & $\begin{array}{l}\text { This variable was } \\
\text { determined by } \\
\text { response to the } \\
\text { following question: } \\
\text { Has anyone in your } \\
\text { family been evaluated } \\
\text { for ADHD? } \\
\text { 1. No } \\
\text { 2. Yes }\end{array}$ & $\begin{array}{l}\text { Responses were } \\
\text { categorized as an } \\
\text { ordinal scale as } \\
\text { follows: } \\
\text { No }=1 \\
\text { Yes }=2\end{array}$ \\
\hline 16 & $\begin{array}{l}\text { Family } \\
\text { member } \\
\text { with ADHD }\end{array}$ & $\begin{array}{l}\text { Indicated if any family } \\
\text { member has been } \\
\text { identified with ADHD } \\
\text { by medical doctor or } \\
\text { psychologist. }\end{array}$ & $\begin{array}{l}\text { This variable was } \\
\text { determined by } \\
\text { response to the } \\
\text { following question: } \\
\text { Has anyone in your } \\
\text { family been identified } \\
\text { by a medical doctor or } \\
\text { psychologist as having } \\
\text { ADHD? } \\
\text { 1. No } \\
\text { 2. Yes }\end{array}$ & $\begin{array}{l}\text { Responses were } \\
\text { categorized as an } \\
\text { ordinal scale as } \\
\text { follows: } \\
\text { No }=1 \\
\text { Yes }=2\end{array}$ \\
\hline
\end{tabular}


Table 2-Continued.

\begin{tabular}{|c|c|c|c|c|}
\hline & Variables & $\begin{array}{l}\text { Conceptual } \\
\text { Definition }\end{array}$ & $\begin{array}{l}\text { Instrumental } \\
\text { Definition }\end{array}$ & $\begin{array}{l}\text { Operational } \\
\text { Definition }\end{array}$ \\
\hline 17 & $\begin{array}{l}\text { Family member } \\
\text { treated for } \\
\text { ADHD }\end{array}$ & $\begin{array}{l}\text { Indicates if any } \\
\text { family member has } \\
\text { been treated for } \\
\text { ADHD. }\end{array}$ & $\begin{array}{l}\text { This variable was } \\
\text { determined by } \\
\text { response to the } \\
\text { following question: } \\
\text { Has anyone in your } \\
\text { family been treated } \\
\text { for ADHD? } \\
\text { 1. Presently treated } \\
\text { 2. Previously treated } \\
\text { 3. Never } \\
\text { 4. Not applicable }\end{array}$ & $\begin{array}{l}\text { Responses were } \\
\text { categorized as an } \\
\text { ordinal scale as } \\
\text { follows: } \\
\text { Presently treated } \\
\quad=1 \\
\text { Previously treated } \\
\quad=2 \\
\text { Never }=3 \\
\text { Not Applicable } \\
\quad=4\end{array}$ \\
\hline 18 & $\begin{array}{l}\text { Lectures/pre- } \\
\text { sentations } \\
\text { attended about } \\
\text { ADHD }\end{array}$ & $\begin{array}{l}\text { Indicates how many } \\
\text { lectures/ } \\
\text { presentations } \\
\text { parents have attended } \\
\text { about ADHD }\end{array}$ & $\begin{array}{l}\text { This variable was } \\
\text { determined by } \\
\text { response to the } \\
\text { following question: } \\
\text { How many lectures/ } \\
\text { presentations about } \\
\text { ADHD have you } \\
\text { attended? } \\
\text { 1. None } \\
2.1 \text { or } 2 \\
3.3 \text { to } 5 \\
4.6 \text { or more }\end{array}$ & $\begin{array}{l}\text { Responses were } \\
\text { categorized as an } \\
\text { ordinal scale as } \\
\text { follows: } \\
\text { None }=1 \\
1 \text { or } 2=2 \\
3 \text { to } 5=3 \\
6 \text { or more }=4\end{array}$ \\
\hline 19 & $\begin{array}{l}\text { Belonged to a } \\
\text { Support Group } \\
\text { for ADHD }\end{array}$ & $\begin{array}{l}\text { Indicates whether } \\
\text { parent has belonged } \\
\text { to an Support Group } \\
\text { for ADHD. }\end{array}$ & $\begin{array}{l}\text { This variable was } \\
\text { determined by } \\
\text { response to the } \\
\text { following question: } \\
\text { Have you ever } \\
\text { belonged to an } \\
\text { ADHD parent } \\
\text { support group? } \\
\text { 1. Presently belong } \\
\text { 2. Previously } \\
\text { belonged } \\
\text { 3. Never } \\
\text { 4. Not Applicable }\end{array}$ & $\begin{array}{l}\text { Responses were } \\
\text { categorized as an } \\
\text { ordinal scale as } \\
\text { follows: } \\
\text { Presently } \\
\quad \text { belonged = } 1 \\
\text { Previously } \\
\quad \text { belonged = } 2 \\
\text { Never }=3 \\
\text { Not applicable = } 4\end{array}$ \\
\hline
\end{tabular}


Table 2-Continued.

\begin{tabular}{|c|c|c|c|c|}
\hline & Variables & $\begin{array}{l}\text { Conceptual } \\
\text { Definition }\end{array}$ & $\begin{array}{l}\text { Instrumental } \\
\text { Definition }\end{array}$ & $\begin{array}{l}\text { Operational } \\
\text { Definition }\end{array}$ \\
\hline 20 & $\begin{array}{l}\text { Number of } \\
\text { articles read } \\
\text { about ADHD }\end{array}$ & $\begin{array}{l}\text { Indicates the } \\
\text { number of } \\
\text { articles read } \\
\text { about ADHD. }\end{array}$ & $\begin{array}{l}\text { This variable was } \\
\text { determined by response } \\
\text { to the following } \\
\text { question: } \\
\text { How many articles have } \\
\text { you read about ADHD? } \\
\text { 1. None } \\
2.1 \text { or } 2 \\
3.3 \text { to } 5 \\
4.6 \text { or more }\end{array}$ & $\begin{array}{l}\text { Responses were } \\
\text { categorized as an } \\
\text { ordinal scale as } \\
\text { follows: } \\
\text { None }=1 \\
1 \text { or } 2=2 \\
3 \text { to } 5=3 \\
6 \text { or more }=4\end{array}$ \\
\hline 21 & $\begin{array}{l}\text { Number of } \\
\text { books } \\
\text { read about } \\
\text { ADHD }\end{array}$ & $\begin{array}{l}\text { Indicates the } \\
\text { number of books } \\
\text { read about } \\
\text { ADHD. }\end{array}$ & $\begin{array}{l}\text { This variable was } \\
\text { determined by response } \\
\text { to the following } \\
\text { question: } \\
\text { How many books have } \\
\text { you read about ADHD? } \\
\text { 1. None } \\
2.1 \text { or } 2 \\
3.3 \text { to } 5 \\
4.6 \text { or more }\end{array}$ & $\begin{array}{l}\text { Responses were } \\
\text { categorized as an } \\
\text { ordinal scale as } \\
\text { follows: } \\
\text { None }=1 \\
1 \text { or } 2=2 \\
3 \text { to } 5=3 \\
6 \text { or more }=4\end{array}$ \\
\hline 22 & $\begin{array}{l}\text { Number of } \\
\text { Informational } \\
\text { programs or } \\
\text { videos viewed } \\
\text { about ADHD }\end{array}$ & $\begin{array}{l}\text { Indicates the } \\
\text { number of videos } \\
\text { viewed about } \\
\text { ADHD. }\end{array}$ & $\begin{array}{l}\text { This variable was } \\
\text { determined by response } \\
\text { to the following } \\
\text { question: } \\
\text { How many informational } \\
\text { programs or videos } \\
\text { about ADHD have you } \\
\text { viewed? } \\
\text { 1. None } \\
2.1 \text { or } 2 \\
3.3 \text { to } 5 \\
4.6 \text { or more }\end{array}$ & $\begin{array}{l}\text { Responses were } \\
\text { categorized as an } \\
\text { ordinal scale as } \\
\text { follows: } \\
\text { None }=1 \\
1 \text { or } 2=2 \\
3 \text { to } 5=3 \\
6 \text { or more }=4\end{array}$ \\
\hline
\end{tabular}


Table 2-Continued.

\begin{tabular}{|c|c|c|c|c|}
\hline & Variables & $\begin{array}{l}\text { Conceptual } \\
\text { Definition }\end{array}$ & $\begin{array}{l}\text { Instrumental } \\
\text { Definition }\end{array}$ & $\begin{array}{l}\text { Operational } \\
\text { Definition }\end{array}$ \\
\hline 23 & $\begin{array}{l}\text { Acquaintances } \\
\text { outside of home } \\
\text { or school with } \\
\text { ADHD }\end{array}$ & $\begin{array}{l}\text { Indicates if } \\
\text { parents/teachers } \\
\text { know anyone } \\
\text { outside of their } \\
\text { home or school } \\
\text { with ADHD. }\end{array}$ & $\begin{array}{l}\text { This variable was } \\
\text { determined by } \\
\text { response to the } \\
\text { following question: } \\
\text { Do you know anyone } \\
\text { outside of } \\
\text { school/home who has } \\
\text { ADHD? } \\
\text { 1. No } \\
\text { 2. Yes }\end{array}$ & $\begin{array}{l}\text { Responses were } \\
\text { categorized as an } \\
\text { ordinal scale as } \\
\text { follows: } \\
\text { No }=1 \\
\text { Yes }=2\end{array}$ \\
\hline 24 & Knowledge & $\begin{array}{l}\text { Knowledge } \\
\text { indicates current } \\
\text { information } \\
\text { parents/teachers } \\
\text { possess about } \\
\text { ADHD. }\end{array}$ & $\begin{array}{l}\text { This variable was } \\
\text { determined by } \\
\text { responses to survey } \\
\text { questions } 3-5,6,8,10- \\
14,16-19,23-29 \\
\text { of knowledge section: } \\
\text { TRUE } \\
\text { FALSE } \\
\text { DON'T KNOW }\end{array}$ & $\begin{array}{l}\text { Correct responses } \\
\text { that were either } \\
\text { true or false were } \\
\text { scored as } 1 \text {, } \\
\text { incorrect } \\
\text { responses were } \\
\text { scored as } 0 \text {, and } \\
\text { Don't know were } \\
\text { scored as } 2 \text {. }\end{array}$ \\
\hline 25 & Belief & $\begin{array}{l}\text { Belief indicates } \\
\text { current information } \\
\text { parents/teachers } \\
\text { believe about } \\
\text { ADHD. }\end{array}$ & $\begin{array}{l}\text { This variable was } \\
\text { determined by } \\
\text { responses to survey } \\
\text { questions } 1,2,7,9,15 \text {, } \\
20,21,22 \text {. } \\
\text { TRUE } \\
\text { FALSE } \\
\text { DON'T KNOW }\end{array}$ & $\begin{array}{l}\text { Belief responses } \\
\text { were } \\
\text { maintained as } \\
\text { TRUE }=1 \\
\text { FALSE }=2 \\
\text { DON'T KNOW } \\
\quad=3 .\end{array}$ \\
\hline 26 & $\begin{array}{l}\text { Knowledge/Belief } \\
\text { Causes }\end{array}$ & $\begin{array}{l}\text { Knowledge } \\
\text { indicates current } \\
\text { information parents } \\
\text { and teachers } \\
\text { possess about } \\
\text { causes of ADHD. } \\
\text { Belief } \\
\text { indicates beliefs } \\
\text { parents/teachers } \\
\text { have about ADHD. }\end{array}$ & $\begin{array}{l}\text { Knowledge variable } \\
\text { was determined by } \\
\text { responses to survey } \\
\text { questions } 3,10,27 \text {. } \\
\text { Belief variable was } \\
\text { determined by } \\
\text { response to question } \\
1,2,21 \text { : } \\
\text { TRUE } \\
\text { FALSE } \\
\text { DON'T KNOW }\end{array}$ & See 24 and 25. \\
\hline
\end{tabular}


Table 2-Continued.

\begin{tabular}{lllll}
\hline \multicolumn{2}{l}{ Variables } & $\begin{array}{l}\text { Conceptual } \\
\text { Definition }\end{array}$ & $\begin{array}{l}\text { Instrumental } \\
\text { Definition }\end{array}$ & $\begin{array}{l}\text { Operational } \\
\text { Definition }\end{array}$ \\
\hline 27 & $\begin{array}{l}\text { Knowledge/Belief } \\
\text { symptoms and } \\
\text { characteristics }\end{array}$ & $\begin{array}{l}\text { Knowledge indicates } \\
\text { current information } \\
\text { parents and teachers } \\
\text { possess about }\end{array}$ & $\begin{array}{l}\text { Knowledge variable } \\
\text { was determined by } \\
\text { responses to survey }\end{array}$ & See 24 and \\
& qumptoms of ADHD. & questions 4,5,8,12,17, \\
& Belief indicates & Belief variable was & \\
& current beliefs of & determined by & \\
parents \& teachers & response to questions & \\
& about symptoms of & 7 \&15. & \\
& ADHD. & TRUE & \\
& FALSE & \\
& DON'T KNOW
\end{tabular}

28 Knowledge/Beliefs- Knowledge indicates general information current general information parents and teachers possess about ADHD. Belief indicates general beliefs parents and teachers have about ADHD.
29 Knowledge/Belief Treatment
Knowledge indicates current information parents and teachers possess about treatments of ADHD. Belief indicates beliefs parents and teachers have about ADHD.
Knowledge variable was determined by responses to survey questions 11,13, 19, $25 \& 29$. Belief variable was determined by responses to questions $9 \& 22$. TRUE

FALSE DON'T KNOW

See 24 and 25.

Knowledge variable was determined by

See 24 and 25. questions 6, 14,16, 20 $\& 28$. TRUE

FALSE DON'T KNOW 
Table 2-Continued.

\begin{tabular}{|c|c|c|c|c|}
\hline & Variables & $\begin{array}{l}\text { Conceptual } \\
\text { Definition }\end{array}$ & $\begin{array}{l}\text { Instrumental } \\
\text { Definition }\end{array}$ & $\begin{array}{l}\text { Operational } \\
\text { Definition }\end{array}$ \\
\hline 30 & Beliefs & $\begin{array}{l}\text { Belief indicates } \\
\text { what teachers and } \\
\text { parents feel or } \\
\text { believe about the } \\
\text { issues relating to } \\
\text { ADHD. }\end{array}$ & $\begin{array}{l}\text { This variable was } \\
\text { determined by } \\
\text { responses to survey } \\
\text { questions } 1-33 \text { of the } \\
\text { belief section on a } \\
\text { Likert scale. } \\
1=\text { Strongly disagree } \\
2=\text { Moderately } \\
\text { disagree } \\
3=\text { Slightly disagree } \\
4=\text { Slightly agree } \\
5=\text { Moderately agree } \\
6=\text { Strongly agree }\end{array}$ & $\begin{array}{l}\text { Responses were } \\
\text { tabulated as an equal } \\
\text { interval score of } \\
\text { strongly agree to } \\
\text { agree and strongly } \\
\text { disagree to disagree. }\end{array}$ \\
\hline 31 & $\begin{array}{l}\text { Beliefs } \\
\text { about } \\
\text { causes of } \\
\text { ADHD }\end{array}$ & $\begin{array}{l}\text { Belief indicates } \\
\text { what teachers and } \\
\text { parents feel or } \\
\text { believe about the } \\
\text { causes of ADHD. }\end{array}$ & $\begin{array}{l}\text { This variable was } \\
\text { determined by } \\
\text { responses to survey } \\
\text { questions } 1 \text { - } 9 \text { of the } \\
\text { belief section on a } \\
\text { Likert-scale. } \\
1=\text { Strongly disagree } \\
2=\text { Moderately } \\
\text { disagree } \\
3=\text { Slightly disagree } \\
4=\text { Slightly agree } \\
5=\text { Moderately agree } \\
6=\text { Strongly agree }\end{array}$ & $\begin{array}{l}\text { Responses were } \\
\text { tabulated as an equal } \\
\text { interval score of } \\
\text { strongly agree to } \\
\text { agree and strongly } \\
\text { disagree to disagree. }\end{array}$ \\
\hline 32 & $\begin{array}{l}\text { Beliefs } \\
\text { about } \\
\text { stimulant } \\
\text { medication }\end{array}$ & $\begin{array}{l}\text { Beliefs indicate } \\
\text { what teachers and } \\
\text { parents feel or } \\
\text { believe about } \\
\text { stimulant } \\
\text { medication as a } \\
\text { treatment for } \\
\text { ADHD. }\end{array}$ & $\begin{array}{l}\text { This variable was } \\
\text { determined by } \\
\text { responses to survey } \\
\text { questions } 12,14-20 \\
\text { of the belief section on } \\
\text { the Likert scale. } \\
1=\text { Strongly disagree } \\
2=\text { Moderately } \\
\text { disagree } \\
3=\text { Slightly disagree } \\
4=\text { Slightly agree } \\
5=\text { Moderately agree } \\
6=\text { Strongly agree }\end{array}$ & $\begin{array}{l}\text { Responses were } \\
\text { tabulated as an equal } \\
\text { interval score of } \\
\text { strongly agree to } \\
\text { agree and strongly } \\
\text { disagree to disagree. }\end{array}$ \\
\hline
\end{tabular}


Table 2-Continued.

\begin{tabular}{|c|c|c|c|c|}
\hline & Variables & $\begin{array}{l}\text { Conceptual } \\
\text { Definition }\end{array}$ & Instrumental Definition & $\begin{array}{l}\text { Operational } \\
\text { Definition }\end{array}$ \\
\hline 33 & $\begin{array}{l}\text { Beliefs about } \\
\text { intervention/ } \\
\text { Treatment } \\
\text { options }\end{array}$ & $\begin{array}{l}\text { Belief about what } \\
\text { teachers and parents } \\
\text { feel or believe about } \\
\text { ADHD intervention/ } \\
\text { treatment options. }\end{array}$ & $\begin{array}{l}\text { This variable was } \\
\text { determined by } \\
\text { responses to survey } \\
\text { questions } 10,13,21-23 \\
\& 27 \text { of the belief } \\
\text { section on the Likert } \\
\text { scale. } \\
1=\text { Strongly disagree } \\
2=\text { Moderately } \\
\text { disagree } \\
3=\text { Slightly disagree } \\
4=\text { Slightly agree } \\
5=\text { Moderately agree } \\
6=\text { Strongly agree }\end{array}$ & $\begin{array}{l}\text { Responses were } \\
\text { tabulated as an } \\
\text { equal interval } \\
\text { score of } \\
\text { strongly agree } \\
\text { to agree and } \\
\text { strongly } \\
\text { disagree to } \\
\text { disagree. }\end{array}$ \\
\hline 34 & $\begin{array}{l}\text { Beliefs about } \\
\text { Other ADHD } \\
\text { Issues }\end{array}$ & $\begin{array}{l}\text { Belief indicates what } \\
\text { teachers and parents } \\
\text { feel or believe about } \\
\text { other issues of ADHD. }\end{array}$ & $\begin{array}{l}\text { This variable was } \\
\text { determined by } \\
\text { responses to survey } \\
\text { questions } 24-26,28-33 \\
\text { of the belief section on } \\
\text { a Likert scale. } \\
1=\text { Strongly disagree } \\
2=\text { Moderately } \\
\text { disagree } \\
3=\text { Slightly disagree } \\
4=\text { Slightly agree } \\
5=\text { Moderately agree } \\
6=\text { Strongly agree }\end{array}$ & $\begin{array}{l}\text { Responses were } \\
\text { tabulated as an } \\
\text { equal interval } \\
\text { score of } \\
\text { strongly agree } \\
\text { to agree and } \\
\text { strongly } \\
\text { disagree to } \\
\text { disagree. }\end{array}$ \\
\hline 35 & $\begin{array}{l}\text { Beliefs about } \\
\text { Intervention/ } \\
\text { Treatment } \\
\text { options } \\
\text { continued }\end{array}$ & $\begin{array}{l}\text { Beliefs indicate what } \\
\text { teachers and parents } \\
\text { feel or believe about } \\
\text { medication, behavioral } \\
\text { and educational inter- } \\
\text { ventions. }\end{array}$ & $\begin{array}{l}\text { This variable was } \\
\text { determined by } \\
\text { responses to survey } \\
\text { questions } 34 \mathrm{a}, 35 \mathrm{a}, 36 \mathrm{a} \text {, } \\
34 \mathrm{~b}, 35 \mathrm{~b}, 36 \mathrm{~b}, 34 \mathrm{c}, 35 \mathrm{c}, \\
36 \mathrm{c} \text { of the belief section } \\
\text { on the Likert scale. } \\
1=\text { Not at all effective } \\
2=\text { Slightly effective } \\
3=\text { Moderately } \\
\text { effective } \\
4=\text { Effective } \\
5=\text { Very effective }\end{array}$ & $\begin{array}{l}\text { Responses were } \\
\text { tabulated as an } \\
\text { equal interval } \\
\text { score. }\end{array}$ \\
\hline
\end{tabular}


Table 2-Continued.

\begin{tabular}{lllll}
\hline Variables & $\begin{array}{l}\text { Conceptual } \\
\text { Definition }\end{array}$ & Instrumental Definition & $\begin{array}{l}\text { Operational } \\
\text { Definition }\end{array}$ \\
\hline 36 & $\begin{array}{l}\text { Overall } \\
\text { knowledge }\end{array}$ & $\begin{array}{l}\text { Overall knowledge } \\
\text { indicates what teachers } \\
\text { and parents know } \\
\end{array}$ & $\begin{array}{l}\text { This variable was } \\
\text { determined by adding } \\
\text { the correct knowledge }\end{array}$ & $\begin{array}{l}\text { Responses were } \\
\text { tabulated as } \\
\text { continuous }\end{array}$ \\
& & $\begin{array}{l}\text { answers together for } \\
\text { items 3-6 8, 10, 11-14, }\end{array}$ & score of 0-22. \\
& & $16-19,20 \& 23-29$. & \\
\hline
\end{tabular}

\section{Survey Format}

The survey format was designed using the Total Design Method (TDM) (Dillman, 1978). The survey was formatted in the following way: lower case letters were used for the text for the questions and upper case letters were used for text for the answers; true/false/don't know responses were on the right in the knowledge/belief section; the Likert scale in the belief section was on the right of the survey; questions in section 3 and 4 were identified with answer categories on the left with numbered multiple-choice format; directions were provided for how to answer questions; the front cover of the survey had a survey title, a graphic illustration, and the name of the district where the study took place, survey purpose and direction, and the emblem and address of the study sponsor; the back cover invited participants to make additional comment; the survey was printed as a booklet, with no questions on the front or back pages, and was reproduced on off-white paper (Dillman, 1978, pp. 119 -154). See Appendix D.

\section{Procedure}

Preparation for Distribution of the Surveys

Superintendents of each of the five school districts sent out letters to every teacher 
and parent (see Appendix E) in their school district, informing them the survey for this research was forthcoming and encouraging them to participate in the study by completing the surveys and returning them. Prior to distribution, parent surveys were placed into envelopes with a generic label addressed to "Parents in the Atlantic Union Conference.” Each envelope contained a survey (see Appendix E), a return envelope addressed to me in care of the appropriate conference (school district) office, a letter (see Appendix E) from me explaining the nature of the study and instructions to follow. Teachers' envelopes were individually addressed to each teacher in care of their school and school district. Each envelope contained a survey (see Appendix D), a return envelope addressed to me in care of the appropriate school district office, a letter (see Appendix E) from me explaining the nature of the study and instructions to follow. In preparation for distribution, I grouped the envelopes first by school district, second by school, and finally by class. I included a letter to principals and teachers (see Appendix E) with instructions regarding the distribution and return of the surveys. Once surveys were ready for distribution, they were given to each superintendent when they convened at a quarterly meeting at the Atlantic Union Conference offices.

\section{Distribution of Surveys}

Subsequently, the distribution of the surveys was handled in various ways. The superintendent from Bermuda Conference distributed pre-bundled parent surveys and each teacher survey directly to each teacher for class distribution. Superintendents from Greater New York Conference and Southern New England Conference distributed prebundled parent surveys and teacher surveys to principals of each school to give to their teachers for class distribution. The only exceptions were Browning Elementary and South 
Lancaster Academy in Southern New England Conference, who received their surveys directly from me. I mailed pre-bundled parent surveys and teacher surveys to all of the schools in the Northern New England Conference and New York Conference, except Pine Tree Academy and Union Springs Academy, who received their surveys from their superintendents.

Once teachers received the surveys, they were supposed to distribute them to their students during the week of October 22, 2006; however, some of the teachers and/or schools did not distribute the surveys in a timely manner, which impacted the return of the surveys to schools by October 30, 2006. In order to ensure a reasonable return, I telephoned each of the schools at least twice to check on the return of surveys. Some of the schools sent out reminders to their parents and teachers via Friday notes or by mouth. Overall, all participating surveys were returned by December 1, 2006.

\section{Return of Surveys}

Return of surveys was handled in various ways. The surveys from Bermuda Conference and Greater New York Conference were returned directly to me via superintendents who collected them from schools. Surveys from New York Conference and Northern New England Conference were mailed directly back to me in pre-stamped return envelopes, except a few which were sent directly to conferences (school districts) who forwarded them to me. Surveys from Southern New England Conference were either mailed directly to me, to the conference office, or were collected by me. Once I received the surveys, they were individually entered into SPSS into a data set. This data set was subsequently sent via email to the methodologist. Both the researcher and the methodologist checked and rechecked the data for accuracy using SPSS to look at the 
mean, range, minimum, and maximum for the data set to check for a possibility of error. Since respondents were not required to put any personal identification on the surveys, their identities were unknown to me, thus ensuring anonymity.

\section{Handling of Returned Surveys}

Returned surveys served as implied consent. All returned surveys were given an ID number upon receipt and were put into binders in the basement of my home. I am the only person who handled the actual surveys and responses were handled confidentially, ensuring the personal privacy of each respondent. I did not receive any complaints from any of the school districts, schools, teachers, or parents who participated in the study, thus it is assumed that respondents' welfare or rights were not compromised nor did they experience any risks or discomfort by participating in the study. There were 76 surveys returned from teachers, which represented a $31.9 \%$ return rate whereas 373 surveys were returned from parents which represented an $18.6 \%$ return rate.

\section{Research Design}

The research design for this study was quantitative and used a survey instrument compiled specifically for the study to examine the knowledge and beliefs of the teachers and parents of children in SDA parochial schools. The objective of this research study was to answer the following questions and test the hypotheses pertaining to the knowledge and beliefs about ADHD.

Research Questions, Hypotheses, Null Hypotheses and Design Analysis

1. What do regular education teachers and parents of children in parochial schools know about ADHD? This question was answered using descriptive statistics. 
2. What do regular education teachers and parents of children in parochial schools believe about ADHD? This question was answered using descriptive statistics

3. Are there differences in the knowledge about ADHD on individual items between regular education teachers and parents of children in parochial schools?

Hypothesis 1: There are significant differences in the knowledge about ADHD on individual items between regular education teachers and parents of children in parochial schools.

Null Hypothesis 1: There are no significant differences in the knowledge of ADHD on individual items between regular education teachers and parents of children in parochial schools.

4. Are there differences in the beliefs about ADHD between regular education teachers and parents of children in parochial schools on individual items?

Hypothesis 2: There are significant differences in the beliefs about ADHD between regular education teachers and parents of children in parochial schools on individual items.

Null Hypothesis 2: There are no significant differences in the beliefs about ADHD between regular education teachers and parents of children in parochial schools on individual items.

5. Is there a difference in the overall knowledge regarding ADHD between regular education teachers and parents of children in parochial schools?

Hypothesis 3: There is a significant difference in the overall knowledge regarding ADHD between regular education teachers and parents of children in parochial schools?

Null Hypothesis 3: There is no significant difference in the overall knowledge 
regarding ADHD between regular education teachers and parents of children in parochial schools. This hypothesis was tested using one-way ANOVA.

6. Do demographic variables (gender, race, conference, grade level taught, teaching experience, and education level), exposure to information about ADHD variables (books read about ADHD, articles read about ADHD, videos viewed about ADHD, instruction about ADHD in teacher training, training about ADHD after beginning teaching, graduate courses pertaining to ADHD) and experience with ADHD variables (former and current students with ADHD, former and current students thought to have ADHD, acquaintances outside of school with ADHD) predict the overall knowledge regarding ADHD of regular education teachers of children in parochial schools?

Hypothesis 2a: One or more of the following demographic variables predicts the overall knowledge regarding ADHD of regular education teachers of children in parochial schools: gender, race, teaching experience, education level, conference, grade level taught, and teacher certification.

Hypothesis 2b: Exposure to information about ADHD by one or more of the following variables predicts the overall knowledge regarding ADHD of regular education teachers of children in parochial schools: books read about ADHD, articles read about ADHD, videos viewed about ADHD, instruction about ADHD in teacher training, training about ADHD after beginning teaching, and graduate courses pertaining to ADHD.

Hypothesis 2c: Experience with ADHD by one or more of the following variables predicts the overall knowledge regarding ADHD of regular education teachers of children 
in parochial schools: former and current students with ADHD, former and current students thought to have ADHD, acquaintances outside of school with ADHD.

7. Do demographic variables (gender, race, education level, conference, marital status), exposure to information about ADHD variables (books read about ADHD, articles read about ADHD, videos viewed about ADHD, lectures attended about ADHD and belonged to support group for ADHD) and experience with ADHD variables (family member with ADHD, family member evaluated for ADHD, family member treated for ADHD, acquaintances outside of home with ADHD) predict the overall knowledge regarding ADHD of parents of children in parochial schools?

Hypothesis 3a: One or more of the following demographic variables predicts the overall knowledge regarding ADHD of parents of children in parochial schools: gender, race, education level, marital status, and conference.

Hypothesis 3b: Exposure to information about ADHD by one or more of the following variables predicts the overall knowledge regarding ADHD of parents of children in parochial schools: books read about ADHD, articles read about ADHD, videos viewed about $\mathrm{ADHD}$, lectures attended about $\mathrm{ADHD}$, and belonged to support group for ADHD.

Hypothesis 3c: Experience with ADHD by one or more of the following variables predicts the overall knowledge regarding ADHD of parents of children in parochial schools: family member with ADHD, family member evaluated for ADHD, family member treated for ADHD, and acquaintances outside of home with ADHD. 


\section{Data Analysis}

The data collected through the teacher and parent questionnaires were coded according to each section.

\section{Knowledge and Beliefs About ADHD Section: True, False and Don't Know Section}

This section had a true, false, and don't know format with 29 items. The items were coded as follows: True $=1 ;$ False $=2 ;$ Don't Know $=3$. For the knowledge items all correct answers were recoded with ' 1 ', all incorrect answers were recoded with ' 0 ' and all Don't Know answers were recoded with '2'. Based on the empirical evidence discussed in chapter 2 , items $3,5,8,12,16,17,19,20$, and 28 were scored as true statements, whereas items 4, 6, 10, 11, 13, 14, 18, 23, 24, 25, 26, 27, and 29 were scored as false statements (see Appendix C). The beliefs statements (1, 2, 7, 9, 15, 21, and 22) in this section were not coded as correct or incorrect since beliefs are not supported by empirical data and are subjective to what respondents believe or do not believe.

As previously discussed, the knowledge section was divided into two sections: knowledge and beliefs. The knowledge statements, which were supported by empirical evidence or diagnostic criteria, were scored as a whole, producing a sum of the 22 items with a continuous score ranging from 0 to 22 . In order to get a continuous score, items with the occurrence of a value of 1 were counted together to produce the overall knowledge variable. This score was then calculated as a percentage. The belief statements were not supported by empirical evidence or diagnostic criteria and were not totaled as a whole since beliefs cannot be judged as correct or incorrect. 


\section{Beliefs About ADHD Section: Likert-Item Format}

This section had a Likert-item format with 36 items. The first 33 items were coded with six statements: 1 = Strongly disagree; 2 = Moderately Disagree; $3=$ Slightly Disagree; 4 = Slightly Agree; 5 = Moderately Agree; and $6=$ Strongly Agree. Raw scores produced an equal interval score of $1,2,3,4,5$, or 6 from the Likert items, since strongly agree to strongly disagree are considered to be equal intervals; the mental distance between strongly agree and agree is the same distance between strongly disagree and disagree (Patten, 2001).These scores were then tabulated to produce a mean and standard deviation score for each item in order to follow Carlson et al.'s (2006) method.

In order to come to a clear understanding of what teachers and parents believe about ADHD issues, raw scores and mean scores were examined. Raw scores showed how the respondents truly responded to each item, which provided their actual position on the issue whereas mean scores provided an average score for each item. This gave a clearer picture of the position of the respondents on each statement. The remaining three items were coded with five statements: 1 = Not at All Effective; 2 = Slightly Effective; 3 = Moderately Effective; 4 = Effective; and 5 = Very Effective, which produced an individual ordinal score of 1,2, 3, 4, or 5. Each item was also tabulated to produce mean scores and standard deviations to compare with Carlson et al. (2006).

\section{Demographics Section}

The first seven questions in the questionnaires were demographics; however, the questions were slightly different for the two groups. The categories were coded as follows:

1. Gender was coded as male $=1$; female $=2$. 
2. Degree earned by teachers was coded into three categories: Bachelor $=1$; Masters $=2 ;$ Doctoral $=3$.

3. Educational level for parents was coded into four categories: Below High School = 1; High School =2; Undergraduate $=3 ;$ Graduate $=4$.

4. Grade level currently taught by teachers was coded into six categories: PreK $/ \mathrm{K}=1 ; 1-3=2 ; 4-6=3 ; 7-8=4 ; 9-12=5 ;$ multigrade $=6$.

5. Certification or licensure held by teachers was coded into six categories: Early Childhood Education $=1$, Elementary Education $=2$, Middle School $=3$, High School $=$ 4, Special Education $=5$, Other $=6$.

6. Marital status for parents was coded into five categories: Single $=1$; Married $=2 ;$ Separated $=3 ;$ Divorced $=4 ;$ Widowed $=5$.

7. Conference was coded into five categories: Bermuda $=1$; Greater New York Conference $=2 ;$ New York Conference $=3 ;$ Northern New England Conference $=4$; Southern New England Conference $=5$.

8. Race was coded into five groups: Asian $=1 ;$ Black $=2$; Caucasian $=3$; Hispanic/Latino $=4$; Other $=5$.

Each of these questions received a nominal score of 1,2,3,4,5,6, or 7. Teaching experience required teachers to fill in the blank with the number of years taught, thus providing a number ranging from $0-40$ years.

\section{Experience With and Exposure to ADHD Section}

There were nine questions in this section, which differed slightly for teachers and parents. The teachers' questions were as follows:

1. Instruction about ADHD in teacher training was coded into three categories: 
No $=1 ;$ Yes, briefly $=2 ;$ Yes, extensively $=3$.

2. Former and current students with ADHD was coded into four categories: none $=1 ; 1$ or $2=2 ; 3-5=3 ; 6$ or more $=4$.

3. Former and current students thought to have ADHD was coded into four categories, none $=1,1$ or $2=2 ; 3-5=3 ; 6$ or more $=4$.

4. Training about ADHD after beginning teaching was coded in three categories: No $=1 ;$ Yes, brief in-service $=2 ;$ Yes, comprehensive workshop $=3$.

5. Graduate courses taken pertaining to ADHD was coded into two categories: No $=1 ;$ Yes $=2$.

6. Articles read about ADHD, books read about ADHD, and informational programs or videos viewed about ADHD was coded into four categories, none $=1 ; 1$ or 2 $=2 ; 3-5=3 ; 6$ or more $=4$.

7. Acquaintances outside of school with ADHD was coded into two groups: No $=1 ;$ Yes $=2$.

The parents' questions were as follows:

1. Family member with ADHD or evaluated for ADHD was coded into two groups: No $=1 ;$ Yes $=2$.

2. Family member treated for ADHD was coded into four categories: Presently treated $=1 ;$ Previously treated $=2 ;$ Never $=3 ; \mathrm{N} / \mathrm{A}=4$.

3. Magazine/newspaper articles read about ADHD, books read about ADHD, informational programs or videos viewed about ADHD, lectures/presentations attended about ADHD were coded into four categories: none $=1 ; 1$ or $2=2 ; 3-5=3 ; 6$ or more $=$ 4. 
4. Belonging to a parent support group for ADHD was coded into four categories: Presently belong $=1 ;$ Previously belonged $=2 ;$ Never $=3 ; \mathrm{N} / \mathrm{A}=4$.

5. Acquaintances outside of home with ADHD was coded into two groups: No = $1 ;$ Yes $=2$

Each question in this section received a nominal score of $1,2,3$, or 4.

All questions were analyzed using SPSS 16.0. A descriptive analysis was conducted on the demographic variables (gender, race, conference, teaching experience, grade taught, educational level, marital status, and teacher certification), exposure to information about ADHD variables (articles and books read about ADHD, videos viewed about ADHD, graduate courses taken pertaining to ADHD, instruction about ADHD in teacher training, training about ADHD since beginning teaching, lectures attending about ADHD and belonged to support group for ADHD) and experience with ADHD variables (acquaintances outside of school/home with ADHD, former and current students with ADHD, former and current students thought to have ADHD, family member evaluated for $\mathrm{ADHD}$, family member identified with $\mathrm{ADHD}$ and family member treated for ADHD). Descriptive analysis was also conducted on the true, false, and don't know items and the Likert items. The analysis used crosstabs to produce frequency distribution and percentages.

Chi-square goodness-of-fit test was used to test hypotheses 1 and 2 by comparing the frequency of responses on true, false, and don't know items and Likert items. Oneway ANOVA was used to test hypothesis 3 by comparing the means of teachers and parents on overall knowledge regarding ADHD to determine if there was a significant difference between the two groups. Eta squared $\left(n^{2}\right)$ was used to interpret effect sizes for 
chi-square and one-way ANOVA, and it has an interpretation similar to a squared correlation coefficient $\left(r^{2}\right)$. A small effect size has a value of .0196 or less, a medium effect size has a value between .1300 and .2599 , and a large effect size has a value of .2600 and higher (Kotrlik \& Williams, 2003).

Categorical regression with optimal scaling (CATREG) was used to test hypotheses $4 \mathrm{a}-\mathrm{c}$ and $5 \mathrm{a}$-c. The goal of CATREG was to describe the relationship between a response variable (dependent variable) and a set of predictors (independent variables). By quantifying this relationship, values of the dependent variable can be predicted for any combination of predictors. Therefore, nominal, ordinal, and numeric variables could be analyzed at the same time. CATREG was conducted with groups of independent variables (demographic variables, exposure to information about ADHD, and experience with ADHD) to determine if there was a relationship between any of them and overall knowledge regarding ADHD. The $R$ square and the adjusted $R$ square are reported in each model. " $R$ square is an accurate value for the sample drawn but is considered an optimistic estimate for the population value. The adjusted $R$ squared is considered a better population estimate" (George \& Mallery, 2006, p. 188). $R$ squared is typically used when the sample size is greater than 60, whereas adjusted $R$ square is appropriate when the sample size is less than 60 and when there are numerous independent variables (Tabachnick \& Fidell, 2001). The $R$ square (coefficient of determination), the adjusted $R$ square (adjusted coefficient of determination), standardized regression coefficients (beta), correlations, zero-order, partial and part, and Pratt's relative importance measure were inspected to interpret predictor contributions to the regression. Effect sizes for $R$ squared are interpreted as follows: .0196 is a small 
effect size, .1300 is a medium effect size, and .2600 is a large effect size (Kotrlik \& Williams, 2003).

\section{Summary}

This chapter discussed the research design and the procedures that were followed to complete this study. The convenience sample was taken from a population of teachers and parents of children in the SDA parochial school system. Permission was granted from five participating school districts in the Atlantic Union Conference: Bermuda, Greater New York, New York, Northern New England, and Southern New England. Surveys were sent out to the teachers and parents and returned in a timely manner with a total of 76 teachers (31.9\% of the sample) and 373 parents (18.6\% of the number of surveys sent out) participating in the study. Information elicited from the surveys included knowledge and beliefs about ADHD, beliefs about issues of ADHD, demographic information, and experience with and exposure to ADHD. SPSS 16.0 was used to conduct the statistical analysis on the data. This included one-way ANOVA, CATREG, descriptive statistics, and chi-square. 


\section{CHAPTER 4}

\section{RESULTS}

\section{Introduction}

The purpose of this study was to determine the knowledge and attitudes of teachers and parents concerning ADHD and issues relating to the disorder. Participants completed surveys that elicited information about knowledge relating to ADHD, beliefs about issues relating to ADHD, demographic information, and information about experience with and exposure to ADHD. The statistical analysis performed on the data included descriptive statistics, chi-square, one way-ANOVA, and categorical regression with optimal scaling (CATREG).

This chapter has four sections. First, a description of the recoding of the variables is explained. Second, an item-discrimination index of the knowledge items is presented. Third, the demographic characteristics of the sample are delineated. Fourth, findings from the research questions and hypotheses are discussed. Finally, the findings of the data are summarized.

\section{Recoding of the Variables}

In this section an explanation and description is provided for the recoding of certain variables. Variables 2, 4-8, 10, 13, 17, 19, 22 (see Table 2) were recoded from their original operational definition due to small numbers in certain categories. Variables 
24-30 were recoded to reflect correct, incorrect, and don't know responses. Responses were recoded as follows:

1. Educational Level of Parents (variable 2) - Below High School and High School were combined, thus the categories were recoded as follows: High School and Below $=$ $1 ;$ Undergraduate $=2 ;$ Graduate $=3$.

2. Marital Status (variable 4) - Single, Divorced, and Widowed were collapsed into one category of Single, thus the categories were recoded as follows: Single $=1$; Married $=2$.

3. Race (variable 5) - Asian and Hispanic/Latino were collapsed and included with Other, thus the categories were recoded as follows: Other $=1$; Black or African American $=2$; Caucasian or White $=3$.

4. Conference (variable 6) - Greater New York and New York were combined and the categories recoded as follows: Bermuda $=1 ;$ New York $=2$; Northern New England $=$ 3; and Southern New England $=4$.

5. Grade (variable 7) - The categories were collapsed and recoded as follows: PreK$8=1 ; 9-12=2 ;$ and Multi grades $=3$.

6. Certification (variable 8) - The categories were collapsed and recoded as follows: Early Childhood/Elementary $=1 ;$ High School $=2$.

7. Instruction about ADHD in Teacher Training (variable 10) - The categories were collapsed and recoded as follows: No Training $=0$; Training $=1$.

8. ADHD Training Since Beginning Teaching (variable 13) - The categories were collapsed and recoded as follows: No Training $=0$; Training $=1$.

9. Family Member Treated for ADHD (variable 17) - The categories were collapsed 
and recoded as follows: Not Treated for $\mathrm{ADHD}=0$; Treated for $\mathrm{ADHD}=1$.

10. Belonged to Support Group for ADHD (variable 19) - The categories were collapsed and recoded as follows: Not Applicable $=0$; Belonged to a Support Group $=1$.

11. Number of Informational Programs or Videos Viewed About ADHD (variable 22) - The categories were collapsed and recoded as follows - No Videos $=0 ; 1$ or 2 Videos Viewed $=1 ; 3$ or More Videos Viewed $=2$

12. Knowledge variables - Correct answers were recoded with '1', Don't Know responses were recoded with '2,' and incorrect answers were recoded with '0'.

13. Overall knowledge variable - An overall knowledge score was calculated by counting only the occurrences with a value of 1 and adding them together, which yielded a continuous score of $0-22$. In order to get a percentage, the overall score was multiplied by 100 and divided by the number of items in the total, which was 22 .

\section{Item Analysis}

This section presents an item analysis for the knowledge items. See Appendix C for item descriptions. The item analysis was conducted on the items to understand how they were functioning in this sample. The formula used for the item-discrimination index was as follows: $d=(U-L) / N$. An item-difficulty index was also calculated on the items to identify items that should be altered or discarded. The formula used for the analysis was as follows: $p=(U+L) / N x 2$. Results of the calculation are displayed in Table 3 . The letters in the formulas symbolized the following: $d$-item-discrimination index; $p$ - index of item difficulty; $U$ - the number of examinees in the upper range who answered the item correctly; $L$ - the number of respondents in the lower range who answered the item correctly; $N$ - the number of examinees in the upper or lower range (Gregory, 2004). 
Table 3

Item-Discrimination and Item-Difficulty Indices of Knowledge Statements for Teachers and Parents

\begin{tabular}{cccccc}
\hline Item & Teachers & Parents & \\
& $d$ & $p$ & $d$ & $p$ & \\
\hline & & & & & Knowledge about Symptoms and Characteristics \\
\hline 4 & .18 & .91 & .50 & .69 & $\begin{array}{l}\text { Easy item for teachers and there is no discrimination between } \\
\text { low and high scorers. Good item for parents for there is } \\
\text { discrimination between low and high scores. It is an item } \\
\text { where there is strong knowledge for teachers and median } \\
\text { knowledge for parents. }\end{array}$
\end{tabular}

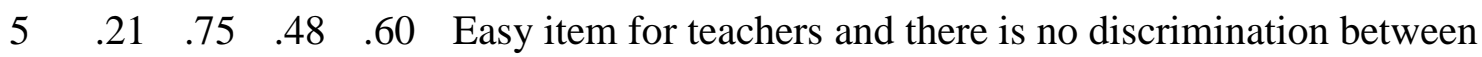
low and high scorers. Good item for parents for there is discrimination between low and high scores. It is an item where there is about strong knowledge for teachers and about median knowledge for parents.

$\begin{array}{llllll}8 & 07 & .89 & .25 & .85 & \text { Easy item and there is no discriminating between low and }\end{array}$ high scorers for both teachers and parents. It is an item where there is strong knowledge.

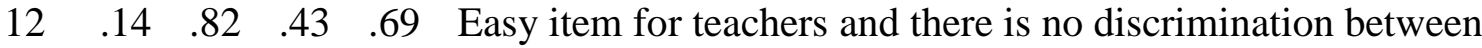
low and high scorers. An item that discriminates well between low and high scores for parents. It is an item of strong knowledge for teachers and median knowledge for parents.

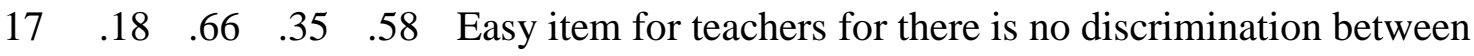
low and high scorers. An item that discriminates well between low and high scores for parents. Item is not too difficult or too easy. It is an item where there is about median knowledge.

$\begin{array}{llllll}18 & .36 & .75 & .56 & .61 & \text { An item that discriminates well between low and high }\end{array}$ scoring for both teachers and parents. Item is easy for teachers. It is an item where there is about median knowledge.

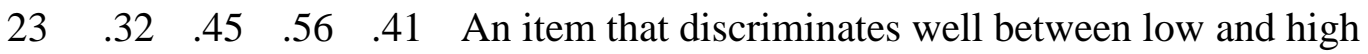
scoring for both teachers and parents. It is an item where there is about median knowledge. 
Table 3-Continued.

\begin{tabular}{|c|c|c|c|c|c|}
\hline \multirow[t]{2}{*}{ Item } & \multicolumn{2}{|c|}{ Teachers } & \multicolumn{2}{|c|}{ Parents } & \multirow[t]{2}{*}{ Comment } \\
\hline & $d$ & $p$ & $d$ & $p$ & \\
\hline 24 & .18 & .16 & .32 & .21 & $\begin{array}{l}\text { Poor item for teachers for there is no discrimination between } \\
\text { low and high scorers. Nearly all answered it wrong. An item } \\
\text { that discriminates well between low and high scores for } \\
\text { parents, although many answered it wrong. It is an item where } \\
\text { there is weak knowledge. }\end{array}$ \\
\hline 26 & .46 & .30 & .27 & .22 & $\begin{array}{l}\text { An item that discriminates well between low and high scoring } \\
\text { for both teachers and parents. It is an item where there is weak } \\
\text { knowledge. }\end{array}$ \\
\hline
\end{tabular}

Knowledge about General Information

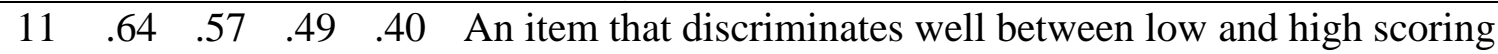 for both teachers and parents. Item is not too difficult or too easy. It is an item where there is about median knowledge.

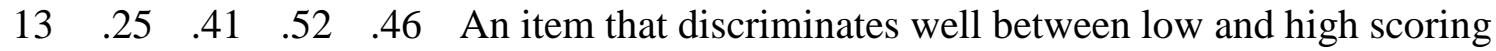 for both teachers and parents. Item is not too difficult or too easy. It is an item where there is about median knowledge.

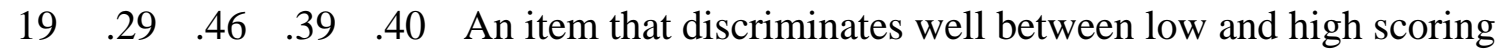 for both teachers and parents. Item is not too difficult or too easy. It is an item where there is about median knowledge.

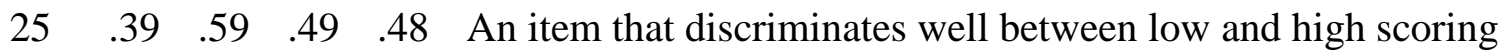 for both teachers and parents. It is an item where there is about median knowledge.

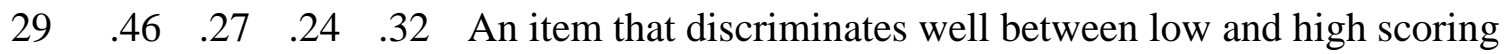
for teachers and parents. Item is not too easy or too difficult. It is an item where there is weak knowledge.

\section{Knowledge about Causes of ADHD}

$\begin{array}{llllll}3 & .54 & .66 & .60 & .60 & \text { An item that discriminates well between low and high scoring }\end{array}$ for both teachers and parents. Item is not too difficult or too easy. It is an item where there is about median knowledge.

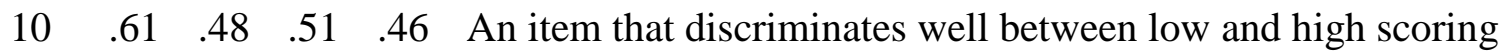
for both teachers and parents. Item is not too difficult or too easy. It is an item where there is about median knowledge.

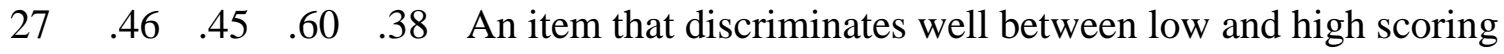
for both teachers and parents. Item is not too easy or too difficult. It is an item where there is about median knowledge. 
Table 3-Continued.

\begin{tabular}{llllll}
\hline Item & Teachers & Parents & \\
& $d$ & $p$ & $d$ & $p$ & \\
\hline 6 & .14 & .82 & .37 & .55 & $\begin{array}{l}\text { Easy item for teachers and there is no discrimination between } \\
\text { low and high scorers. Good item for parents for there is } \\
\text { discrimination between low and high scores. It an item where } \\
\text { there is strong knowledge for teachers and about median } \\
\text { knowledge for parents. }\end{array}$ \\
& & & & &
\end{tabular}

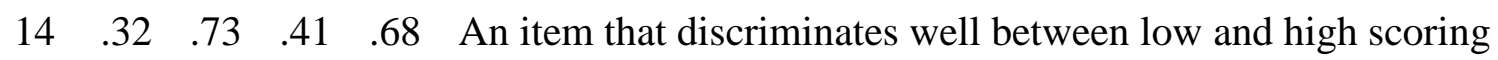
for both teachers and parents. Item is not too difficult or too easy. It is an item where there is about median knowledge.

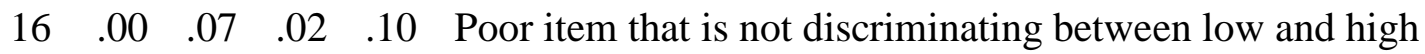
scorers for both teachers and parents. Nearly everyone answered it wrong, thus it should be examined to see if it makes sense. It is an item of weak knowledge.

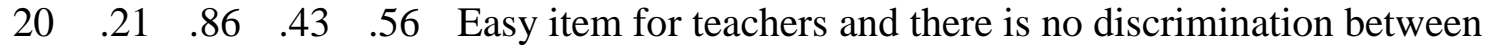
low and high scorers. An item that discriminates well between low and high scores for parents. It is an item where there is strong knowledge for teachers and about median knowledge for parents.

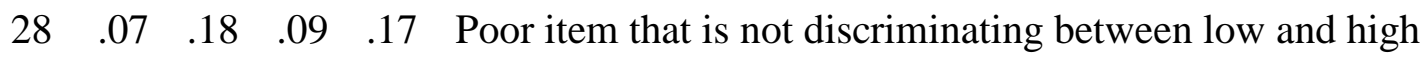
scorers for both teachers and parents. Nearly everyone answered it wrong, thus it should be rewritten because the type of therapy that is commonly associated with ADHD is called behavior therapy not obedience. It is an item where there is weak knowledge.

Note. $\mathrm{T}=$ Teachers; $\mathrm{P}=$ Parents

\section{Characteristics of the Sample}

In this section, characteristics of the sample are discussed and described with the use of tables. The surveys for this study were sent to 232 teachers (see Table 1) in the five conferences. Because the total number of children and parents represented in the schools was unknown, 2,000 surveys were sent to schools for teachers to distribute to the children. These children were instructed to take the survey home to their parents; 
however, it is not known how many parents actually received the survey. A total of 76 teachers (31.9\% of the population) and 373 parents (18.6\% of the number of surveys sent out) returned the surveys to participate in the study. Tables 4-10 summarize the teachers' demographic characteristics; tables 11-16 summarize the teachers' exposure to information about ADHD; and tables 17-19 summarize the teachers' experience with ADHD. Tables 20-24 summarize the parents' demographic characteristics; tables 25-29 summarize the parents' exposure to information about ADHD; and tables 30-33 summarize the parents' experience with ADHD.

\section{Teachers' Demographic Variables}

\section{Gender}

The majority of teachers in the sample were female (80.3\%) compared with male teachers (18.4\%). See Table 4.

Table 4

Teachers' Gender

\begin{tabular}{lcc}
\hline Gender & Frequency & Percentage \\
\hline Male & 14 & 18.4 \\
Female & 61 & 80.3 \\
Unknown & 1 & 1.3 \\
Total & 76 & 100 \\
\hline
\end{tabular}


Race

Almost half of the sample of teachers was Caucasian (46.1\%) with Black or African American representing almost 35\%. Teachers classified as 'Other' (18.4\%) included Hispanics, Asians, and other races. See Table 5.

Table 5

Teachers' Race

\begin{tabular}{lcc}
\hline Race & Frequency & Percentage \\
\hline Other & 14 & 18.4 \\
Black or African American & 26 & 34.2 \\
Caucasian & 35 & 46.1 \\
Unknown & 1 & 1.3 \\
Total & 76 & 100 \\
\hline
\end{tabular}

\section{Conference (School District)}

The majority of teachers worked in New York (38.2\%) which is comprised of both the New York and Greater New York conferences (school districts). The least number of teachers worked in Bermuda Conference (11.8\%). See Table 6.

Table 6

Teachers' Conference (School District)

\begin{tabular}{lcc}
\hline Conference (School District) & Frequency & Percentage \\
\hline Bermuda & 9 & 11.8 \\
New York & 29 & 38.2 \\
Northern New England & 15 & 19.7 \\
Southern New England & 22 & 28.9 \\
Unknown & 1 & 1.3 \\
Total & 76 & 100 \\
\hline
\end{tabular}




\section{Education Level}

More than half of the teachers held a Master's degree (55.3\%), while $43.4 \%$ held

a Bachelor's degree. See Table 7.

Table 7

Teachers' Education Level

\begin{tabular}{lcc}
\hline Education Level & Frequency & Percentage \\
\hline Bachelor's degree & 33 & 43.4 \\
Master's degree & 42 & 55.3 \\
Unknown & 1 & 1.3 \\
Total & 76 & 100 \\
\hline
\end{tabular}

\section{Certification}

Approximately two-thirds of the teachers (67.1\%) were certified in early childhood education or elementary education. See Table 8.

Table 8

Teachers' Certification

\begin{tabular}{lcc}
\hline Certification & Frequency & Percentage \\
\hline Early Childhood/Elementary Education & 51 & 67.1 \\
High School & 19 & 25.0 \\
Unknown & 6 & 7.9 \\
Total & 76 & 100 \\
\hline
\end{tabular}

\section{Grade/s Taught}

Almost half of the teachers taught either in multi-grade settings or multiple grades (44.7\%), whereas about 30\% taught elementary grades (27.6\%). See Table 9. 
Table 9

Teachers' Grade Taught

\begin{tabular}{lcc}
\hline Grade & Frequency & Percentage \\
\hline PreK-8 & 21 & 27.6 \\
$9^{\text {th }}-12^{\text {th }}$ & 16 & 21.1 \\
Multiple Grades & 34 & 44.7 \\
Unknown & 5 & 6.6 \\
Total & 76 & 100 \\
\hline
\end{tabular}

\section{Years of Teaching Experience}

Table 10 summarizes the years of teaching experience for the teachers ranging from 0 years to 40 years with a mean of 15.60. Six teachers had the following years of teaching experience: 2 years, 16 years, 20 years, 30 years, and 35 or more. Two teachers were in their first year of teaching, thus having 0 years of teaching experience.

Table 10

Years of Teaching Experience

\begin{tabular}{lcc}
\hline Years Taught & Frequency & Percentage \\
\hline 0 years & 2 & 2.6 \\
1 year & 3 & 3.9 \\
2 years & 6 & 7.9 \\
3 years & 2 & 2.6 \\
4 years & 1 & 1.3 \\
5 years & 4 & 5.3 \\
6 years & 1 & 1.3 \\
6 1/2 years & 1 & 1.3 \\
7 years & 2 & 2.6 \\
8 years & 5 & 6.6 \\
10 years & 3 & 3.9 \\
11 years & 1 & 1.3 \\
12 years & 2 & 2.6
\end{tabular}


Table 10-Continued.

\begin{tabular}{lcc}
\hline Years Taught & Frequency & Percentage \\
\hline 14 years & 1 & 1.3 \\
15 years & 2 & 2.6 \\
16 years & 6 & 7.9 \\
17 years & 3 & 3.9 \\
19 years & 2 & 2.6 \\
20 years & 6 & 7.9 \\
21 years & 1 & 1.3 \\
25 years & 1 & 1.3 \\
26 years & 3 & 3.9 \\
27 years & 1 & 1.3 \\
28 years & 1 & 1.3 \\
30 years & 6 & 7.9 \\
31 years & 6 & 1.3 \\
35 years & 1 & 1.3 \\
36 years & 1 & 1.3 \\
37 years & 1 & 1.3 \\
38 years & 1 & 2.6 \\
40 years & 1.3 \\
Unknown & 1.3 \\
Total & 3 & 3.9 \\
\hline
\end{tabular}

Teachers' Exposure to Information About ADHD Variables

\section{Articles Read About ADHD}

The majority of teachers (96\%) have read at least one article regarding ADHD.

See Table 11.

\section{Books Read About ADHD}

More than half of teachers (57.9\%) have read at least one book regarding ADHD.

See Table 12. 
Table 11

Articles Read About ADHD

\begin{tabular}{lcc}
\hline Number of Articles & Frequency & Percentage \\
\hline None & 2 & 2.6 \\
1 or 2 & 21 & 27.6 \\
$3-5$ & 33 & 43.4 \\
6 or more & 19 & 25 \\
Unknown & 1 & 1.3 \\
Total & 76 & 100 \\
\hline
\end{tabular}

Table 12

Books Read About ADHD

\begin{tabular}{lcc}
\hline Number of Books & Frequency & Percentage \\
\hline None & 31 & 40.8 \\
1 or 2 & 32 & 42.1 \\
$3-5$ & 12 & 15.8 \\
Unknown & 1 & 1.3 \\
Total & 76 & 100 \\
\hline
\end{tabular}

Videos Viewed About ADHD

Most teachers (81.6\%) have viewed at least one video regarding ADHD. See

Table 13.

\section{Graduate Courses Taken Pertaining to ADHD}

Most teachers (81.6\%) have not taken graduate courses pertaining to ADHD. See

Table 14. 
Table 13

Videos Viewed About ADHD

\begin{tabular}{lcc}
\hline Number of Videos & Frequency & Percentage \\
\hline None & 13 & 17.1 \\
1 or 2 & 25 & 32.9 \\
3 or more & 37 & 48.7 \\
Unknown & 1 & 1.3 \\
Total & 76 & 100 \\
\hline
\end{tabular}

Table 14

Graduate Courses Taken Pertaining to ADHD

\begin{tabular}{lcc}
\hline Courses Taken & Frequency & Percentage \\
\hline No & 62 & 81.6 \\
Yes & 13 & 17.1 \\
Unknown & 1 & 1.3 \\
Total & 76 & 100 \\
\hline
\end{tabular}

Instruction About ADHD in Teacher Training

Almost $70 \%$ of teachers did not receive instruction about ADHD in teacher training. See Table 15.

Table 15

Instruction about ADHD in Teacher Training

\begin{tabular}{lcc}
\hline Teacher Training & Frequency & Percentage \\
\hline No Training & 53 & 69.7 \\
Training & 22 & 28.9 \\
Unknown & 1 & 1.3 \\
Total & 76 & 100 \\
\hline
\end{tabular}




\section{Training About ADHD Since Beginning Teaching}

More than half of teachers (52.6\%) have not received training about ADHD since beginning teaching. See Table 16.

Table 16

Training About ADHD Since Beginning Teaching

\begin{tabular}{lcc}
\hline Training Since Beginning Teaching & Frequency & Percentage \\
\hline No Training & 40 & 52.6 \\
Training & 35 & 46.1 \\
Unknown & 1 & 1.3 \\
Total & 76 & 100 \\
\hline
\end{tabular}

Teachers' Experience With ADHD Variables

\section{Current and Former Students With ADHD}

Table 17 shows three-fourths of teachers (76.3\%) have taught students with ADHD.

Table 17

Current and Former Students With ADHD

\begin{tabular}{lcc}
\hline Number of Students & Frequency & Percentage \\
\hline None & 16 & 21.1 \\
1 or 2 & 20 & 26.3 \\
$3-5$ & 25 & 32.9 \\
6 or more & 13 & 17.1 \\
Unknown & 2 & 2.6 \\
Total & 76 & 100 \\
\hline
\end{tabular}




\section{Current and Former Students Thought to Have ADHD}

Table 18 shows the majority of teachers $(88.2 \%)$ have taught students whom they thought had ADHD.

Table 18

Current and Former Children Thought to Have ADHD

\begin{tabular}{lcc}
\hline Students Thought to Have ADHD & Frequency & Percentage \\
\hline None & 6 & 7.9 \\
1 or 2 & 24 & 31.6 \\
$3-5$ & 20 & 26.3 \\
6 or more & 23 & 30.3 \\
Unknown & 3 & 3.9 \\
Total & 76 & 100 \\
\hline
\end{tabular}

\section{Acquaintances Outside of School With ADHD}

Three-fourths of teachers are acquainted with someone with ADHD outside of school. See Table 19.

Table 19

Acquaintances Outside of School with ADHD

\begin{tabular}{lcc}
\hline Acquaintances with ADHD & Frequency & Percentage \\
\hline No & 18 & 23.7 \\
Yes & 57 & 75 \\
Unknown & 1 & 1.3 \\
Total & 76 & 100 \\
\hline
\end{tabular}




\section{Parents' Demographic Variables}

\section{Gender}

Female parents represented the majority of the sample (81.5\%) compared to male parents (17.7\%). See Table 20.

Table 20

Parents' Gender

\begin{tabular}{lcc}
\hline Gender & Frequency & Percentage \\
\hline Male & 66 & 17.7 \\
Female & 304 & 81.5 \\
Unknown & 3 & .8 \\
Total & 373 & 100 \\
\hline
\end{tabular}

\section{Race}

Almost half of the parent sample consisted of Black or African American (48\%) parents. The Other group included Hispanic, Asian, or parents from other races $(21.4 \%)$. See Table 21.

Table 21

Parents' Race

\begin{tabular}{lcc}
\hline Race & Frequency & Percentage \\
\hline Other & 80 & 21.4 \\
Black or African American & 180 & 48.0 \\
Caucasian & 105 & 28.2 \\
Unknown & 9 & 2.4 \\
Total & 373 & 100 \\
\hline
\end{tabular}




\section{Conference (School District)}

The majority of parents in the sample sent their children to schools in New York (45.6\%) either in New York or Greater New York Conference. See Table 22.

Table 22

Parents' Conference (School District)

\begin{tabular}{lcc}
\hline Conference (School District) & Frequency & Percentage \\
\hline Bermuda & 53 & 14.2 \\
New York & 170 & 45.6 \\
Northern New England & 71 & 19.0 \\
Southern New England & 79 & 21.2 \\
Total & 373 & 100 \\
\hline
\end{tabular}

\section{Education Level}

The majority of the parents in the sample had been educated to either the undergraduate level (41.6\%) or to the graduate level (38.1\%). See Table 23.

Table 23

Parents' Education Level

\begin{tabular}{lcc}
\hline Education Level & Frequency & Percentage \\
\hline High School and Below & 69 & 18.5 \\
Undergraduate Level & 155 & 41.6 \\
Graduate Level & 142 & 38.1 \\
Unknown & 7 & 1.9 \\
Total & 373 & 100 \\
\hline
\end{tabular}




\section{Marital Status}

Table 24 shows the majority of parents in the sample were married (75.3\%). Those who were classified as single (23.3\%) were unmarried, separated, divorced, or widowed.

Table 24

Parents' Marital Status

\begin{tabular}{lcc}
\hline Marital Status & Frequency & Percentage \\
\hline Single Parents & 87 & 23.3 \\
Married Parents & 281 & 75.3 \\
Unknown & 5 & 1.3 \\
Total & 373 & 100 \\
\hline
\end{tabular}

Parents' Exposure to Information About ADHD Variables

\section{Lectures Attended About ADHD}

More than two-thirds of parents $(66.2 \%)$ have not attended a lecture regarding ADHD, while almost one-fourth $(22.3 \%)$ have attended at least one lecture. See Table 25.

Table 25

Lectures Attended About ADHD

\begin{tabular}{lcc}
\hline Lectures & Frequency & Percentage \\
\hline None & 247 & 66.2 \\
1 or 2 & 83 & 22.3 \\
$3-5$ & 20 & 5.4 \\
6 or more & 14 & 3.8 \\
Unknown & 9 & 2.4 \\
Total & 373 & 100 \\
\hline
\end{tabular}




\section{Articles Read About ADHD}

More than $70 \%$ of parents $(71 \%)$ have read at least one article regarding ADHD.

See Table 26.

Table 26

Articles Read About ADHD by Parents

\begin{tabular}{lcc}
\hline Number of Articles & Frequency & Percentage \\
\hline None & 99 & 26.5 \\
1 or 2 & 101 & 27 \\
$3-5$ & 95 & 25.5 \\
6 or more & 69 & 18.5 \\
Unknown & 9 & 2.4 \\
Total & 373 & 100 \\
\hline
\end{tabular}

\section{Books Read About ADHD}

More than two-thirds of parents $(67.6 \%)$ have not read any books regarding

ADHD. See Table 27.

Table 27

Books Read About ADHD by Parents

\begin{tabular}{lcc}
\hline Number of Books & Frequency & Percentage \\
\hline None & 252 & 67.6 \\
1 or 2 & 73 & 19.6 \\
$3-5$ & 22 & 5.9 \\
6 or more & 16 & 4.3 \\
Unknown & 10 & 2.7 \\
Total & 373 & 100 \\
\hline
\end{tabular}




\section{Videos Viewed About ADHD}

Table 28 shows most parents $(81.2 \%)$ have viewed at least one video regarding ADHD.

Table 28

Videos Viewed About ADHD by Parents

\begin{tabular}{lcc}
\hline Number of Videos & Frequency & Percentage \\
\hline None & 60 & 16.1 \\
1 or 2 & 194 & 52.0 \\
3 or more & 109 & 29.2 \\
Unknown & 10 & 2.7 \\
Total & 373 & 100 \\
\hline
\end{tabular}

\section{Belonged to Support Group for ADHD}

The majority of parents (95\%) do not belong to a support group for ADHD.

See Table 29.

Table 29

Belonged to Support Group for ADHD

\begin{tabular}{lcc}
\hline Support Group & Frequency & Percentage \\
\hline No & 354 & 95 \\
Yes & 9 & 2.3 \\
Unknown & 10 & 2.7 \\
Total & 373 & 100 \\
\hline
\end{tabular}




\section{Parents' Experience With ADHD Variables}

\section{Acquaintances Outside of Home With ADHD}

About two-thirds of parents (64\%) are acquainted with someone with ADHD outside of the home. See Table 30.

Table 30

Acquaintances Outside of Home With ADHD

\begin{tabular}{lcc}
\hline Acquaintances & Frequency & Percentage \\
\hline No & 123 & 33 \\
Yes & 239 & 64 \\
Unknown & 11 & 2.9 \\
Total & 373 & 100 \\
\hline
\end{tabular}

\section{Family Member Evaluated for ADHD}

More than three-fourths of parents do not have a family member who was evaluated for ADHD. See Table 31.

Table 31

Family Member Evaluated for ADHD

\begin{tabular}{lcc}
\hline Family Member Evaluated & Frequency & Percentage \\
\hline No & 282 & 75.6 \\
Yes & 84 & 22.5 \\
Unknown & 7 & 1.9 \\
Total & 373 & 100 \\
\hline
\end{tabular}




\section{Family Member Identified With ADHD}

Most parents (80.9\%) do not have a family member who has been identified with

ADHD. See Table 32.

Table 32

Family Member Identified With ADHD

\begin{tabular}{lcc}
\hline Family Member Identified & Frequency & Percentage \\
\hline No & 302 & 80.9 \\
Yes & 64 & 17.2 \\
Unknown & 7 & 1.9 \\
Total & 373 & 100 \\
\hline
\end{tabular}

Family Member Treated for ADHD

Most parents $(82.3 \%)$ do not have a family member who has been treated for

ADHD. See Table 33.

Table 33

Family Member Treated for ADHD

\begin{tabular}{lcc}
\hline Family Member Treated & Frequency & Percentage \\
\hline No & 307 & 82.3 \\
Yes & 57 & 15.3 \\
Unknown & 9 & 2.4 \\
Total & 373 & 100 \\
\hline
\end{tabular}




\section{Results by Question/Null Hypothesis}

In this section, the research questions and/or hypotheses stated in chapter 3 are restated and results are provided for individual items, which are grouped into appropriate sections. All hypotheses were tested at the .05 level of significance.

Analysis of Research Questions 1, 2, 3, and 4

Question 1: What do regular education teachers and parents of children in parochial schools know about ADHD?

Question 2: What do regular education teachers and parents of children in parochial schools believe about ADHD?

Question 3: Are there differences in the knowledge about ADHD on individual items between regular education teachers and parents of children in parochial schools?

Null Hypothesis 1: There are no significant differences in the knowledge of ADHD on individual items between regular education teachers and parents of children in parochial schools.

Question 4: Are there differences in the beliefs about ADHD between regular education teachers and parents of children in parochial schools on individual items?

Null Hypothesis 2: There are no significant differences in beliefs about ADHD between regular education teachers and parents of children in parochial schools on individual items.

The statements were in two different formats: true, false, and don't know and Likert items. Descriptive statistics using crosstabs were used for the analysis of individual items. One-way ANOVA was used to analyze the difference between the mean scores of teachers and parents. Chi-square was used to analyze the difference in the 
pattern of responses between teachers and parents on individual items. Items were analyzed individually, but for discussion purposes and ease of understanding, statements were grouped into sections consistently found in the literature: symptoms and characteristics of ADHD, general information about ADHD, causes of ADHD, intervention/treatment options of ADHD, and other issues about ADHD.

Respondents with more than $15 \%$ of missing data were eliminated from the analysis, which is consistent with the rule of thumb for missing data (George \& Mallery, 2006). Thus, 76 teachers and 365 parents were included in the analysis for the true, false, and don't know section and 75 teachers and 353 parents were included in the analysis for the Likert-items section of the survey. Of the 461 respondents who completed the true, false, and don't know section, missing data ranged from 1 to 7 for individual items. Item 5 had the most missing data. Of these 427 respondents who completed the Likert-items section, missing data ranged from 1 to 21 for individual items. Item $34 \mathrm{a}$ had the most missing data.

\section{Knowledge and Beliefs About Symptoms and Characteristics of ADHD}

The content of items $4,5,7,8,12,15,17,18,23,24$, and 26 pertained to symptoms and characteristics of ADHD; therefore, these true, false, and don't know items were grouped together and discussed in the symptoms and characteristics of ADHD section. Results of teachers' and parents' knowledge of and beliefs about symptoms and characteristics of ADHD are presented in Table 34. 
Table 34

Teachers' and Parents' True, False, and Don't Know Responses to Knowledge Statements About Symptoms and Characteristics Regarding ADHD (in percentages)

\begin{tabular}{|c|c|c|c|c|c|c|c|c|c|}
\hline Item & $\begin{array}{l}\text { Knowledge and } \\
\text { Beliefs about } \\
\text { Symptom and } \\
\text { Characteristic } \\
\text { Statements }\end{array}$ & (T) & $\begin{array}{l}\text { Teache } \\
\text { (F) }\end{array}$ & $\begin{array}{l}\text { rs } \\
\text { (DK) }\end{array}$ & (T) & $\begin{array}{l}\text { Parents } \\
\text { (F) }\end{array}$ & $(\mathrm{DK})$ & $\begin{array}{l}\text { Chi- } \\
\text { square }\end{array}$ & $P$ \\
\hline 4 & $\begin{array}{l}\text { Children with } \\
\text { ADHD misbehave } \\
\text { primarily because } \\
\text { they don't want to } \\
\text { follow rules and } \\
\text { complete } \\
\text { assignments. }\end{array}$ & $\begin{array}{c}3.9 \\
n=76\end{array}$ & $90.8 *$ & 5.3 & $\begin{array}{c}12.6 \\
n=365\end{array}$ & $74.2 *$ & 13.2 & 9.793 & .007 \\
\hline 5 & $\begin{array}{l}\text { The inattention of } \\
\text { children with } \\
\text { ADHD is not } \\
\text { primarily a } \\
\text { consequence of } \\
\text { defiance, } \\
\text { oppositionality, and } \\
\text { an unwillingness to } \\
\text { please others. }\end{array}$ & $\begin{array}{c}80.3^{*} \\
n=76\end{array}$ & 7.9 & 11.8 & $\begin{array}{l}61.2 * \\
n=358\end{array}$ & 16.2 & 22.6 & 9.990 & .007 \\
\hline 7 & $\begin{array}{l}\text { Children with } \\
\text { ADHD could do } \\
\text { better if they only } \\
\text { would try harder. }\end{array}$ & $\begin{array}{l}10.7 \\
n=75\end{array}$ & 76 & 13.3 & $\begin{array}{c}15.9 \\
n=364\end{array}$ & 66.5 & 17.6 & 2.641 & .267 \\
\hline 8 & $\begin{array}{l}\text { Children with } \\
\text { ADHD have } \\
\text { difficulty } \\
\text { sustaining attention } \\
\text { in tasks or play } \\
\text { activities. }\end{array}$ & $\begin{array}{c}89.5^{*} \\
n=76\end{array}$ & 9.2 & 1.3 & $\begin{array}{l}86.8 * \\
n=365\end{array}$ & 5.8 & 7.4 & 4.898 & .086 \\
\hline 12 & $\begin{array}{l}\text { Children with } \\
\text { ADHD can be } \\
\text { described as } \\
\text { children on the go } \\
\text { or who act as if } \\
\text { driven by a motor. }\end{array}$ & $\begin{array}{c}78.9 * \\
n=76\end{array}$ & 11.8 & 9.2 & $\begin{array}{l}70.6^{*} \\
n=360\end{array}$ & 7.8 & 21.7 & 6.829 & .033 \\
\hline
\end{tabular}


Table 34-Continued.

\begin{tabular}{|c|c|c|c|c|c|c|c|c|c|}
\hline \multirow[t]{2}{*}{ Item } & \multirow[b]{2}{*}{$\begin{array}{l}\text { Knowledge and } \\
\text { Beliefs about } \\
\text { Symptoms and } \\
\text { Characteristic } \\
\text { Statements }\end{array}$} & \multicolumn{3}{|c|}{ Teachers } & \multicolumn{3}{|c|}{ Parents } & \multirow{2}{*}{$\begin{array}{l}\text { Chi- } \\
\text { square }\end{array}$} & \multirow[t]{2}{*}{$P$} \\
\hline & & (T) & $(\mathrm{F})$ & (DK) & (T) & (F) & (DK) & & \\
\hline 15 & $\begin{array}{l}\text { If a child can get } \\
\text { excellent grades one } \\
\text { day and awful } \\
\text { grades the next, } \\
\text { then he/she must } \\
\text { not be ADHD. }\end{array}$ & $\begin{array}{c}5.3 \\
n=76\end{array}$ & 77.6 & 17.1 & $\begin{array}{c}10.7 \\
n=364\end{array}$ & 66.5 & 22.8 & 3.989 & .136 \\
\hline 17 & $\begin{array}{l}\text { Children with } \\
\text { ADHD usually } \\
\text { avoid tasks that } \\
\text { require sustained } \\
\text { mental effort. }\end{array}$ & $\begin{array}{c}69.7^{*} \\
n=76\end{array}$ & 13.2 & 17.1 & $\begin{array}{l}60.6^{*} \\
n=360\end{array}$ & 13.9 & 25.6 & 2.736 & .255 \\
\hline 18 & $\begin{array}{l}\text { If a child can play } \\
\text { video games for } \\
\text { hours, he/she } \\
\text { probably isn't } \\
\text { ADHD. }\end{array}$ & $\begin{array}{c}5.3 \\
n=75\end{array}$ & $77.6^{*}$ & 17.1 & $\begin{array}{c}11.5 \\
n=364\end{array}$ & $64.8^{*}$ & 23.6 & 5.092 & .078 \\
\hline 23 & $\begin{array}{l}\text { Hallucinations are } \\
\text { associated with } \\
\text { ADHD. }\end{array}$ & $\begin{array}{c}3.9 \\
n=76\end{array}$ & $43.4^{*}$ & 52.6 & $\begin{array}{c}6.9 \\
n=361\end{array}$ & $38.5^{*}$ & 54.6 & 1.298 & .523 \\
\hline 24 & $\begin{array}{l}\text { In order to have the } \\
\text { diagnosis of } \\
\text { ADHD, both } \\
\text { hyperactivity and } \\
\text { inattentiveness must } \\
\text { be present. }\end{array}$ & $\begin{array}{l}56.6 \\
n=76\end{array}$ & $18.4^{*}$ & 25 & $\begin{array}{c}48.8 \\
n=363\end{array}$ & $18.2^{*}$ & 33.1 & 2.057 & .358 \\
\hline 26 & $\begin{array}{l}\text { Children with } \\
\text { ADHD generally } \\
\text { display an inflexible } \\
\text { adherence to } \\
\text { specific routines } \\
\text { and rituals. }\end{array}$ & $\begin{array}{l}35.5 \\
n=76\end{array}$ & $32.9^{*}$ & 31.6 & $\begin{array}{c}41 \\
n=361\end{array}$ & $20.2^{*}$ & 38.8 & 5.833 & .054 \\
\hline
\end{tabular}


Knowledge statements: True, false, and don't know

Results show $90.8 \%$ of teachers and $74.2 \%$ of parents correctly answered with false to the statement that children with ADHD misbehave because they don't want to follow rules or complete assignment (item 4), which indicates teachers had adequate knowledge for this non-symptom of ADHD. A chi-square goodness-of fit test was calculated comparing the frequency of responses between teachers and parents on this statement. A significant difference was found $\left(\chi^{2}(1)=9.793, p<.01\right)$ between the two groups on this statement (see Table 34). This indicates that the pattern of responses was significantly different between teachers and parents on this statement.

Results show $80.3 \%$ of teachers and $61.2 \%$ of parents responded correctly with true to the following statement: The inattention of children with ADHD is not primarily a consequence of defiance, oppositionality, and an unwillingness to please others (item 5), which indicates teachers had adequate knowledge for this non-symptom of ADHD. A chi-square goodness-of-fit test was calculated comparing the frequency of responses between teachers and parents on this statement. A significant difference was found $\left(\chi^{2}(1)\right.$ $=9.990, p<.01$ ) between the two groups (see Table 34). This indicates that the pattern of responses was significantly different between teachers and parents on this statement.

Results show $89.5 \%$ of teachers and $86.8 \%$ of parents responded correctly with true to the following statement: Children with ADHD have difficulty sustaining attention in tasks or play activities (item 8), which indicates both groups had adequate knowledge about this primary symptom of ADHD.

Results show $78.9 \%$ of teachers and $70.6 \%$ of parents responded correctly with true to the following statement: Children with ADHD can be described as children on the 
go or who act as if driven by a motor (item 12), which indicates both groups had inadequate knowledge about this primary symptom. A chi-square goodness-of-fit test was calculated comparing the frequency of responses between teachers and parents on this statement. A significant difference was found $\left(\chi^{2}(1)=6.829, p<.05\right)$ between the two groups (see Table 34). This indicates that the pattern of responses was significantly different between teachers and parents on this statement.

Results show $69.7 \%$ of teachers and $60.6 \%$ of parents responded correctly with true to the following statement: Children with ADHD usually avoid tasks that require sustained mental effort (item 17), which indicates both groups had inadequate knowledge about this primary symptom. Additionally, $17.1 \%$ of teachers and $25.6 \%$ of parents responded with 'don't know' to the statement.

Results show $18.4 \%$ of teachers and $18.2 \%$ of parents responded correctly with false to the following statement: In order to have a diagnosis of ADHD, both hyperactivity and inattentiveness must be present (item 24), which indicates both groups had inadequate knowledge about the diagnostic symptoms of ADHD. Twenty-five percent of teachers and $33.1 \%$ of parents responded with 'don't know' to the statement. These results suggest about half of both groups have incorrect knowledge about the diagnosis of ADHD.

Results show $32.9 \%$ of teachers and $20.2 \%$ of the parents correctly answered with false that children with ADHD generally display an inflexible adherence to specific routines and rituals (item 26), which indicates both groups had inadequate knowledge about this non-symptom of ADHD. Additionally, $31.6 \%$ of teachers and $38.8 \%$ of parents responded with 'don't know' to the statement. A chi-square goodness-of-fit test was 
calculated comparing the frequency of responses between teachers and parents on this statement. A significant difference was found $\left(\chi^{2}(1)=5.833, p=.054\right)$ between the two groups (see Table 34). This indicates that the pattern of responses was significantly different between teachers and parents on this statement.

Belief statements: True, false and don't know

Results show only $10.7 \%$ of teachers and $15.9 \%$ of parents believed children with ADHD could do better if they would only try harder (item 7). Results show only 5.3\% of teachers and $10.7 \%$ of parents believed if a child can get excellent grades one day and awful grades the next, he/she must not be ADHD (item 15). More parents (22.9\%) than teachers $(17.1 \%)$ responded with 'don't know' to the statement.

A chi-square goodness-of-fit test was calculated comparing the frequency of responses between teachers and parents on symptom statements. No significant differences were found on statements 7, 8, 15, 17, 18, 23, and 24 (see Table 34); therefore, teachers and parents do not differ in their knowledge and beliefs about these statements. However, significant differences exist on items 4, 5, 12, and 26 (see Table 34). This indicates that the pattern of responses was significantly different between teachers and parents on these statements.

In summary, teachers have adequate knowledge only about the hallmark symptom of sustaining attention, but they do not have adequate knowledge about the hallmark symptoms of hyperactivity, avoiding tasks, and the symptoms required to diagnose ADHD. They do have adequate knowledge about non-ADHD symptoms of misbehavior and defiance. Parents have adequate knowledge about the hallmark symptom of sustaining attention, but they do not have adequate knowledge about the hallmark 
symptoms of inattention, hyperactivity, avoiding tasks, and the symptoms required to diagnose ADHD. Many teachers and parents responded with don't know to knowledge statements about hallucinations and the displaying of an inflexible adherence to routines and rituals. Teachers and parents have some knowledge but not adequate knowledge about children with ADHD and video-game playing.

Chi-square results show that the patterns of responses were significantly different between teachers and parents on the inattention and hyperactive symptoms of ADHD and on the non-symptom of misbehavior. Nonetheless, chi-square results show both patterns of responses were similar pertaining to the knowledge about the symptoms of sustaining attention, avoiding tasks, diagnostic symptoms, and hallucinations and similar beliefs about the characteristics of ADHD.

\section{Knowledge and Beliefs About General Information Regarding ADHD}

The content of true/false/don't know items 9, 11, 13, 19, 22, 25, and 29 pertained to general information of ADHD; therefore, they were grouped together and discussed in the general information about ADHD section. Results of teachers' and parents' knowledge and beliefs about the general information of ADHD are presented in Table 35.

Knowledge statements: True, false and don't know

Results show $57.3 \%$ of teachers and $36.8 \%$ of parents responded correctly with false to the following statement: ADHD occurs equally as often in girls as boys (item 11), which indicates both groups had inadequate knowledge about this issue. A chi-square goodness-of-fit test was calculated comparing the frequency of responses between teachers and parents on this statement. A significant difference was found $\left(\chi^{2}(1)=\right.$ 
Table 35

Teachers' and Parents' True, False, and Don't Know Responses to Knowledge and Belief Statements About General Information Regarding ADHD (in percentages)

\begin{tabular}{|c|c|c|c|c|c|c|c|c|c|}
\hline \multirow[t]{4}{*}{ Item } & Knowledge and & \multicolumn{3}{|c|}{ Teachers } & \multicolumn{3}{|c|}{ Parents } & \multirow{4}{*}{$\begin{array}{l}\text { Chi- } \\
\text { square }\end{array}$} & \multirow[t]{4}{*}{$P$} \\
\hline & Beliefs about & $(\mathrm{T})$ & $(\mathrm{F})$ & $(\mathrm{DK})$ & $(\mathrm{T})$ & $(\mathrm{F})$ & $(\mathrm{DK})$ & & \\
\hline & General Information & & & & & & & & \\
\hline & Statements & & & & & & & & \\
\hline 9 & $\begin{array}{l}\text { Most children with } \\
\text { ADHD outgrow their } \\
\text { disorder and are normal } \\
\text { as adults. }\end{array}$ & $\begin{array}{l}13.2 \\
n=76\end{array}$ & 55.3 & 31.6 & $\begin{array}{c}22.3 \\
n=364\end{array}$ & 40.4 & 37.4 & 6.333 & .042 \\
\hline 11 & $\begin{array}{l}\text { ADHD occurs equally } \\
\text { as often in girls as boys. }\end{array}$ & $\begin{array}{c}6.7 \\
n=75\end{array}$ & $57.3 *$ & 36 & $\begin{array}{c}21.1 \\
n=361\end{array}$ & $36.8 *$ & 42.1 & 13.941 & .001 \\
\hline 13 & $\begin{array}{l}\text { ADHD occurs more in } \\
\text { minority groups than in } \\
\text { Caucasian groups. }\end{array}$ & $\begin{array}{c}3.9 \\
n=75\end{array}$ & $36.8 *$ & 59.2 & $\begin{array}{c}4.1 \\
n=363\end{array}$ & $43.3 *$ & 52.6 & 1.126 & .570 \\
\hline 19 & $\begin{array}{l}\text { Children with ADHD } \\
\text { have a high risk for } \\
\text { becoming delinquent as } \\
\text { teenagers. }\end{array}$ & $\begin{array}{c}45.3 * \\
n=75\end{array}$ & 16.0 & 38.7 & $\begin{array}{l}41.2 * \\
n=364\end{array}$ & 20.6 & 38.2 & 0.921 & .631 \\
\hline 22 & $\begin{array}{l}\text { Children with ADHD } \\
\text { have lower IQ than their } \\
\text { peers. }\end{array}$ & $\begin{array}{c}1.3 \\
n=76\end{array}$ & $\begin{array}{r}82.9 \\
\text { Sig. }\end{array}$ & 15.8 & $\begin{array}{c}13.5 \\
n=364\end{array}$ & 58.0 & 28.6 & 18.332 & .000 \\
\hline 25 & $\begin{array}{l}\text { ADHD may express } \\
\text { itself in only one } \\
\text { environment. }\end{array}$ & $\begin{array}{l}13.2 \\
n=76\end{array}$ & $59.2 *$ & 27.6 & $\begin{array}{c}9.7 \\
n=361\end{array}$ & $52.4 *$ & 38.0 & 3.131 & .209 \\
\hline 29 & $\begin{array}{l}\text { ADHD may begin in } \\
\text { adolescence. }\end{array}$ & $\begin{array}{l}30.3 \\
n=76\end{array}$ & $27.6^{*}$ & 42.1 & $\begin{array}{c}31.4 \\
n=363\end{array}$ & $32.2 *$ & 36.4 & 1.004 & .605 \\
\hline
\end{tabular}

Note. Knowledge items are \#s 11, 13, 19, 25, \& 29; Beliefs are \#s $9 \&$ 22; T = Teachers; P = Parent; T = True; F = False; DK = Don’t Know.* Indicates correct answer.

13.941, $p<.01$ ) between the two groups (see Table 35). This indicates that the pattern of responses was significantly different between teachers and parents on this statement. Additionally, $36 \%$ of teachers and $42.1 \%$ of parents responded with 'don't know' to the statement. 
Results show more than half of both groups, $59.2 \%$, of teachers and $52.4 \%$ of parents responded correctly with false to the following statement: ADHD may express itself in only one environment (item 25), which indicates both groups had inadequate knowledge about this diagnostic criterion for ADHD. Additionally, 27.6\% of teachers and $38 \%$ of parents responded with 'don't know'.

Results show $27.6 \%$ of teachers and $32.2 \%$ of parents responded correctly with false to the following statement: ADHD may begin in adolescence (item 29), although both groups had inadequate knowledge about this diagnostic criterion for ADHD. Less than half of teachers (42.1\%) and 36.4\% of parents responded with 'don't know'.

Belief statements: True, false and don't know

Results show $13.2 \%$ of teachers and $22.3 \%$ of parents believed children with ADHD outgrow their disorder and are normal as adults (item 9). However, $31.6 \%$ of teachers and $37.4 \%$ of parents responded with 'don't know' to the statement. A chisquare goodness-of-fit test was calculated comparing the frequency of responses between teachers and parents on this statement. A significant difference was $\left(\chi^{2}(1)=6.333, p<\right.$ .05) between the groups (see Table 35). This indicates that the pattern of responses was significantly different between teachers and parents on this statement.

Results show only $1.3 \%$ of teachers and $13.5 \%$ of parents believed children with ADHD have a lower IQ than their peers (item 22). A chi-square goodness-of-fit test was calculated comparing the frequency of responses between teachers and parents on this statement. A significant difference was found $\left(\chi^{2}(1)=18.332, p<.001\right)$ between the groups (see Table 35). This indicates that the pattern of responses was significantly different between teachers and parents on this statement. 
In summary, results indicate teachers and parents do not have adequate knowledge about the occurrence by gender and ethnic group, the expression of ADHD, and the onset of the disorder, with many responding with don't know. However, chisquare results show the patterns of responses were similar between teachers and parents for these statements. Nonetheless, the patterns of responses were significantly different between teachers and parents on their beliefs pertaining to ADHD being outgrown and that children with ADHD have a lower IQ than their peers. Many teachers and parents responded with don't know concerning the high risk for delinquency for children with ADHD, although the pattern of responses was similar between the two groups on this statement.

\section{Knowledge and Beliefs About Causes of ADHD}

The content of true/false/don't know items 1, 2, 3, 10, 21, and 27 pertained to causes of ADHD; therefore, they were grouped together and discussed in the causes of ADHD section. Results of teachers' and parents' knowledge and beliefs of ADHD causes are presented in Table 16. In addition, Likert items 1-9 were grouped by Carlson et al. (2006) under causes of ADHD and this grouping was retained. Results of teachers' and parents' beliefs about causes of ADHD are summarized in Table 36 .

Knowledge statements: True, false, and don't know

Results show $67.1 \%$ of teachers and $59.1 \%$ of parents chose "true" which is the correct response for the following statement: Children with ADHD are born with biological vulnerabilities toward inattention and poor self-control (item 3), which indicates both groups have inadequate knowledge about this possible cause of ADHD. 
Table 36

Teachers' and Parents' True, False and Don't Know Responses to Knowledge and Belief Statements Regarding Causes of ADHD (in percentages)

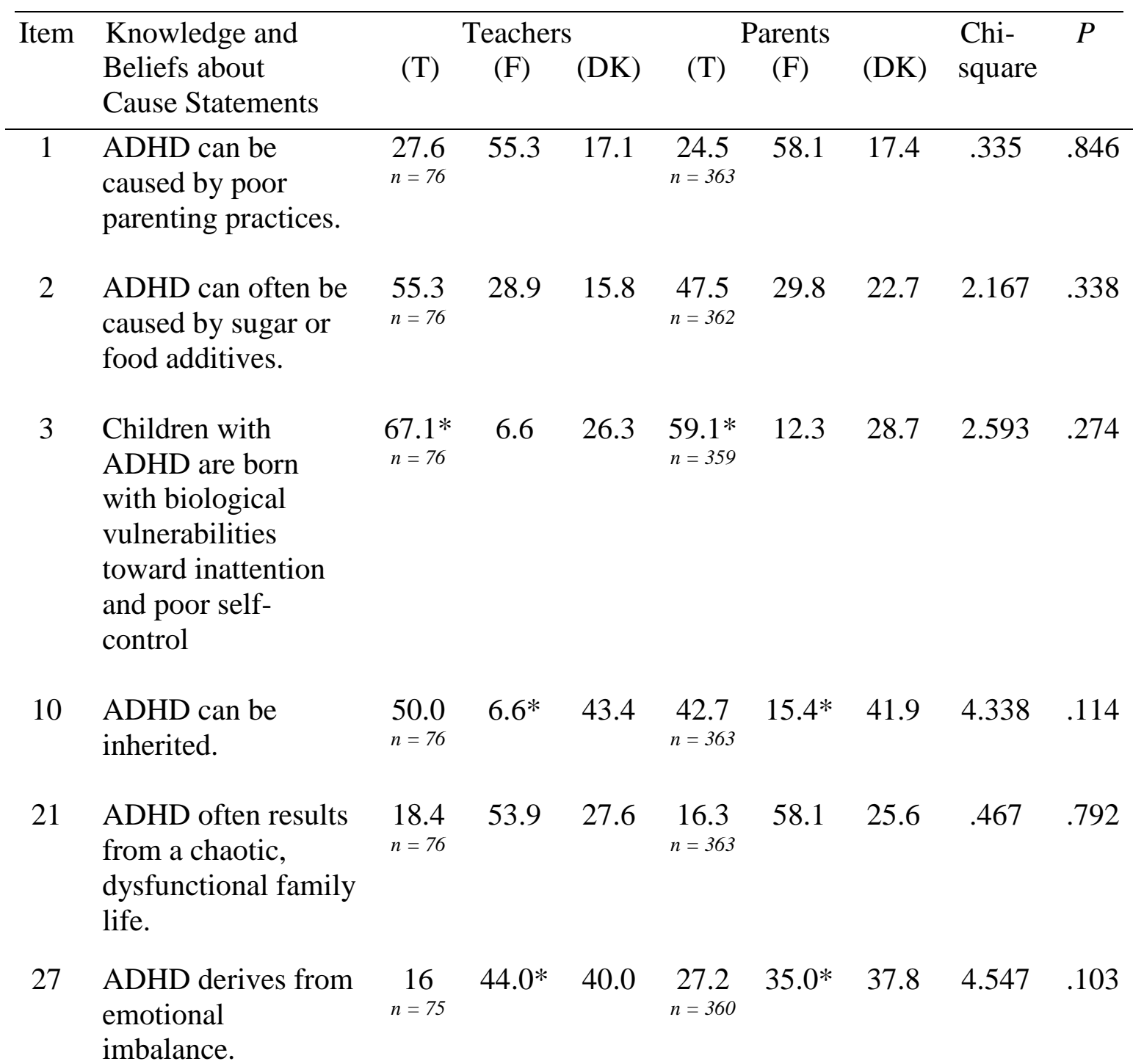

Note. Knowledge items are \#s 3, 10, \& 27; Belief items are \#s 1, 2 \& 21; T = Teachers; P = Parent; T = True;F = False; DK = Don’t Know. * Indicates correct answer.

However, almost $30 \%$ of both teachers $(26.3 \%)$ and parents $(28.7 \%)$ responded with 'don't know' to the statement.

Results show only $6.6 \%$ of teachers and $15.4 \%$ of parents chose "false," which is the correct response to the following statement: ADHD can be inherited (item 10), which 
also indicates inadequate knowledge in this area. More than $40 \%$ of both teachers (43.4\%) and parents (41.9\%) responded with 'don't know' for this statement.

Belief statements: True, false and don't know

Results show $27.6 \%$ of teachers and $24.5 \%$ of the parents believed ADHD is caused by poor parenting practices (item 1), while more than half of both groups did not believe the statement. Similarly, more than half of both groups $(53.9 \%)$ of teachers and $58.1 \%$ of parents did not believe ADHD results from a chaotic, dysfunctional family life, although more than one-fourth did not know.

Results show $55.3 \%$ of teachers and $47.5 \%$ of parents believed ADHD can often be caused by sugar or food additives (item 2), whereas $15.8 \%$ of teachers and $22.7 \%$ of parents responded with 'don't know' to the statement.

A chi-square goodness-of-fit test was calculated comparing the frequency of responses between teachers and parents on the six possible cause statements. No significant differences were found for the patterns of responses between teachers and parents for any of the statements. (See Table 36).

Belief statements: Likert items ranging from slightly disagree to strongly agree

Percentage results show more teachers and parents tended to agree that children with Adam's behaviors are probably born with a genetic predisposition towards hyperactivity and poor self-control (item 1). Specifically, the greatest percentage of teachers $(33.8 \%)$ and parents $(25.9 \%)$ moderately agreed with the statement. In comparison, the least percentage of teachers $(5.4 \%)$ strongly disagreed, whereas the least percentage of parents (11.2\%) slightly disagreed with the statement. Mean scores show 
teachers $(m=3.99)$ and parents $(m=3.78)$ displayed beliefs between slight disagreement and slight agreement. See Tables 37 and 38.

Percentage results show more teachers and parents tended to agree that stress and conflict in the child's home life can cause behaviors like Adam's (item 2). Specifically, the greatest percentage of teachers $(33.3 \%)$ and parents $(27.8 \%)$ moderately agreed with the statement. Mean scores show teachers $(m=4.61)$ displayed beliefs between slight agreement and moderate agreement while parents $(m=4.22)$ displayed beliefs of slight agreement. See Tables 37 and 38.

Results show more teachers and parents tended to disagree that behaviors like Adam's are more likely to be the result of an active personality rather than a disorder (item 3). Specifically, the greatest percentage of teachers $(24.3 \%)$ moderately disagreed while the greatest percentage of parents $(23.1 \%)$ strongly disagreed with the statement. Mean scores show teachers $(m=2.91)$ displayed beliefs between moderate disagreement and slight disagreement while parents $(m=3.12)$ displayed beliefs of slight disagreement.

Results show more teachers and parents tended to agree that behaviors like Adam's can result from certain parenting methods such as little positive reinforcement for good behavior and attention for bad behavior (item 8). Specifically, the greatest percentage of teachers $(22.7 \%)$ moderately agreed and the greatest percentage of parents $(21.9 \%)$ slightly and moderately agreed with the statement. Mean scores show teachers $(m=3.64)$ and parents $(m=3.49)$ displayed beliefs between slight disagreement and slight agreement to the statement. See Tables 37 and 38. 
Table 37

Teachers' and Parents' Likert Item Responses to Beliefs About Causes of ADHD (in percentages)

\begin{tabular}{|c|c|c|c|c|c|c|c|c|c|}
\hline Item & $\begin{array}{l}\text { Beliefs about Causes of } \\
\text { ADHD }\end{array}$ & 1 & 2 & 3 & 4 & 5 & 6 & $\begin{array}{c}\text { Chi- } \\
\text { square. }\end{array}$ & $P$ \\
\hline \multirow[t]{3}{*}{1} & $\begin{array}{l}\text { Children with Adam's } \\
\text { behaviors are probably } \\
\text { born with a genetic } \\
\text { predisposition towards } \\
\text { hyperactivity and poor } \\
\text { self-control. }\end{array}$ & & & & & & & & \\
\hline & Teachers: $n=74$ & 5.4 & 16.2 & 10.8 & 21.6 & 33.8 & 12.2 & 7.196 & .206 \\
\hline & Parents: $n=347$ & 15.0 & 12.4 & 11.2 & 19.0 & 25.9 & 16.4 & & \\
\hline \multirow[t]{3}{*}{2} & $\begin{array}{l}\text { Stress and conflict in the } \\
\text { child's home life can } \\
\text { cause behaviors like } \\
\text { Adam's. }\end{array}$ & & & & & & & & \\
\hline & Teachers: $n=75$ & 4.0 & 6.7 & 5.3 & 21.3 & 33.3 & 29.3 & 5.008 & .415 \\
\hline & Parents: $n=352$ & 12.2 & 7.4 & 6.5 & 19.9 & 27.8 & 26.1 & & \\
\hline
\end{tabular}

3 Behaviors like Adam's are more likely to be the result of an active personality rather than a disorder.

Teachers: $n=74$

$\begin{array}{llllllll}23.0 & 24.3 & 21.6 & 10.8 & 10.8 & 9.5 & 6.670 & .246\end{array}$

Parents: $n=350$

$\begin{array}{llllll}23.1 & 18.9 & 14.3 & 18.3 & 17.1 & 8.3\end{array}$

4 Behaviors like Adam's are often the result of unclear expectations in the classroom.

Teachers: $n=75$

$\begin{array}{llllllll}32.0 & 22.7 & 10.7 & 24 & 5.3 & 5.3 & 7.554 & .183\end{array}$

Parents: $n=351$

$\begin{array}{llllll}38.5 & 20.8 & 13.4 & 12.8 & 9.4 & 5.1\end{array}$

5 Adam has probably

learned to be the way he is.

Teachers: $n=75$

$\begin{array}{lll}29.3 & 20.0 \quad 8.0\end{array}$

$8.0 \quad 21.3$

1.3

$\begin{array}{ll}18.7 & 2.7\end{array}$

$9.939 \quad .077$

Parents: $n=350$

$\begin{array}{llllll}38.9 & 20.3 & 10.9 & 16.9 & 8.3 & 4.9\end{array}$


Table 37-Continued.

\begin{tabular}{|c|c|c|c|c|c|c|c|c|c|}
\hline Item & $\begin{array}{l}\text { Beliefs about Causes } \\
\text { of ADHD }\end{array}$ & 1 & 2 & 3 & 4 & 5 & 6 & $\begin{array}{l}\text { Chi- } \\
\text { square }\end{array}$ & $P$ \\
\hline \multirow[t]{3}{*}{6} & $\begin{array}{l}\text { Lacking basic skills in } \\
\text { an academic area (e.g. } \\
\text { Adam's lack of basic } \\
\text { reading skills) often } \\
\text { causes children to have } \\
\text { difficulty paying } \\
\text { attention. }\end{array}$ & & & & & & & & \\
\hline & Teachers: $n=74$ & 8.1 & 8.1 & 9.5 & 21.6 & 29.7 & 23.0 & 4.175 & .525 \\
\hline & Parents: $n=349$ & 16.9 & 7.4 & 11.2 & 18.9 & 25.5 & 20.1 & & \\
\hline \multirow[t]{3}{*}{7} & $\begin{array}{l}\text { Adam's behaviors are } \\
\text { more likely the result } \\
\text { of immaturity than an } \\
\text { attentional disorder } \\
\text { (ADHD). }\end{array}$ & & & & & & & & \\
\hline & Teachers: $n=75$ & 30.7 & 20.0 & 24.0 & 12.0 & 5.3 & 8.0 & 4.000 & .549 \\
\hline & Parents: $n=350$ & 34.6 & 18.9 & 16.6 & 11.4 & 10.6 & 8.0 & & \\
\hline \multirow[t]{3}{*}{8} & $\begin{array}{l}\text { Behaviors like Adam's } \\
\text { can result from certain } \\
\text { parenting methods } \\
\text { such as little positive } \\
\text { reinforcement for good } \\
\text { behavior and attention } \\
\text { for bad behavior. }\end{array}$ & & & & & & & & \\
\hline & Teachers: $n=75$ & 12.0 & 18.7 & 12.0 & 21.3 & 22.7 & 13.3 & 2.206 & .820 \\
\hline & Parents: $n=351$ & 17.7 & 14.5 & 12.8 & 21.9 & 21.9 & 11.1 & & \\
\hline \multirow[t]{3}{*}{9} & $\begin{array}{l}\text { Behaviors like Adam's } \\
\text { can result when } \\
\text { classroom expectation } \\
\text { are incongruent with } \\
\text { the developmental } \\
\text { abilities of the student. }\end{array}$ & & & & & & & & \\
\hline & Teachers: $n=75$ & 10.7 & 13.3 & 16.0 & 30.7 & 24.0 & 5.3 & 1.915 & .861 \\
\hline & Parents: $n=346$ & 13.9 & 14.2 & 17.3 & 25.4 & 21.4 & 7.8 & & \\
\hline
\end{tabular}


Table 38

Teachers' and Parents' Beliefs About Causes of ADHD by Mean and Standard Deviation \begin{tabular}{llll}
\hline Item & Beliefs about Causes of ADHD & Teachers & Parents
\end{tabular}

\begin{tabular}{llrrrrrrr}
\cline { 6 - 7 } & & $N$ & $M$ & $S D$ & & & $M$ & $S D$ \\
\hline 1 & $\begin{array}{l}\text { Children with Adam's behaviors are probably } \\
\text { born with a genetic predisposition towards } \\
\text { hyperactivity and poor self-control. }\end{array}$ & 74 & 3.99 & 1.45 & 347 & 3.78 & 1.68
\end{tabular}

2 Stress and conflict in the child's home life $\begin{array}{llllll}75 & 4.61 & 1.35 & 352 & 4.22 & 1.66\end{array}$ can cause behaviors like Adam's.

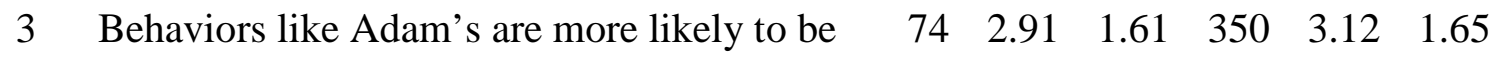
the result of an active personality rather than a disorder.

$4 \quad$ Behaviors like Adam's are often the result of $\quad \begin{array}{llllll}75 & 2.64 & 1.53 & 351 & 2.49 & 1.57\end{array}$ unclear expectations in the classroom.

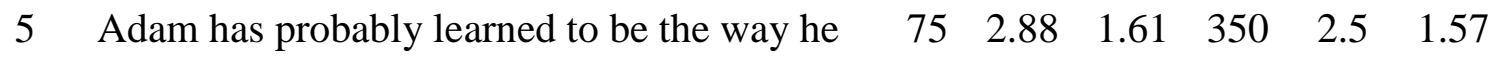
is.

$6 \quad$ Lacking basic skills in an academic area (e.g., $\begin{array}{llllll}74 & 4.26 & 1.53 & 349 & 3.89 & 1.73\end{array}$ Adam's lack of basic reading skills) often causes children to have difficulty paying attention.

7 Adam's behaviors are more likely the result $\quad \begin{array}{llllll}75 & 2.65 & 1.55 & 350 & 2.69 & 1.65\end{array}$ of immaturity than an attentional disorder (ADHD).

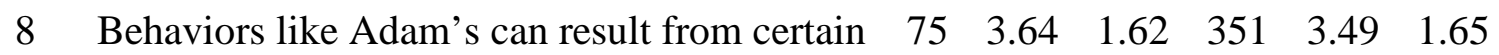
parenting methods such as little positive reinforcement for good behavior and attention for bad behavior.

9 Behaviors like Adam's can result when $\quad \begin{array}{llllll}75 & 3.6 & 1.40 & 346 & 3.5 & 1.51\end{array}$ classroom expectation are incongruent with the developmental abilities of the student. 
A chi-square goodness-of-fit test was calculated comparing the frequency of responses between teachers and parents on the nine cause statements. Table 37 summarizes the results and shows no significant differences were found between the patterns of responses for teachers and parents for any of the statements.

A one-way ANOVA was conducted comparing the means of teachers and parents concerning causes of ADHD. Non-significant differences were found $\left(F_{(1,420 ; 1,426 ; 1,423 ; 1}\right.$, $425 ; 1,425 ; 1,422 ; 1,424 ; 1,425 ; 1,420)=.980 ; 3.671 ; 1.071 ; .548 ; 3.602 ; 2.888 ; .024 ; .496 ; .294), p$ $>$.05) for the nine possible cause statements between teachers and parents. Therefore, teachers and parents do not differ in their beliefs about the causes of ADHD. Table 39 summarizes ANOVA results.

Table 39

ANOVA Summary Table for Mean Scores

\begin{tabular}{ccccc}
\hline Item & $d f$ & $M S$ & $F$ & $P$ \\
\hline 1 & $1 / 420$ & 2.649 & 0.980 & .323 \\
2 & $1 / 426$ & 9.488 & 3.671 & .056 \\
3 & $1 / 423$ & 2.888 & 1.071 & .301 \\
4 & $1 / 425$ & 1.338 & 0.548 & .460 \\
5 & $1 / 425$ & 8.919 & 3.602 & .058 \\
6 & $1 / 422$ & 8.291 & 2.888 & .090 \\
7 & $1 / 424$ & 0.065 & 0.024 & .876 \\
8 & $1 / 425$ & 1.338 & 0.496 & .482 \\
9 & $1 / 420$ & 0.653 & 0.294 & .588 \\
\hline
\end{tabular}


In summary, chi-square results show there are no significant differences between the pattern of responses on causes of ADHD between teachers and parents. One-way ANOVA results show there are no significant differences between the means of causes of ADHD between teachers and parents. Therefore, teachers and parents have similar knowledge and beliefs about causes of ADHD. Teachers and parents do not have adequate knowledge and many responded with don't know about the causes of ADHD concerning biological causation, emotional imbalance, and inheritability of ADHD.

\section{Knowledge and Beliefs About ADHD Intervention/Treatment Options}

The content of true/false/don't know items $6,14,16,20$, and 28 pertained to intervention/treatment options for ADHD; therefore, these items were grouped together and discussed in the intervention/treatment options section. In addition, Likert items 12 and 14-20 were grouped and discussed in a stimulant medication for ADHD section and statements 10,13, and 34-36 were grouped and discussed in an intervention options section (Carlson et al., 2006). In addition, statements 21-23 were included and discussed in the interventions section.

Knowledge statements: True, false, and don't know

Results show $78.9 \%$ of teachers and $61 \%$ of parents responded correctly with false to the following statement: ADHD is a medical disorder that can only be treated with medication (item 6), which indicates both groups had inadequate knowledge. A chisquare goodness-of-fit test was calculated comparing the frequency of responses between teachers and parents on this statement. A significant difference was found $\left(\chi^{2}(1)=8.952\right.$, 
$p<.05$ ) between the groups (see Table 40). This indicates that the pattern of responses was significantly different between teachers and parents on this statement.

Results show $73.7 \%$ of teachers and $69.6 \%$ of parents responded correctly with false to the following statement: If medication is prescribed educational interventions are often unnecessary (item 14), although this indicates inadequate knowledge about this issue.

Results show only $6.7 \%$ of teachers and $9.1 \%$ of parents responded correctly with true to the following statements: Diets are usually not helpful in treating most children with ADHD (item 16), which indicates that many teachers and parents incorrectly believed that they are helpful in treating ADHD. This represents an area of inadequate knowledge for both groups. See Table 40.

Results show $78.9 \%$ of teachers and $61 \%$ of parents responded correctly with true that children with ADHD are better behaved in 1-to-1 interactions than in group situations (item 20), although this indicates an area of inadequate knowledge for both groups. A chi-square goodness-of-fit test was calculated comparing the frequency of responses between teachers and parents on this statement. A significant difference was found $\left(\chi^{2}(1)=8.952, p<.05\right)$ between the two groups (see Table 40). This indicates that the pattern of responses was significantly different between teachers and parents on this statement.

Chi-square goodness-of-fit tests were calculated comparing the frequency of responses between teachers and parents on intervention option statements. No significant differences between their patterns of responses were found for statements 14,16 , and 28 . 
In summary, chi-square results show teachers and parents have similar knowledge about therapy, educational interventions and diet treatment as intervention methods for ADHD. Teachers and parents do not have adequate knowledge about intervention/treatment options about ADHD and many responded with don't know concerning therapy in the treatment of ADHD. See Table 40.

Table 40

Teachers' and Parents' True, False, and Don't Know Responses to Knowledge Statements About ADHD Intervention/Treatment Options (in percentages)

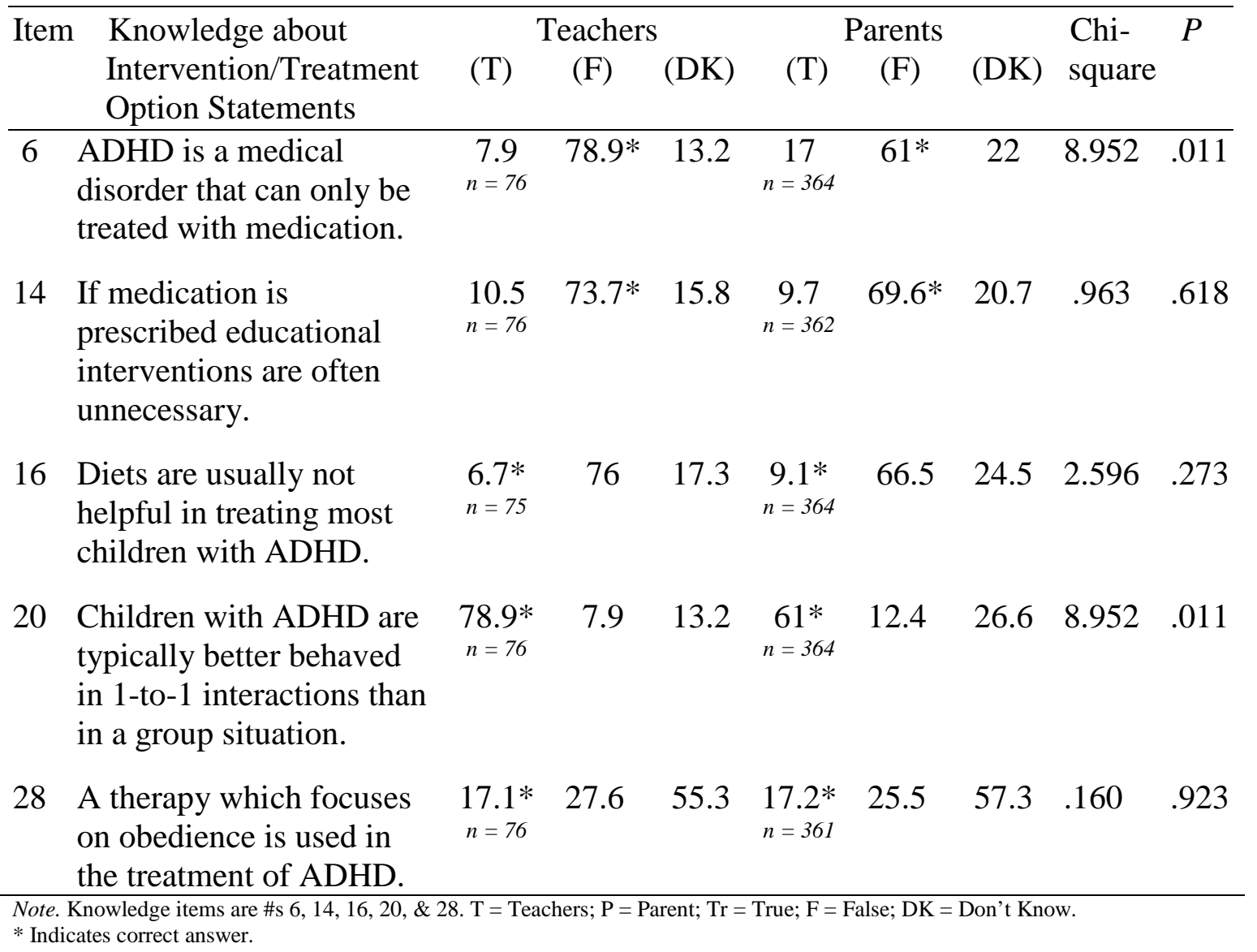


Beliefs about stimulant medication: Likert items

of agree and disagree

Percentage results show more teachers and parents tended to disagree that behavior interventions for children like Adam often will not work unless they are treated with stimulant medication first (item 12). Specifically, the greatest percentage of teachers $(38.7 \%)$ and parents $(39.3 \%)$ strongly disagreed with the statement. Mean scores show teachers $(m=2.22)$ and parents $(m=2.47)$ displayed beliefs of moderate disagreement. See Tables 41 and 42.

Percentage results show teachers' and parents' beliefs ranged across the six scales of agreement and disagreement to the following statement: If students like Adam do not receive stimulant treatment to treat their hyperactivity, impulsivity, and/or inattention, they will probably be worse off in the long run (item 14). The greatest percentage of teachers $(24 \%)$ and parents $(21.1 \%)$ strongly disagreed, whereas $20 \%$ of teachers moderately disagreed and $20.8 \%$ of parents strongly agreed with the statement. Mean scores show teachers $(m=3.11)$ and parents $(m=3.48)$ displayed beliefs of slight disagreement.

Percentage results show teachers and parents tended to disagree that stimulant medication is a safe way to improve behaviors like Adam's (item 16). Specifically, the greatest percentage of teachers $(31.5 \%)$ and parents $(26.5 \%)$ strongly disagreed. Mean scores showed teachers $(m=2.55)$ and parents $(m=3.03)$ displayed beliefs between moderate and slight disagreement. See Tables 41 and 42. 
Table 41

Teachers' and Parents' Beliefs About Stimulant Medication (in percentages)

\begin{tabular}{|c|c|c|c|c|c|c|c|c|c|}
\hline Item & $\begin{array}{l}\text { Beliefs about Stimulant } \\
\text { Medication }\end{array}$ & 1 & 2 & 3 & 4 & 5 & 6 & $\begin{array}{l}\text { Chi- } \\
\text { square }\end{array}$ & $P$ \\
\hline 12 & $\begin{array}{l}\text { Behavior interventions } \\
\text { with children like Adam } \\
\text { often will not work } \\
\text { unless they are treated } \\
\text { with stimulant } \\
\text { medication first. } \\
\text { Teachers: } n=75 \\
\text { Parents: } n=349\end{array}$ & $\begin{array}{l}38.7 \\
39.3\end{array}$ & $\begin{array}{l}30.7 \\
19.2\end{array}$ & $\begin{array}{c}9.3 \\
17.5\end{array}$ & $\begin{array}{l}13.3 \\
10.3\end{array}$ & $\begin{array}{l}6.7 \\
7.2\end{array}$ & $\begin{array}{l}1.3 \\
6.6\end{array}$ & 9.939 & .077 \\
\hline 14 & $\begin{array}{l}\text { If students like Adam } \\
\text { do not receive stimulant } \\
\text { treatment to treat their } \\
\text { hyperactivity, } \\
\text { impulsivity, and/or } \\
\text { inattention, they will } \\
\text { probably be worse off in } \\
\text { the long run. } \\
\text { Teachers: } n=75 \\
\text { Parents: } n=351\end{array}$ & $\begin{array}{c}24 \\
21.1\end{array}$ & $\begin{array}{c}20 \\
13.1\end{array}$ & $\begin{array}{l}18.7 \\
17.4\end{array}$ & $\begin{array}{l}10.7 \\
14.5\end{array}$ & $\begin{array}{c}12 \\
13.1\end{array}$ & $\begin{array}{l}14.7 \\
20.8\end{array}$ & 4.256 & .513 \\
\hline 15 & $\begin{array}{l}\text { If Adam's behavior } \\
\text { markedly improves after } \\
\text { taking stimulant } \\
\text { medication, it would } \\
\text { seem to indicate that he } \\
\text { has an attentional } \\
\text { disorder (ADHD). } \\
\text { Teachers: } n=73 \\
\text { Parents: } n=349\end{array}$ & $\begin{array}{l}13.7 \\
14.3\end{array}$ & $\begin{array}{c}8.2 \\
11.5\end{array}$ & $\begin{array}{l}16.4 \\
12.3\end{array}$ & $\begin{array}{l}31.5 \\
22.3\end{array}$ & $\begin{array}{l}23.3 \\
22.9\end{array}$ & $\begin{array}{c}6.8 \\
16.6\end{array}$ & 7.363 & .195 \\
\hline 16 & $\begin{array}{l}\text { Stimulant medication is } \\
\text { a safe way to improve } \\
\text { behaviors like Adam's. } \\
\text { Teachers: } \mathrm{n}=73 \\
\text { Parents: } \mathrm{n}=351\end{array}$ & $\begin{array}{l}31.5 \\
26.5\end{array}$ & $\begin{array}{l}19.2 \\
14.2\end{array}$ & $\begin{array}{l}23.3 \\
18.2\end{array}$ & $\begin{array}{l}17.8 \\
18.2\end{array}$ & $\begin{array}{l}5.5 \\
16\end{array}$ & $\begin{array}{l}2.7 \\
6.8\end{array}$ & 8.684 & .122 \\
\hline 17 & $\begin{array}{l}\text { Too many children in } \\
\text { the U.S. like Adam } \\
\text { receive stimulant } \\
\text { medication. } \\
\text { Teachers: } \mathrm{n}=75 \\
\text { Parents: } \mathrm{n}=343\end{array}$ & $\begin{array}{l}5.3 \\
7.6\end{array}$ & $\begin{array}{l}4.0 \\
7.9\end{array}$ & $\begin{array}{l}1.3 \\
7.3\end{array}$ & $\begin{array}{l}16.0 \\
14.9\end{array}$ & $\begin{array}{l}24.0 \\
15.2\end{array}$ & $\begin{array}{l}49.3 \\
47.2\end{array}$ & 8.335 & .139 \\
\hline
\end{tabular}


Table 41-Continued.

\begin{tabular}{|c|c|c|c|c|c|c|c|c|c|}
\hline Item & $\begin{array}{l}\text { Beliefs about Stimulant } \\
\text { Medication }\end{array}$ & 1 & 2 & 3 & 4 & 5 & 6 & $\begin{array}{l}\text { Chi- } \\
\text { Square. }\end{array}$ & $P$ \\
\hline \multirow[t]{3}{*}{18} & $\begin{array}{l}\text { Before his behavior can be } \\
\text { improved, Adam needs to } \\
\text { be evaluated by a } \\
\text { pediatrician or child } \\
\text { psychiatrist, so he can be } \\
\text { treated with stimulant } \\
\text { medication. }\end{array}$ & & & & & & & & \\
\hline & Teachers: $n=75$ & 17.3 & 25.3 & 13.3 & 16.0 & 18.7 & 9.3 & 16.503 & .006 \\
\hline & Parents: $n=347$ & 17.0 & 11.8 & 14.7 & 14.4 & 15.3 & 26.8 & & \\
\hline \multirow[t]{3}{*}{19} & $\begin{array}{l}\text { It is a disservice to } \\
\text { children with behaviors } \\
\text { like Adam's when they do } \\
\text { not receive stimulant } \\
\text { medication. }\end{array}$ & & & & & & & & \\
\hline & Teachers: $n=74$ & 35.1 & 23.0 & 17.6 & 20.3 & 2.7 & 1.4 & 11.153 & .048 \\
\hline & Parents: $n=341$ & 24.9 & 19.9 & 17.9 & 18.2 & 13.5 & 5.6 & & \\
\hline \multirow[t]{3}{*}{20} & $\begin{array}{l}\text { There are many children } \\
\text { like Adam who are in } \\
\text { need of stimulant } \\
\text { medication for their } \\
\text { behavior but do not } \\
\text { presently receive it. }\end{array}$ & & & & & & & & \\
\hline & Teachers: $n=75$ & 13.3 & 26.7 & 20.0 & 25.3 & 9.3 & 5.3 & 15.26 & .009 \\
\hline & Parents: $n=340$ & 16.5 & 12.9 & 15.6 & 23.2 & 16.8 & 15.0 & & \\
\hline
\end{tabular}

A one-way ANOVA was conducted comparing the means of teachers and parents on this statement. A significant difference was found $(F(1,423)=14.288, p<.05)$ between teachers and parents on this issue. See Table 43. These findings suggest teachers felt stronger disagreement than parents that stimulant medication is a safe way to improve behaviors like Adam's. However, eta squared $\left(n^{2}=.013\right)$ represents a small effect size indicating a low practical meaningfulness of the difference between teachers' and parents' mean scores. 
Table 42

Teachers' and Parents' Beliefs About Stimulant Medication by Mean and Standard Deviation

\begin{tabular}{llll}
\hline Item & Beliefs about Stimulant Medication & Teachers & Parents
\end{tabular}

\begin{tabular}{llrrrrrrr}
\cline { 3 - 4 } \cline { 6 - 7 } & & $N$ & $M$ & $S D$ & & & $M$ & $S D$ \\
\hline 12 & Behavior interventions with children like Adam & 75 & 2.22 & 1.34 & & 349 & 2.47 & 1.57
\end{tabular}
often will not work unless they are treated with stimulant medication first.

14 If students like Adam do not receive stimulant $\begin{array}{llllll}75 & 3.11 & 1.76 & 351 & 3.48 & 1.82\end{array}$ treatment to treat their hyperactivity, impulsivity, and/or inattention, they will probably be worse off in the long run.

15 If Adam's behavior markedly improves after $\begin{array}{llllll}73 & 3.63 & 1.46 & 349 & 3.78 & 1.65\end{array}$ taking stimulant medication, it would seem to indicate that he has an attentional disorder (ADHD).

16 Stimulant medication is a safe way to improve $\begin{array}{llllll}73 & 2.55 & 1.38 & 351 & 3.03 & 1.63\end{array}$ behaviors like Adam's.

17 Too many children in the U.S. like Adam receive stimulant medication.

18 Before his behavior can be improved, Adam $\begin{array}{llllll}75 & 3.21 & 1.64 & 347 & 3.8 & 1.83\end{array}$ needs to be evaluated by a pediatrician or child psychiatrist, so he can be treated with stimulant medication.

19 It is a disservice to children with behaviors like $\begin{array}{llllll}74 & 2.36 & 1.30 & 341 & 2.92 & 1.56\end{array}$ Adam's when they do not receive stimulant medication.

20 There are many children like Adam who are in $\begin{array}{llllll}75 & 3.07 & 1.39 & 340 & 3.56 & 1.65\end{array}$ need of stimulant medication for their behavior but do not presently receive it.

Note. Disagree scores range from 1 (strongly disagree), 2 (moderately disagree) \& 3 (slightly disagree); agree scores range from 4 (slightly agree), 5 (moderately agree) \& 6 (strongly agree).

Percentage results show almost half of both teachers (49.3\%) and parents (47.2\%) strongly believed that too many children in the U.S. like Adam receive stimulant medication (item 17). Mean scores show teachers $(m=5.00)$ moderately agreed while 
parents $(m=4.64)$ beliefs were between slight agreement and moderate agreement on this issue. See Tables 41 and 42.

Percentage results show teachers' and parents' beliefs differed on the following statement: Before his behavior can be improved, Adam needs to be evaluated by a pediatrician or child psychiatrist, so he can be treated with stimulant medication (item 18). Specifically, the greatest percentage of teachers (25.3\%) moderately disagreed while parents $(26.8 \%)$ strongly agreed with the statement. Mean scores show teachers $(m=$ 3.21) slightly disagreed, whereas parents' $(m=3.8)$ beliefs were between slightly disagree and slightly agree on this issue. See Tables 41 and 42.

Table 43

ANOVA Summary Table for Mean Scores

\begin{tabular}{ccccc}
\hline Item & $d f$ & $M S$ & $F$ & $P$ \\
\hline 12 & $1 / 423$ & 3.567 & 1.517 & .219 \\
14 & $1 / 425$ & 8.550 & 2.622 & .106 \\
15 & $1 / 421$ & 1.345 & 0.513 & .474 \\
16 & $1 / 423$ & 14.288 & 5.669 & .018 \\
17 & $1 / 417$ & 8.043 & 3.153 & .077 \\
18 & $1 / 421$ & 20.893 & 6.476 & .011 \\
19 & $1 / 414$ & 18.794 & 8.205 & .004 \\
20 & $1 / 414$ & 14.883 & 5.742 & .017 \\
\hline
\end{tabular}


A chi-square goodness-of-fit test comparing the frequency of responses between teachers and percentages for this statement found a significant difference $\left(\chi^{2}(1)=\right.$ $16.503, p<.01)$ between the two groups on this issue. This indicates that the pattern of responses was significantly different between teachers and parents on this statement.

A one-way ANOVA was conducted comparing the means of teachers and parents on this statement. A significant mean difference was found $F(1,421)=6.476, p<.05)$ between the two groups on this statement. These findings suggest teachers felt stronger disagreement than parents that Adam should be treated with stimulant medication before his behavior can improve. However, eta squared $\left(n^{2}=.015\right)$ for both analyses represents a small effect size, indicating a low practical meaningfulness of the difference between teachers' and parents' mean scores and percentages. See Table 41 and 43.

Percentage results show teachers and parents tended to disagree that it is a disservice to children with behaviors like Adam's when they do not receive stimulant medication (item 19). Specifically, the greatest percentage of teachers $(35.1 \%)$ and parents $(24.9 \%)$ strongly disagreed with the statement. Mean scores show teachers $(m=$ 2.36) moderately disagreed while parents $(m=2.92)$ displayed responses between moderate disagreement and slight disagreement on this issue. See Tables 41 and 42.

A chi-square goodness-of-fit test comparing the frequency of responses between teachers and parents found a significant difference $\left(\chi^{2}(1)=11.153, p<.05\right)$ between the two groups on this issue. This indicates that the pattern of responses was significantly different between teachers and parents on this statement.

A one-way ANOVA was conducted comparing the means of teachers and parents on this statement. A significant mean difference was found $(F(1,421)=8.205, p<.01)$ 
between the two groups on this issue. These findings suggest teachers felt stronger disagreement than parents that it is a disservice to children with behaviors like Adam when they do not receive stimulant medication. However, eta squared $\left(n^{2}=.019\right)$ for both analyses represents a small effect size, indicating a low practical meaningfulness of the difference between teachers' and parents' percentages and mean scores. See Tables 41 and 43.

Percentage results show teachers' and parents' beliefs were spread out across the six scales for the following statement: There are many children like Adam who are in need of stimulant medication for their behavior but do not presently receive it (item 20). Specifically, the greatest percentage of teachers (26.7\%) moderately disagreed while parents $(23.2 \%)$ slightly agreed with the statement. Mean scores show teachers $(m=$ 3.07) and parents $(m=3.56)$ slightly disagreed with this issue. See Tables 41 and 42.

A chi-square goodness-of-fit test comparing the frequency of responses between teachers and parents found a significant difference $\left(\chi^{2}(1)=15.26, p<.01\right)$ between the two groups on this issue. This indicates that the pattern of responses was significantly different between teachers and parents on this statement.

A one-way ANOVA was conducted comparing the means of teachers and parents on this statement. A significant difference was found $(F(1,414)=14.883, p<.05)$ between the two groups on this issue. These findings suggest teachers felt stronger disagreement than parents that there are many children like Adam who are in need of stimulant medication for their behavior but do not presently receive it. However, eta squared $\left(n^{2}=.019\right)$ for both analyses represents a small effect size, indicating a low 
practical meaningfulness of the difference between teachers' and parents' percentages and mean scores. See Tables 41 and 43.

In summary, teachers and parents have negative beliefs towards stimulant medication. They tend to strongly disagree that behavioral interventions will not work without stimulant medications, that stimulant medication is a safe way to improve ADHD-like behaviors, and that it is a disservice to children with ADHD-like behaviors when they don't receive stimulant medication. On the other hand, they tend to strongly agree that too many children in the U.S. receive stimulant medication. Considering the mean, both teachers and parents tend to have negative beliefs towards stimulant medication, although many scores were between slightly disagree and slightly agree. Teachers moderately agreed and parents slightly agreed that too many children in the U.S. receive stimulant medication. Teachers felt stronger disagreement than parents on four stimulant statements; however, the effect sizes were small, indicating low practical meaningfulness. They also have more responses of disagree compared to parents.

Beliefs about interventions: Likert items ranging from slightly disagree to strongly agree

Percentage results show teachers and parents tended to believe that rather than refer him to a doctor for these behaviors, Adam's teacher should first find ways to try classroom interventions to improve Adam's disruptive behavior (item 10). Specifically, the greatest percentage of teachers $(33.3 \%)$ and parents $(27.9 \%)$ strongly agreed with the statement. These results show more than $60 \%$ of teachers moderately and strongly agreed with the statement, whereas about $50 \%$ of parents moderately and strongly agreed with the statement. Mean scores show teachers $(m=4.73)$ and parents $(m=4.15)$ slightly 
agreed with this issue, although teachers' responses approached moderate agreement. See Tables 44 and 45.

A chi-square goodness-of-fit test comparing the frequency of responses between teachers and parents found a significant difference $\left(\chi^{2}(1)=12.977, p<.05\right)$ between the two groups on this issue. This indicates that the pattern of responses was significantly different between teachers and parents on this statement.

A one-way ANOVA was conducted comparing the means of teachers and parents on this same statement. A significant mean difference was found $(F(1,425)=7.918, p<$ $.01)$ between the two groups. These findings suggest teachers felt stronger agreement than parents that classroom interventions should be tried first to improve Adam's disruptive behaviors before referral to a doctor. However, eta squared $\left(n^{2}=.018\right)$ for both analyses represents a small effect size, indicating a low practical meaningfulness of the difference between teachers' and parents' percentages and mean scores. See Tables 44 and 46.

Percentage results show teachers and parents tended to agree that Adam's teacher should try classroom interventions to improve his academic achievement before referring him for a special education evaluation (item 13). Specifically, the greatest percentage of teachers $(34.7 \%)$ and parents $(30.5 \%)$ strongly agreed with the statement. Mean scores show teachers $(m=4.75)$ and parents $(m=4.20)$ slightly agreed with this issue, although teachers' responses approached moderate agreement. See Tables 44 and 45. 
Table 44

Teachers' and Parents' Beliefs About Interventions (in percentages)

\begin{tabular}{|c|c|c|c|c|c|c|c|c|c|}
\hline Item & Interventions for ADHD & 1 & 2 & 3 & 4 & 5 & 6 & $\begin{array}{l}\text { Chi- } \\
\text { square }\end{array}$ & $p$ \\
\hline 10 & $\begin{array}{l}\text { Rather than refer him to a } \\
\text { doctor for these behaviors, } \\
\text { Adam's teacher should } \\
\text { first find ways to try } \\
\text { classroom interventions to } \\
\text { improve Adam's } \\
\text { disruptive behavior. } \\
\text { Teachers: } n=75 \\
\text { Parents: } n=351\end{array}$ & $\begin{array}{r}5.3 \\
12.5\end{array}$ & $\begin{array}{l}2.7 \\
8.5\end{array}$ & $\begin{array}{l}2.7 \\
9.7\end{array}$ & $\begin{array}{l}25.3 \\
18.2\end{array}$ & $\begin{array}{l}30.7 \\
23.1\end{array}$ & $\begin{array}{l}33.3 \\
27.9\end{array}$ & 12.977 & .024 \\
\hline 13 & $\begin{array}{l}\text { Adam's teacher should try } \\
\text { classroom interventions to } \\
\text { improve his academic } \\
\text { achievement before } \\
\text { referring him for a special } \\
\text { education evaluation. } \\
\text { Teachers: } n=75 \\
\text { Parents: } n=351\end{array}$ & $\begin{array}{r}4.0 \\
11.7\end{array}$ & $\begin{array}{l}4.0 \\
8.3\end{array}$ & $\begin{array}{l}5.3 \\
8.0\end{array}$ & $\begin{array}{l}21.3 \\
19.1\end{array}$ & $\begin{array}{l}30.7 \\
22.5\end{array}$ & $\begin{array}{l}34.7 \\
30.5\end{array}$ & 7.82 & .166 \\
\hline 21 & $\begin{array}{l}\text { Children like Adam can be } \\
\text { treated with behavior } \\
\text { modifications for their } \\
\text { behaviors. } \\
\text { Teachers: } n=75 \\
\text { Parents: } n=347\end{array}$ & $\begin{array}{l}0.0 \\
4.0\end{array}$ & $\begin{array}{l}4.0 \\
4.9\end{array}$ & $\begin{array}{l}4.0 \\
8.4\end{array}$ & $\begin{array}{l}30.7 \\
26.2\end{array}$ & $\begin{array}{l}37.3 \\
31.7\end{array}$ & $\begin{array}{l}24.0 \\
24.8\end{array}$ & 5.739 & .332 \\
\hline
\end{tabular}

22 Children like Adam would benefit from therapy.

Teachers: $n=75$

Parents: $\mathrm{n}=347$

$\begin{array}{llllllll}1.3 & 1.3 & 4.0 & 26.7 & 41.3 & 25.3 & 12.529 & .028\end{array}$

$\begin{array}{llllll}4.9 & 6.3 & 5.8 & 20.5 & 26.8 & 35.7\end{array}$

23 Because of their disruptive ways, children like Adam are best handled in a special education classroom.

Teachers: $n=74$

Parents: $n=345$

$\begin{array}{llllllll}12.2 & 14.9 & 20.3 & 29.7 & 14.9 & 8.1 & 10.938 & 053\end{array}$ $\begin{array}{llllll}14.8 & 15.4 & 12.5 & 20.0 & 16.8 & 20.6\end{array}$ 
Table 44-Continued.

\begin{tabular}{|c|c|c|c|c|c|c|c|c|c|}
\hline Item & Interventions for ADHD & 1 & 2 & 3 & 4 & 5 & 6 & $\begin{array}{l}\text { Chi- } \\
\text { square }\end{array}$ & $P$ \\
\hline 27 & $\begin{array}{l}\text { Classroom teachers should } \\
\text { make } \\
\text { modification/accommodations } \\
\text { to help children like Adam } \\
\text { succeed academically and } \\
\text { socially in the school setting. }\end{array}$ & & & & & & & & \\
\hline & Teachers: $n=75$ & 2.7 & 1.3 & 0.0 & 30.7 & 26.7 & 38.7 & 8.702 & .122 \\
\hline & Parents: $n=352$ & 3.7 & 3.4 & 7.4 & 22.2 & 23.9 & 39.5 & & \\
\hline
\end{tabular}

A one-way ANOVA was conducted comparing the means of teachers and parents on this statement. A significant mean difference was found $(F(1,425)=15.907, p<.05)$ between the two groups. These findings suggest teachers felt stronger agreement than parents that Adam's teacher should try classroom interventions to improve academic achievement before referring for an evaluation. However, eta squared $\left(n^{2}=.014\right)$ for both analyses represents a small effect size, indicating a low practical meaningfulness of the difference between teachers' and parents' mean scores. See Table 46.

Percentage results show teachers and parents tended to agree that children like Adam would benefit from therapy (item 22). More than one third of teachers $(41.3 \%)$ moderately agreed, whereas parents $(35.7 \%)$ strongly agreed with the statement. Mean scores show teachers $(m=4.81)$ and parents $(m=4.65)$ slightly agreed with the statement although their responses approached moderate agreement. See Tables 44 and 45.

A chi-square goodness-of-fit test comparing the frequency of responses between teachers and parents found a significant difference $\left(\chi^{2}(1)=12.529, p<.05\right)$ between the two groups on this statement. This indicates that the pattern of responses was 
Table 45

Teachers' and Parents' Beliefs About Interventions by Mean and Standard Deviation

\begin{tabular}{|c|c|c|c|c|c|c|c|}
\hline \multirow[t]{2}{*}{ Item } & \multirow[t]{2}{*}{ Beliefs about Interventions } & \multicolumn{3}{|c|}{ Teachers } & \multicolumn{3}{|c|}{ Parents } \\
\hline & & $N$ & $M$ & $S D$ & $N$ & $M$ & $S D$ \\
\hline 10 & $\begin{array}{l}\text { Rather than refer him to a doctor for } \\
\text { these behaviors, Adam's teacher } \\
\text { should first find ways to try } \\
\text { classroom interventions to improve } \\
\text { Adam's disruptive behavior. }\end{array}$ & 75 & 4.73 & 1.32 & 351 & 4.15 & 1.70 \\
\hline 13 & $\begin{array}{l}\text { Adam's teacher should try classroom } \\
\text { interventions to improve his } \\
\text { academic achievement before } \\
\text { referring him for a special education } \\
\text { evaluation. }\end{array}$ & 75 & 4.75 & 1.32 & 351 & 4.20 & 1.70 \\
\hline 21 & $\begin{array}{l}\text { Children like Adam can be treated } \\
\text { with behavior modifications for their } \\
\text { behaviors. }\end{array}$ & 75 & 4.73 & 1.00 & 347 & 4.51 & 1.30 \\
\hline 22 & $\begin{array}{l}\text { Children like Adam would benefit } \\
\text { from therapy. }\end{array}$ & 75 & 4.81 & .99 & 347 & 4.65 & 1.43 \\
\hline 23 & $\begin{array}{l}\text { Because of their disruptive ways, } \\
\text { children like Adam are best handled } \\
\text { in a special education classroom. }\end{array}$ & 74 & 3.45 & 1.44 & 345 & 3.70 & 1.73 \\
\hline 27 & $\begin{array}{l}\text { Classroom teachers should make } \\
\text { modification/accommodations to } \\
\text { help children like Adam succeed } \\
\text { academically and socially in the } \\
\text { school setting. }\end{array}$ & 75 & 4.93 & 1.12 & 350 & 4.78 & 1.33 \\
\hline
\end{tabular}

Note. Disagree scores range from 1 (strongly disagree), 2 (moderately disagree) \& 3 (slightly disagree); agree scores range from 4 (slightly agree), 5 (moderately agree) \& 6 (strongly agree).

significantly different between teachers and parents on this statement. However, eta squared $\left(n^{2}=.002\right)$ for both analyses represents a small effect size, indicating a low practical meaningfulness of the difference between teachers and parents percentages. See Table 44. 
Table 46

ANOVA Summary Table for Mean Scores

\begin{tabular}{ccccc}
\hline Item & $d f$ & $M S$ & $F$ & $P$ \\
\hline 10 & $1 / 425$ & 21.368 & 7.918 & .005 \\
13 & $1 / 425$ & 15.907 & 5.979 & .015 \\
21 & $1 / 421$ & 3.074 & 1.952 & .163 \\
22 & $1 / 421$ & 1.619 & 0.876 & .350 \\
23 & $1 / 418$ & 4.068 & 1.440 & .231 \\
27 & $1 / 426$ & 1.539 & 0.919 & .338 \\
\hline
\end{tabular}

Percentage results show teachers and parents tended to agree that classroom teachers should make modification/accommodations to help children like Adam succeed academically and socially in the school setting (item 27). More than one third of both teachers $(38.7 \%)$ and parents $(39.5 \%)$ strongly agreed with the statement. Mean scores show teachers $(m=4.93)$ and parents $(m=4.78)$ slightly agreed with the statement, although their responses approached moderate agreement. See Tables 44 and 45.

In summary, teachers and parents tend to strongly agree that classroom interventions should be tried to improve disruptive behaviors and academic achievement before referral takes place. They also tend to strongly agree that classroom teachers should make modifications/accommodations to help children like Adam succeed in school. Considering the mean, teachers' and parents' beliefs range from slight agreement to approaching moderate agreement to most of the intervention statements. Teachers felt stronger agreement than parents on two intervention statements. They also have more responses of agreement than parents on two intervention statements. Nevertheless, the effect sizes are small, indicating low meaningfulness. 


\section{Beliefs About Medication, Behavioral and Educational Interventions: Likert Items}

Teachers' and parents' beliefs about medication and behavioral and educational interventions were examined using Likert items with five scales: not effective, slightly effective, moderately effective, effective, and very effective.

\section{Medication intervention}

Percentage results show the greatest percentage of teachers (30.6\%) agreed medication intervention is effective in improving Adam's academic achievement in the long run (35a) while the greatest percentage of parents (23.7\%) agreed it is moderately effective. Mean scores show teachers $(m=2.86)$ beliefs about the effectiveness of medication intervention were approaching moderately effective while parents $(m=3.1)$ agreed it is moderately effective in improving academic achievement in the long run. See Tables 47 and 48 .

A chi-square goodness-of-fit test was calculated comparing the frequency of responses between teachers and parents and found a significant difference $\left(\chi^{2}(1)=13.66\right.$, $p<.01)$ between the two groups on the effectiveness of medication intervention in improving academic achievement in the long run. This indicates that the pattern of responses was significantly different between teachers and parents on this statement. However, eta squared $\left(n^{2}=.004\right)$ represents a small effect size indicating a low practical meaningfulness of the difference between teachers' and parents' percentages. See Table 47.

Percentage results show the greatest percentage of teachers (40.3\%) and parents (25.4\%) agreed medication intervention is effective in improving Adam's attention in 
Table 47

Teachers' and Parents' Beliefs About Medication, Behavioral, and Educational Interventions (in percentages)

\begin{tabular}{|c|c|c|c|c|c|c|c|c|}
\hline Item & Beliefs about Interventions & $\mathrm{NE}$ & SE & $\mathrm{ME}$ & $\mathrm{E}$ & VE & $\begin{array}{l}\text { Chi- } \\
\text { square }\end{array}$ & p. \\
\hline \multirow[t]{7}{*}{34} & $\begin{array}{l}\text { How effective will each intervention } \\
\text { be in improving Adam's disruptive, } \\
\text { hyperactive, and impulsive classroom } \\
\text { behavior? }\end{array}$ & & & & & & & \\
\hline & a. Medication Intervention (T) $n=71$ & 2.8 & 23.9 & 28.2 & 35.2 & 9.9 & 6.45 & .168 \\
\hline & $\begin{array}{l}\text { a. Medication Intervention }(\mathrm{P}) n= \\
335\end{array}$ & 9.0 & 21.8 & 24.2 & 27.8 & 17.3 & & \\
\hline & b. Behavioral Intervention (T) $n=75$ & & 1.3 & 24.0 & 48.0 & 26.7 & 9.75 & .045 \\
\hline & b. Behavioral Intervention (P) $n=340$ & 0.9 & 4.7 & 16.2 & 37.1 & 41.2 & & \\
\hline & c. Educational Intervention (T) $n=75$ & & 1.3 & 28.0 & 46.7 & 24.0 & 17.24 & .002 \\
\hline & $\begin{array}{l}\text { c. Educational Intervention }(\mathrm{P}) n= \\
343\end{array}$ & 1.7 & 8.2 & 15.2 & 35.6 & 39.4 & & \\
\hline \multirow[t]{7}{*}{35} & $\begin{array}{l}\text { How effective will each intervention } \\
\text { be in improving Adam's academic } \\
\text { achievement in the long run? }\end{array}$ & & & & & & & \\
\hline & a. Medication Intervention (T) $n=72$ & 11.1 & 27.8 & 27.8 & 30.6 & 2.8 & 13.66 & .008 \\
\hline & $\begin{array}{l}\text { a. Medication Intervention }(\mathrm{P}) n= \\
338\end{array}$ & 14.5 & 21.0 & 23.7 & 21.9 & 18.9 & & \\
\hline & b. Behavioral Intervention (T) $n=75$ & & 1.3 & 18.7 & 46.7 & 33.3 & 8.18 & .085 \\
\hline & b. Behavioral Intervention (P) $n=344$ & 0.9 & 4.7 & 17.4 & 32.0 & 45.1 & & \\
\hline & c. Educational Intervention (T) $n=75$ & & & 21.3 & 42.7 & 36.0 & 12.27 & .015 \\
\hline & $\begin{array}{l}\text { c. Educational Intervention }(\mathrm{P}) n= \\
340\end{array}$ & 1.2 & 4.1 & 13.2 & 30.6 & 50.9 & & \\
\hline \multirow[t]{7}{*}{36} & $\begin{array}{l}\text { How effective will each intervention } \\
\text { be in improving Adam's attention in } \\
\text { the classroom? }\end{array}$ & & & & & & & \\
\hline & a. Medication Intervention $(\mathrm{T}) \mathrm{n}=72$ & 8.3 & 18.1 & 26.4 & 40.3 & 6.9 & 14.56 & .006 \\
\hline & $\begin{array}{l}\text { a. Medication Intervention }(\mathrm{P}) \mathrm{n}= \\
338\end{array}$ & 10.4 & 21.6 & 19.2 & 25.4 & 23.4 & & \\
\hline & b. Behavioral Intervention (T) $n=75$ & & & 21.3 & 45.3 & 33.3 & 9.14 & .058 \\
\hline & b. Behavioral Intervention (P) $n=343$ & 1.5 & 5.2 & 17.5 & 33.5 & 42.3 & & \\
\hline & c. Educational Intervention (T) $n=75$ & & & 18.7 & 53.3 & 28.0 & 13.93 & .008 \\
\hline & $\begin{array}{l}\text { c. Educational Intervention }(\mathrm{P}) n= \\
342\end{array}$ & 2.0 & 4.4 & 16.1 & 34.8 & 42.7 & & \\
\hline
\end{tabular}


the classroom (36a), whereas mean scores show teachers $(m=3.19)$ and parents $(m=$ 3.3) agreed medication intervention is moderately effective in improving attention in the classroom. See Tables 47 and 48.

Table 48

Teachers' and Parents' Beliefs About Medication, Behavioral, and Educational Interventions by Mean and Standard Deviation

\begin{tabular}{llll}
\hline Item & Beliefs about Interventions & Teachers
\end{tabular}

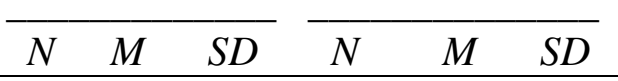

34 How effective will each intervention be in improving Adam's disruptive, hyperactive and impulsive classroom behavior?
a. Medication Intervention
$\begin{array}{llllll}71 & 3.25 & 1.02 & 335 & 3.23 & 1.22\end{array}$
b. Behavioral Intervention
$\begin{array}{ll}75 & 4.0\end{array}$
$0.75 \quad 340$
$\begin{array}{ll}4.13 & 0.91\end{array}$
c. Educational Intervention
$\begin{array}{llll}75 & 3.93 & 0.76 & 343\end{array}$
$4.03 \quad 1.02$

35 How effective will each intervention be in improving Adam's academic achievement in the long run?
a. Medication Intervention
$\begin{array}{llllll}72 & 2.86 & 1.07 & 338 & 3.1 & 1.33\end{array}$
b. Behavior Intervention
$\begin{array}{llll}75 & 4.12 & 0.75 & 344\end{array}$
$4.16 \quad 0.93$
c. Education Intervention
$\begin{array}{llllll}75 & 4.15 & 0.75 & 340 & 4.26 & 0.93\end{array}$

36 How effective will each intervention be in improving Adam's attention in the classroom?
a. Medication Intervention
$\begin{array}{llllll}72 & 3.19 & 1.08 & 338 & 3.3 & 1.32\end{array}$
b. Behavioral Intervention
$\begin{array}{llll}75 & 4.12 & 0.73 & 343\end{array}$
$4.10 \quad 0.97$
c. Educational Intervention

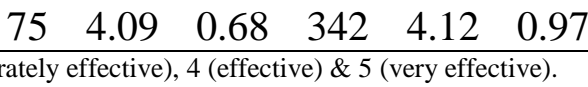

A chi-square goodness-of-fit test was calculated comparing the frequency of responses between teachers and parents and found a significant difference $\left(\chi^{2}(1)=14.56\right.$, $p<.01)$ between the two groups on the effectiveness of medication intervention in improving attention in the classroom. This indicates that the pattern of responses was 
significantly different between teachers and parents on this statement. However, eta squared $\left(n^{2}=.001\right)$ represents a small effect size, indicating a low practical meaningfulness of the difference between teachers' and parents' percentages.

Behavioral interventions

Percentage results show the greatest percentage of teachers (48\%) agreed behavioral intervention is effective in improving Adam's disruptive, hyperactive, and impulsive classroom behavior (item 34b), whereas the greatest percentage of parents $(41.2 \%)$ agreed it is very effective. Mean scores show teachers $(m=4.0)$ and parents $(m$ $=4.13$ ) believe behavioral intervention is effective in improving disruptive, hyperactive, and impulsive classroom behaviors. See Tables 47 and 48 .

A chi-square goodness-of-fit test comparing the frequency of responses between teachers and parents found a significant difference $\left(\chi^{2}(1)=9.75, p<.05\right)$ between the two groups on the effectiveness of behavioral intervention. This indicates that the pattern of responses was significantly different between teachers and parents on this statement. However, eta squared $\left(n^{2}=.003\right)$ represents a small effect size, indicating a low practical meaningfulness of the difference between teachers' and parents' percentages.

Educational intervention

Percentage results show almost half of teachers (46.7\%) agreed educational intervention is effective in improving Adam's disruptive, hyperactive and impulsive classroom behavior (item 34c), whereas fewer parents (39.4\%) agreed it is very effective. Mean scores show teachers' $(m=3.93)$ beliefs about the effectiveness of educational intervention approached effective while parents $(m=4.03)$ agreed it is effective in 
improving disruptive, hyperactive and impulsive classroom behaviors. See Tables 47 and 48.

A chi-square goodness-of-fit test comparing the frequency of responses between teachers and parents found a significant difference $\left(\chi^{2}(1)=17.24, p<.01\right)$ between the two groups on the effectiveness of educational intervention. This indicates that the pattern of responses was significantly different between teachers and parents on this statement. However, eta squared $\left(n^{2}=.001\right)$ represents a small effect size, indicating a low practical meaningfulness of the difference between teachers' and parents' percentages. See Table 47.

Percentage results show more than half of parents (50.9\%) agreed educational intervention is very effective in improving Adam's academic achievement in the long run (35c), whereas few teachers (36\%) agreed it was very effective. Mean scores show teachers $(m=4.15)$ and parents $(m=4.26)$ agreed educational intervention is effective in improving academic achievement in the long run. See Tables 47 and 48.

A chi-square goodness-of-fit test comparing the frequency of responses between teachers and parents found a significant difference $\left(\chi^{2}(1)=12.27, p<.05\right)$ between the two groups on the effectiveness of educational intervention in improving academic achievement in the long run. This indicates that the pattern of responses was significantly different between teachers and parents on this statement. However, eta squared $\left(n^{2}=\right.$ .002) represents a small effect size indicating a low practical meaningfulness of the difference between teachers' and parents' percentages. See Table 47.

Percentage results show more than half of teachers (53.3\%) agreed educational intervention is effective in improving Adam's attention in the classroom (36c), whereas 
the greatest percentage of parents $(42.7 \%)$ agreed it is very effective. Mean scores show teachers $(m=4.09)$ and parents $(m=4.12)$ agreed educational intervention is effective in improving attention in the classroom.

A chi-square goodness-of-fit test comparing the frequency of responses between teachers and parents found a significant difference $\left(\chi^{2}(1)=12.27, p<.05\right)$ between the two groups on the effectiveness of educational intervention in improving attention in the classroom. This indicates that the pattern of responses was significantly different between teachers and parents on this statement. However, eta squared $\left(n^{2}=.0001\right)$ represents a small effect size, indicating a low practical meaningfulness of the difference between teachers' and parents' percentages.

There were no significant differences between the patterns of responses for teachers and parents for items 34a, 35b and 36b. Table 47 summarizes chi-square results. There were no significant differences between teachers and parents on mean scores for any of the interventions in this section. Table 49 summarizes ANOVA results. In summary, teachers and parents believe medication, behavioral and educational interventions are effective in improving disruptive, hyperactive and impulsive behaviors, academic achievement in the long run, and attention in the classroom.

Chi-square results show that there were significant differences in the patterns of responses between teachers and parents concerning educational interventions in improving ADHD behaviors, academic achievement in the long run, and attention in the classroom. There were also significant differences in the patterns of responses between teachers and parents concerning medication interventions in improving academic achievement and attention in the classroom. Finally, there was a significant difference in 
the pattern of responses between teachers and parents concerning behavioral interventions in improving ADHD behaviors. There were no significant mean differences between teachers and parents on any of the interventions.

Table 49

ANOVA Summary Table for Mean Scores

\begin{tabular}{ccccc}
\hline Item & $d f$ & $M S$ & $F$ & $P$ \\
\hline $34 \mathrm{a}$ & $1 / 405$ & 0.042 & 0.029 & .864 \\
$34 \mathrm{~b}$ & $1 / 414$ & 1.029 & 1.319 & .252 \\
$34 \mathrm{c}$ & $1 / 417$ & 0.531 & 0.559 & .455 \\
$35 \mathrm{a}$ & $1 / 409$ & 3.321 & 2.009 & .157 \\
$35 \mathrm{~b}$ & $1 / 418$ & 0.084 & 0.103 & .748 \\
$35 \mathrm{c}$ & $1 / 414$ & 0.773 & 0.971 & .325 \\
$36 \mathrm{a}$ & $1 / 409$ & 0.647 & 0.395 & .530 \\
$36 \mathrm{~b}$ & $1 / 417$ & 0.027 & 0.031 & .860 \\
$36 \mathrm{c}$ & $1 / 416$ & 0.034 & 0.040 & .841 \\
\hline
\end{tabular}

\section{Other Beliefs About ADHD Issues Likert Items of Agreement and Disagreement}

Percentage results show almost three-fourths of teachers (72\%) and more than two-thirds of parents $(64.9 \%)$ strongly agreed that it is important to communicate and/or collaborate more often with the parents (teachers) of children like Adam (item 28). Mean scores show teachers $(m=5.61)$ and parents $(m=5.41)$ moderately agreed with teachers' score approaching strong agreement towards the statement. See Tables 50 and 51.

Percentage results show almost $70 \%$ of teachers $(69.3 \%)$ and $61.6 \%$ of parents strongly agreed that children like Adam can be successful academically (item 29). Mean 
Table 50

Teachers' and Parents' Other Beliefs about ADHD Issues (in percentages)

\begin{tabular}{|c|c|c|c|c|c|c|c|c|c|}
\hline Item & $\begin{array}{l}\text { Other Beliefs about } \\
\text { ADHD Issues }\end{array}$ & 1 & 2 & 3 & 4 & 5 & 6 & $\begin{array}{l}\text { Chi- } \\
\text { square }\end{array}$ & $P$ \\
\hline 24 & $\begin{array}{l}\text { At times it is difficult to } \\
\text { work effectively with } \\
\text { children like Adam. } \\
\text { Teachers: } n=75 \\
\text { Parents: } n=350\end{array}$ & $\begin{array}{l}6.7 \\
4.3\end{array}$ & $\begin{array}{l}0.0 \\
2.9\end{array}$ & $\begin{array}{l}1.3 \\
4.9\end{array}$ & $\begin{array}{l}13.3 \\
18.9\end{array}$ & $\begin{array}{l}28.0 \\
30.0\end{array}$ & $\begin{array}{l}50.7 \\
39.0\end{array}$ & 7.827 & .166 \\
\hline 25 & $\begin{array}{l}\text { Children like Adam need } \\
\text { to try harder in school. } \\
\text { Teachers: } n=74 \\
\text { Parents: } n=345\end{array}$ & $\begin{array}{l}14.9 \\
21.2\end{array}$ & $\begin{array}{r}9.5 \\
14.8\end{array}$ & $\begin{array}{l}21.6 \\
16.8\end{array}$ & $\begin{array}{l}36.5 \\
24.1\end{array}$ & $\begin{array}{l}12.2 \\
13.0\end{array}$ & $\begin{array}{r}5.4 \\
10.1\end{array}$ & 8.342 & .138 \\
\hline 26 & $\begin{array}{l}\text { Other children in the } \\
\text { classroom suffer the most } \\
\text { because Adam is in the } \\
\text { classroom. } \\
\text { Teachers: } n=73 \\
\text { Parents: } n=350\end{array}$ & $\begin{array}{r}8.2 \\
12.0\end{array}$ & $\begin{array}{r}9.6 \\
12.9\end{array}$ & $\begin{array}{l}23.3 \\
18.9\end{array}$ & $\begin{array}{l}35.6 \\
23.1\end{array}$ & $\begin{array}{l}15.1 \\
16.9\end{array}$ & $\begin{array}{r}8.2 \\
16.3\end{array}$ & 8.361 & .137 \\
\hline 28 & $\begin{array}{l}\text { It is important to } \\
\text { communicate and/or } \\
\text { collaborate more often } \\
\text { with the parents (teachers) } \\
\text { of children like Adam. } \\
\text { Teachers: } n=75 \\
\text { Parents: } n=350\end{array}$ & $\begin{array}{l}1.3 \\
1.4\end{array}$ & $\begin{array}{l}0.0 \\
1.4\end{array}$ & $\begin{array}{l}0.0 \\
3.4\end{array}$ & $\begin{array}{l}5.3 \\
6.9\end{array}$ & $\begin{array}{l}21.3 \\
22.0\end{array}$ & $\begin{array}{l}72.0 \\
64.9\end{array}$ & 4.354 & .500 \\
\hline 29 & $\begin{array}{l}\text { Children like Adam can be } \\
\text { successful academically. } \\
\text { Teachers: } n=75 \\
\text { Parents: } n=352\end{array}$ & $\begin{array}{l}1.3 \\
2.6\end{array}$ & $\begin{array}{l}1.3 \\
1.1\end{array}$ & $\begin{array}{l}1.3 \\
4.3\end{array}$ & $\begin{array}{l}5.3 \\
7.7\end{array}$ & $\begin{array}{l}21.3 \\
22.7\end{array}$ & $\begin{array}{l}69.3 \\
61.6\end{array}$ & 2.929 & .711 \\
\hline 30 & $\begin{array}{l}\text { Teachers (parents) can } \\
\text { experience stress when } \\
\text { teaching (parenting) } \\
\text { children like Adam. } \\
\text { Teachers: } n=75 \\
\text { Parents: } n=351\end{array}$ & $\begin{array}{l}1.3 \\
1.4\end{array}$ & $\begin{array}{l}1.3 \\
2.0\end{array}$ & $\begin{array}{l}0.0 \\
3.4\end{array}$ & $\begin{array}{l}4.0 \\
6.6\end{array}$ & $\begin{array}{l}13.3 \\
17.4\end{array}$ & $\begin{array}{l}80.0 \\
69.2\end{array}$ & 4.986 & .418 \\
\hline
\end{tabular}


Table 50—Continued.

\begin{tabular}{|c|c|c|c|c|c|c|c|c|c|}
\hline Item & $\begin{array}{l}\text { Other Beliefs about ADHD } \\
\text { Issues }\end{array}$ & 1 & 2 & 3 & 4 & 5 & 6 & $\begin{array}{l}\text { Chi- } \\
\text { square }\end{array}$ & $P$ \\
\hline \multirow[t]{3}{*}{31} & $\begin{array}{l}\text { Teachers (parents) should be } \\
\text { willing to support and assist } \\
\text { children like Adam in any way } \\
\text { possible. }\end{array}$ & & & & & & & & \\
\hline & Teachers: $n=75$ & 1.3 & 0.0 & 0.0 & 9.3 & 33.3 & 56.0 & 27.382 & .000 \\
\hline & Parents: $n=350$ & 2.0 & 0.9 & 2.3 & 3.1 & 13.1 & 78.6 & & \\
\hline \multirow[t]{3}{*}{32} & $\begin{array}{l}\text { Teachers (parents) should learn } \\
\text { as much as they can about } \\
\text { ADHD. }\end{array}$ & & & & & & & & \\
\hline & Teachers: $n=75$ & 1.3 & 0.0 & 0.0 & 5.3 & 18.7 & 74.7 & 3.853 & .571 \\
\hline & Parents: $n=350$ & 2.6 & 1.1 & 1.1 & 5.7 & 12.6 & 76.9 & & \\
\hline \multirow[t]{3}{*}{33} & $\begin{array}{l}\text { Teachers (parents) would } \\
\text { benefit from additional ADHD } \\
\text { training. }\end{array}$ & & & & & & & & \\
\hline & Teachers: $n=74$ & 1.4 & 0.0 & 0.0 & 4.1 & 10.8 & 83.8 & 5.117 & .402 \\
\hline & Parents: $n=348$ & 2.0 & 0.9 & 2.3 & 7.2 & 14.9 & 72.7 & & \\
\hline
\end{tabular}

scores show teachers $(m=5.52)$ and parents $(m=5.32)$ moderately agreed with the statement. See Tables 50 and 51.

Percentage results show most teachers (80\%) and fewer parents (69.2\%) strongly agreed that teachers (parents) can experience stress when teaching (parenting) children like Adam (item 30). Mean scores show teachers $(m=5.67)$ and parents $(m=5.44)$ moderately agreed with the statement with teachers' score approaching strong agreement towards the statement.

Percentage results show more than half of teachers (56\%) and almost $80 \%$ of parents $(78.6 \%)$ strongly agreed that teachers (parents) should be willing to support and assist children like Adam in any way possible (item 31). Mean scores show teachers ( $m=$ 5.41) and parents $(m=5.6)$ moderately agreed with the statement. 
Table 51

Teachers' and Parents' Other Beliefs About ADHD by Mean and Standard Deviation

Item Other Beliefs about ADHD Teachers Parents
Issues

24 At times it is difficult to work effectively with $\quad \begin{array}{llllll}75 & 5.08 & 1.33 & 350 & 4.85 & 1.30\end{array}$ children like Adam.

25 Children like Adam need to try harder in $\quad \begin{array}{llllll}74 & 3.38 & 1.38 & 345 & 3.23 & 1.62\end{array}$ school.

26 Other children in the classroom suffer the most $\quad \begin{array}{llllll}73 & 3.64 & 1.32 & 350 & 3.69 & 1.59\end{array}$ because Adam is in the classroom.

28 It is important to communicate and/or

$\begin{array}{llllll}75 & 5.61 & 0.79 & 350 & 5.41 & 1.02\end{array}$ collaborate more often with the parents (teachers) of children like Adam.

29 Children like Adam can be successful academically.

30 Teachers (parents) can experience stress when $\begin{array}{llllll}75 & 5.67 & 0.86 & 351 & 5.44 & 1.05\end{array}$ teaching (parenting) children like Adam.

$\begin{array}{llllllll}31 & \text { Teachers (parents) should be willing to support } & 75 & 5.41 & 0.84 & 350 & 5.6 & .97\end{array}$ and assist children like Adam in any way possible.

32 Teachers (parents) should learn as much as they $\begin{array}{lllllll}75 & 5.64 & 0.78 & 350 & 5.55 & 1.04\end{array}$ can about ADHD.

33 Teachers (parents) would benefit from $\begin{array}{llllll}74 & 5.74 & 0.74 & 348 & 5.50 & 1.02\end{array}$ additional ADHD training.

Note. Disagree scores range from 1 (strongly disagree), 2 (moderately disagree) \& 3 (slightly disagree); agree scores range from 4 (slightly agree), 5 (moderately agree) $\& 6$ (strongly agree).

A chi-square goodness-of-fit test comparing the frequency of responses between teachers and parents found a significant difference $\left(\chi^{2}(1)=27.382, p<.001\right)$ between the two groups on the statement. This indicates that the pattern of responses was significantly different between teachers and parents on this statement. However, eta 
squared $\left(n^{2}=.005\right)$ represents a small effect size, indicating a low practical meaningfulness of the difference between teachers' and parents' percentages.

Percentage results show about three-fourths of both teachers (74.7\%) and parents (76.9\%) strongly agreed that teachers (parents) should learn as much as they can about ADHD (item 32). Mean scores show teachers $(m=5.64)$ and parents $(m=5.55)$ moderately agreed with the statement with beliefs approaching strong belief.

Similarly, percentage results show most teachers $(83.8 \%)$ and $72.7 \%$ of parents strongly agreed that teachers (parents) would benefit from additional ADHD training (item 33). Mean scores show teachers $(m=5.74)$ and parents $(m=5.50)$ moderately agreed with the statement, although agreement approached strong agreement.

There were no significant differences found between the pattern of responses for teachers' and parents' percentages in this section except for item 31. Teachers moderately agreed, whereas parents strongly agreed that children like Adam should be supported and assisted in any way possible. Table 50 summarizes chi-square results. There were no significant differences found between teachers' and parents' mean scores in this section. Table 52 summarizes ANOVA results.

In summary, teachers agreed more strongly than parents that it is difficult to work effectively with children like Adam. However, teachers and parents have strong agreement towards six of the nine statements. Mean scores show that teachers and parents moderately agree with six of the nine statements whereas the remaining two statements show slight agreement. 
Table 52

ANOVA Summary Table for Mean Scores

\begin{tabular}{ccccc}
\hline Item & $D f$ & $M S$ & $F$ & $P$ \\
\hline 24 & $1 / 424$ & 3.308 & 1.931 & .165 \\
25 & $1 / 418$ & 1.256 & 0.503 & .479 \\
26 & $1 / 422$ & 0.121 & 0.051 & .822 \\
28 & $1 / 424$ & 2.518 & 2.594 & .108 \\
29 & $1 / 426$ & 2.518 & 2.086 & .149 \\
30 & $1 / 425$ & 3.130 & 2.995 & .084 \\
31 & $1 / 424$ & 2.219 & 2.457 & .118 \\
32 & $1 / 424$ & 0.485 & 0.484 & .487 \\
33 & $1 / 421$ & 0.042 & 0.029 & .864 \\
\hline
\end{tabular}

Null Hypothesis 1 was retained since there were only 6 out of 22 significant differences in the individual knowledge items of ADHD between regular education teachers and parents of children in parochial schools.

Null Hypothesis 2 was retained since there were only 16 out of 43 significant differences in belief about ADHD between regular education teachers and parents of children in parochial schools on individual items.

\section{Analysis of Research Question 5}

Question 5: Is there a difference in the overall knowledge of ADHD between regular education teachers and parents of children in parochial schools?

Null Hypothesis 3: There is no significant difference in the overall knowledge of ADHD between regular education teachers and parents of children in parochial schools. This hypothesis was tested using one-way ANOVA. 


\section{Overall Knowledge of ADHD Between Teachers and Parents}

There were 22 questions in the knowledge section; therefore, a maximum raw score of $22(100 \%)$ was possible for both teachers and parents. Nonetheless, regular education teachers' correct scores ranged from $3(13.6 \%)$ to $18(81.82 \%)$ and parents' correct scores ranged from 0 to $19(86.36 \%)$. The variable, overall knowledge regarding ADHD, was normally distributed for both teachers and parents.

A one-way ANOVA was conducted comparing the overall knowledge regarding ADHD between regular education teachers and parents of children in parochial schools. A significant difference was found $\left(F_{(1,439)}=9.910, p<.01\right)$ between the overall knowledge regarding ADHD between the teachers and parents. Table 53 summarizes the ANOVA results. However, eta squared $\left(\eta^{2}=0.022\right)$ was a small effect size, indicating a low practical meaningfulness of the mean difference between teachers and parents. Therefore, knowing whether one is a teacher or a parent does not provide much valuable information in determining the level of knowledge expected based on the group.

Teachers $(m=53.6, S D=14.25)$ scored significantly higher than parents ( $m=46.38, S D=18.88)$ on overall ADHD knowledge, indicating teachers have significantly more knowledge than do parents about ADHD (see Table 54). The standard deviations suggested a higher degree of consensus among teachers' responses as compared to parents' responses. Nonetheless, both teachers and parents have inadequate knowledge about ADHD as evidenced by their mean scores of less than $80 \%$ on overall knowledge regarding ADHD. See Table 54. 
Table 53

Teachers' and Parents' Overall Knowledge Regarding ADHD

\begin{tabular}{lrrrrrc} 
& Sum of Squares & $d f$ & Mean Square & $F$ & Sig. & $\eta^{2}$ \\
\hline Between Groups & 3273.131 & 1 & 3272.131 & 9.910 & .002 & .022 \\
Within Groups & 144951.009 & 439 & 330.185 & & & \\
\hline Total & 148223.140 & 440 & & & & \\
\hline
\end{tabular}

Table 54

Overall Knowledge Regarding ADHD Group Statistics

\begin{tabular}{lrccc}
\hline & \multicolumn{1}{c}{$N$} & Mean & $S D$ & $S E$ \\
\hline Teacher & 76 & 53.5885 & 14.24531 & 1.63405 \\
Parent & 365 & 46.3761 & 18.87869 & 0.98816 \\
\hline Total & 441 & 47.6190 & 18.35404 & 0.87400 \\
\hline
\end{tabular}

Null Hypothesis 3 was rejected since there is a significant difference on overall ADHD knowledge between teachers and parents.

\section{Analysis of Research Questions 6 and 7}

CATREG was used to test hypotheses 4 and 5 to answer questions 6 and 7. The exclusion of missing data was the default setting of optimal scaling, and because of the rule of excluding cases with $15 \%$ or more of missing data in the knowledge section, this default setting was not altered (George \& Mallery, 2006). Thus, cases that had missing data were excluded from the analysis leaving only valid active cases.

Multicollinearity or high intercorrelation between independent variables can be problematic for regression analysis because it can cause invalid results for individual predictors, which are highly correlated. SPSS remedies this problem by producing a 
tolerance factor statistic. Tolerance reflects whether independent variables are linearly related to each other. When the tolerance of a predictor is .01 or less, multicollinearity is problematic for that particular variable or variables; however, when tolerance values near 1 , multicollinearity is not problematic. All of the predictor variables used in the categorical regression model for this study had tolerances that far exceeded .01, ranging from .199 to .998 before transformation and .199 to .988 after transformation; therefore, multicollinearity was not a problem for the analysis.

\section{Research Question 6}

Question 6: Do demographic variables (gender, race, conference, grade level taught, teaching experience, and education level), exposure to information about ADHD variables (books read about ADHD, articles read about ADHD, videos viewed about ADHD, instruction about ADHD in teacher training, training about ADHD after beginning teaching, graduate courses pertaining to ADHD), and experience with ADHD variables (former and current students with ADHD, former and current students thought to have ADHD, acquaintances outside of school with ADHD) predict the overall knowledge regarding ADHD of regular education teachers of children in parochial schools?

Null Hypothesis 4a: None of the following demographic variables predicts the overall knowledge regarding ADHD of teachers of children in parochial schools: gender, race, teaching experience, education level, conference, grade level taught, and teacher certification. This hypothesis was tested using CATREG.

A significant regression equation was found $\left(F_{(11,54)}=2.462 ; p<.05\right)$ with an $R^{2}$ of .334 and adjusted $R^{2}$ of .198 which, indicates that $33 \%$ and almost $20 \%$ respectively of 
the variance in overall knowledge of ADHD was explained by the demographic variables. The adjusted $R^{2}$ is the preferred goodness-of-fit of the regression model to the sample and the population due to the number of independent variables in the model; therefore, the effect size is medium and may have some practical meaningfulness for the sample and the population.

Pratt's measure of relative importance indicated the variable Conference $($ Importance $=.305)$ contributes the most to the variance of the overall knowledge of ADHD followed by Race $($ Importance $=.282)$, Grade Taught $($ Importance $=.191)$, and finally Years of Teaching Experience (Importance $=.183$ ), thus accounting for $96 \%$ of the importance for this combination of predictors. The remaining variables contributed much less to the regression model. Consequently, null hypothesis $4 \mathrm{a}$ was rejected and the research hypothesis retained. See Table 55.

Table 55

Correlations, Coefficients, and Importance of Demographic Variable Contributors to Teachers' Overall Knowledge Regarding ADHD (CATREG)

\begin{tabular}{|c|c|c|c|c|c|}
\hline \multirow[t]{2}{*}{ Variable } & \multirow{2}{*}{$\begin{array}{c}\text { Standardized } \\
\text { Coefficient Beta }\end{array}$} & \multicolumn{3}{|c|}{ Correlations } & \multirow[b]{2}{*}{ Importance } \\
\hline & & Zero-Order & Partial & Part & \\
\hline Gender & .040 & -.041 & .044 & .036 & -.005 \\
\hline $\begin{array}{l}\text { Teacher Education } \\
\text { Level }\end{array}$ & .065 & .220 & .068 & .055 & .043 \\
\hline $\begin{array}{l}\text { Years of Teaching } \\
\text { Experience }\end{array}$ & .218 & .281 & .221 & .185 & .183 \\
\hline Race & .305 & .308 & .333 & .288 & .282 \\
\hline Conference & .356 & .287 & .379 & .335 & .305 \\
\hline Teacher Certification & .017 & .021 & .015 & .012 & .001 \\
\hline Grade/s Taught & .334 & .191 & .301 & .258 & .191 \\
\hline
\end{tabular}


Null Hypothesis 4b: Exposure to information about ADHD by one or more of the following variables predicts the overall knowledge regarding ADHD of regular education teachers of children in parochial schools: books read about ADHD, articles read about ADHD, videos viewed about ADHD, instruction about ADHD in teacher training, training about ADHD after beginning teaching, and graduate courses pertaining to ADHD. This hypothesis was tested using CATREG.

A non-significant regression equation was found $\left(F_{(6,68)}=2.082 ; p>.05\right)$ with an $R^{2}$ of .155 . This suggests that a combination of the variables grouped under exposure to information about ADHD variables cannot be used to predict the overall knowledge regarding ADHD of regular education teachers of children in parochial schools. Therefore, the null hypothesis was retained and the research hypothesis rejected. Nonetheless, it was prudent to run an exploratory analysis with three variables since the correlations, coefficients, and importance results suggested they were important contributors to the regression model. See Table 56.

\section{Exploratory Analysis}

A significant regression equation was found $\left(F_{(3,71)}=3.805 ; p<.05\right)$ with an $R^{2}$ of .139 and adjusted $R^{2}$ of .102 , which indicates almost $14 \%$ and $10 \%$ respectively of the variance in overall knowledge of ADHD is explained by the exposure to information about ADHD variables. The adjusted $R^{2}$ is the preferred goodness-of-fit of the regression model to the sample and the population due to the number of independent variables in the model; therefore, the effect size is small and may had have limited practical meaningfulness for the sample and the population. Pratt's measure of relative importance indicates Training about ADHD after Beginning Teaching $($ Importance $=.514)$ 
contributes the most to the variance of the overall knowledge of ADHD followed by Articles read about ADHD (Importance = .266) and finally Books read about ADHD $($ Importance $=.220)$. See Table 57.

Table 56

Correlations, Coefficients, and Importance of Exposure to Information About ADHD Variable Contributors to Teachers' Overall Knowledge Regarding ADHD (CATREG)

\begin{tabular}{|c|c|c|c|c|c|}
\hline \multirow[t]{2}{*}{ Variable } & \multirow{2}{*}{$\begin{array}{l}\text { Standardized } \\
\text { Coefficient Beta }\end{array}$} & \multicolumn{3}{|c|}{ Correlations } & \multirow[b]{2}{*}{ Importance } \\
\hline & & Zero-Order & Partial & Part & \\
\hline Graduate Courses & .087 & .156 & .090 & .083 & .087 \\
\hline Articles Read about ADHD & .175 & .244 & .158 & .147 & .275 \\
\hline Books Read about ADHD & .103 & .234 & .093 & .086 & .156 \\
\hline $\begin{array}{l}\text { Instruction about ADHD } \\
\text { in Teacher Training }\end{array}$ & -.033 & -.037 & -.034 & -.031 & .088 \\
\hline $\begin{array}{l}\text { Training about ADHD } \\
\text { after Beginning Teaching }\end{array}$ & .274 & .284 & .264 & .252 & .501 \\
\hline $\begin{array}{l}\text { Videos Viewed about } \\
\text { ADHD }\end{array}$ & -.102 & .043 & -.094 & -.087 & -.028 \\
\hline
\end{tabular}

Table 57

Correlations, Coefficients, and Importance of Three Exposures to Information About ADHD Variable Contributors to Teachers' Overall Knowledge Regarding ADHD (CATREG)

\begin{tabular}{lccccc}
\hline \multicolumn{1}{c}{ Variable } & $\begin{array}{c}\text { Standardized } \\
\text { Coefficient Beta }\end{array}$ & \multicolumn{3}{c}{ Correlations } & \\
\cline { 3 - 5 } & Zero-Order & Partial & Part & Importance \\
\hline Articles Read about ADHD & .151 & .244 & .139 & .131 & .266 \\
Books Read about ADHD & .130 & .234 & .120 & .112 & .220 \\
$\begin{array}{l}\text { Training about ADHD after } \\
\text { beginning teaching }\end{array}$ & .251 & .284 & .259 & .249 & .514 \\
$\begin{array}{l}\text { Note. Dependent Variable: Overall Knowledge Regarding ADHD. Multiple } R=.372 ; R^{2}=.139 ; \text { Adjusted } R^{2}=.102 ; F=3.805 ; \text { Sig. }= \\
\text { 014. }\end{array}$
\end{tabular}


Hypothesis 4c: Experience with ADHD by one or more of the following variables predicts the overall knowledge regarding ADHD of RE teachers of children in parochial schools: former and current students with ADHD, former and current students thought to have ADHD, acquaintances outside of school with ADHD. This hypothesis was tested using CATREG.

A significant regression equation was found $\left(F_{(3,68)}=8.826 ; p<.001\right)$ with an $R^{2}$ of .277 and adjusted $R^{2}$ of .246 , which indicates almost $28 \%$ and almost $25 \%$ respectively of the variance in overall knowledge of ADHD is explained by the experience with ADHD variables. The adjusted $R^{2}$ is the preferred goodness-of-fit of the regression model to the sample and the population due to the number of independent variables in the model; therefore, the effect size is medium and may have some practical meaningfulness for the sample and the population.

Pratt's measure of relative importance indicates Acquaintances Outside of School with $A D H D$ (Importance $=.653)$ contributes the most to the variance of the overall knowledge of ADHD followed by Former and Current Students Thought to Have ADHD (Importance $=.322)$. The remaining variable had low importance in the regression model. Consequently, null hypothesis $4 \mathrm{c}$ was rejected and the research hypothesis retained. See Table 58

\section{Research Question 7}

Question 7: Do demographic variables (gender, race, education level, conference, marital status), exposure to information about ADHD variables (books read about ADHD, articles read about ADHD, videos viewed about ADHD, lectures attended about 
ADHD and belonged to support group for ADHD) and experience with ADHD variables (family member with ADHD, family member evaluated for ADHD, family member treated for ADHD, acquaintances outside of home with ADHD) predict the overall knowledge regarding ADHD of parents of children in parochial schools?

Null Hypothesis 5a: None of the following demographic variables predicts the overall knowledge regarding ADHD of parents of children in parochial schools: gender, race, education level, marital status, and conference. This hypothesis was tested using CATREG.

The regression equation was not significant $\left(F_{(9,341)}=1.421 ; \mathrm{p}>.05\right)$ with an $R^{2}$ of .036. The combination of the variables grouped under demographics cannot be used to predict the overall knowledge regarding ADHD of parents of children in parochial schools. These findings did not warrant an exploratory analysis. Consequently, null hypothesis 5a was retained and the research hypothesis rejected. Table 59 summarizes the categorical regression results.

\section{Table 58}

Correlations, Coefficients, and Importance of Experience With ADHD Variable Contributors to Teachers' Overall Knowledge Regarding ADHD (CATREG)

\begin{tabular}{|c|c|c|c|c|c|}
\hline \multirow[t]{2}{*}{ Variable } & \multirow{2}{*}{$\begin{array}{c}\text { Standardized } \\
\text { Coefficient Beta }\end{array}$} & \multicolumn{3}{|c|}{ Correlations } & \multirow[b]{2}{*}{ Importance } \\
\hline & & Zero-Order & Partial & Part & \\
\hline $\begin{array}{l}\text { Former and current } \\
\text { children with ADHD }\end{array}$ & .083 & .086 & .097 & .083 & .026 \\
\hline $\begin{array}{l}\text { Former and current } \\
\text { children thought to have } \\
\text { ADHD }\end{array}$ & .263 & .339 & .290 & .258 & .322 \\
\hline $\begin{array}{l}\text { Acquaintances outside of } \\
\text { school with ADHD }\end{array}$ & .401 & .451 & .420 & .394 & .653 \\
\hline
\end{tabular}


Table 59

Correlations, Coefficients, and Importance of Demographic Variable Contributors to Parents' Overall Knowledge Regarding ADHD (CATREG)

\begin{tabular}{lccccc}
\hline \multirow{2}{*}{ Variable } & $\begin{array}{c}\text { Standardized } \\
\text { Coefficient Beta }\end{array}$ & \multicolumn{3}{c}{ Correlations } & \\
\cline { 3 - 5 } Gender & .032 & Zero-Order & Partial & Part & Importance \\
Race & .108 & .033 & .032 & .032 & .029 \\
Conference & .088 & .149 & .093 & .091 & .483 \\
Education Level & -.032 & -.055 & -.032 & -.031 & .048 \\
Marital Status & .051 & .056 & .051 & .050 & .078 \\
\hline $\begin{array}{l}\text { Note. Dependent Variable: Overall Knowledge Regarding ADHD. Multiple } R=.190 ; R^{2}=.036 ; \text { Adjusted } R^{2}=.011 ; F=1.421 ; \text { Sig. } \\
=.177 .\end{array}$
\end{tabular}

Null Hypothesis 5b: Exposure to information about ADHD by one or more of the following variables predicts the overall knowledge regarding ADHD of parents of children in parochial schools: books read about ADHD, articles read about ADHD, videos viewed about ADHD, lectures attended about ADHD, and belonged to support group for ADHD. This hypothesis was tested using CATREG.

A significant regression equation was found $\left(F_{(9,344)}=13.512 ; p<.001\right)$ with an $R^{2}$ of .261 and adjusted $R^{2}$ of .242 , which indicates $26 \%$ and $24 \%$ respectively of the variance in overall knowledge of ADHD are explained by the predictor variable model. The adjusted $R^{2}$ is the preferred goodness-of-fit of the regression model to the sample and the population due to the number of independent variables in the model; therefore, the effect size is medium and may have some practical meaningfulness for the sample and the population.

Pratt's measure of relative importance indicates Articles Read about ADHD (Importance $=.606)$ contributes the most to the variance of the overall knowledge 
regarding ADHD. The remaining variables Lectures Attended about ADHD (Importance $=.174)$ and Videos Viewed about ADHD (Importance $=.122)$ contribute much less to the variance, thus they are less important to the regression model. Nonetheless, together these three variables account for $89 \%$ of the importance for this combination of predictors. The remaining variables show low importance in predicting the overall knowledge of ADHD of parents of children in parochial schools. Consequently, null hypothesis $5 \mathrm{~b}$ was rejected and the research hypothesis retained. See Table 60.

Table 60

Correlations, Coefficients, and Importance of Exposure to Information About ADHD Variable Contributors to Parents' Overall Knowledge Regarding ADHD

\begin{tabular}{|c|c|c|c|c|c|}
\hline \multirow[t]{2}{*}{ Variable } & \multirow{2}{*}{$\begin{array}{c}\text { Standardized } \\
\text { Coefficient Beta }\end{array}$} & \multicolumn{3}{|c|}{ Correlations } & \multirow[b]{2}{*}{ Importance } \\
\hline & & Zero-Order & Partial & Part & \\
\hline $\begin{array}{l}\text { Lectures Attended about } \\
\text { ADHD }\end{array}$ & .125 & .363 & .166 & .100 & .174 \\
\hline Articles Read about ADHD & .337 & .470 & .310 & .280 & .606 \\
\hline Books Read about ADHD & .092 & .286 & .091 & .078 & .101 \\
\hline $\begin{array}{l}\text { Belonged to Support Group } \\
\text { for ADHD }\end{array}$ & .040 & -.012 & .045 & .039 & -.002 \\
\hline Videos Viewed about ADHD & .099 & .321 & .099 & .085 & .122 \\
\hline
\end{tabular}

Null Hypothesis 5c: Experience with ADHD by one or more of the following variables predicts the overall knowledge regarding ADHD of parents of children in parochial schools: family member with ADHD, family member evaluated for ADHD, family member treated for ADHD, and acquaintances outside of home with ADHD. This hypothesis was tested using CATREG. 
A significant regression equation was found $\left(F_{(4,347)}=12.171 ; p<.001\right)$ with an $R^{2}$ of .123 and adjusted $R^{2}$ of .113 , which indicates $12 \%$ and $11 \%$ respectively of the variance in overall knowledge of ADHD are explained by the predictor variable model. The adjusted $R^{2}$ is the preferred goodness-of-fit of the regression model to the sample and the population due to the number of independent variables in the model; therefore, the effect size is small and may have limited practical meaningfulness for the sample and for the population.

Pratt's measure of relative importance indicates Acquaintances Outside of Home with $A D H D($ Importance $=.874)$ contributes the most to the variance of the overall ADHD. The remaining three variables show low importance in predicting the overall knowledge of ADHD of parents of children in parochial schools. Consequently, null hypothesis 5c was rejected and the research hypothesis retained. See Table 61.

Table 61

Correlations, Coefficients, and Importance of Experience With ADHD Variable Contributors to Parents' Overall Knowledge Regarding ADHD (CATREG)

\begin{tabular}{lccccc}
\hline \multicolumn{1}{c}{ Variable } & $\begin{array}{c}\text { Standardized } \\
\text { Coefficient Beta }\end{array}$ & \multicolumn{3}{c}{ Correlations } & \\
\cline { 3 - 4 } & .048 & .143 & .029 & .027 & .055 \\
\hline $\begin{array}{l}\text { Family member evaluated } \\
\text { for ADHD }\end{array}$ & & & & & \\
$\begin{array}{l}\text { Family member identified } \\
\text { with ADHD }\end{array}$ & .055 & .153 & .026 & .025 & .069 \\
$\begin{array}{l}\text { Acquaintances outside of } \\
\text { home with ADHD }\end{array}$ & .319 & .337 & .317 & .313 & .874 \\
$\begin{array}{l}\text { Family Member Treated for } \\
\text { ADHD }\end{array}$ & .001 & -.138 & .000 & .000 & .001 \\
\hline
\end{tabular}
Note. Dependent Variable: Overall Knowledge Regarding ADHD. Multiple $R=.351 ; R^{2}=.123$; Adjusted $R^{2}=.113 ; \mathrm{F}=12.171 ;$ Sig. $=.000$. 
In summary, demographic variables (conference, race, grade taught and years of teaching experience) and experience with ADHD variables (acquaintances outside of school with ADHD and former and current students they thought had ADHD) contributed to the overall knowledge regarding ADHD of regular education teachers of children in parochial schools. An exploratory analysis suggested that exposure to information about ADHD variables (training about ADHD since beginning teaching, articles and books read about ADHD) possibly contribute to the overall knowledge regarding ADHD of regular education teachers of children in parochial schools.

Exposure to information about ADHD variables (articles read about ADHD, lectures about ADHD attended, and videos about ADHD viewed) and experience with ADHD variables (acquaintances outside of home with ADHD) contribute to the overall knowledge regarding ADHD of parents of children in parochial schools.

\section{Summary}

Five sections of knowledge and beliefs about ADHD were examined in the data analysis: causes of ADHD; symptoms and characteristics of ADHD; intervention/treatment options of ADHD; general information of ADHD, and other issues about ADHD. Results show teachers and parents have similar knowledge and beliefs regarding ADHD. They have inadequate knowledge about most areas of ADHD, although they do have adequate knowledge about certain primary symptoms and nonsymptoms. Teachers and parents have similar beliefs about areas of ADHD although there are significant differences between the beliefs of teachers and parents concerning stimulant medication, intervention/treatment options, and the willingness to support and assist children with ADHD. 
Null Hypotheses 1 and 2 were retained for there were few significant differences between the knowledge and beliefs regarding ADHD of regular education teachers and parents of children in parochial schools. Null Hypothesis 3 was rejected because regular education teachers have significantly higher overall knowledge than parents.

Null Hypotheses 4a and $\mathrm{c}$ were rejected because variables grouped under demographics and experience with ADHD contributes to the overall knowledge regarding ADHD of regular education teachers of children in parochial schools. The effect sizes were medium, indicating there is some confidence that the findings have practical meaningfulness for the sample and population. Null Hypothesis $4 \mathrm{~b}$ was retained because variables grouped under exposure to information about ADHD do not contribute to the overall knowledge regarding ADHD of these teachers. However, an exploratory analysis suggested that a combination of three variables grouped under exposures to information about ADHD contributed to the knowledge of teachers in this study. The effect size was small, indicating there is limited confidence that the findings have practical meaningfulness for the sample and for the population.

Null Hypothesis 5a was retained because variables grouped under demographics were not able to predict the overall knowledge regarding ADHD of parents of children in parochial schools. Null Hypotheses $5 \mathrm{~b}$ and $\mathrm{c}$ were rejected because variables grouped under exposure to information about ADHD and a variable grouped under experience with ADHD contributed to the overall knowledge regarding ADHD of parents of children in parochial schools. The effect size was medium for $5 \mathrm{~b}$, indicating there is some confidence and small for $5 \mathrm{c}$ indicating there is limited confidence that the finding has practical meaningfulness for the sample and the population. 


\section{CHAPTER 5}

\section{DISCUSSION}

\section{Introduction}

This study utilized a survey research designed to investigate the knowledge and beliefs of teachers and parents of children in Seventh-day Adventist schools, the second largest parochial school system in North America, concerning ADHD and issues relating to the disorder. It also investigated possible differences between the knowledge and beliefs of teachers and parents for individual knowledge and belief items and overall knowledge. Predictor variables were examined to determine if they are important contributors to the overall knowledge regarding ADHD of teachers and parents. In addition, the surveys provided demographic characteristics of the teachers and the parents. This chapter presents the summary of this study, a discussion of the findings, the importance of the study, limitations and delimitations, implications for practice, directions for future research, and conclusions.

\section{Summary of Purpose and Methodology}

The purpose of this study was to investigate the knowledge and beliefs of regular education teachers and parents of children in SDA parochial schools regarding Attention Deficit Hyperactivity Disorder. The convenience sample from the Atlantic Union Conference consisted of 232 teachers and approximately 1,800 parents. Participants in 
the study included 76 teachers $(31.9 \%$ of the sample) and 373 parents (18.6\% of the number of surveys sent out) from five school districts in the AU: Bermuda, Greater New York, New York, Northern New England, and Southern New England.

Surveys in the form of a questionnaire were used to collect the data for the study. The surveys were segmented into four sections: demographic information, experience with/exposure to ADHD, knowledge and beliefs about ADHD, and beliefs about ADHD issues. There were 29 true/false/don't know questions in the knowledge and beliefs section, 36 questions with a Likert-item format in the beliefs section, 9 multiple- choice questions in the experience with/exposure to ADHD section, and 7 questions for teachers and 5 questions for parents in the demographic section.

This study attempted to find out what regular education teachers and parents of children in parochial schools know and believe about ADHD and if there were differences between their knowledge and beliefs on individual items. It also attempted to find out if there was a difference between the overall knowledge regarding ADHD of teachers and parents. Finally, the study attempted to find out if demographic variables, exposure to information about ADHD variables, and experience with ADHD variables contribute to the overall knowledge regarding ADHD of regular education teachers and parents of children in parochial schools?

Statistical analysis of the data was conducted using SPSS version 16.0. Descriptive statistics was used to answer questions 1 and 2, chi-square and one-way ANOVA was used to test null hypotheses 1 and 2 in order to answer questions 3 and 4, one-way ANOVA was used to test null hypotheses 3 to answer question 5, and CATREG was used to test null hypotheses $4 \mathrm{a}-\mathrm{c}$ and $5 \mathrm{a}-\mathrm{c}$ to answer questions 6 and 7. 


\section{Summary of Major Findings}

\section{Demographic Information}

In terms of gender, teachers in the study were predominantly female (80\%), which was consistent with past studies. In terms of race, education level, grade taught, teaching experience, and conference, $46 \%$ were Caucasian, $43 \%$ had bachelor degrees, $55 \%$ had graduate degrees, $67 \%$ had early childhood or elementary education certification, $45 \%$ taught in multi-grade settings or in multiple grades, $49 \%$ worked in New England, and they had an average of $15.6 \%$ years of teaching experience. Almost half of parents (48\%) were Black or African America, 46\% sent their children to New York schools, $42 \%$ held bachelor degrees, $38 \%$ held graduate degrees, and $75 \%$ were married.

\section{Exposure to Information About ADHD}

The majority of teachers (96\%) had read at least one article about ADHD, 58\% had read at least one book, $82 \%$ had viewed at least one video about ADHD, $82 \%$ had not taken any graduate course pertaining to $\mathrm{ADHD}, 70 \%$ had not received any training about ADHD in teacher training, and 53\% had not received any training about ADHD since beginning teaching. More than two-thirds of parents $(66 \%)$ had not attended any lectures about ADHD nor read any books about ADHD (68\%), although 71\% had read articles about ADHD and $81 \%$ had viewed videos about ADHD. The majority of parents (95\%) had not belonged to a support group for ADHD.

\section{Experience With ADHD}

In terms of experience with ADHD, $76 \%$ of teachers had former and current students with ADHD, $88 \%$ had former and current students thought to have ADHD, and 
75\% had acquaintances outside of school with ADHD. Most parents (76\%) did not have a family member evaluated for ADHD, identified with ADHD (81\%), or treated for ADHD (82\%), although 64\% had acquaintances outside of the home with ADHD.

\section{Questions and Null Hypotheses}

Questions 1 and 2 investigated what teachers and parents of children in parochial schools know and believe about ADHD by examining five sections: symptoms and characteristics of ADHD, general information about ADHD, causes of ADHD, intervention/treatment options of ADHD, and other issues regarding ADHD. Findings suggest teachers and parents have similar knowledge and beliefs regarding symptoms and characteristics of ADHD, general information about ADHD, and causes of ADHD. They have inadequate knowledge about most of the ADHD issues, although they have adequate knowledge about some of the symptoms. Teachers and parents have similar beliefs about most issues regarding ADHD, although there are significant differences between the beliefs of teachers and parents concerning stimulant medication, interventions, and support and assistance of children with ADHD.

Null hypotheses 1 and 2 were retained because on individual items there were few significant differences between the knowledge and beliefs of regular education teachers and parents of children in parochial schools. Null hypothesis 3 was rejected since regular education teachers have significantly higher overall knowledge than do parents regarding ADHD. Null hypotheses $4 \mathrm{a}$ and $4 \mathrm{c}$ were rejected since demographic variables and experience with ADHD variables were important contributors to the overall knowledge regarding ADHD of regular education teachers of children in parochial schools. Null 
hypothesis $4 \mathrm{~b}$ was retained since variables grouped under exposure to information about ADHD do not contribute to teachers' greater knowledge regarding ADHD. However, an exploratory analysis suggests that three variables grouped under exposures to information about ADHD could possibly contribute to teachers' overall knowledge. Null hypotheses 5a was retained since demographic variables do not contribute to the overall knowledge regarding ADHD of parents of children in parochial schools. Null hypotheses $5 \mathrm{~b}$ and $5 \mathrm{c}$ were rejected since variables grouped under exposure to information about ADHD and variables grouped under experience with ADHD were important contributors to the overall knowledge regarding ADHD of parents of children in parochial schools.

\section{Discussion of Major Findings}

\section{Adequate Knowledge Versus Inadequate Knowledge Regarding ADHD}

This study analyzed what regular education teachers and parents of children in parochial schools know about ADHD. This analysis examined their knowledge about symptoms and characteristics, general information about ADHD, causes, and intervention/treatment options of ADHD and overall knowledge.

The information for this discussion comes from three analyses: the item analysis, the chi-square analysis, and the one-way ANOVA. For the purposes of this study, knowledge is considered to be adequate if $80 \%$ or higher of the group of teachers or parents answered the knowledge statements correctly. An average score of $80 \%$ or higher was considered adequate for the overall knowledge of participants. See chapter 3 , for a discussion of this criteria. For the purposes of this study, inadequate knowledge was 
conceptualized as less than $80 \%$ of participants who correctly answered the individual knowledge items or received an overall knowledge score below $80 \%$.

Both parents and teachers have inadequate knowledge regarding ADHD, which is reflected in their overall knowledge score of 54\% (teachers) and 46\% (parents). This same picture is gleaned by an examination of the item analysis where only four of the symptom items and two intervention items are rated as areas of strong knowledge for teachers. All other items are rated as medium (11 items) and weak (5 items). With 16 of the 22 items falling in the medium and weak areas, it is clear that there is inadequate knowledge. It must, however, be noted that most items (11 items) are rated as medium knowledge and strong (6 items); therefore, teachers do have some knowledge of ADHD but probably not enough to be very helpful to children with the disorder. The same items that were weak for teachers are weak for parents and all other items were rated as medium except 1 symptom item, which was rated as strong. Parents certainly do not have enough information to be very helpful to children with ADHD with whom they come in contact. Two of the five items where there is a significant difference between teachers and parents are in the area of symptoms where teachers had strong (adequate) knowledge, but parents had only medium knowledge. One of the other two items where teachers and parents show significant differences is in the area of knowledge about interventions and the other is in general information. Because significant differences are evident on only 5 of 22 knowledge items, it is difficult to make a case that there was a meaningful overall difference in knowledge between the two groups.

Although the statistical analysis shows that teachers had significantly $(p<.01)$ greater knowledge than parents, the effect size was small $\left(\eta^{2}=0.022\right)$, which supported 
the small effect size $\left(\eta^{2}=0.04\right)$ of West et al. $(2005)$, thus indicating that this difference is not very meaningful. Teachers also had greater knowledge than parents regarding some individual knowledge items. However, these statistically significant findings had small effect sizes, which indicate they have limited practical importance. Teachers had more experience with ADHD than did parents, but both groups lacked training regarding ADHD, which would affect their knowledge. Teacher and parent training about ADHD would presumably include information about the symptoms and characteristics, diagnostic criteria, causes, course, outcomes, intervention/treatment options, and other pertinent information. Teachers who had engaged in training regarding ADHD had an increase in knowledge when participating in pre-and post-test studies (Barbaresi \& Olsen, 1998; Lewis, 2000). Tsai (2003) and West et al. (2005) found that teachers who participated in in-service training regarding ADHD had greater knowledge than those who had not. Parents who belonged to a support group for ADHD or attended information seminars about ADHD had higher scores than those who did not (West et al., 2005).

Implications of Inadequate Knowledge

By analyzing the results (see Tables 34-36, and 40) it can be noted that there are two main issues with inadequate knowledge: One is the areas where the participants just do not know the information and the other is where they actually have misinformation. In terms of "don't know" responses, symptom item 23 shows that $52.6 \%$ of teachers and $54.6 \%$ of parents responded with “don't know," which was the largest category of responses. This indicates that participants do not have incorrect knowledge-they simply did not know. On item 26, 31.6\% of teachers and $38.8 \%$ of parents responded with "don't 
know," which is similar to the frequencies with which they answered True and False for this item. On item $24,25 \%$ of teachers and $33.1 \%$ of parents did not know if both hyperactivity and inattentiveness must be present for a diagnosis of ADHD.

With regard to general information items (see Table 35), results on item 13 show that $59.2 \%$ of teachers and $52.6 \%$ of parents did not know the answer and these percentages of "don't know" responses are considerably higher than the percentage who answered correctly. In fact, participants did not generally have incorrect information (since only about $4 \%$ of both teachers and parents answered the item incorrectly); most participants simply did not have information at all. For item $19,38.7 \%$ of teachers and $38.2 \%$ of parents did not know the answer. On item $11,42.1 \%$ of parents did not know the answer, which was higher than the percentage of parents correctly answering the item (36.8\%). For item $29,42.1 \%$ of teachers and $36.4 \%$ of parents did not know the answer and these percentages were actually higher than the percentages answering the item correctly (27.6\% and $32.2 \%$ respectively). On item $25,27.6 \%$ of teachers and $38 \%$ of parents did not know the answer.

With regard to causes of ADHD (see Table 36), results on item 27 show $40 \%$ of teachers and $37.8 \%$ of parents responded with "don't know," which is similar to the frequencies with which they answered True (44\% and 35\% respectively). For item 10, $43.4 \%$ of teachers and $41.9 \%$ of parents did not know the answer, which was actually higher than the percentages answering the item correctly (6.6\% and $15.4 \%$ respectively). On item 3, 26.3\% of teachers and $28.7 \%$ of parents did not know the answer. With regard to intervention/treatment options for item $28,55.3 \%$ of teachers and $57.3 \%$ of parents 
(which is more than half) did not know the answer, which is much higher than the percentages answering the item correctly $(17.1 \%$ and $17.2 \%$ respectively).

At least four of these items $(24,26,28$, and 29) were found to be areas of weak knowledge for both teachers and parents in the item analysis. In addition, items 23,26 , 27, and 28 are typically not associated with ADHD; therefore, it is possible that participants were cautious when they responded to them.

In terms of misinformation, teachers (50\%) and parents (42.7\%) believed ADHD is inherited. As previously discussed in chapter 2, ADHD is highly heritable, but it is not inherited. The incorrect responses suggest that participants could have been confused about the meaning of "inherited" rather than a misunderstanding about how ADHD is genetically influenced. The fact that $76 \%$ of teachers and $66.5 \%$ of parents believed diet is helpful as a treatment suggests that they are misinformed. These two findings indicate areas that both teachers and parents need accurate and current information about ADHD.

Several past studies included the third option of "don't know" with their true and false formats (Liesveld, 2007; Sciutto et al., 2000; Tsai, 2003; West et al., 2005). Sciutto et al. (2000) first incorporated this option to limit guessing and differentiate between incorrect knowledge and unknown knowledge. Liesveld (2007), Sciutto et al. (2000), Tsai (2003), and West et al. (2005) cited the most common “don't know” responses in the results section of their studies; however, this study did not replicate this method. Like the current study, Liesveld (2007), Sciutto et al. (2000), and Tsai (2003) found that participants responded with "don't know" the most on general information items, whereas West et al. (2005) found that participants responded with "don't know" the most on treatment items. Since it is clear that participants in four studies responded the most 
with "don't know" about general information items, this indicates an area that should be addressed in training. Nonetheless, further studies should include the "don't know" option to determine specific areas where participants do not have knowledge regarding ADHD.

\section{Teachers of Children in Parochial Schools}

Knowledge Regarding ADHD of Teachers of Children in Parochial Schools

The finding that teachers' overall knowledge score of $53.6 \%$ is similar to the findings of West et al. (2005), Kos et al. (2004), and Liesveld (2007). This finding is lower than those of Jerome et al. (1994, 1999), Bekle (2004), Barbaresi and Olsen (1998), Ohan et al. (2008), and Lewis (2000), yet higher than those of Sciutto et al. (2000) and Tsai (2003). The overall knowledge score of the teachers in this study is not surprising since they had inadequate knowledge concerning the symptoms and characteristics, diagnostic criteria, causes, outcomes, nature, and intervention/treatment options of ADHD.

One area that teachers had adequate knowledge (about $90 \%$ answered the item correctly) was the item about children with ADHD having difficulty sustaining attention in tasks or play activities. This supports past findings of Jerome et al. (1994, 1999); Bekle (2004); Ohan et al. (2008); Barbaresi and Olsen (1998). In contrast, they had inadequate knowledge about the salient DSM hallmark symptoms of hyperactivity and inattention, thus supporting the findings of Pentecost and Wood (2002). Surprisingly, these teachers adequately rejected symptoms that are not based on the DSM criteria pertaining to following directions and completing assignments $(91 \%)$ and that defiance 
and oppositionality are not associated with the inattention symptoms of ADHD (80\%), which supports the findings of Jerome et al. (1994, 1999), Bekle (2004), Ohan et al. (2008), and Barbaresi and Olsen (1998).

Because teachers have inadequate knowledge about most of the hallmark DSM symptoms of $\mathrm{ADHD}$, it is consistent that they also have inadequate knowledge pertaining to the diagnostic criteria. Specifically, these teachers have inadequate knowledge regarding the age of onset, the expression in more than one setting, and the presence of hyperactivity and/or inattention. Item analysis indicated teachers had weak knowledge in the areas of age of onset and hyperactivity and/or inattention. These findings support those of Ohan et al. (2008), Stormont and Stebbins (2005), and Õim (2004), which suggest the diagnostic criteria is an area of inadequate knowledge for both current and past participants. The DSM is clear that children with ADHD must show symptoms of the disorder before age 7 , that the disorder must be expressed in more than one setting, and that a child can be diagnosed with either the hyperactive/impulsive subtype, the inattention subtype, or the combined subtype (DSM-IV-TR, 2000). Teachers are often the first one to suggest to parents that their child may have ADHD and they play a crucial role before a diagnosis is made (Ghanizadeh, 2007; Snider et al., 2003); therefore, they need to have adequate knowledge about these criteria.

ADHD occurs in both girls and boys, although more boys are identified since they tend to exhibit overt symptoms, whereas girls tend to exhibit covert symptoms (Biederman et al., 2002). Teachers (57\%) in this study had inadequate knowledge of the occurrence by gender which could impact children with ADHD negatively since many teachers often underidentify girls and overidentify boys with ADHD even when both 
groups present with the same symptoms (Sciutto et al., 2004); therefore, knowledge pertaining to this issue is important for these teachers to have. This finding is lower than the findings of Jerome et al. (1994, 1999), Barbaresi and Olsen (1998), and Bekle (2004).

Children with ADHD are at risk for developing delinquency especially if they have not had their disorder managed properly and if they enter the teenage years with major issues (Boyles \& Contadino, 1999; Hann \& Borek, 2001). These teachers had inadequate knowledge concerning the high risk for teenage delinquency (45\%). This finding supports those of Jerome et al. (1994, 1999), Bekle (2004), Ghanizadeh et al. (2006), Ohan et al. (2008), and Õim (2004) suggesting this lack of knowledge is consistent across teachers in general. Even though these teachers have experience with ADHD, 72\% taught in elementary grades, which includes multiple grades; therefore, they possibly have not experienced children with ADHD as teenagers, thus they are not aware of the risk for delinquency. Regular education teachers of children in parochial schools in the $\mathrm{AU}$ who believe children are at high risk for teenage delinquency may be more motivated to take action while they are in elementary school (Ohan et al., 2008).

Teachers in this study also have inadequate knowledge about the possible causes of ADHD, specifically biological vulnerabilities and genetic inheritance. These findings are not surprising since there is confusion concerning the genetic causes of ADHD. There is sufficient evidence to support a biological component in the etiology of ADHD since the disorder is evident in families (Biederman et al., 1995; Farone et al., 1993; Farone \& Biederman, 2000), but there is no evidence to support a direct inheritance of the disorder (Joseph, 2000). The disorder is most likely caused multifactorially by both genetic and environmental factors (Joseph, 2000; Nigg, 2006; Papalia et al., 2004; Thapar et al., 
1999). These findings support past findings of Jerome et al. (1994, 1999), Bekle, (2004), Barbaresi and Olsen (1998), Kos et al. (2004); and Ohan et al. (2008).

In terms of intervention/treatment options, regular education teachers of children in parochial schools in the AU need to have knowledge of how to effectively use classroom interventions for their students with ADHD and that a multimodal approach with both educational and medication interventions is effective (DuPaul, Ervin, et al., 1998; Plumer \& Stoner, 2005). However, these teachers (79\%) have inadequate knowledge regarding one-to-one interventions and a multimodal approach with educational and medication interventions, which is lower than findings from Jerome et al. (1994, 1999), Bekle (2004), West et al. (2005), and Ohan et al. (2008). More than threefourths of teachers in this study also incorrectly believed diet can be used to treat most children with ADHD. A meta-analysis suggested that an elimination diet is not effective in treating ADHD (Kavale \& Forness, 2001), although some evidence exists that suggested diet can reduce symptoms of ADHD in some children (Bateman et al., 2004; Richardson \& Puri, 2002), but there is no evidence that it is effective in treating most children with ADHD.

It is surprising that teachers in this study do not adequately know the hallmark symptoms of ADHD since they would be observable in the classroom. More than threefourths of participants indicated they had experience with ADHD either in the form of former and current students with ADHD (76\%) or thought to have ADHD (88\%) and acquaintances outside of school with ADHD (75\%). This indicates these teachers must have observed ADHD-like behaviors in these children since they have experience teaching them. Also, if they thought some children had ADHD but were not formally 
identified, then they must have some criteria with which to support their thoughts. However, this experience with ADHD did not seem to transfer over to their specific knowledge regarding ADHD. Even though teachers had experience with ADHD, more than two-thirds (70\%) received no training about ADHD in teacher training, 53\% had received no training about ADHD since beginning teaching, and $82 \%$ had not taken a graduate course pertaining to ADHD. Training regarding ADHD for teachers can include information concerning the history of ADHD and its prevalence, diagnostic criteria, and long-term outcomes (Barbaresi \& Olsen, 1998).

\section{Consequences of Teachers' Inadequate Knowledge Versus Adequate Knowledge for the Children They Teach}

What are the consequences of this lack of knowledge? Children with ADHD have symptoms and characteristics that can cause them to fail academically, be retained in a grade, drop out of high school, and develop at-risk delinquent behaviors (Barkley, 1998; Barkley et al., 1990; DuPaul \& Stoner, 2003; Woodward \& Fergusson, 1999), which can result in them becoming a menace to society. Since children with ADHD are encountered in every school setting, all educators, including those in parochial schools, need to have adequate knowledge about the disorder so they can support their students with ADHD (DuPaul \& Stoner, 2003; Tucker, 2001). Additionally, all references to the knowledge of ADHD that teachers in general should have also apply to the regular education teachers of children in parochial schools.

Regular education teachers of children in parochial schools should have adequate knowledge of the nature, course, causes, characteristics, diagnostic criteria, outcomes, appropriate education interventions, and stimulant medication regarding ADHD (Glass \& 
Wegar, 2001; Kasten et al., 1992; Pfiffner \& Barkley, 1998; Shapiro et al., 1996; Snider et al., 2003). This knowledge must include information about the characteristics beyond the primary symptoms, which can help them make necessary referrals and avoid the negative impact of underidentyfying or overidentifying boys and girls (Arcia et al., 2000; Sciutto et al., 2004). Inadequate knowledge about the diagnostic criteria could cause teachers to overidentify disruptive children, especially boys, and underidentify inattentive children, especially girls (Arcia et al., 2000; Glass \& Wegar, 2001; Sciutto et al., 2004).

One of the greatest barriers to providing effective services for children with ADHD and meeting their needs is the lack of knowledge and skills regarding the disorder among teachers (Reid et al., 1994). A lack of teacher knowledge about ADHD may cause stress for teachers, thus inducing a stressful classroom, which can adversely affect the performance of students with the disorder (Barbaresi \& Olsen, 1998; Barkley, 1998; Ghanizadeh et al., 2006; Tsai, 2003). Therefore, teachers of children in parochial schools need to have adequate knowledge to help them be effective in their classrooms by optimizing the best classroom strategies that are appropriate for these students, and by providing accommodations and meeting their students' needs so they can have the best outcome in the classroom and in society (Arcia et al., 2000; Bekle, 2004; DuPaul, Ervin, et al., 1998; DuPaul \& Stoner, 2003; Plumer \& Stoner, 2005; Shapiro et al., 1996).

Ohan et al. (2008) found that teachers with high knowledge (80\% and higher) about ADHD were more likely to endorse the need for assessment for the child and to seek for and/or encourage the child's parents to seek professional services than teachers with low knowledge (less than 70\%). Teachers with high knowledge were more likely to perceive the benefits of learning assistance, home-based behavioral therapy, and changes 
to the classroom than teachers with low knowledge (below 70\%). Teachers with adequate knowledge recognized that ADHD could impact the child's classroom and peer relationships. They were not confident in their ability to manage children with ADHD in the classroom. Ohan et al. (2008) also found that teachers with low knowledge believed they could effectively handle children with ADHD in the classroom in comparison to teachers with high knowledge. The authors suggest that these teachers do not understand the difficult dynamics of the disorder, whereas teachers with high knowledge have this understanding. Arcia et al. (2000) found that teachers with little understanding of ADHD lacked information on the behavioral profiles of ADHD and lacked comprehensive plans of action for classroom management. They also found that these teachers with a lack of knowledge about ADHD were not well prepared to meet the demands they faced daily from children with ADHD, lacked the ability to make referrals for special services, and do not make educational modifications. Therefore, children with ADHD are less likely to experience support and adjustment in a classroom with a teacher with low knowledge (Ohan et al., 2008).

\section{Parents of Children in Parochial Schools}

\section{Knowledge Regarding ADHD of Parents of Children in} Parochial Schools

Like teachers in this study, parents clearly have inadequate knowledge regarding ADHD as evidenced by their overall knowledge score of $46 \%$, which is lower than the parents' overall knowledge score in the study by West et al. (2005). The overall knowledge score of these parents is not surprising since they had inadequate knowledge concerning the symptoms and characteristics, diagnostic criteria, causes, outcomes, and 
intervention/treatment options of ADHD. Like the teachers in this study, parents $(87 \%)$ had only adequate knowledge about one DSM hallmark symptom of ADHD pertaining to the difficulty of sustaining attention in tasks or play activities, whereas they had inadequate knowledge about the hallmark symptoms of hyperactivity and inattention. It is not surprising that parents in this study do not adequately know the hallmark symptoms of ADHD since more than three-fourths do not have a family member who has been evaluated for $(76 \%)$ or identified $(81 \%)$ with ADHD. Like teachers in this study, they did not know enough about the diagnostic criteria of ADHD. Parents are the ones who need to agree to a referral and follow this up with a visit to the physician; therefore, they too need to have adequate knowledge about these criteria.

In terms of outcomes for children with ADHD, parents (41\%) in this study also had inadequate knowledge concerning the high risk for teenage delinquency. Parents of children in parochial schools in the AU can provide their children with house and street rules to govern their activities and provide them with the necessary compensatory skills and bypass strategies that can protect them against delinquency (Barkley, 2000; Boyles \& Contadino, 1999). In addition, parents did not know enough about the possible causes of ADHD, biological vulnerabilities, and genetic inheritance, which supports the findings of Ghanizadeh (2007) but is contrasted by the findings of S. Robin (1998) and Bussing et al. (1998). Stimulant medication is often the norm for children with ADHD, but there are non- pharmacological interventions that can be used successfully for children with ADHD (DuPaul, Ervin, et al., 1998; Hoagwood et al., 2000; Hook \& DuPaul, 1999; MTA, 1999; Plumer \& Stoner, 2005;). However, parents in this study did not know enough about effective strategies such as one-to-one interactions and a multi-modal 
approach. They also had inadequate knowledge that medication is not the only treatment for ADHD. In addition, more than two-thirds of parents in this study incorrectly believed diet can be used to treat most children with ADHD.

Parents in this study had little experience with ADHD, whereas more than twothirds $(66 \%)$ had not attended a lecture about ADHD and 95\% had not belonged to a support group for ADHD. Most parents $(82 \%)$ had no experience with a family member being treated for ADHD. Therefore, it is not surprising that these parents have inadequate knowledge about the disorder.

Consequences of Parents' Inadequate Knowledge Versus Adequate Knowledge for the Children With Whom They Come in Contact

Parents of children in parochial schools should have adequate knowledge about the etiology, symptoms, duration, diagnostic criteria, strategies, treatment options, secondary characteristics, home-based interventions, and problems associated with ADHD (Barkley, 2000; Bussing et al., 2007; Corkum et al., 1999; A.L. Robin, 1998; Rostain et al., 1992) in the event their child or a child in their care has ADHD.

Parents who are knowledgeable about ADHD support a multimodal approach to treatment and learn strategies to help their child succeed (Barkley, 2000; Hook \& DuPaul, 1999). Parents who do not have adequate knowledge of the disorder are unable to make informed decisions about treatment options, are unwilling to pursue treatment options, can become overstressed in dealing with the disorder, and are less likely to seek services from the school (Barkley, 2000; Corkum et al., 1999; Davidson \& Ford, 2002; Rostain et al., 1992). Positive relationships are fostered between parents and their child with ADHD when parents have adequate knowledge about ADHD and when they support 
their child (Boyles \& Contadino, 1999; Hurt et al., 2007). Corkum et al. (1999) found that parents who had higher knowledge about ADHD were more accepting of enrolling their children in pharmacological and nonpharmacological interventions. On the other hand, parents who had inadequate knowledge about ADHD delay having their children assessed and minimize the benefits of treatment options (Bussing et al., 2007; Ghanizadeh, 2007).

\section{Predictors of the Knowledge of Regular Education}

Teachers and Parents

Demographic variables conference (school district), race, grade taught, and teaching experience) and experience with ADHD variables (acquaintances outside of the school with ADHD, and former and current students thought to have ADHD) contributed to the knowledge regarding ADHD of regular education teachers of children in parochial schools. There are indicators that exposure to information about ADHD variables (training about ADHD since beginning teaching, and reading articles and books about ADHD) also contributed to teachers' knowledge. Exposure to information about ADHD variables (reading articles about ADHD, attending lectures about ADHD, and viewing videos about $\mathrm{ADHD}$ ) and experience with ADHD variable (acquaintances outside of the home with ADHD) contributed to the knowledge regarding ADHD of parents of children in parochial schools in the AU. It is important to note that other studies examined predictors of teachers' knowledge and found significant results; however, none combined the variables in the same categories as the current study. Liesveld (2007) combined six variables in a regression model which had a small effect size. Blume-D' Ausilio (2005) combined 12 variables in a regression model, which also had a small effect size. 


\section{Demographic Implications}

A combination of demographic variables, conference (school district), race, grade taught, and years of teaching experience is associated with teachers' knowledge of ADHD. The effect size (adjusted $R^{2}=.198$ ) for this finding was medium. Since only about $20 \%$ of the variance for teachers' knowledge can be explained by the demographic variables in the model, other variables not included in the model must explain the variation in teachers' knowledge. Conference (school district) was the most important variable in the regression model followed by race. Õim (2004) found that school location was associated with higher knowledge scores, because teachers who lived in the larger towns had more knowledge than those who lived in smaller towns. Race was the next most important variable in the regression model. Liesveld (2007) found that ethnicity was not associated with higher knowledge scores; however, $80 \%$ of her sample was Caucasian, whereas $18 \%$ was made up of African American, American Indian, Hispanic, and Asian. Conversely, less than half (46\%) of teachers in this current study were Caucasian and 34\% were African American or Black and $18 \%$ were other (Hispanic/Latino or Asian). The racial demographics of this study were quite interesting with a large Black or African American influence. This racial group includes persons of Caribbean descent, Bermudian descent, American descent, and African descent; therefore, there are possibly cultural differences represented in this one racial category. However, the regression analysis does not provide data to explain why these variables were the most important contributors to teachers' knowledge; therefore, an explanation is beyond the scope of this study and would require further exploration. 
The remaining variables in the combination model, grade taught and years of teaching experience, also contributed to teachers' knowledge regarding ADHD. The positive beta coefficients indicated that as grade taught and years of teaching experience increase, the overall knowledge regarding ADHD of teachers in this study increases. Blume-D’Ausilio (2005) found teaching position (grade taught) had an inverse relationship with knowledge of ADHD, indicating that as teaching position increased, overall knowledge about ADHD decreased. Jerome et al. (1994), Sciutto et al. (2000), and Õim (2004) found an association between years of teaching experience and teachers' knowledge about ADHD. In contrast, Kos et al. (2004), Brook et al. (2000), and Stormont and Stebbins (2005) did not find years of teaching experience was associated with higher knowledge regarding ADHD. Interestingly, Liesveld (2007) found an inverse association between teaching experience and knowledge regarding ADHD, indicating an increase in years taught meant less knowledge about ADHD. It is possible that as teachers in the current study teach in different grades and longer they will most likely encounter more students with ADHD since 76\% have experience teaching children with ADHD and $88 \%$ have experience teaching children they thought had ADHD. Thus, their teaching experience coupled with other factors may influence their knowledge regarding ADHD. A definitive explanation would require further exploration beyond the scope of the current study.

\section{Exposure to Information About ADHD}

A combination of variables grouped under exposure to information about ADHD could not be used to predict teachers' knowledge of ADHD. However, an exploratory analysis revealed three possible contributors to teachers' knowledge of ADHD: training 
about ADHD since beginning teaching, reading articles, and reading books about ADHD. Since this current study did not test a hypothesis based on this exploratory analysis, further exploration is warranted. It is sufficient to suggest that these variables possibly contribute to teachers' overall knowledge regarding ADHD and as teachers are exposed to information about ADHD via these specific variables, their knowledge of the disorder increases. Even though the finding is statistically significant, the small effect size $\left(R^{2}\right.$ of .102) suggests this finding has low importance in practical meaningfulness. Since only $10 \%$ of the variance for teachers' knowledge can be explained by the exposure to information about variables in the model, other variables not included in the model must explain the variation in teachers' knowledge. Past studies found an association between training regarding ADHD and teachers' knowledge (Barbaresi \& Olsen, 1998; Kos et al., 2004; Liesveld, 2007; Vereb \& DiPerna, 2004; West et al., 2005). Liesveld (2007) also found an association between reading articles and books about ADHD and teachers' knowledge, whereas Stormont and Stebbins (2005) and Blume-D'Ausilio (2005) did not find a relationship between reading about ADHD and knowledge.

A combination model of reading articles about ADHD, attending lectures about ADHD, and viewing videos about ADHD contributed to teachers' knowledge regarding ADHD. The medium effect size ( $R^{2}$ of .242) suggests this finding has some importance in practical meaningfulness. Since $24 \%$ of the variance for teachers' knowledge can be explained by the exposure to information about ADHD variables in the model, other variables not included in the model must explain the variation in parents' knowledge. Nonetheless, this finding suggests that parents' exposure to information about ADHD is associated with greater knowledge of the disorder. Almost three-fourths of parents (71\%) 
in this study had read at least one article about ADHD and $81 \%$ had viewed at least one video, although only $32 \%$ of parents had attended at least one lecture about ADHD. It is possible that those who read articles, attended lecture, and viewed videos about ADHD are parents of children with ADHD. In order to test this possibility, further analysis would need to be conducted. West et al. (2005) found that parents who attended lectures about ADHD had greater knowledge about ADHD.

\section{Experience With ADHD Implications}

The regression model suggests that acquaintances outside of school with ADHD and former and current students thought to have ADHD are associated with teachers' greater knowledge regarding ADHD. The medium effect size $\left(R^{2}\right.$ of .246) suggests this finding has some importance in practical meaningfulness. Since about $25 \%$ of the variance for parents' knowledge can be explained by the experience with ADHD variables in the model, other variables not included in the model must explain the variation in their knowledge. Liesveld (2007) and Blume-D'Ausilio (2005) also found an association between acquaintances with ADHD and teachers' greater knowledge of ADHD, although they included other variables in their regression model. Therefore, it is can be assumed that teachers in this study have family members or friends who either have ADHD or who have children with the disorder.

Similarly, acquaintance outside of the home with ADHD was the salient contributor to parents' overall knowledge regarding ADHD. Even though this finding is statistically significant, the small effect size (adjusted $R^{2}$ of .113) suggests it has low importance for practical meaningfulness. Since only $11 \%$ of the variance for parents' knowledge can be explained by the experience with ADHD variables in the model, other 
variables not included in the model must explain the variation in their knowledge. Threefourths of teachers reported having acquaintances outside of school with ADHD, whereas $64 \%$ of parents reported having acquaintances outside of the home. The majority of teachers $(88 \%)$ had taught children they thought had ADHD but had not been identified with the disorder. Bussing et al. (1998), Ghanizadeh et al. (2006), and Ghanizadeh (2007) found that teachers and parents in their studies received information about ADHD from friends or relatives. It is possible that the teachers and parents in this study discussed ADHD with their acquaintances, which provided them with greater knowledge about ADHD. As teachers have former and current students thought to have ADHD, their overall knowledge of ADHD increases.

\section{Beliefs Regarding ADHD}

This study analyzed what regular education teachers and parents of children in parochial schools believe about ADHD. This analysis examined their beliefs about symptoms and characteristics, general information about ADHD, causes, and intervention/treatment options of ADHD.

The information for this discussion comes from two analyses: the chi-square analysis and the one-way ANOVA. For the purposes of this study, a belief was conceptualized as information about ADHD that has not been supported by empirical evidence or diagnostic criteria. Therefore, a belief cannot be considered correct or incorrect. It was also conceptualized as a value or attitude towards ADHD that was expressed in terms of agreement or disagreement. In comparison to knowledge, beliefs can be more influential than knowledge in determining how people define problems and they strongly predict behavior (Nespor, 1987). A myth can be defined as a popular idea 
or belief that is considered to be true by a large amount of people. Second, a myth is an inaccurate or untrue belief.

Several websites and researchers listed "myth" statements pertaining to several issues of ADHD; however, many of these statements were not found to be "myths" according to empirical research and research findings discussed in chapter 2. Empirical evidence shows that ADHD is not caused by poor parenting practices and that children with ADHD do not have lower IQs than their peers. Additionally, the current study and past studies show that the majority of participants do not believe that poor parenting causes ADHD or that children with ADHD have lower IQs. Therefore, neither of these ideas can be considered myths because the majority of people have a correct understanding. More than $50 \%$ of teachers and less than $50 \%$ of parents believe ADHD can be caused by sugar or food additives, whereas more than $50 \%$ of teachers and less than $50 \%$ of parents do not believe that children outgrow ADHD. Because research has not yet definitively established the correct answers to these two issues, it cannot be determined at this time if these are myths or not.

In regard to stimulant medication, both teachers and parents tended to have negative beliefs towards this intervention option, that is, they disagreed with its use to treat ADHD. In fact, both teachers and parents believe that stimulant medication is overprescribed in the U.S. It is important to note that Seventh-day Adventists espouse a health message that generally avoids the use of stimulants such as caffeine; therefore, teachers' and parents' negative beliefs towards stimulant medication might be a reflection of this stand. Nonetheless, both teachers and parents believe that medication can be effective in improving ADHD behaviors, inattention in the classroom, and academic 
achievement in the long run, but they believe behavioral and educational interventions are more effective than medication in improving these issues of ADHD. This finding is understandable since Seventh-day Adventists are more inclined to use natural or alternative treatments rather than medication.

Both teachers and parents believe children with ADHD can be successful academically and that teachers and parents should support and assist them in any way possible. This finding is important in this parochial school setting since the SDA church has a strong education system that is not only the second largest in North America, but one which is global. This education system supports education to the highest level possible and these teachers' and parents' beliefs reflect that educational spirit of academic success. In regard to support and assistance, the SDA church is invested in its children and youth. There are programs in place that are designed to support and assist the children and youth in their growth as leaders and laypersons in the church; therefore, teachers' and parents' beliefs in this area reflects the church's commitment to nurturing its children and youth.

Since beliefs can be more influential than knowledge and can predict behavior towards those with ADHD, what teachers and parents of children in parochial schools in the AU believe about the disorder is equally as important. Therefore, the beliefs held by these teachers and parents of children in parochial schools regarding any of these issues would provide useful information for future training purposes.

\section{Beliefs of Regular Education Teachers in Parochial Schools}

In terms of the course of ADHD, more than half of teachers (55\%) do not believe children with ADHD outgrow the disorder. These findings support the findings of Jerome 
et al. (1994, 1999), Kiffer (1996), Bekle (2004), and Ohan et al. (2008). There is contradictory empirical evidence that indicates ADHD continues into adulthood (Barkley et al., 2002; Claude \& Firestone, 1995) while there is evidence to suggest that it does not continue into adulthood (Mannuzza et al., 1998). Most teachers $(83 \%)$ believed that children with ADHD do not have a lower IQ than their peers, which supports the findings of Ghanizadeh et al. (2006). This finding is not surprising since the average years of teaching experience for teachers in this study was 15.6 with $76 \%$ having taught at least one student with ADHD and $88 \%$ having taught at least one student thought to have ADHD. These experiences would have provided them with the opportunity to know the academic abilities of these students, thus leading to the majority belief that children with ADHD do not have a lower IQ than their peers.

More than half of teachers (55\%) in this study believed that ADHD can be caused by sugar or food additives, which supports the findings of Jerome et al. (1994, 1999), Bekle (2004), and Barbaresi and Olsen (1998), whereas Ohan et al. (2008) reported higher findings. In contrast, these findings do not support the findings of Kos et al. (2004), Stormont and Stebbins (2005), and Ghanizadeh et al. (2006) that indicated more teachers did not believe the issue. DiBattista and Shepherd (1993) found the majority of teachers believed sugar contributes to the behavioral problems of hyperactive children. Harley, Ray, et al. (1978), Harley, Matthews, et al. (1978), and Weiss et al. (1980) found that children were not adversely affected by food additives; however, Conners et al. (1976), Bateman et al. (2004), and Schab and Trinh (2004) found food additives can have an effect on the behaviors of some children. In regard to sugar, Milich et al. (1986), Kaplan et al. (1986), Wolraich et al. (1995), and Kinsbourne (1994) did not find evidence 
to support the idea that sugar causes ADHD. The empirical evidence shows that sugar does not cause ADHD; however, there is some evidence that food additives can affect children.

More than half of teachers in this study did not believe ADHD can be caused by poor parenting or can result from a chaotic, dysfunctional family. These findings were lower than past studies (Bekle, 2004; Jerome et al., 1994, 1999; Kos et al., 2004; Ohan et al., 2008; Sciutto et al., 2000; Stormont \& Stebbins, 2005; Williams, 1996). The majority of teachers $(84 \%)$ also believed stress and conflict in the home can cause ADHD-like behaviors. This finding supports Carlson et al. (2006) and Snider et al. (2003). Research studies found a relationship between parenting issues and family dynamics and symptoms of ADHD (Goodman \& Stevenson, 1989b; Kepley \& Ostrander, 2007; Lange et al., 2005; Pressman et al., 2006; Rielly et al., 2006). However, this relationship may be reciprocal meaning that parenting or family issues can exacerbate and maintain ADHD characteristics or ADHD behaviors can lead to these issues (Barkley, 1998; Nigg, 2006; Woodward et al., 1998).

In terms of stimulant medication as a treatment option for children with ADHD, most teachers $(89 \%)$ in this study believed too many children receive stimulant medication in the U.S. These teachers did not have positive beliefs towards stimulant medication since they believed stimulant medication was not safe or necessary to treat symptoms/behaviors of ADHD. Interestingly, the majority believed it was effective in improving disruptive, hyperactive, impulsive, attention, and academic achievement in the classroom. These findings support Carlson et al. (2006); however, other studies found 
their teachers had positive beliefs about stimulant medication (Kiffer, 1996; Snider et al., 2003).

In terms of non-pharmocological interventions, the majority of teachers in this study believed interventions such as classroom interventions, behavioral modifications, classroom modification/accommodations, or therapy should be used to improve behaviors of ADHD and/or help students succeed academically and socially in the school setting. In addition, they also believed that behavioral and educational interventions are effective in improving the symptoms of ADHD. These beliefs are confirmed by studies that found educational interventions (classroom or school-based interventions) work effectively as interventions for ADHD for improving academic goals (DuPaul \& Eckert, 1997; DuPaul, Ervin, et al., 1998; Jitendra et al., 2007; Plumer \& Stoner, 2005; Purdie et al., 2002). Behavior therapy, also called behavior modification, is also effective in treating ADHD (Purdie et al., 2002).

The majority of teachers in this study believed it is difficult to work effectively with children with ADHD and that teachers can experience stress when teaching them, but they also believed these children can be successful academically, which supports Kiffer (1996). The majority also believed they themselves would benefit from additional training regarding ADHD, which supports the beliefs of teachers in past studies (Barbaresi \& Olsen, 1998; Bekle, 2004; Jerome et al., 1994; Kos et al., 2004; Vereb \& DiPerna, 2004) and that they should learn as much as possible about ADHD. The majority of these teachers also believed teachers should be willing to support and assist children with ADHD in any way possible. 


\section{Consequences of Teachers' Beliefs for the Children They Teach}

Teachers who have inadequate knowledge about ADHD can have negative beliefs and are less likely to accommodate children with the disorder (Kiffer, 1996). It is difficult to modify negative beliefs of teachers who tend to have negative attitudes towards children with special needs (Alexandra \& Strain, 1978; Beare, 1985). Teachers who have positive attitudes in general tend to believe that every student can be successful at something and they also believe that devaluing a child's differences does them injustice (Krugar \& Love, 2005). Teachers who have incorrect information about ADHD often share this information with parents in the form of counsel, which parents often follow (DiBattista \& Shepherd, 1993).

Parents tend to believe what teachers tell them about ADHD issues and follow their advice without checking to see if it is valid information (DiBattista \& Shepherd, 1993). They get information about ADHD from the media, friends, and family (Ghanizadeh, 2007), thus they possibly believe myths about ADHD or incorrect information. When people believe they are knowledgeable about ADHD, they are less likely to seek information about the disorder thus tending to believe whatever information they have, regardless of whether it is accurate or inaccurate (Kos et al., 2006).

\section{Beliefs of Parents of Children in Parochial Schools}

Less than half of parents (40\%) in this study do not believe most children outgrow ADHD, which supports the findings of Ghanizadeh (2007). Parents who believe ADHD continues into adulthood can guide these children through adolescence (Barkley, 2000). As previously discussed, ADHD can be outgrown in some children while others maintain 
the disorder into adulthood. Similarly, more than half (58\%) do not believe ADHD is caused by poor parenting or dysfunctional, chaotic families, whereas almost three-fourths (74\%) believed stress and conflict in the home can cause ADHD-like behaviors. In contrast, almost half of parents (48\%) believe sugar or food additives cause ADHD, which is higher than the findings of Ghanizadeh (2007). Sixty-seven percent of parents in this study believe diets are usually helpful in treating most children with ADHD. However, the statement referred to most children with ADHD, whereas the evidence suggests it is helpful in only some children. Parents often believe information and counsel that teachers provide, and one study found teachers encouraged parents to eliminate sugar from their child's diet in order to manage their hyperactive behaviors (DiBattista \& Shepherd, 1993).

In terms of stimulant medication, parents in this study had beliefs that were distributed across the continuum of agreement and disagreement; however, more than three-fourths $(77 \%)$ believed too many children receive stimulant medication in the U.S. Interestingly, the majority of parents believed medication was effective in improving disruptive, hyperactive, impulsive, attention, and academic achievement in the classroom. In terms of non-pharmocological interventions, most parents believed behavior modification, therapy, classroom interventions, and classroom accommodations/modifications should be used to treat children with ADHD. These beliefs were confirmed since the majority of parents believed educational and behavioral interventions were effective in improving disruptive, hyperactive, impulsive, attention, and academic achievement in the classroom. 
Like teachers in this study, the majority of parents believed that it is difficult to work effectively with children with ADHD and that parents experience stress when parenting a child with ADHD. The majority also believed children with ADHD can be successful academically and that parents should be willing to support and assist these children in any way possible. Parents believed they would benefit from additional training regarding ADHD and learning more about the disorder.

\section{Consequences of Parents' Beliefs for the Children With Whom They Come in Contact}

Parents tend to believe what teachers tell them about ADHD issues and follow their advice without checking to see if it is valid information (DiBattista \& Shepherd, 1993). They get information about ADHD from the media, friends, and family (Ghanizadeh, 2007), thus they possibly believe myths about ADHD or incorrect information. When people believe they are knowledgeable about ADHD, they are less likely to seek information about the disorder thus tending to believe whatever information they have, regardless of whether it is accurate or inaccurate (Kos et al., 2006).

\section{Comparison and Discussion of Findings of the Current Study to Past Studies}

Previous studies found their participants had adequate knowledge on more individual knowledge items than the current study. This may be explained by methodological differences. The current study used the true, false, and don't know options, whereas other studies used only the true and false options (Barbaresi \& Olsen, 1998; Bekle, 2004; Ghanizadeh et al., 2006; Jerome et al., 1994; Stormont Ohan et al., 2008; Õim, 2004; \& Stebbins, 2005). It is possible these past findings may actually be 
artificially inflated due to guessing (Kos et al., 2006; Sciutto et al., 2000) since participants had a 50\% chance of getting an item correct without really knowing the correct answer. The incorporation of the three options may give a truer picture of the specific knowledge held by teachers in general and has been used by other studies (Kos et al., 2004; Liesveld, 2007; Sciutto et al., 2000; Tsai, 2003; West et al., 2005).

Previous studies found teachers had greater overall knowledge than the findings of the current study. These differences can be explained by the inclusion of belief items in the overall knowledge score of several studies (Barbaresi \& Olsen, 1998, Bekle, 2004; Jerome et al., 1994; Ohan et al., 2008), which indicates this score was not truly representative of knowledge regarding ADHD. In addition, some studies included incorrect answers in their knowledge scores. Therefore, overall knowledge scores from past studies do not truly represent the overall knowledge of teachers and parents, whereas the current study included only knowledge items in the overall score which is a better indicator of teachers' and parents' overall knowledge of ADHD.

Like the current study, Bekle (2004) did not find an association between teacher training about ADHD and higher knowledge. Former and current students with ADHD did not contribute to teachers' overall knowledge of the disorder in this study, although this relationship was found by Liesveld (2007). Similarly, Bekle (2004), Sciutto et al. (2000), and Tsai (2003) found that a relationship between teaching a child or children with ADHD was associated with higher knowledge. It is possible that the small sample size of teachers in this study and in Bekle's study may have affected this finding, since the sample of teachers in the other studies was larger. 
Taking graduate courses pertaining to ADHD does not contribute to knowledge regarding ADHD, which supports Liesveld (2007), Blume-D’Ausilio (2005), Sciutto et al. (2000), and Stormont and Stebbins (2005) but contrasts the findings of Jerome et al. (1994), Tsai (2003), Õim (2004), and West et al. (2005). Similarly, educational level of teachers was not a contributor to knowledge regarding ADHD which supports Gunderson (1994) and Sciutto et al. (2000) but contrasts Ghanizadeh et al. (2006). Gender does not contribute to knowledge about ADHD, which supports Jerome et al. (1994) but contrasts with Gunderson (1994), Õim (2004), and Liesveld (2007) who found being female is associated with higher knowledge about ADHD. Differences in these results can be attributed to different methodologies. The current study used regression to predict relationships, also used by Blume-D' Ausilio (2005) and Liesveld (2007), whereas other past studies used correlation or $t$-tests to examine associations. Even though BlumeD'Ausilio and Liesveld found significance in their regression models, they included variables identified by the current study as experience with ADHD, exposure to information about ADHD, and demographic variables all together in their models. They also included variables not included in the current study. Like the current study, they did find significant results although with small effect sizes, whereas the current study found medium effect sizes. Since their regression models did not include the same variables as the current study, results cannot be compared.

\section{Importance of the Study}

The findings from this study have extended the research literature regarding the knowledge and beliefs of teachers and parents regarding ADHD in parochial schools in several ways. First, there is little published research pertaining to parents' knowledge; 
therefore, findings from this study provide another layer to what parents know about the disorder. Second, there is no published research pertaining to parents' beliefs; therefore, this study provided a foundation in this area. Third, even though past studies claimed to have examined teachers' beliefs about ADHD, they did not distinguish between knowledge and belief items; however, this study did and as a result there is a foundation pertaining to what teachers believe about ADHD.

Fourth, the use of three options (true, false, don't know) instead of two (true, false) by this study and past studies (Kos et al., 2004; Liesveld, 2007; West et al., 2005) to examine knowledge regarding ADHD indicated that teachers have inadequate overall knowledge regarding the disorder, which may be a better indicator of overall knowledge than other studies using only two options (Barbaresi \& Olsen, 1998; Bekle, 2004; Jerome et al., 1994;). Fifth, the use of percentages for the Likert items added another dimension to the literature pertaining to the beliefs of teachers towards issues of ADHD. Sixth, the sample represented a unique population from the SDA church that has unique beliefs pertaining to a health message.

Seventh, many studies have stated that teachers believe myths about ADHD (Bekle, 2004; Jerome et al., 1999); however, most of the statements categorized as "myths" are not really "myths" according to the criteria set in this current study. Findings from past studies and the current study show that teachers and parents do not believe most of these "myths." The fact that these researchers categorized some statements as myths indicates that they may not have had a clear definition of "myth" and they possibly overestimated how many people would believe the inaccurate statements. Nonetheless, 
the current study provided a clear definition of a "myth" and used this definition to determine if a statement was a "myth" or not, which is an important aspect of the study.

Finally, evidence of predictors of knowledge regarding ADHD categorized as demographic, exposure to information about ADHD, and experience with ADHD variables for both teachers and parents has set a foundation for future studies and contributed new findings to the literature.

\section{Limitations of Study}

The current study has six main limitations. Primarily, the findings of this study have limited generalizability because data utilized came from a nonrandom sample from five out of six conferences (school districts) in the Atlantic Union Conference. Data from the teachers and parents in this sixth conference may have significantly changed the findings since this conference (school district) was the largest of the six. Therefore, findings may not adequately represent the population of teachers and parents in the Atlantic Union Conference of SDA. This lack of data from this conference (school district) may be a significant limitation to generalizing the results to other SDA unions.

Second, many of the knowledge items were not written clearly in previous studies and were used in the current study without modification. This could have confused participants, causing them to answer with "don't know" instead of true or false, which could have reduced the number of correct answers, thus lowering the overall knowledge score. Past studies which used these same items did not have the third option of "don't know"; therefore, their participants were forced to choose true or false and their overall knowledge score may not have been affected. 
Third, due to the distribution of the parents' surveys via the children, it is unknown as to how many actually were given to parents to complete. This lack of control regarding the distribution of the surveys could mean that many parents who may have responded did not receive the surveys. Past studies using parent samples sent the surveys directly to the parents for completion, so this was not a limitation for them (Ghanizadeh, 2007; West et al., 2005). It is also unknown as to how many surveys were sent with children back to school but never reached me. These possible issues could have impacted the data.

The sample size for teachers was small, thus limiting generalizabilty to other teacher populations. A larger sample including teachers from the sixth conference (school district) have affected the demographic data and may have affected the exposure to information about ADHD and the experience with ADHD data. Finally, teachers and parents might not have known that ADHD is the inclusive term for both ADHD and ADD. As a result they might have incorrectly answered questions in section 4 pertaining to ADHD, which could have negatively impacted the exposure to and experience with ADHD data, thus affecting the findings.

\section{Delimitations of the Study}

The current study has three main delimitations. First of all, question 5 in section 3 of the parents' survey should have asked parents to identify the conference (school district) in which their children attended school, instead of which conference (school district) they lived in. This created a problem in Greater New York Conference (GNYC). Many parents lived in Northeastern Conference, which was not a choice on the form, but sent their children to schools in GNYC. Because of this oversight, it was reported to the 
researcher that some parents refused to complete the surveys because their conference (school district) was not listed as a choice on the form.

Second, translation of the surveys into Spanish could have produced more returned surveys from Spanish speakers. In addition, the study did not address which group responded the most with "don't know" nor did it address the items most answered with “don't know”. These areas were analyzed in previous studies (Sciutto et al., 2000; Tsai, 2003; West et al., 2005). Finally, the return of some surveys could have been lost or misplaced.

\section{Implications for Practice}

This study has a few implications for practice in SDA parochial schools. First, it is now known that regular education teachers have inadequate knowledge regarding ADHD, but they have positive beliefs pertaining to many important issues. However, indicators of higher knowledge regarding ADHD derive from experience with ADHD, exposure to information about ADHD, and demographics. Extrapolating the findings strongly suggests that teachers with years of teaching experience, possibly in multigrades, who have experience teaching students thought to have ADHD, who have acquaintances with ADHD, who have participated in training about ADHD, and who read books and articles about ADHD are more knowledgeable about the disorder and could be considered mentor teachers for teaching children with ADHD. Teachers in the AU who have these attributes could mentor novice teachers in their conferences (school districts).

Second, children with ADHD who have teachers who are knowledgeable about the disorder and who have positive beliefs have greater opportunities to succeed academically and socially. As evidenced by the data, children with ADHD attend SDA 
parochial schools; therefore, this parochial school system needs to ensure that their teachers are equipped and able to provide these children with the best academic experience as possible. Even though the SDA church has a strong education system, it does not typically address special needs in the schools. Children with special needs do not typically attend SDA schools because of the lack of services and support. The fact that SDA schools don't address special needs explains the findings of inadequate knowledge about ADHD. It is possible that since teachers don't have to necessarily deal with children with special needs, they are less likely to seek information about the disorder. However, this would be a misunderstanding since children with ADHD do attend these SDA schools. Therefore, this parochial school system needs to recognize the importance of providing relevant training to their teachers.

Third, since training about ADHD contributes to increasing knowledge about the disorder, the AU should provide its teachers with comprehensive training regarding ADHD to increase and improve their knowledge about the disorder. This training can be delegated to individual conferences (school districts) and implemented by mentor teachers in the conferences (school districts). This comprehensive training should include information about the history, background, symptoms and characteristics, diagnostic criteria, possible causes, intervention/treatment options, and outcomes of the disorder. The positive beliefs of these teachers about educational and behavioral interventions coupled with comprehensive training would be beneficial for children with ADHD. Teachers can increase their reading of books and journals about ADHD in order to increase their knowledge about the disorder. Reading accurate and current information about ADHD can help teachers reject myths about the disorder. 
Fourth, teachers and parents in this parochial school system have negative beliefs towards stimulant medication. This finding is understandable since Seventh-day Adventists are supporters of a healthful lifestyle and typically avoid the use of caffeine and drugs, preferring to use alternative treatment options. They believe stimulants are unhealthy for the body, mind, and spirit and should be avoided. However, both teachers and parents have positive beliefs towards behavioral and educational interventions, which support alternative treatment options. These teachers and parents need to receive training about the benefits of stimulant medication so that they can be well informed about this important intervention option.

Fifth, it is now known that parents of children in this parochial school system have inadequate knowledge of the disorder, but they too have positive beliefs pertaining to many important issues. Extrapolating the findings strongly suggests that parents with acquaintances with ADHD, who attend lectures, read articles and books about ADHD, and view videos about ADHD are more knowledgeable about the disorder. SDA parents with these characteristics can be utilized by school districts to share their knowledge with other parents.

Schools can provide accurate information regarding ADHD during home and school meetings. Parents can join online support groups such as CHADD or ADDA to keep abreast of the up-dated information regarding ADHD. Parents can join local libraries to gain access to books, journal articles, and videos about ADHD. Increasing their use of these resources can help them gain accurate and current knowledge about the disorder. 
Implications for practice are for the benefit of children in parochial schools with ADHD. If school districts in the SDA parochial school system provide their teachers with comprehensive training about ADHD, their teachers will be equipped to provide children with ADHD support and assistance to help them become successful academically and socially. Providing training regarding educational and behavioral interventions will help students with ADHD receive the necessary interventions in the classroom. Parents who attend lectures about ADHD will become more knowledgeable about the disorder, learn about home-based strategies, have positive relationships with these children, and also provide them with the necessary support and assistance at home. Coupled together, children with ADHD in SDA parochial schools can have positive experiences at home and at school that can lead to positive outlooks for their future.

\section{Directions for Future Research}

This study makes a valuable contribution to the body of knowledge regarding (a) parochial school teachers' knowledge and beliefs regarding ADHD, (b) parents' knowledge and beliefs regarding ADHD, and (c) predictors of teachers' and parents' knowledge. However, the findings also highlight the need for more studies pertaining to teachers' beliefs regarding ADHD and parents' knowledge and beliefs regarding ADHD. Additional studies pertaining to beliefs would contribute to the literature since beliefs can be more influential than knowledge and a stronger predictor of behavior (Nespor, 1987).

This study may serve as a catalyst for future research in this area since it revealed problems with knowledge items. Therefore, future research needs to utilize a survey instrument that is void of obscure items, that contains clearly written items that are clearly distinguished as knowledge or beliefs, and that includes items reflecting current 
information about ADHD. This survey instrument would be realized only if clear items were developed, assessed by experts, and then modified according to their recommendations. The survey could then be administered in a pilot study to participants representative of the target population who would provide feedback in regard to clarity and understanding of the items, and an explanation of why they answered the way they did. Survey items could then be modified based on this feedback. This process ensures that the validity and the reliability can be tested by re-administering the survey to the original participants. Since this study revealed teachers' positive beliefs towards intervention options in the classroom, future research can examine the strategies and/or interventions used by teachers in parochial schools to accommodate children with ADHD.

\section{Conclusions}

The purpose of this study was to examine the knowledge and beliefs of regular education teachers and parents of children in parochial schools and the predictors of their knowledge. In summary, this study had several findings:

1. Regular education teachers and parents of children in parochial schools have inadequate knowledge regarding ADHD. This inadequate knowledge was evident on the individual knowledge items and on the overall knowledge score. Neither teachers nor parents had adequate knowledge regarding the hallmark symptoms, diagnostic criteria, or intervention/treatment options of the disorder.

2. Regular education teachers and parents of children in parochial schools have 
positive beliefs about educational and behavioral interventions in the classroom, support and assistance for children with ADHD, and about the academic success of these children. However, they also have negative beliefs about stimulant medication.

3. Regular education teachers and parents of children in parochial schools do not believe the "myth" statements listed on websites and in past studies.

4. Conference (school district), race, teaching experience, grade taught, former and current students thought to have ADHD, and acquaintances outside of school with ADHD contribute to teachers' greater knowledge regarding the disorder. Training about ADHD and reading articles and books about ADHD possibly contribute to greater knowledge regarding the disorder.

5. Acquaintances outside of the home with ADHD, attending lectures about ADHD, reading articles and books about ADHD, and viewing videos about ADHD contribute to parents' knowledge regarding the disorder.

6. Surprisingly, teachers in this study did not have adequate knowledge about the $D S M$ hallmark symptoms of inattentive and hyperactive students even though they had former and current students they thought had ADHD. It would be of interest to find out what symptoms these children had in order for the teachers to believe they had ADHD without adequately knowing what the symptoms are.

\section{Summary}

In summary, this research presented several important findings even though it has several limitations. First, this study contributed data pertaining to parents' knowledge about ADHD since there is a dearth in this area. Second, this study provided a foundation for research pertaining to parents' beliefs since there was no published research in this 
area. Third, it provided a foundation pertaining to what teachers believe about ADHD. Fourth, the use of three options (true, false \& don't know) may be a better indicator of teachers' overall knowledge than two options (true \& false). Fifth, the use of percentages for Likert items added another dimension to the literature pertaining to teachers' beliefs. Sixth, the sample represented a unique population from the SDA church. Seventh, this study demonstrated that many statements that have been considered "myths" in the past cannot be considered myths because, for many of these statements, a majority of people do not believe them and some of the statements do not yet have clearly established empirical answers. Finally, evidence of predictors of teachers' and parents' knowledge regarding ADHD confirmed previous findings and contributed new findings to the literature.

These findings may help school districts in the SDA parochial school system realize the importance of comprehensive training regarding ADHD for their teachers. They may also help conferences (school districts) realize the importance of providing lectures about ADHD for parents who send their children to these schools. Teachers and parents who realize reading articles and books about ADHD increases their knowledge may be encouraged to read more. Coupled together, teachers and parents of children in parochial schools can provide children with ADHD the best possible support and assistance to help them have a positive outlook in school, at home, and in society. 
APPENDIX A

DSM CRITERIA FOR ADHD 
According to the DSM-IV-TR (2000, p. 92-93) the diagnostic criteria for AD/HD

are as follows:

A. Either (1) or (2):

(1) six (or more) of the following symptoms of inattention have persisted for at least 6 months to a degree that is maladaptive and inconsistent with developmental level:

\section{Inattention}

(a) often fails to give close attention to details or makes careless mistakes in schoolwork, work, or other activities

(b) often has difficulty sustaining attention in tasks or play activities

(c) often does not seem to listen when spoken to directly

(d) often does not follow through on instructions and fails to finish schoolwork, chores, or duties in the workplace (not due to oppositional behavior or failure to understand instructions)

(e) often has difficulty organizing tasks and activities

(f) often avoids, dislikes, or is reluctant to engage in tasks that require sustained mental effort (such as schoolwork or homework)

(g) often loses things necessary for tasks or activities (e.g., toys, school assignments, pencils, books, or tools)

(h) is often easily distracted by extraneous stimuli

(i) is often forgetful in daily activities

(2) six (or more) of the following symptoms of hyperactivity-impulsivity have persisted for at least 6 months to a degree that is maladaptive and inconsistent with developmental level:

\section{Hyperactivity}

(a) often fidgets with hands or feet or squirms in seat

(b) often leaves seat in classroom or in other situations in which remaining seated is expected

(c) often runs about or climbs excessively in situations in which it is inappropriate (in adolescents or adults, may be limited to subjective feelings of restlessness)

(d) often has difficulty playing or engaging in leisure activities quietly

(e) is often "on the go" or often acts as if "driven by a motor"

(f) often talks excessively

\section{Impulsivity}

(g) often blurts out answers before questions have been completed

(h) often has difficulty awaiting turn

(i) often interrupts or intrudes on others (e.g., butts into conversations or games) 
B. Some hyperactive-impulsive or inattentive symptoms that caused impairment were present before age 7 years.

C. Some impairment from the symptoms is present in two or more setting (e.g., at school [or work] and at home).

D. There must be clear evidence of clinically significant impairment in social, academic or occupational functioning.

E. The symptoms do not occur exclusively during the course of a pervasive Developmental Disorder, Schizophrenia, or other Psychotic Disorder and are not better accounted for by another mental disorder (e.g., Mood Disorder, Anxiety Disorder, Dissociative Disorder, or a Personality Disorder).

$\mathrm{AD} / \mathrm{HD}$, Predominantly Inattentive Type - In order to be diagnosed with $\mathrm{AD} / \mathrm{HD}$, Predominantly Inattentive Type Criterion A1 must be met for at least 6 months.

AD/HD, Predominantly Hyperactive-Impulsive Type - In order to be diagnosed with $\mathrm{AD} / \mathrm{HD}$, Predominantly Hyperactive-Impulsive Type Criterion A2 must be met for at least 6 months.

AD/HD, Combined Type - In order to be diagnosed with AD/HD, Combined Type both Criteria $\mathrm{A} 1$ and $\mathrm{A} 2$ must be met for at least 6 months. 
APPENDIX B

STUDIES REGARDING KNOWLEDGE, BELIEFS AND/OR

ATTITIDES OF ADHD 
Studies conducted about Knowledge, Beliefs and/or Attitudes of ADHD

\begin{tabular}{|c|c|c|c|c|c|}
\hline & Author/s & Date & Sample & Country/State & $\begin{array}{l}\text { Instrument/Variable/s } \\
\text { measured }\end{array}$ \\
\hline 1 & $\begin{array}{l}\text { Jerome, } \\
\text { Gordon \& } \\
\text { Hustler }\end{array}$ & 1994 & $\begin{array}{l}\text { Public school } \\
\text { elementary } \\
\text { teachers }\end{array}$ & $\begin{array}{l}\text { United States } \\
\text { \& Canada }\end{array}$ & $\begin{array}{l}\text { Jerome's T/F questionnaire/ } \\
\text { knowledge and } \\
\text { attitudes of ADHD }\end{array}$ \\
\hline 2 & Gunderson & 1994 & $\begin{array}{l}\text { Public school } \\
\text { elementary } \\
\text { teachers }\end{array}$ & Michigan & $\begin{array}{l}\text { Likert-scale/knowledge and } \\
\text { attitudes of ADHD }\end{array}$ \\
\hline 3 & Kiffer & 1996 & $\begin{array}{l}\text { Public school } \\
\text { elementary } \\
\text { teachers }\end{array}$ & Florida & $\begin{array}{l}\text { Likert-scale/knowledge and } \\
\text { attitudes of ADHD }\end{array}$ \\
\hline 4 & Grynewich & 1996 & $\begin{array}{l}\text { Elementary } \\
\text { and } \\
\text { secondary } \\
\text { preservice } \\
\text { teachers }\end{array}$ & $\begin{array}{l}\text { Southwestern } \\
\text { university in } \\
\text { United States }\end{array}$ & $\begin{array}{l}\text { Likert-scale/knowledge and } \\
\text { attitudes of ADHD }\end{array}$ \\
\hline 5 & Williams & 1996 & $\begin{array}{l}\text { Elementary } \\
\text { Principals } \\
\text { in public } \\
\text { schools }\end{array}$ & Illinois & $\begin{array}{l}\text { Likert scale/Knowledge of } \\
\text { ADHD }\end{array}$ \\
\hline 6 & Robin & 1997 & $\begin{array}{l}\text { Preservice } \\
\text { teachers }\end{array}$ & Saskatchewan & $\begin{array}{l}\text { Multiple-choice question- } \\
\text { naire by researcher/ } \\
\text { knowledge and opinions of } \\
\text { ADHD }\end{array}$ \\
\hline 7 & $\begin{array}{l}\text { Barbaresi \& } \\
\text { Olsen }\end{array}$ & 1998 & $\begin{array}{l}\text { Public school } \\
\text { elementary } \\
\text { teachers }\end{array}$ & $\begin{array}{l}\text { Southeast } \\
\text { Minnesota }\end{array}$ & Jerome's questionnaire \\
\hline 8 & $\begin{array}{l}\text { Bussing, } \\
\text { Schoenberg \& } \\
\text { Perwien }\end{array}$ & 1998 & $\begin{array}{l}\text { African } \\
\text { American } \\
\text { and White } \\
\text { parents of } \\
\text { children at } \\
\text { high risk for } \\
\text { ADHD }\end{array}$ & Florida & $\begin{array}{l}\text { Survey ranging from } 0 \text { to } \\
5 / \text { knowledge of ADHD }\end{array}$ \\
\hline 9 & $\begin{array}{l}\text { Corkum, } \\
\text { Rimer \& } \\
\text { Schachar }\end{array}$ & 1999 & $\begin{array}{l}\text { Parents of } \\
\text { children with } \\
\text { ADHD }\end{array}$ & Ontario & $\begin{array}{l}\text { T/F questionnaire and 4- } \\
\text { point Likert-Scale/parents } \\
\text { knowledge of ADHD and } \\
\text { opinions of treatment } \\
\text { interventions }\end{array}$ \\
\hline
\end{tabular}




\begin{tabular}{|c|c|c|c|c|c|}
\hline & Author/s & Date & Sample & Country/State & $\begin{array}{l}\text { Instrument/Variable/s } \\
\text { measured }\end{array}$ \\
\hline 10 & $\begin{array}{l}\text { Jerome, } \\
\text { Washington, } \\
\text { Laine \& Segal }\end{array}$ & 1999 & $\begin{array}{l}\text { Public school } \\
\text { elementary \& } \\
\text { preservice } \\
\text { teachers }\end{array}$ & Canada & $\begin{array}{l}\text { Jerome's questionnaire/ } \\
\text { knowledge and attitudes of } \\
\text { ADHD }\end{array}$ \\
\hline 11 & Smith & 1999 & $\begin{array}{l}\text { School } \\
\text { Psychologists } \\
\text { in public } \\
\text { schools }\end{array}$ & United States & $\begin{array}{l}\text { Likert scale/knowledge and } \\
\text { attitudes of ADHD }\end{array}$ \\
\hline 12 & $\begin{array}{l}\text { Brook, } \\
\text { Watemberg, \& } \\
\text { Geva }\end{array}$ & 2000 & $\begin{array}{l}\text { Regular or } \\
\text { special ed. } \\
\text { High school } \\
\text { teachers }\end{array}$ & Israel & $\begin{array}{l}\text { Yes/no or choose one } \\
\text { format developed by } \\
\text { authors/knowledge and } \\
\text { attitudes of ADHD }\end{array}$ \\
\hline 13 & Lewis & 2000 & $\begin{array}{l}\text { General } \\
\text { education } \\
\text { teachers in } \\
\text { public } \\
\text { schools } \\
\end{array}$ & $\begin{array}{l}\text { West } \\
\text { Alabama }\end{array}$ & $\begin{array}{l}\text { 1-4 point Likert- } \\
\text { scale/knowledge of and } \\
\text { attitudes towards students } \\
\text { with ADHD }\end{array}$ \\
\hline 14 & $\begin{array}{l}\text { Scuitto, } \\
\text { Teriesen \& } \\
\text { Frank }\end{array}$ & 2000 & $\begin{array}{l}\text { Public school } \\
\text { elementary } \\
\text { teachers }\end{array}$ & New York & $\begin{array}{l}\text { Knowledge of Attention } \\
\text { Deficit Disorder Scale } \\
\text { (KADDS) /knowledge } \\
\text { about ADHD }\end{array}$ \\
\hline 15 & $\begin{array}{l}\text { Frankenberger, } \\
\text { Farmer, Parker } \\
\text { \& Cermak }\end{array}$ & 2001 & $\begin{array}{l}\text { School } \\
\text { psychologists } \\
\text { in public } \\
\text { schools }\end{array}$ & $\begin{array}{l}\text { Wisconsin \& } \\
\text { United States }\end{array}$ & $\begin{array}{l}\text { Likert scale/knowledge and } \\
\text { attitudes of ADHD }\end{array}$ \\
\hline 16 & $\begin{array}{l}\text { Pisecco, } \\
\text { Huzinee \& } \\
\text { Curtis }\end{array}$ & 2001 & $\begin{array}{l}\text { Public school } \\
\text { elementary } \\
\text { teachers }\end{array}$ & Southwest & Jerome's instrument \\
\hline 17 & $\begin{array}{l}\text { Bussing, Gary, } \\
\text { Leon, Barvan } \\
\text { \& Reid }\end{array}$ & 2002 & $\begin{array}{l}\text { Public school } \\
\text { elementary } \\
\text { teachers }\end{array}$ & North Florida & Jerome's instrument \\
\hline 18 & $\begin{array}{l}\text { Pentecost \& } \\
\text { Wood }\end{array}$ & 2002 & $\begin{array}{l}\text { Social } \\
\text { Workers }\end{array}$ & $\begin{array}{l}\text { Southeast } \\
\text { England }\end{array}$ & $\begin{array}{l}\text { List of } 10 \text { common } \\
\text { symptoms and ADHD } \\
\text { behaviors/knowledge of } \\
\text { ADHD }\end{array}$ \\
\hline 19 & Pugh & 2002 & $\begin{array}{l}\text { Parents of } \\
\text { children with } \\
\text { ADHD } \\
\text { belonging to } \\
\text { CHADD }\end{array}$ & United States & $\begin{array}{l}50 \text {-item yes/no/perspective } \\
\text { of causes of ADHD }\end{array}$ \\
\hline 20 & $\begin{array}{l}\text { Shaw, } \\
\text { Mitchell, } \\
\text { Wagner \& } \\
\text { Eastwood }\end{array}$ & 2002 & $\begin{array}{l}\text { General } \\
\text { practitioners }\end{array}$ & Queensland & $\begin{array}{l}\text { Cross sectional } \\
\text { questionnaire/understanding } \\
\text { of ADHD }\end{array}$ \\
\hline
\end{tabular}




\begin{tabular}{|c|c|c|c|c|c|}
\hline & Author/s & Date & Sample & Country/State & $\begin{array}{l}\text { Instrument/Variable/s } \\
\text { measured }\end{array}$ \\
\hline 21 & $\begin{array}{l}\text { Frisch, Moser, } \\
\text { Hawley, } \\
\text { Johnston \& } \\
\text { Romereim }\end{array}$ & 2003 & $\begin{array}{l}\text { School } \\
\text { nurses in } \\
\text { public } \\
\text { schools }\end{array}$ & Kansas & $\begin{array}{l}\text { T/F and Likert } \\
\text { scale/knowledge and } \\
\text { opinions of ADHD }\end{array}$ \\
\hline 22 & $\begin{array}{l}\text { Couture, } \\
\text { Royer, Dupris, } \\
\& \text { Potvin }\end{array}$ & 2003 & $\begin{array}{l}\text { Primary } \\
\text { school } \\
\text { teachers }\end{array}$ & $\begin{array}{l}\text { Britain \& } \\
\text { Quebec }\end{array}$ & $\begin{array}{l}\text { 4-level Likert-Scale } \\
\text { /knowledge of ADHD }\end{array}$ \\
\hline 23 & $\begin{array}{l}\text { Snider, Busch } \\
\& \text { Arrowood }\end{array}$ & 2003 & $\begin{array}{l}\text { Public school } \\
\text { general and } \\
\text { special } \\
\text { education } \\
\text { teachers }\end{array}$ & Wisconsin & $\begin{array}{l}\text { 4-point Likert- } \\
\text { scale/knowledge about } \\
\text { Stimulant medication and } \\
\text { ADHD }\end{array}$ \\
\hline 24 & Tsai & 2003 & $\begin{array}{l}\text { Public school } \\
\text { elementary } \\
\text { school } \\
\text { teachers } \\
\end{array}$ & Taiwan & $\begin{array}{l}\text { KADDS/ knowledge about } \\
\text { ADHD }\end{array}$ \\
\hline 25 & Bekle & 2004 & $\begin{array}{l}\text { Public school } \\
\text { elementary } \\
\text { teachers and } \\
\text { prospective } \\
\text { teachers }\end{array}$ & Australia & $\begin{array}{l}\text { Jerome's instrument } \\
\text { (modified)/knowledge and } \\
\text { attitudes of ADHD }\end{array}$ \\
\hline 26 & $\begin{array}{l}\text { Kos, Richdale } \\
\text { \& Jackson }\end{array}$ & 2004 & $\begin{array}{l}\text { Primary } \\
\text { school } \\
\text { teachers from } \\
\text { Catholic and } \\
\text { private } \\
\text { schools and } \\
\text { preservice } \\
\text { teachers }\end{array}$ & Australia & $\begin{array}{l}\text { Self-report questionnaire } \\
\text { with true/false/don't know } \\
\text { format/ knowledge of } \\
\text { ADHD }\end{array}$ \\
\hline 27 & Õim & 2004 & $\begin{array}{l}\text { Public } \\
\text { primary and } \\
\text { basic school } \\
\text { teachers }\end{array}$ & $\begin{array}{l}\text { Estonia \& } \\
\text { Norway }\end{array}$ & $\begin{array}{l}\text { True/False } \\
\text { questionnaire/knowledge of } \\
\text { ADHD }\end{array}$ \\
\hline 28 & Stief & 2004 & $\begin{array}{l}\text { African } \\
\text { American \& } \\
\text { White } \\
\text { parents of } \\
\text { children with } \\
\text { ADHD } \\
\text { recruited } \\
\text { through } \\
\text { public } \\
\text { schools }\end{array}$ & $\begin{array}{l}\text { Virginia } \\
\text { Beach, } \\
\text { Virginia }\end{array}$ & $\begin{array}{l}\text { Multiple choice, Likert- } \\
\text { scale \& yes/no } \\
\text { questionnaire/ beliefs about } \\
\text { ADHD }\end{array}$ \\
\hline
\end{tabular}




\begin{tabular}{|c|c|c|c|c|c|}
\hline & Author/s & Date & Sample & Country/State & $\begin{array}{l}\text { Instrument/Variable/s } \\
\text { measured }\end{array}$ \\
\hline 29 & $\begin{array}{l}\text { Venter, Van } \\
\text { der Linde, du } \\
\text { pleases \& } \\
\text { Joubert }\end{array}$ & 2004 & $\begin{array}{l}\text { Psychiatrists \& } \\
\text { pediatricians }\end{array}$ & South Africa & $\begin{array}{l}\text { Likert scale/knowledge and } \\
\text { attitudes of ADHD }\end{array}$ \\
\hline 30 & $\begin{array}{l}\text { Vereb \& } \\
\text { DuPerna }\end{array}$ & 2004 & $\begin{array}{l}\text { Public school } \\
\text { elementary school } \\
\text { teachers }\end{array}$ & $\begin{array}{l}\text { New Jersey \& } \\
\text { Pennsylvania }\end{array}$ & $\begin{array}{l}\text { Knowledge of ADHD } \\
\text { Rating Evaluation } \\
\text { (KARE)/knowledge about } \\
\text { ADHD }\end{array}$ \\
\hline 31 & $\begin{array}{l}\text { Blume- } \\
\text { D'Ausilio }\end{array}$ & 2005 & K-G5 teachers & Florida & $\begin{array}{l}\text { Survey designed by } \\
\text { researcher and an } \\
\text { adaptation of } \\
\text { KADDS/relationship of } \\
\text { variables to knowledge and } \\
\text { attitudes of ADHD }\end{array}$ \\
\hline 32 & $\begin{array}{l}\text { Cornell- } \\
\text { Swanson, } \\
\text { Irwin, Johnson } \\
\& \text { others } \\
\end{array}$ & 2005 & Social Workers & United States & $\begin{array}{l}\text { 49-item Likert } \\
\text { scale/knowledge and } \\
\text { attitudes of ADHD }\end{array}$ \\
\hline 33 & $\begin{array}{l}\text { Havey, Olsen, } \\
\text { Mccormick \& } \\
\text { Cates }\end{array}$ & 2005 & $\begin{array}{l}\text { Public school } \\
\text { elementary } \\
\text { teachers }\end{array}$ & $\begin{array}{l}\text { Rural } \\
\text { Midwestern } \\
\text { city }\end{array}$ & $\begin{array}{l}1 \text { item asking about cause } \\
\text { of ADHD and } 1 \text { item asking } \\
\text { about effective medication/ } \\
\text { knowledge about cause of } \\
\text { ADHD }\end{array}$ \\
\hline 34 & $\begin{array}{l}\text { Stormont \& } \\
\text { Stebbins }\end{array}$ & 2005 & Preschool teachers & $\begin{array}{l}\text { Midwestern } \\
\text { city }\end{array}$ & $\begin{array}{l}\text { True/false questionnaire/ } \\
\text { knowledge related to } \\
\text { ADHD }\end{array}$ \\
\hline 35 & $\begin{array}{l}\text { West, Taylor, } \\
\text { Houghton \& } \\
\text { Hudyma }\end{array}$ & 2005 & $\begin{array}{l}\text { Primary and } \\
\text { secondary } \\
\text { teachers and } \\
\text { parents of } \\
\text { children with } \\
\text { ADHD }\end{array}$ & $\begin{array}{l}\text { Perth, } \\
\text { Australia }\end{array}$ & $\begin{array}{l}\text { True/False/Don't know } \\
\text { questionnaire/knowledge } \\
\text { and attitudes of ADHD }\end{array}$ \\
\hline 36 & $\begin{array}{l}\text { Carlson, } \\
\text { Frankenberger, } \\
\text { Hall, Totten \& } \\
\text { House }\end{array}$ & 2006 & $\begin{array}{l}\text { Public school } \\
\text { teachers from } \\
\text { Wisconsin and } \\
\text { Sweden }\end{array}$ & $\begin{array}{l}\text { Wisconsin \& } \\
\text { Sweden }\end{array}$ & $\begin{array}{l}\text { Likert-scale/attitudes about } \\
\text { causes and treatment of } \\
\text { ADHD }\end{array}$ \\
\hline 37 & $\begin{array}{l}\text { Dryer, Kiernan } \\
\& \text { Tyson }\end{array}$ & 2006 & $\begin{array}{l}\text { Various } \\
\text { professionals, } \\
\text { teachers \& parents } \\
\text { of children with } \\
\text { \& without } \\
\text { ADHD }\end{array}$ & $\begin{array}{l}\text { New South } \\
\text { Wales, } \\
\text { Australia }\end{array}$ & $\begin{array}{l}\text { 6-part questionnaire with } \\
117 \text { items using Likert- } \\
\text { scale / beliefs about causal } \\
\text { factors \& characteristics of } \\
\text { ADHD }\end{array}$ \\
\hline
\end{tabular}




\begin{tabular}{|c|c|c|c|c|c|}
\hline & Author/s & Date & Sample & Country/State & $\begin{array}{l}\text { Instrument/Variable/s } \\
\text { measured }\end{array}$ \\
\hline 38 & $\begin{array}{l}\text { Ghanizadeh, } \\
\text { Bahredar \& } \\
\text { Moeini }\end{array}$ & 2006 & $\begin{array}{l}\text { Elementary } \\
\text { school } \\
\text { teachers }\end{array}$ & Iran & $\begin{array}{l}\text { Self-report true/false } \\
\text { questionnaire prepared by } \\
\text { authors/knowledge and } \\
\text { attitudes of ADHD }\end{array}$ \\
\hline 39 & Kawagoe & 2006 & $\begin{array}{l}\text { General } \\
\text { education and } \\
\text { special } \\
\text { education } \\
\text { teachers }\end{array}$ & California & $\begin{array}{l}\text { KARE/knowledge about } \\
\text { ADHD }\end{array}$ \\
\hline 40 & $\begin{array}{l}\text { Bussing, } \\
\text { Gary, Mills \& } \\
\text { Garvan }\end{array}$ & 2007 & $\begin{array}{l}\text { African } \\
\text { American and } \\
\text { White parents } \\
\text { of children at } \\
\text { high risk for } \\
\text { ADHD }\end{array}$ & Florida & $\begin{array}{l}\text { Survey ranging from } 0 \text { to } \\
5 / \text { cultural variations in } \\
\text { ADHD knowledge }\end{array}$ \\
\hline 41 & Ghanizadeh & 2007 & $\begin{array}{l}\text { Parents of } \\
\text { children with } \\
\text { ADHD }\end{array}$ & Iran & $\begin{array}{l}\text { Ghanizadeh's } \\
\text { survey/knowledge and } \\
\text { attitudes }\end{array}$ \\
\hline 42 & Havey & 2007 & $\begin{array}{l}\text { Public } \\
\text { elementary } \\
\text { school } \\
\text { teachers }\end{array}$ & $\begin{array}{l}\text { Rural } \\
\text { Midwestern } \\
\text { city \& } \\
\text { Netherlands }\end{array}$ & $\begin{array}{l}1 \text { item asking about cause } \\
\text { of ADHD and } 1 \text { item } \\
\text { asking about effective } \\
\text { medication/ knowledge } \\
\text { about cause of ADHD }\end{array}$ \\
\hline 43 & Liesveld & 2007 & $\begin{array}{l}\text { Public } \\
\text { elementary } \\
\text { school } \\
\text { teachers }\end{array}$ & New Mexico & $\begin{array}{l}\text { KADDS/knowledge and } \\
\text { beliefs of ADHD }\end{array}$ \\
\hline 44 & $\begin{array}{l}\text { Ohan, } \\
\text { Cormier, } \\
\text { Hepp, Visser } \\
\text { \& Strain }\end{array}$ & 2008 & $\begin{array}{l}\text { Public } \\
\text { elementary } \\
\text { school } \\
\text { teachers }\end{array}$ & $\begin{array}{l}\text { Melbourne, } \\
\text { Australia }\end{array}$ & Jerome's Instrument \\
\hline 45 & Holst & 2008 & $\begin{array}{l}\text { Teachers and } \\
\text { kindergarten } \\
\text { educationalists } \\
\text { in public } \\
\text { schools }\end{array}$ & Denmark & $\begin{array}{l}\text { Semi-structured interviews } \\
\text { - attitudes towards } \\
\text { challenging behaviors and } \\
\text { knowledge about } \\
\text { ADHD/DAMP }\end{array}$ \\
\hline
\end{tabular}


APPENDIX C

KNOWLEDGE STATEMENT ANSWER KEY 
Knowledge Statements Keyed Answers

\begin{tabular}{|c|l|c|}
\hline $\begin{array}{c}\text { Item } \\
\#\end{array}$ & \multicolumn{1}{|c|}{ Knowledge Statements } & $\begin{array}{c}\text { Keyed } \\
\text { Answer }\end{array}$ \\
\hline 3 & $\begin{array}{l}\text { Children with ADHD are born with biological vulnerabilities toward } \\
\text { inattention and poor self-control. }\end{array}$ & TRUE \\
\hline 4 & $\begin{array}{l}\text { Children with ADHD misbehave primarily because they don't want } \\
\text { to follow rules and complete assignments. }\end{array}$ & FALSE \\
\hline 5 & $\begin{array}{l}\text { The inattention of children with ADHD is not primarily a } \\
\text { consequence of defiance, oppositionality and an unwillingness to } \\
\text { please others. }\end{array}$ & TRUE \\
\hline 6 & $\begin{array}{l}\text { ADHD is a medical disorder that can only be treated with } \\
\text { medication. }\end{array}$ & FALSE \\
\hline 8 & $\begin{array}{l}\text { Children with ADHD have difficulty sustaining attention in tasks or } \\
\text { play activities. }\end{array}$ & TRUE \\
\hline 10 & ADHD can be inherited. & FALSE \\
\hline 11 & ADHD occurs equally as often in girls as boys. & FALSE \\
\hline 12 & $\begin{array}{l}\text { Children with ADHD can be described as children on the go or who } \\
\text { act as if driven by a motor. }\end{array}$ & TRUE \\
\hline 13 & ADHD occurs more in minority groups than in Caucasian groups. & FALSE \\
\hline 14 & $\begin{array}{l}\text { If medication is prescribed educational interventions are often } \\
\text { unnecessary. }\end{array}$ & FALSE \\
\hline 16 & Diets are usually not helpful in treating most children with ADHD. & TRUE \\
\hline 17 & $\begin{array}{l}\text { Children with ADHD usually avoid tasks that require sustained } \\
\text { mental effort. }\end{array}$ & TRUE \\
\hline 18 & $\begin{array}{l}\text { If a child can play video games for hours, he/she probably isn't } \\
\text { ADHD. }\end{array}$ & FALSE \\
\hline 19 & $\begin{array}{l}\text { Children with ADHD have a high risk for becoming delinquent as } \\
\text { teenagers. }\end{array}$ & TRUE \\
\hline 20 & $\begin{array}{l}\text { Children with ADHD are typically better behaved in 1-to-1 } \\
\text { interactions than in a group situation. }\end{array}$ & TRUE \\
\hline 23 & Hallucinations are associated with ADHD. & FALSE \\
\hline 24 & $\begin{array}{l}\text { In order to have the diagnosis of ADHD, both hyperactivity and } \\
\text { inattentiveness must be present. }\end{array}$ & $\begin{array}{l}\text { FALSE } \\
\text { specific routines and rituals. }\end{array}$ \\
\hline 25 & ADHD may express itself in only one environment. \\
\hline 28 & $\begin{array}{l}\text { ADHD derives from emotional imbalance. } \\
\text { ADHD. }\end{array}$ & ADHD may begin in adolescence. \\
\hline 29 & FALSE \\
\hline 26 & FALSE \\
\hline
\end{tabular}


APPENDIX D

TEACHERS' AND PARENTS' QUESTIONNAIRE 


\section{ANDREWS UNIVERSITY}

Educational and Psychology Department

Bell Hall

100 Old US 31

Berrien Springs, MI 49104

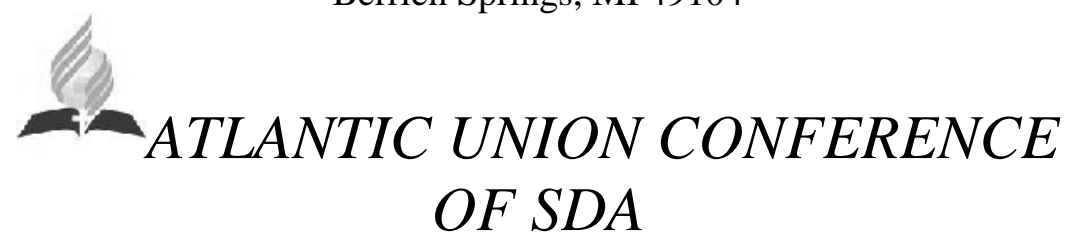

\section{Ideas and Views of Teachers about Students Who Need Special Assistance ${ }_{1}$}

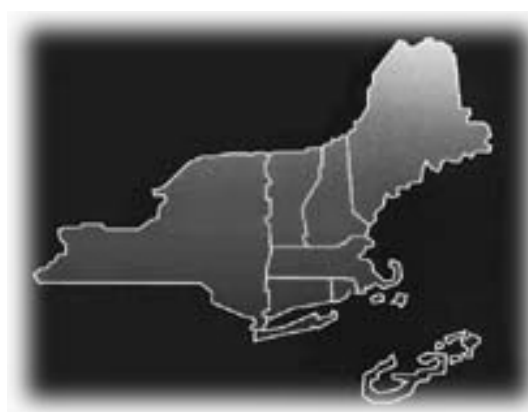

This questionnaire seeks to capture vital information about the ideas and views of teachers in the Atlantic Union Conference about children who need special assistance. Your participation is completely voluntary, and your responses will be kept strictly confidential. Please try to answer all of the questions. We think you will find the questions interesting and we greatly appreciate your participation. 


\section{Section 1}

The following questions help us obtain a picture of what ideas you have about Attention Deficit/Hyperactivity Disorder. Please base your responses on the current knowledge that you have. If you are unsure of an answer, respond "Don't Know" (DK). Do not guess. (Circle choice)

Q-1 ADHD can be caused by poor parenting practices.

T F DK

Q-2 ADHD can often be caused by sugar or food additives.

T F DK

Q-3 Children with ADHD are born with biological vulnerabilities

T F DK toward inattention and poor self-control.

Q-4 Children with ADHD misbehave primarily because they don't want to follow rules and complete assignments.

Q-5 The inattention of children with ADHD is not primarily a

T F DK consequence of defiance, oppositionality, and a unwillingness to please others.

Q-6 ADHD is a medical disorder that can only be treated with medication.

Q-7 Children with ADHD could do better if they only would try harder.

T F DK

Q-8 Children with ADHD have difficulty sustaining attention in tasks or play activities.

Q-9 Most children with ADHD outgrow their disorder and are normal as adults.

T F DK

T F DK

Q-10 ADHD can be inherited.

T F DK

T F DK

Q-11 ADHD occurs equally as often in girls as boys.

T F DK

Q-12 Children with ADHD can be described as children on the go

T F DK or who act as if driven by a motor.

Q-13 ADHD occurs more in minority groups than in Caucasian groups. $\quad T \quad F \quad D K$

Q-14 If medication is prescribed educational interventions are

T F DK are often unnecessary.

Q-15 If a child can get excellent grades one day and awful grades the next, then he/she must not be ADHD.

T F DK

Q-16 Diets are usually not helpful in treating most children with ADHD. T F DK

Q-17 Children with ADHD usually avoid tasks that require sustained $\quad$ T F DK mental effort.

Q-18 If a child can play video games for hours, he/she probably isn't ADHD.

T F DK 
Q-19 Children with ADHD have a high risk for becoming delinquent as teenagers.

Q-20 Children with ADHD are typically better behaved in 1-to-1 interactions than in a group situation.

Q-21 ADHD often results from a chaotic, dysfunctional family life.

Q-22 Children with ADHD have lower IQ than their peers.

Q-23 Hallucinations are associated with ADHD.

Q-24 In order to have the diagnosis of ADHD, both hyperactivity and inattentiveness must be present.

Q-25 ADHD may express itself in only one environment.

Q-26 Children with ADHD generally display an inflexible adherence to specific routines and rituals.

Q-27 ADHD derives from emotional imbalance.

Q-28 A therapy which focuses on obedience is used in the treatment of ADHD.

Q-29 ADHD may begin in adolescence.
T F DK

T F DK

T F DK

T F DK

T F DK

T F DK

T F DK

T F DK

T F DK

T F DK

T F DK

\section{$\underline{\text { Section } 2}$}

Read the following vignette to prepare you to answer the questions in this section.

Adam is a 9-year old student who has a long history of being easily distracted by extraneous stimuli, has problems with keeping his attention focused, fails to pay attention to details, and makes careless mistakes in his school work. He has also consistently failed in reading. In addition to being distracted, Adam has a tendency to blurt out answers before questions have been completed, has a difficult time waiting his turn, and often interrupts others. Compounding these problems is the fact that Adam often forgets to complete daily activities and loses things necessary for various assignments (e.g. pencils, books, homework, etc.). Also problematic is his tendency to disrupt the class by leaving his seat at inappropriate times. Both parents and teachers say that in one-to-one situations, Adam can be frustrating to work with because he often does not seem to listen when spoken to directly and has a difficult time organizing himself in tasks and activities. Adam also seems to be on the go and acts as if driven by a motor, frequently fidgets and talks excessively. His mother describes him as having difficulty sustaining attention to tasks and play activities and avoids tasks that require mental effort such as homework.

Taking the vignette into consideration, please circle the number that appears most like your views. Use the following scale for each statement.

$1=$ Strongly disagree

4 = Slightly Agree

$$
\begin{aligned}
& 2=\text { Moderately Disagree } \\
& 5=\text { Moderately Agree }
\end{aligned}
$$

$$
\begin{aligned}
& 3=\text { Slightly Disagree } \\
& 6=\text { Strongly Agree }
\end{aligned}
$$


Q-1 Children with Adam's behaviors are probably born with

$\begin{array}{llllll}1 & 2 & 3 & 4 & 5 & 6\end{array}$ a genetic predisposition towards hyperactivity and poor self-control.

Q-2 Stress and conflict in the child's home life can cause $\begin{array}{llllll}1 & 2 & 3 & 4 & 5 & 6\end{array}$ behaviors like Adam's.

Q-3 Behaviors like Adam's are more likely to be the result of $\quad 1 \quad 2 \quad \begin{array}{llllll}1 & 2 & 3 & 4 & 5 & 6\end{array}$ an active personality rather than a disorder.

Q-4 Behaviors like Adam's are often the result of unclear expectations in the classroom.

Q-5 Adam has probably learned to be the way that he is. $\quad \begin{array}{llllll}1 & 2 & 3 & 4 & 5 & 6\end{array}$

Q-6 $\quad$ Lacking basic skills in an academic area (e.g. Adam's $\quad \begin{array}{lllllll}1 & 2 & 3 & 4 & 5 & 6\end{array}$ lack of basic reading skills) often causes children to have difficulty paying attention.

Q-7 Adam's behaviors are more likely the result of immaturity than an attentional disorder (ADHD).

$\begin{array}{llllll}1 & 2 & 3 & 4 & 5 & 6\end{array}$

Q-8 $\quad \begin{array}{llllllll} & \text { Behaviors like Adam's can result from certain parenting } & 1 & 2 & 3 & 4 & 5 & 6\end{array}$ methods, such as little positive reinforcement for good behavior and attention for bad behavior.

Q-9 Behaviors like Adam's can result when classroom expectations are incongruent with the developmental abilities of the student.

Q-10 Rather than refer him to a doctor for these behaviors, Adam's teacher should first find ways to try classroom interventions to improve Adam's disruptive behavior.

Q-12 Behavior interventions with children like Adam often not work unless they are treated with stimulant medications first.

Q-13 Adam's teacher should try classroom interventions to improve his academic achievement before referring him $\begin{array}{llllll}1 & 2 & 3 & 4 & 5 & 6\end{array}$ for a special education evaluation.

Q-14 If students like Adam do not receive stimulant treatment $\quad \begin{array}{llllll}1 & 2 & 3 & 4 & 5 & 6\end{array}$ to treat their hyperactivity, impulsivity, and/or inattention, they will probably be worse off in the long run.

Q-15 If Adam's behavior markedly improves after taking the $\begin{array}{llllll}1 & 2 & 3 & 4 & 5 & 6\end{array}$ stimulant medication, it would seem to indicate that the has an attentional disorder (ADHD).

Q-16 Stimulant medication is a safe way to improve behaviors $\quad \begin{array}{llllll}1 & 2 & 3 & 4 & 5 & 6\end{array}$ like Adam's. 
Q-17 Too many children in the U.S., like Adam, receive stimulant medication.

Q-18 $\quad$ Before his behavior can be improved, Adam needs to be $\quad \begin{array}{lllllll}1 & 2 & 3 & 4 & 5 & 6\end{array}$ evaluated by a pediatrician or child psychiatrist, so he can be treated with stimulant medication.

Q-19 It is a disservice to children with behaviors like Adam's $\quad \begin{array}{llllll}1 & 2 & 3 & 4 & 5 & 6\end{array}$ when they do not receive stimulant medication.

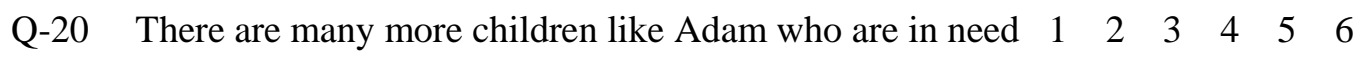
of stimulant treatment for their behaviors but do not presently receive it.

Q-21 Children like Adam can be treated with behavior modifications for their behaviors.

Q-22 Children like Adam would benefit from therapy. $\quad \begin{array}{llllll}1 & 2 & 3 & 4 & 5 & 6\end{array}$

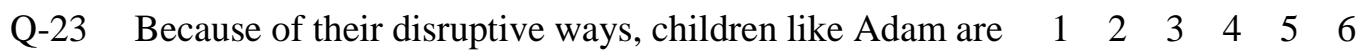
best handled in a special education classroom

Q-24 At times it is difficult to work effectively with children $\quad \begin{array}{llllll}1 & 2 & 3 & 4 & 5 & 6\end{array}$ like Adam.

Q-25 Children like Adam need to try harder in school. $\quad \begin{array}{llllll}1 & 2 & 3 & 4 & 5 & 6\end{array}$

Q-26 Other children in the classroom suffer the most because $\quad \begin{array}{llllll}1 & 2 & 3 & 4 & 5 & 6\end{array}$ Adam is in classroom

Q-27 Classroom teachers should make modifications/ $\begin{array}{llllll}1 & 2 & 3 & 4 & 5 & 6\end{array}$ accommodations to help children like Adam succeed academically and socially in the school setting.

Q-28 It is important to communicate and/or collaborate more $\quad \begin{array}{lllllll}1 & 2 & 3 & 4 & 5 & 6\end{array}$ often with the parents of children like Adam .

Q-29 Children like Adam can be successful academically. $\quad \begin{array}{lllllll}1 & 2 & 3 & 4 & 5 & 6\end{array}$

Q-30 Teachers can experience stress when teaching children $\quad \begin{array}{lllllll}1 & 2 & 3 & 4 & 5 & 6\end{array}$ like Adam.

Q-31 Teachers should be willing to support and assist children $\quad 1 \quad 2 \quad \begin{array}{lllll} & 2 & 4 & 5 & 6\end{array}$ like Adam in any way possible.

Q-32 Teachers should learn as much as they can about ADHD. $\begin{array}{llllll}1 & 2 & 3 & 4 & 5 & 6\end{array}$

Q-33 Teachers would benefit from additional ADHD training. $\quad \begin{array}{llllll}1 & 2 & 3 & 4 & 5 & 6\end{array}$ 
For the following questions, use the following scale for each statement.

$1=$ Not at all Effective $2=$ Slightly Effective $3=$ Moderately Effective

$4=$ Effective $5=$ Very Effective

Q-34 How effective will each intervention be in improving Adam's disruptive, hyperactive and impulsive classroom behaviors?
a. Medication Intervention
$\begin{array}{lllll}1 & 2 & 3 & 4 & 5\end{array}$
b. Behavioral Intervention
$\begin{array}{lllll}1 & 2 & 3 & 4 & 5\end{array}$
c. Educational Intervention
$\begin{array}{lllll}1 & 2 & 3 & 4 & 5\end{array}$

Q-35 How effective will each intervention be in improving Adam's academic achievement in the long run?
a. Medication Intervention
$\begin{array}{lllll}1 & 2 & 3 & 4 & 5\end{array}$
b. Behavioral Intervention
$\begin{array}{lllll}1 & 2 & 3 & 4 & 5\end{array}$
c. Educational Intervention
$\begin{array}{lllll}1 & 2 & 3 & 4 & 5\end{array}$

Q-36 How effective will each intervention be in improving Adam's attention in the classroom?
a. Medication Intervention
$\begin{array}{lllll}1 & 2 & 3 & 4 & 5\end{array}$
b. Behavioral Intervention
$\begin{array}{lllll}1 & 2 & 3 & 4 & 5\end{array}$
c. Educational Intervention
$\begin{array}{lllll}1 & 2 & 3 & 4 & 5\end{array}$

\section{$\underline{\text { Section } 3}$}

The next questions are about your background. In studies like these, we like to compare the experiences of people from varying backgrounds. (Circle correct number)

Q-1 What is your gender?

1. MALE

2. FEMALE

Q-2 What is highest degree you have earned?

1. BACHELOR'S DEGREE (BA, BS, ETC)

2. MASTER'S DEGREE (MA, MS, ETC)

3. DOCTORAL DEGREE (PH.D OR ED.D)

4. OTHER ADVANCED DEGREE 
Q-3 What grade/s level/s are you currently teaching?

1. $\mathrm{PREK} / \mathrm{K}$

2. 1-3

3. $4-6$

4. $7-8$

5. $9-12$

6. MULTIGRADE (1-4)_ OR (5-8)

7. OTHER

Q-4 What certificate/s or license/s do your currently hold?

1. EARLY CHILDHOOD EDUCATION

2. ELEMENTARY EDUCATION

3. MIDDLE SCHOOL

4. HIGH SCHOOL

5. SPECIAL EDUCATION

6. OTHER

Q-5 How many years of teaching experience do you have?

Q-6 What is your racial or ethnic background?

1. ASIAN

2. BLACK OR AFRICAN AMERICAN

3. CAUSIAN OR WHITE (NOT HISPANIC)

4. HISPANIC/LATINO

5. OTHER

Q-7 What conference do you teach in?

1. BERMUDA

2. GREATER NEW YORK

3. NEW YORK

4. NORTHERN NEW ENGLAND

5. SOUTHERN NEW ENGLAND

\section{$\underline{\text { Section } 4}$}

Finally, tell us about your experience with and exposure to ADHD. (Circle number)

Q-1 Did you receive any instruction about ADHD as part of your teacher training?

1. NO

2. YES, BRIEFLY DURING COURSEWORK/FIELD PRACTICUM

3. YES, EXTENSIVELY DURING COURSEWORK/FIELD PRACTICUM 
Q-2 How many children have you taught whom you know were identified by a medical doctor or psychologist as having ADHD?

1. NONE

2. 1 or 2

$3.3-5$

4. 6 or MORE

Q-3 How many children have you taught whom you know were not identified as ADHD but you think should have been?

1. NONE

2. 1 or 2

$3.3-5$

4. 6 or MORE

Q-4 Have you received any training about ADHD after your began teaching?

1. NO

2. YES, BRIEF IN-SERVICE TRAINING

3. YES, COMPREHENSIVE WORKSHOP

Q-5 Have you taken any graduate courses pertaining to ADHD?

1. NO

2. YES

Q-6 How many articles have you read about ADHD?

1. NONE

2. 1 or 2

$3.3-5$

4. 6 or MORE

Q-7 How many books have you read about ADHD?

1. NONE

2. 1 or 2

3. $3-5$

4. 6 or MORE

Q-8 How many informational programs or videos about ADHD have you viewed?

1. NONE

2. 1 or 2

$3.3-5$

4. 6 or MORE

Q-9 Do you know anyone outside of school who has ADHD?

1. NO

2. YES 
This completes the survey. Thank you for taking your time to help us with our research study. Is there any additional information that you would like to share with us? If so, please use this space for that purpose.

Thank you for taking the time to participate in this survey! Your contribution is greatly appreciated. 


\section{ANDREWS UNIVERSITY}

Educational and Psychology Department

Bell Hall

100 Old US 31

Berrien Springs, MI 49104

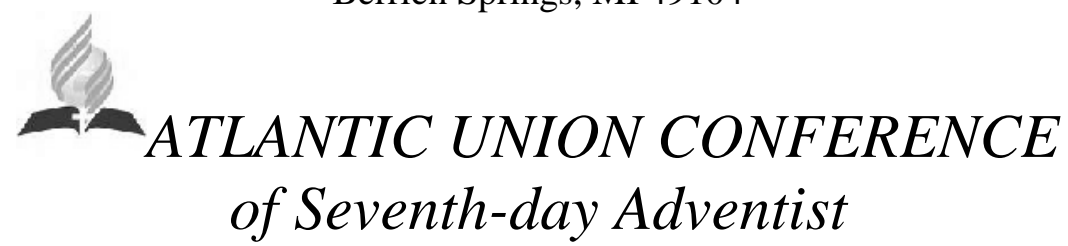

\section{Ideas and Views of Parents about Children Who Need Special Assistance ${ }_{1}$}

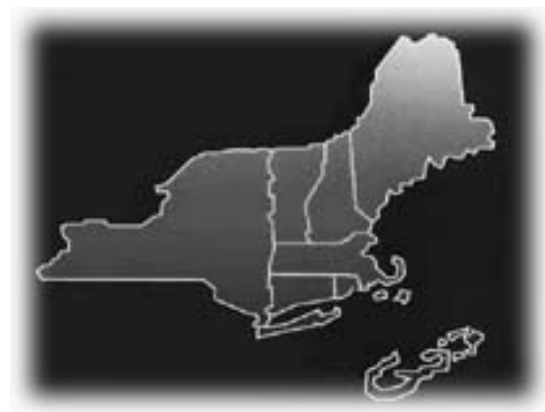

This questionnaire seeks to capture vital information about the ideas and views of parents in the Atlantic Union Conference about children who need special assistance. Your participation is completely voluntary, and your responses will be kept strictly confidential. Please try to answer all questions. We think you will find the questions interesting and we greatly appreciate your participation. 


\section{Section 1}

The following questions help us obtain a picture of what ideas you have about Attention Deficit/Hyperactivity Disorder. Please base your responses on the current knowledge that you have. If you are unsure of an answer, respond "Don't Know" (DK). Do not guess. (Circle choice)

Q-1 ADHD can be caused by poor parenting practices.

T F DK

Q-2 ADHD can often be caused by sugar or food additives.

T F DK

Q-3 Children with ADHD are born with biological vulnerabilities toward inattention and poor self-control.

T F DK

Q-4 Children with ADHD misbehave primarily because they don't want to follow rules and complete assignments.

Q-5 The inattention of children with ADHD is not primarily a consequence of defiance, oppositionality, and a unwillingness to please others.

Q-6 ADHD is a medical disorder that can only be treated with medication.

Q-7 Children with ADHD could do better if they only would try harder.

T F DK

T F DK

T F DK

T F DK

T F $\quad$ DK

Q-8 Children with ADHD have difficulty sustaining attention in tasks or play activities.

Q-9 Most children with ADHD outgrow their disorder and are $\quad$ T $\quad$ F $\quad$ DK normal as adults.

Q-10 ADHD can be inherited. $\quad$ T F DK

Q-11 ADHD occurs equally as often in girls as boys. $\quad$ T $F \quad$ DK

Q-12 Children with ADHD can be described as children on the go or $\quad$ T $\quad F \quad$ DK who act as if driven by a motor.

Q-13 ADHD occurs more in minority groups than in Caucasian groups. $\quad \mathrm{T} \quad \mathrm{F} \quad \mathrm{DK}$

Q-14 If medication is prescribed, educational interventions are $\quad$ T $\quad F \quad$ DK are often unnecessary.

Q-15 If a child can get excellent grades one day and awful grades $\quad$ T $\quad F \quad$ DK the next, then he/she must not be ADHD.

Q-16 Diets are usually not helpful in treating most children with ADHD. T F DK

Q-17 Children with ADHD usually avoid tasks that require sustained $\quad$ T F DK mental effort.

Q-18 If a child can play video games for hours, he/she probably $\quad$ T F DK isn't ADHD. 
Q-19 Children with ADHD have a high risk for becoming delinquent as teenagers.

Q-20 Children with ADHD are typically better behaved in 1-to-1 interactions than in a group situation.

Q-21 ADHD often results from a chaotic, dysfunctional family life.

Q-22 Children with ADHD have lower IQ than their peers.

Q-23 Hallucinations are associated with ADHD.

Q-24 In order to have the diagnosis of ADHD, both hyperactivity and inattentiveness must be present.

Q-25 ADHD may express itself in only one environment.

Q-26 Children with ADHD generally display an inflexible adherence to specific routines and rituals.

Q-27 ADHD derives from emotional imbalance.

Q-28 A therapy which focuses on obedience is used in the treatment of ADHD.

Q-29 ADHD may begin in adolescence.
T F DK

T F DK

T F DK

T F DK

T F DK

T F DK

T F DK

T F DK

T F DK

T F DK

T F DK

\section{$\underline{\text { Section } 2}$}

Read the following vignette to prepare you to answer the questions in this section.

Adam is a 9-year old student who has a long history of being easily distracted by irrelevant stimuli, has problems with keeping his attention focused, fails to pay attention to details, and makes careless mistakes in his school work. He has also consistently failed in reading. In addition to being distracted, Adam has a tendency to blurt out answers before questions have been completed, has a difficult time waiting his turn, and often interrupts others. Compounding these problems is the fact that Adam often forgets to complete daily activities and loses things necessary for various assignments (e.g. pencils, books, homework, etc.). Also problematic is his tendency to disrupt the class by leaving his seat at inappropriate times. Both parents and teachers say that in one-to-one situations, Adam can be frustrating to work with because he often does not seem to listen when spoken to directly and has a difficult time organizing himself in tasks and activities. Adam also seems to be on the go and acts as if driven by a motor, frequently fidgets and talks excessively. His mother describes him as having difficulty sustaining attention to tasks and play activities and avoids tasks that require mental effort such as homework.

Taking the vignette into consideration, please circle the number that appears most like your views. Use the following scale for each statement.

$1=$ Strongly disagree $\quad 2=$ Moderately Disagree

$4=$ Slightly Agree
$2=$ Moderately Disagree
$5=$ Moderately Agree
$3=$ Slightly Disagree

$6=$ Strongly Agree 
Q-1 $\quad \begin{array}{llllllll} & \text { Children with Adam's behaviors are probably born with a } & 1 & 2 & 3 & 4 & 5 & 6\end{array}$ genetic predisposition towards hyperactivity and poor self-control.

Q-2 $\quad$ Stress and conflict in the child's home life can cause $\quad \begin{array}{llllll}1 & 2 & 3 & 4 & 5 & 6\end{array}$ behaviors like Adam's.

Q-3 Behaviors like Adam's are more likely to be the result of $\quad 1 \quad 2 \quad \begin{array}{llllll}1 & 2 & 3 & 4 & 5 & 6\end{array}$ an active personality rather than a disorder.

Q-4 Behaviors like Adam's are often the result of unclear $\quad \begin{array}{llllll}1 & 2 & 3 & 4 & 5 & 6\end{array}$ expectations in the classroom.

Q-5 Adam has probably learned to be the way that he is. $\quad \begin{array}{llllll}1 & 2 & 3 & 4 & 5 & 6\end{array}$

Q-6 $\quad$ Lacking basic skills in an academic area (e.g. Adam's $\quad \begin{array}{llllll}1 & 2 & 3 & 4 & 5 & 6\end{array}$ lack of basic reading skills) often causes children to have difficulty paying attention.

Q-7 Adam's behaviors are more likely the result of immaturity than an attentional disorder (ADHD).

Q-8 $\quad$ Behaviors like Adam's can result from certain parenting $\quad 1 \quad 2 \quad 2 \quad 3 \quad 4 \quad 5 \quad 6$ methods, such as little positive reinforcement for good behavior and attention for bad behavior.

Q-9 Behaviors like Adam's can result when classroom expectations are dissimilar with the developmental abilities of the student.

Q-10 Rather than refer him to a doctor for these behaviors, $\quad \begin{array}{llllll}1 & 2 & 3 & 4 & 5 & 6\end{array}$ Adam's teacher should first find ways to try classroom interventions to improve Adam's disruptive behavior.

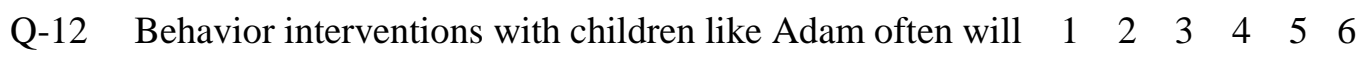
not work unless they are treated with stimulant medications first.

Q-13 Adam's teacher should try classroom interventions to $\quad \begin{array}{llllll}1 & 2 & 3 & 4 & 5 & 6\end{array}$ improve his academic achievement before referring him for a special education evaluation.

Q-14 If students like Adam do not receive stimulant treatment $\quad 1 \quad 2 \quad 2 \quad 3 \quad 4 \quad 4 \quad 5 \quad 6$ to treat their hyperactivity, impulsivity, and/or inattention, they will probably be worse off in the long run.

Q-15 If Adam's behavior markedly improves after taking the $\begin{array}{llllll}1 & 2 & 3 & 4 & 5 & 6\end{array}$ stimulant medication, it would seem to indicate that the has an attentional disorder (ADHD). 
Q-16 Stimulant medication is a safe way to improve behaviors $\quad 1 \quad 2 \quad \begin{array}{llllll}1 & 2 & 4 & 5 & 6\end{array}$ like Adam's.

Q-17 Too many children in the U.S., like Adam, receive $\quad \begin{array}{llllll}1 & 2 & 3 & 4 & 5 & 6\end{array}$ stimulant medication.

Q-18 Before his behavior can be improved, Adam needs to be $\begin{array}{llllll}1 & 2 & 3 & 4 & 5 & 6\end{array}$ evaluated by a pediatrician or child psychiatrist, so he can be treated with stimulant medication.

Q-19 It is a disservice to children with behaviors like Adam's $\quad \begin{array}{llllll}1 & 2 & 3 & 4 & 5 & 6\end{array}$ when they do not receive stimulant medication.

Q-20 There are many more children like Adam who are in need of stimulant treatment for their behaviors but do not presently receive it.

Q-21 Children like Adam can be treated with behavior modifications for their behaviors.

Q-22 Children like Adam would benefit from therapy.

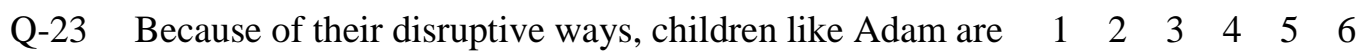
best handled in a special education classroom.

Q-24 At times it is difficult to work effectively with children $\quad \begin{array}{llllll}1 & 2 & 3 & 4 & 5 & 6\end{array}$ like Adam.

Q-25 Children like Adam need to try harder in school.

Q-26 Other children in the classroom suffer the most because $\quad \begin{array}{llllll}1 & 2 & 3 & 4 & 5 & 6\end{array}$ Adam is in classroom

Q-27 Classroom teachers should make modifications/ accommodations to help children like Adam succeed academically and socially in the school setting.

Q-28 It is important to communicate and/or collaborate more $\begin{array}{lllllll}1 & 2 & 3 & 4 & 5 & 6\end{array}$ often with the teachers of children like Adam.

Q-29 Children like Adam can be successful academically. $\quad \begin{array}{lllllll}1 & 2 & 3 & 4 & 5 & 6\end{array}$

Q-30 Parents can experience stress when parenting children $\quad \begin{array}{llllllll}1 & 2 & 3 & 4 & 5 & 6\end{array}$ like Adam.

Q-31 Parents should be willing to support and assist children $\quad \begin{array}{llllll}1 & 2 & 3 & 4 & 5 & 6\end{array}$ like Adam in any way possible.

Q-32 Parents should learn as much as they can about ADHD. $\quad \begin{array}{llllll}1 & 2 & 3 & 4 & 5 & 6\end{array}$

Q-33 Parents would benefit from additional ADHD training. $\quad \begin{array}{lllllll}1 & 2 & 3 & 4 & 5 & 6\end{array}$ 
For the following questions, use the following scale for each statement.

$1=$ Not at all Effective $2=$ Slightly Effective $3=$ Moderately Effective

$4=$ Effective $5=$ Very Effective

Q-34 How effective will each intervention be in improving Adam's disruptive, hyperactive and impulsive classroom behaviors?
a. Medication Intervention
$\begin{array}{lllll}1 & 2 & 3 & 4 & 5\end{array}$
b. Behavioral Intervention
$\begin{array}{lllll}1 & 2 & 3 & 4 & 5\end{array}$
c. Educational Intervention
$\begin{array}{lllll}1 & 2 & 3 & 4 & 5\end{array}$

Q-35 How effective will each intervention be in improving Adam's academic achievement in the long run?
a. Medication Intervention
$\begin{array}{lllll}1 & 2 & 3 & 4 & 5\end{array}$
b. Behavioral Intervention
$\begin{array}{lllll}1 & 2 & 3 & 4 & 5\end{array}$
c. Educational Intervention
$\begin{array}{lllll}1 & 2 & 3 & 4 & 5\end{array}$

Q-36 How effective will each intervention be in improving Adam's attention in the classroom?
a. Medication Intervention
$\begin{array}{lllll}1 & 2 & 3 & 4 & 5\end{array}$
b. Behavioral Intervention
$\begin{array}{lllll}1 & 2 & 3 & 4 & 5\end{array}$
c. Educational Intervention
$\begin{array}{lllll}1 & 2 & 3 & 4 & 5\end{array}$

\section{$\underline{\text { Section } 3}$}

The next questions are about your background. In studies like these, we like to compare the experiences of people from varying backgrounds. (Circle correct number)

Q-1 What is your gender?

1. MALE

2. FEMALE

Q-2 What is your education level?

1. BELOW HIGH SCHOOL

2. HIGH SCHOOL

3. UNDERGRADUATE

4. GRADUATE 
Q-3 What is your marital status?

1. SINGLE

2. MARRIED

3. SEPARATED

4. DIVORCED

5. WIDOWED

Q-4 What is your racial or ethnic background?

1. ASIAN

2. BLACK OR AFRICAN AMERICAN

3. CAUCASIAN OR WHITE (NOT HISPANIC)

4. HISPANIC/LATINO

5. OTHER

Q-5 What conference do you live in?

1. BERMUDA

2. GREATER NEW YORK

3. NEW YORK

4. NORTHERN NEW ENGLAND

5. SOUTHERN NEW ENGLAND

\section{$\underline{\text { Section } 4}$}

Finally, tell us about your experience with and exposure to ADHD. (Circle number)

Q-1 Has anyone in your family been evaluated for ADHD?

1. NO

2. YES

Q-2 Has anyone in your family been identified by a medical doctor or psychologist as having ADHD?

1. NO

2. YES

Q-3 Has anyone in your family been treated for ADHD?

1. PRESENTLY TREATED

2. PREVIOUSLY TREATED

3. NEVER

4. NOT APPLICABLE

Q-4 How many magazine/newspaper articles have you read about ADHD?

1. NONE

2. 1 or 2

$3.3-5$

4. 6 or MORE 
Q-5 How many informational programs or videos about ADHD have you viewed?

1. NONE

2. 1 or 2

$3.3-5$

4. 6 or MORE

Q-6 How many books about ADHD have you read?

1. NONE

2. 1 or 2

3. $3-5$

4. 6 or MORE

Q-7 How many lectures/presentations about ADHD have you attended?

1. NONE

2. 1 or 2

$3.3-5$

4. 6 or MORE

Q-8 Have you ever belonged to an ADHD Parent Support Group?

1. PRESENTLY BELONG

2. PREVIOUSLY BELONGED

3. NEVER

4. NOT APPLICABLE

Q-9 Do you know anyone outside of your family who has ADHD?

1. NO

2. YES 
This completes the survey. Thank you for taking your time to help us with our research study. Is there any additional information that you would like to share with us? If so, please use this space for that purpose.

Thank you for taking the time to participate in this survey! Your contribution is greatly appreciated. 
APPENDIX E

LETTERS 
Letter to Atlantic Union Conference K-12 Board

To: K-12 Boards of the Atlantic Union

From: Kendra-Lee Pearman

September $27^{\text {th }}, 2005$

My name is Kendra-Lee Pearman and I am a PhD candidate who is endeavoring to do my dissertation research in the area of Attention Deficit Hyperactivity Disorder (ADHD). This research will take the form of a survey directed to teachers and parents of students from K-12 in the Atlantic Union schools. Currently I am an assistant professor at Atlantic Union College serving in the Center for Academic Success and the Education/Psychology departments. I am a strong believer in Christian education and all three of my children have attended SDA schools for the duration of their education.

My interest in ADHD stems from my teenage son who was identified as having ADHD (inattentive type) in the $2^{\text {nd }}$ grade. As an educator and a parent of a child with ADHD, I have realized the importance of having adequate knowledge about this disorder in order to interact positively and effectively with children who have it. Of all of the disabilities and disorders that students may present with, the most common is ADHD, which affects about $3-7 \%$ of school aged children in the United States and other countries. As a result of these statistics, it is probable that every classroom in the Atlantic Union could have a child with ADHD enrolled in it; therefore, it is necessary for both teachers and parents to have an adequate knowledge of the disorder in order to positively and effectively interact with those who have the disorder. Much information is available in the public media and from many sources today, but we do not know how much of this information is retained by the public and how that information influences our feelings about children with ADHD. There are some studies available but none investigating the knowledge base of SDA parents and teachers.

Should this research project be approved, the results would be beneficial to the conferences, schools, parents, and students of the Atlantic Union for it would put into perspective the knowledge levels of both teachers and parents. Once these results are known, conferences and schools could implement training for teachers and parents about the disorder if it is deemed necessary. If adequate knowledge is already possessed, then the results will show that our conferences and schools are where they need to be in reference to this disorder.

Dissertation Topic:

An investigation of the knowledge held by parents and teachers in the Atlantic Union concerning Attention Deficit/Hyperactivity Disorder. 
Intended Participants:

Randomly selected teachers and parents of students from K-12 in the Atlantic Union Schools

\section{Research Purpose:}

The purpose of this research is to ascertain the knowledge levels and attitudes of teachers and parents in the Atlantic Union with regard to ADHD.

Date Collection:

The data collection will be quantitative in nature (tentative surveys attached)

The Office of Scholarly Research of Andrews University requires me to complete an application for approval to conduct human subject research, send a cover letter to all participants in the research, and obtain informed consent from them to participate in the data collection process. They also expect me to adhere to all of the preset guidelines for conducting this type of research.

Please note the following in regards to the nature of this research:

- The survey is intended ONLY for parents and teachers

- The survey is knowledge based only

- Students/children will not be surveyed or contacted in reference to this research

- Both parents and teachers will be randomly selected to participate in the research

- The survey is anonymous

- No student will be labeled as having "ADHD" by this research/er. If a parent discloses that his/her child has ADHD, it will not be known to the researcher who that parent or child is due to the anonymity of the instrument

- The only information that I will need is the addresses of parents who have been randomly selected for participation in the research so that I can mail the surveys to them and follow-up reminders. Once this has been done, the addresses will be destroyed. If the disclosing of parents' addresses is a sensitive issue, then the addresses can be compiled by the education office of the Atlantic Union with the surveys and reminders being distributed from there so that the researcher never has to be privy to that information.

- The randomly selected teachers will receive their surveys via the school; therefore, there is no need to disclose addresses for them.

If there are any other questions or concerns, please contact me at your earliest convenience. Thank you for your attention in this matter and I hope to have approval for this dissertation research soon. May God continue to bless you all.

Kendra-Lee Pearman 


\section{Permission Letters from Conferences}

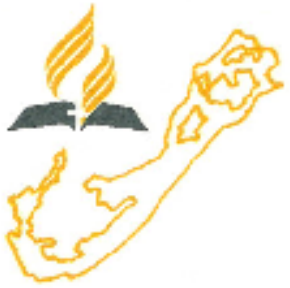

Octoher I1,2005

\section{SEVENTH-DAY ADVENTIST \\ CHURCH}

Bermuda Conference

P.O. Box HM 1170

Harrilton HM EX

Bermutla

Felephon: $141 \cdot 292-1110$

Fax: $441-295-2993$

Kendra L.ee Pearman

P.O. Box 1631

South I.ancuster. MA

01561, USA

Dear Kendra Lec:

Christian Greeting!

The Bemnuda Insti.ule Schocol Boari voted at its scheduled meeting to grant permission for you to conduct research on ADHD using our parcnt and teacher population.

We are unable however, to release our student'parent data base information. We suggest that all of the students' parents be given the opportunity to fill oul the survey and you can collect the data from the returned responses.

We wish you every success as you pursue your educational goals.

Most sincerely,

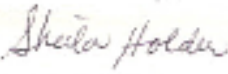

Sheila Holder

Superintendent of Education

$\mathrm{mh}$ 

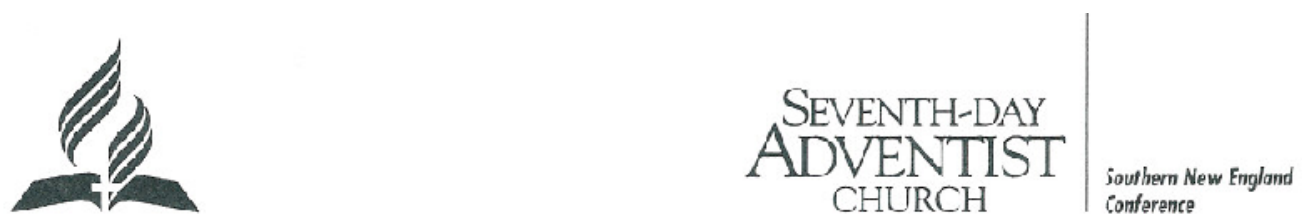

October 19, 2005

Kendra-Lee Pearman

(1) Bax 1139

$\therefore$ Sawyer Steet

'cutn Lancosta', MM 01567*16 6

Telephone: (978) $355-4551$

Atlantic Union College

$\operatorname{Fax}(778) 3353838$

South Lancaster MA 01561

Dear Kendra,

On September 29, 2005, the Southern New England PreK-12 Board of Education voted to supporl your research ascertaining the knowledge levels and attitudes of teachers and parents in the Atlantic Union Conference with regard to attention deficit hyperactive disorder. We are unable, however, to provide you with the names, addresses or grade level of students enrolled in our schools.

The official action states, "Voted to approve the request from Kendra Lee Pearman to conduct research subject to the following: names and personal data will not be released to the researcher, and parents may opt out of participating in the survey."

You would be welcome to have the surveys distributed via the schools to all of their students in such a way that no personal information would be disclosed.

Kendra, I hope this helps and that the rest of your dissertation flows smoothly and easily to successful completion!

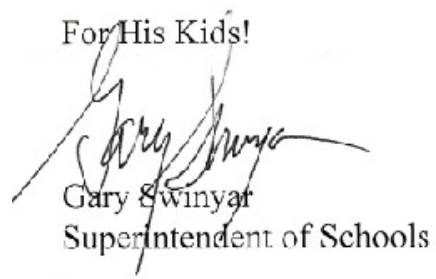




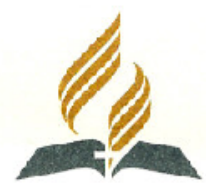

November 2, 2005

Dear Kendra-I.ee,

The Northern New England Conference voted that you may send a survey letter through our conference schools to all parents and tcachers. Each family can then make a decision on joining the research project and voluntarily participate. This action was taken on Octobner 7,2005.

It is my hope that this project will be a blessing to children and families in the future.

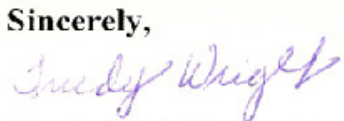

Trudy Wright 


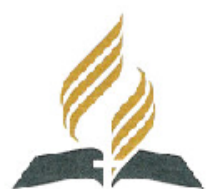

February 14, 2006

Professor Kendra-Lec Pearman

Atlantic Union College

Fducation Department

South Lancaster, MA 01561

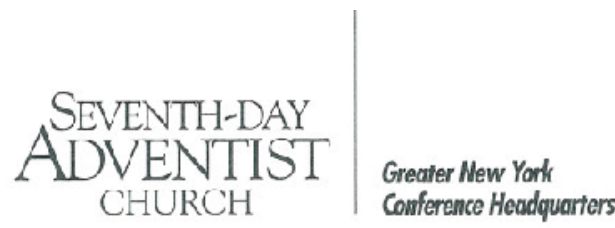

Departmeni of Education

PD Bo 5029

7 Sheler Rock Rood

Nonhossot, NY $11030-9878$

Telagivo: (516i 627.935:

Fax: (516) 627.927?

email: 1014712315@compuserve.con

Dear Professor Pearman:

Christian greetings!

This notice is to inform you that the GNYC K-12 Board of Education met on December 7,2005 and voted unanimously to authorize the distribution of your survey to our teachers and parents. (We look forward to recciving your final draft).

It was a pleasure seeing you last week. I wish you all the best as you complete your dissertation research. Your findings could prove to be very beneficial to SDA educators as well as families having ADHD children. (Incidentally, your son demonstrated extreme patience for a young man his age. We conversed for quite awhile, and he conducted himself as a Christian gentleman during the entire time). Please say "hi" to your son.

May God bless you in your continued service for the Master.

Sincerely,

Dowe

David A. Cadavero

Superintendent of Schools

$\mathrm{DC} / \mathrm{kj}$ 

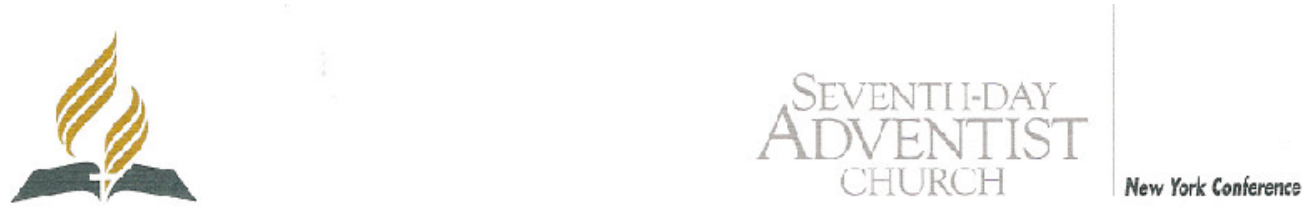

December 7, 2005

4530 Nest Seneco uripike

Syrocuse, Nen York 1:215-4203

(slemone (3 5) 459.6921

Fax (315) 465.00 .24

Kendra-Lee Pearman

Atlantic Union College

PO Box 100

South Lancaster MA 01561

\section{Dear Kendra-Lee}

This letter is to officially notify you that the New York Conference K-12 Board voted on November 3, 2005 "to accept the dissertation request by Kendra-Lee Pearmen to solicit random samples of the parents/teachers in the New York Conference to participate in a study seeking to discover the level of understanding ahout $A$ DHD."

We will try to be of assistance to you as much as needed and to the level that we are capable. We trust that all the information that you've gleaned will be confidentially used for research purposes only.

May this research bring information that will be of benefit to the education of our young people.

Sincercly,

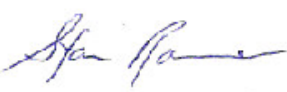

Stan Rouse

President'Superintendent

SR:dr 


\title{
Letters to Parents/Guardians
}

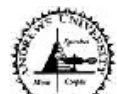 ANDREWS UNIVERSITY}

\author{
Educational and Psychology Department \\ Bell Hall \\ 100 Old US 31 \\ Berrien Springs, MI 49104
}

October 16th, 2006

Dear Parent or Guardian,

In today's schools, there are many children who require special assistance for many reasons. In Seventh-day Adventist schools, this is becoming the norm and it is necessary for both parents and teachers to work together to help our children be successful in the academic environment. For this reason, I am conducting a research project for my doctoral dissertation at Andrews University and in cooperation with Atlantic Union Conference to gather important information that can be useful to the union in helping to adequately plan for children who require special assistance. I, myself, am a parent of a child who requires special assistance and who has always attended schools in the Atlantic Union Conference.

Because you have chosen to send your child to a Seventh-day Adventist school in the Atlantic Union Conference, this makes your home a special home to gather information from on this subject. Your ideas and views about children who need special assistance are of great value to this research project and will be used to help better serve the schools in the Atlantic Un ion Conference in the area of special needs.

Your part in this research project requires you to provide information about yourself and your family. You will also be required to disclose your ideas and views about children who need special assistance in SDA schools. The surveys do not require you to identify yourself or your child/children at any time and are completely anonymous. To ensure anonymity, the envelopes sent to each parent were uniformly addressed. The information that you disclose will be treated confidentially. By completing the survey, you indicate your consent to participate in this study. Participation in the study is voluntary and if at any time you decide to withdraw your participation, you are free to do so with no negative consequences to you. Therefore, your participation will in no way negatively affect you or your child/children.

The results of this research will be made available to the Atlantic Union Conference and each individual conference office in the Atlantic Union. Should you desire to receive the results directly, then you may contact me once the study is completed.

I would be most happy to answer any questions that you might have about this study. Please email me at kendraleep@comcast.net or call me in my office at 978 368-2416 or you may contact my dissertation chair, Dr. Rudi Bailey at 269 471-3346 or email him at rbailey@andrews.edu.

Thank you for your willingness to participate by completing this survey. Your participation is vitally important. Kindly return the survey by Monday, October $30^{\text {th }}, 2006$.

Sincerely,

Kendra-Lee Pearman, MS, PhD Candidate 


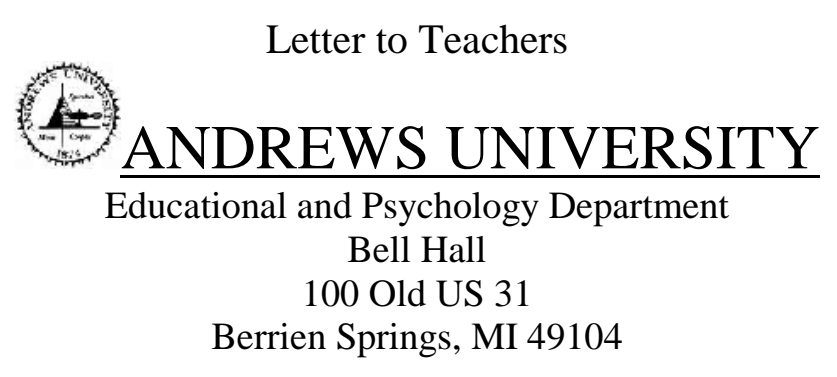

October 16th, 2006

Dear Teacher,

In today's schools, there are many children who require special assistance for many reasons. In Seventh-day Adventist schools, this is becoming the norm and it is necessary for both parents and teachers to work together to help our children be successful in the academic environment. For this reason, I am conducting a research project for my doctoral dissertation at Andrews University and in cooperation with Atlantic Union Conference to gather important information that can be useful to the union in helping to adequately plan for children who require special assistance. I, myself, am an educator in the Atlantic Union Conference who has worked with many students who need special assistance.

Because you have chosen to serve in a Seventh-day Adventist school in the Atlantic Union Conference, this makes you a special person to gather information from on this subject. Your ideas and views about children who need special assistance are of great value to this research project and will be used to help better serve the schools in the Atlantic Union Conference in the area of special needs.

Your part in this research project requires you to provide information about yourself and your students. You will also be required to disclose your ideas and views about children who need special assistance in SDA schools. The surveys do not require you to identify yourself at any time and are completely anonymous. The information that you disclose will be treated confidentially. By completing the survey, you indicate your consent to participate in this study. Participation in the study is voluntary and if at any time you decide to withdraw your participation, you are free to do so with no negative consequences to you. Consequently, your participation will in no way negatively affect you or your students.

The results of this research will be made available to the Atlantic Union Conference and each individual conference office in the Atlantic Union. Should you desire to receive the results directly, then you may contact me once the study is completed.

I would be most happy to answer any questions that you might have about this study. Please email me at kendraleep@comcast.net or call me in my office at 978 368-2416 or you may contact my dissertation chair, Dr. Rudi Bailey at 269 471-3346 or email him at rbailey@andrews.edu.

Thank you for your willingness to participate by completing this survey. Your participation is vitally important. Kindly return the survey by Monday, October $30^{\text {th }}, 2006$.

Sincerely,

Kendra-Lee Pearman, MS, PhD Candidate 
Sample letter for Parents from Superintendents

TO: Parents/Guardians

Bermuda Conference of Seventh-day Adventists

Greater New York Conference of Seventh-day Adventists

New York Conference of Seventh-day Adventists

Northern New England Conference of Seventh-day Adventists

Southern New England Conference of Seventh-day Adventists

FR: Sheila Holder, Superintendent of Schools

David A. Cadavero, Superintendent of Schools

Kim Kaiser, Superintendent of Schools

Trudy Wright, Superintendent of Schools

Gary Swinyar, Superintendent of Schools

\section{RE: Dissertation Research Project}

Christian greetings!

Kendra-Lee Pearman, a Professor at Atlantic Union College, is conducting a research project on the ideas and views of parents/guardians about children who need special assistance in the Atlantic Union Conference of Seventh-day Adventists. This study is a part of her doctorial dissertation from Andrews University and is supported by the Atlantic Union Conference and this conference. The results of this study will help in developing a better appreciation and understanding of how to better support children in the Atlantic Union who have special needs.

As part of her research study, she is requesting that each parent/guardian in the (Bermuda Conference; Greater New York Conference; New York Conference; Northern New England Conference; Southern New England Conference) complete an anonymous survey. After you have completed the survey, kindly return it to your child's teacher, who will forward them to the (BDAC, GNYC, NYC, NNEC, SNEC) Office of Education. I will forward them to Professor Pearman for final tabulation.

Professor Pearman's survey will be sent to all parents in this conference and the Atlantic Union by hand with every child in each class. The envelopes will be uniformly addressed to ensure anonymity. Because the surveys will be sent with every child in the conference, it is possible that some parents will receive more than one survey; however, it is necessary to complete only one survey. Kindly complete the surveys and return them in a timely manner so that the results can be used to better serve the schools in this conference and the Atlantic Union.

Thank you in advance for your attention in this matter. Should you have any questions or concerns, please feel free to contact me at your earliest convenience at ......... May God continue to bless you and your family abundantly. 
Sample Letter to Teachers from Superintendents

TO: Teachers

Bermuda Conference of Seventh-day Adventists

Greater New York Conference of Seventh-day Adventists

New York Conference of Seventh-day Adventists

Northern New England Conference of Seventh-day Adventists

Southern New England Conference of Seventh-day Adventists

FR: $\quad$ Sheila Holder, Superintendent of Schools

David A. Cadavero, Superintendent of Schools

Kim Kaiser, Superintendent of Schools

Trudy Wright, Superintendent of Schools

Gary Swinyar, Superintendent of Schools

\section{RE: Dissertation Research Project}

Christian greetings!

Kendra-Lee Pearman, a Professor at Atlantic Union College, is conducting a research project on the ideas and views of teachers about children who need special assistance in the Atlantic Union Conference of Seventh-day Adventists. This study is a part of her doctorial dissertation from Andrews University and is supported by the Atlantic Union Conference and this conference. The results of this study will help in developing a better appreciation and understanding of how to better support children in the Atlantic Union who have special needs.

As part of her research study, she is requesting that each teacher in the (Bermuda Conference; Greater New York Conference; New York Conference; Northern New England Conference; Southern New England Conference) complete an anonymous survey. After you have completed the survey, kindly return it to your principal or designee, who will forward them to the (BDAC, GNYC, NYC, NNEC, SNEC) Office of Education. I will forward them to Professor Pearman for final tabulation.

Professor Pearman's survey will be sent to all teachers in this conference and the Atlantic Union. Kindly complete the surveys and return them in a timely manner so that the results can be used to better serve the schools in this conference and the Atlantic Union.

Thank you in advance for your attention in this matter. Should you have any questions or concerns, please feel free to contact me at your earliest convenience at May God continue to bless you in your teaching abundantly. 
To: Teachers

From: Kendra-Lee Pearman

October 19, 2006

Good day all,

Here are the surveys for my dissertation research project that is supported by the Atlantic Union and your conference. Please distribute them to your students on Monday, October 22, 2006 or as close to that date as possible. Kindly encourage your students to take them home to their parents/guardians. Kindly encourage your parents to return them to you.

Once you have received the completed surveys, I will send you a postage paid envelope or box to return the surveys to me.

Those from larger schools should give the completed surveys to the principle or his/her designee and arrangements will be made for the return to me.

In regards to your surveys, I have included a postage paid return envelope in your packet. Please return your survey to me in that envelope.

Thank you for your attention and support in this project. May God bless you all in your service to the Master. If you have any questions or concerns, please contact me at 978 368-2416 or via email at kendraleep@comcast.net. 
To: Principals

From: Kendra-Lee Pearman

October 19, 2006

Good day all,

Here are the surveys for my dissertation research project that is supported by the Atlantic Union and your conference. Please ensure that your teachers distribute them to your students on Monday, October 22, 2006 or as close to that date as possible. Kindly encourage your teachers to encourage their parents to support the project. This information will be used to better serve the schools in the Atlantic Union concerning special needs.

The surveys from larger schools should be returned to you or your designee and arrangements will be made for their return to me.

Thank you for your attention and support in this project. May God bless you all in your service to the Master. If you have any questions, please contact me at 978 368-2416 or via email at kendraleep@comcast.net. 
APPENDIX F

WEBSITES LISTING “MYTHS”OF ADHD 


$$
\text { Websites Listing "Myths" of ADHD }
$$

1. National Resource Center on AD/HD: A Program of CHADD. http://www.help4adhd.org

2. Attention Deficit Disorder Association. http://www.add.org

3. Novartis: ADHD info. http://www.adhdinfo.com

4. Bipolar Central: http://www.bipolarcentral.com

5. Play Attention. http://www.playattention.com

6. Learning Disabilities Association of Kentucky. http://literacynetwork.verizon.org

7. ADHD Library. http://www.adhdlibrary.org

8. Concerta. http://concerta.net

9. Janseen-Cilag: Psychiatry 24X7. http://www.psychiatry24x7.com

10. Momference: A Meeting of the Moms. http://momference.wordpress.com

11. About Kids Health. http://www.aboutkidshealth.ca

12. Change Your Thinking. http://changeyourthinking.com

13. New Ideas.net: The ADHD Information Library.

http://newideas.net/adhd.adhd-information/adhd-myths 
REFERENCE LIST 


\section{REFERENCE LIST}

About Kids Health. (2008, September 4). Myths and facts about ADHD. Retrieved March 6, 2009, from http://www.aboutkidshealth.ca/ADHD/Myths-and-facts-aboutADHD.aspx?articleID $=6878$

ADHDLibrary.org. (2004). ADHD myths and misconceptions. Retrieved March 6, 2009, from http://www.adhdlibrary.org/library/adhd-myths-and-misconceptions/

Alberts-Corush, J., Firestone, P., \& Goodman, J.T. (1986). Attention and impulsivity characteristics of the biological and adoptive parents of hyperactive and normal control children. American Journal of Orthopsychiatric, 56(3), 413-423.

Alexander, C., \& Strain, P.S. (1978). A review of educators' attitudes toward handicapped children and the concept of mainstreaming. Psychology in the Schools, 15(3), 390-396.

Alghazo, E.M., Dodeen, H. \& Algaryouti, I.A. (2003). Attitudes of pre-service teachers towards persons with disabilities: Predicting for the success of inclusion. College Student Journal, 37(4), 515-522.

Algozzine, B., (1980). The disturbing child: A matter of opinion. Journal of the Council for Children with Behavioral Disorders, 5(2), 112-115.

American Psychiatric Association (APA). (1968). Diagnostic and statistical manual of mental disorders ( $2^{\text {nd }}$ ed.). Washington, DC: Author.

American Psychiatric Association (APA). (1980). Diagnostic and statistical manual of mental disorders ( ${ }^{\text {rd }}$ ed.). Washington, DC: Author.

American Psychiatric Association (APA). (1987). Diagnostic and statistical manual of mental disorders ( ${ }^{\text {rd }}$ ed., revised). Washington, DC: Author.

American Psychiatric Association (APA). (1994). Diagnostic and statistical manual of mental disorders ( $4^{\text {th }}$ ed.).Washington, DC: Author.

American Psychiatric Association (APA). (2000). Diagnostic and statistical manual of mental disorders (Text Revision). Washington, DC: Author. 
Anastopoulos, A. D., Guevremont, D. C., Shelton, T. L., \& DuPaul, G. J. (1992). Parenting stress among families of children with attention deficit hyperactivity disorder. Journal of Abnormal Child Psychology, 20(5), 503-520.

Anastopoulos, A.D., Smith, J.M., \& Wien, E.E. (1998). Counseling and training parents. In R.A. Barkley (Ed.), Attention deficit hyperactivity disorder: A handbook of diagnosis and treatment. New York: Guilford Press.

Applegate, B., Lahey, B. B., Hart, E. L., Biederman, J., Hynd, G. W., Barkley, R. A., et al. (1997). Validity of the age-of-onset criterion for ADHD: A report from the DSM-IV field trials. Journal of the American Academy of Child \& Adolescent Psychiatry, 36(9), 1211-1221.

Arcia, E., Frank, R., Sánchez-LaCay, A., \& Fernández, M.C. (2000). Teacher understanding of ADHD as reflected in attributions and classroom strategies. Journal of Attention Disorders, 4(2), 91-101.

Arnold, L. E. (1999). Treatment alternatives for attention-deficit/hyperactivity disorder (ADHD). Journal of Attention Disorders, 3(1), 30-48.

Atlantic Union Conference of SDA, Office of Education. (1999-2009). Retrieved March 4, 2008, from http://www.atlantic-union.org/schools.html

Attention Deficit Disorder Association. (1996-2006). Myths about ADD/ADHD. Retrieved March 6, 2009 from http://www.add.org/articles/myth.html

Banerjee, T.D., Middleton, F., \& Faraone, S.V. (2007). Environmental risk factors for attention-deficit hyperactivity disorder. Acta Paediatrica, 96, 1269-1274.

Barbaresi, W.J., \& Olsen, R.D. (1998). An ADHD educational intervention for elementary schoolteachers: A pilot study. Developmental and Behavioral Pediatrics, 19, 94-100.

Barkley, R.A. (1998). Attention deficit hyperactivity disorder: A handbook for diagnosis and treatment ( $2^{\text {nd }}$ ed.). New York: Guilford Press.

Barkley, R.A. (2000). Taking charge of ADHD: The complete, authoritative guide for parents (Rev. ed.). New York: Guilford Press.

Barkley, R.A., DuPaul, G., \& McMurray, M.B. (1990). Comprehensive evaluation of attention deficit disorder with and without hyperactivity as defined by research criteria. Journal of Consulting \& Clinical Psychology, 58, 775-789. 
Barkley, R. A., Fischer, M., Edelbrock, C. S., \& Smallish, L. (1990). The adolescent outcome of hyperactive children diagnosed by research criteria: I. An 8-year prospective follow-up study. Journal of the American Academy of Child \& Adolescent Psychiatry, 29(4), 546-557.

Barkley, R. A., \& Biederman, J. (1997). Toward a broader definition of the age-ofonset criterion for attention-deficit-hyperactivity-disorder. Journal of the American Academy of Child \& Adolescent Psychiatry, 36(9), 1204-1210.

Barkley, R.A., Fischer, M., Smallish, L., \& Fletcher, K. (2002). The persistence of attention-deficit/hyperactivity disorder into young adulthood as a function of reporting source and definition of disorder. Journal of Abnormal Psychology, 111, 279-289.

Bateman, B., Warner, J.O., Hutchinson, E., Dean, T., Rowlandson, P., Gant, C., et al. (2004). The effects of a double-blind, placebo controlled, artificial food colorings and benzoate preservative challenge on hyperactivity in a general population sample of preschool children. Archives of Disease in Childhood, 89, 506-511.

Beare, P.L. (1985). Regular classroom teachers' attitudes toward mainstreaming the emotionally disturbed: Can they be changed? (Eric Document Reproduction Service No.253981)

Bekle, B. (2004). Knowledge and attitudes about attention-deficit hyperactivity disorder (ADHD): A comparison between practicing teachers and undergraduate students. Journal of Attention Disorders, 7, 151-161.

Biederman, J., Faraone, S.V., Keenan, K., Benjamin, J., Krifcher, B., Moore, C., et al. (1992). Further evidence for family-genetic risk factors in attention deficit hyperactivity disorder: Patterns of comorbidity in probands and relatives in psychiatrically and referred samples. Archives of General Psychiatry, 4(9), 728738.

Biederman, J., Faraone, S.V., Mick, E., Spencer, T., Wilens, T., Kiely, K., et al. (1995). High risk for attention deficit hyperactivity disorder among children of parents with childhood onset of the disorder: A pilot study. American Journal of Psychiatry, 152(3), 431-435.

Biederman, J., \& Faraone, S.V. (2002). Current concepts on the neurobiology of attention-deficit/hyperactivity disorder. Journal of Attention Disorders, 6(Supplement 1), 7-16.

Biederman, J., Mick, E., Faraone, S.V., Braaten, E., Doyle, A., Spencer, T., et al. (2002). Influence of gender on attention deficit hyperactivity disorder in children referred to a psychiatric clinic. American Journal of Psychiatry, 159(1), 36-42. 
Biederman, J., Petty, C., Wilens, T.E., Fraire, M., Purcell, C.A., Mick, E., et al. (2008). Familial risk analysis of attention deficit hyperactivity disorder and substance use disorders. American Journal of Psychiatry, 165(1), 107-115.

Bioulac, S., Arfi, L., \& Bouvard, M.P. (2008). Attention deficit/hyperactivity disorder and video games: A comparative study of hyperactive and control children. European Psychiatry, 23, 134-141.

Bipolar Central. (2004-2009). ADHD myths vs. facts. Retrieved March 6, 2009, from http://www.biolarcentral.com/articles/ADHDMYTHS.asp.

Blume-D'Ausilio, C. (2005). Sources of information and selected variables and their relationship to teachers' knowledge and attitudes regarding attention deficit hyperactivity disorder (ADHD). Retrieved from ProQuest Digital Dissertations. (Publication No. AAT 3193709).

Boyles, N.S., \& Contadino, D. (1999). Parenting a child with attention deficit/hyperactivity disorder (Rev. $2^{\text {nd }}$ ed.). Chicago: Lowell House.

Brook, U., Watemberg, N., \& Geva, D. (2000). Attitude and knowledge of attention deficit hyperactivity disorder and learning disability among high school teachers. Patient Education and Counseling, 40, 247-252.

Bussing, R., Schoenberg, N.E., \& Perwien, A.R. (1998). Knowledge and information about ADHD: Evidence of cultural differences among African-American and White parents. Social Science Medicine, 46, 919-928.

Bussing, R., Gary, F.A., Leon, C.E., Garvan, C.W., \& Reid, R. (2002). General classroom teachers' information and perceptions of attention deficit hyperactivity disorder. Behavioral Disorders, 27, 327-339.

Bussing, R., Gary, F.A., Mills, T.L., \& Garvan, C.W. (2007). Cultural variations in parental health beliefs, knowledge, and information sources related to attentiondeficit/hyperactivity disorder. Journal of Family Issues, 28(1), 291-318.

Carlson, S., Frankenberger, W., Hall, K.M., Totten, S.J., \& House, K. (2006). International perspectives on attention-deficit/hyperactivity disorder: A comparison of teachers in the United States and Sweden. International Journal of Special Education, 21, 24-34.

Chess, S.(1959). Diagnosis and treatment of the hyperactive child. New York State Journal of Medicine, 237-2385.

Children and Adults with Attention-Deficit/Hyperactivity Disorders (CHADD). (2006). The disorder named AD/HD—CHADD fact sheet \#1. Retrieved November 12, 2004, from www.chadd.org 
Claude, D., \& Firestone, P. (1995). The development of ADHD boys: A 12-year follow-up. Canadian Journal of Behavioral Science, 27, 226-249.

Concannon, P.E., \& Tang, Y.P. (2005). Management of attention deficit hyperactivity disorder: A parental perspective. Journal of Paediatric Child Health, 41, 625-630.

Conners, C.K., Goyette, C.H., Southwick, D.A., Lees, J.M., \& Andrulonis, P.A. (1976). Food additives and hyperkinesis: A controlled double-blind experiment. Pediatrics, 58(2), 154-166.

Corkum, P., Rimer, P., \& Schachar, R. (1999). Parental knowledge of attentiondeficit hyperactivity disorder and opinions of treatment options: Impact on enrollment and adherence to a 12-month treatment trial. Canadian Journal of Psychiatry, 44(10), 1043-1048.

Counts, C. A., Nigg, J. T., Stawicki, J. A., Rappley, M. D., \& Von Eye, A. (2005). Family Adversity in DSM-IV ADHD Combined and Inattentive Subtypes and Associated Disruptive Behavior Problems. Journal of the American Academy of Child \& Adolescent Psychiatry, 44(7), 690-698.

Crenshaw, T. M. (1997). Attention deficit hyperactivity disorder and the efficacy of stimulant medication: A meta-analysis. Dissertation Abstracts International, 58(3-B), 1524.

Cuffe, S.P., Moore, C.G., \& McKeown, R.E. (2005). Prevalence and correlates of ADHD symptoms in the National Health Interview Survey. Journal of Attention Disorders, 9(2), 392-401.

Daly, B. P., Creed, T., Xanthopoulos, M., \& Brown, R. T. (2007). Psychosocial treatments for children with attention deficit/hyperactivity disorder. Neuropsychology Review, 17(1), 73-89.

Davidson, J.C., \& Ford, D.Y. (2002). Perceptions of attention deficit hyperactivity disorder in one African American community. Journal of Negro Education, 70(4), 264-274.

Davis, D., \& Sorrell, J. (1995). Mastery learning in public schools. Paper prepared for PSY 702: Conditions of Learning. Valdosta, GA: Valdosta State University.

Department of Education, Seventh-day Adventist Church. (2008). Retrieved March 5, 2008, from http://education.gc.adventist.org/

Destefano, L., Shriner, J.G., \& Lloyd, C.A. (2001). Teacher decision making in participation of students with disabilities in large-scale assessment. Exceptional Children, 68(1), 7-22. 
DiBattista, D., \& Shepherd, M. (1993). Primary school teachers' beliefs and advice to parents concerning sugar consumption and activity in children. Psychological Reports, 72, 47-55.

Dillman, D.A. (1978). Mail and telephone surveys: The total design method. New York: John Wiley \& Sons.

Doggett, A.M. (2004). ADHD and drug therapy: Is it still a valid treatment? Journal of Child Health Care, 8(1), 69-81.

dosReis, S., Zito, J. M., Safer, D. J., Soeken, K. L., Mitchell, J. W., Jr., \& Ellwood, L. C. (2003). Parental perceptions and satisfaction with stimulant medication for attention-deficit hyperactivity disorder. Journal of Developmental \& Behavioral Pediatrics, 24(3), 155-162.

Douglas, V.I. (1972). Stop, look, listen: The problem of sustained attention and impulse control in hyperactive and normal children. Canadian Journal of Behavioural Science, 4, 259-282.

Dryer, R., Kiernan, M.J., \& Tyson, G.A. (2006). Implicit theories of the characteristics and causes of attention-deficit hyperactivity disorder held by parents and professionals in the psychological, educational, medical and allied health fields. Australian Journal of Psychology, 58, 79-92.

DuPaul, G.J. (2007). School-based interventions for students with attention deficit hyperactivity disorder: Current status and future directions. School Psychology Review, 36, 183-194.

DuPaul, G.J., \& Eckert, T. L. (1997). The effects of school-based interventions for attention deficit hyperactivity disorder: A meta-analysis. School Psychology Review, 26, 5-27.

DuPaul, G.J., Anastopoulos, A.D., Power, T.J., Reid, R., Ikeda, M.J. \& McGoey, K.E. (1998). Parent ratings of attention-deficit/hyperactivity disorder symptoms: Factor structure and normative data. Journal of Psychopathology and Behavioral Assessment, 20(1), 83-102.

DuPaul, G.J., Ervin, R.A., Hook, C.L., \& McGoey, K.E. (1998). Peer tutoring for children with attention deficit hyperactivity disorder: Effects on classroom behavior and academic performance. Journal of Applied Behavior Analysis, 31, 579-592.

DuPaul, G.J., \& Stoner, G. (2003). ADHD in the schools: Assessment and intervention strategies ( $2^{\text {nd }}$ ed.). New York: Guilford Press. 
DuPaul, G.J., \& Weyandt, L.L. (2006). School-based interventions for children and adolescents with attention deficit hyperactivity disorder: Enhancing academic and behavioral outcomes. Education and Treatment of Children, 29, 341-358.

Durston, S. (2003). A review of the biological bases of ADHD: What have we learned from imaging studies? Mental Retardation and Developmental Disabilities, 9, 184-195.

Eaves, L., Rutter, M., Silberg, J.L., Shillady, L., Maes, H. \& Pickles, A. (2000). Genetic and environmental causes of covariation in interview assessments of disruptive behavior in child and adolescent twins. Behavior Genetics, 30(4), 321334.

Ebaugh, F.G. (2007). Neuropsychiatric sequelae of acute epidemic encephalitis in children. Journal of Attention Disorders, 11(3), 336-338.

Encyclopedia of cognitive science. (2003). New York: Nature Publishing Group

Encyclopedia of psychology. (2000). Washington, DC: American Psychological Association.

Ernest, P. (1989). The knowledge, beliefs and attitudes of the mathematics teacher: A model. Journal of Education of Teachers, 15, 13-34.

Faraone, S.V., Biederman, J., Lehman, B.K., Keenan, K., Norman, D., Seidman, L.J., et al. (1993). Evidence for the independent familial transmission of attention deficit hyperactivity disorder and learning disabilities: Results from a family genetic study. American Journal of Psychiatry, 150, 891-895.

Faraone, S.V., \& Biederman, J. (2000). Nature, nurture, and attention deficit hyperactivity disorder. Developmental Review, 20, 568-581.

Faraone, S.V., Biederman, J., Mick, E., Williamson, S., Wilens, T., Spencer, T., et al. (2000). Family study of girls with attention deficit hyperactivity disorder. American Journal of Psychiatry, 157(7), 1077-1083.

Faraone, S.V., Sergeant, J., Gillberg, C., \& Biederman, J. (2003). The worldwide prevalence of ADHD: Is it an American condition? World Psychiatry, 2(2), 104113.

Feingold, B. (1975). Hyperkinesis and learning disabilities linked to artificial food flavors and colors. American Journal of Nursing, 75, 797-803. 
Fischer, M., Barkley, R. A., Fletcher, K. E., \& Smallish, L. (1993). The adolescent outcome of hyperactive children: Predictors of psychiatric, academic, social, and emotional adjustment. Journal of the American Academy of Child \& Adolescent Psychiatry, 32(2), 324-332.

Frankenberger, W., \& Cannon, C. (1999). Effects of Ritalin on academic achievement from first to fifth grade. International Journal of Disability, Development and Education, 46, 199-221.

Frankenberger, W., Farmer, C., Parker, L., \& Cermak, J. (2001). The use of stimulant medication for treatment of attention-deficit/hyperactivity disorder: A survey of school psychologists' knowledge, attitudes, and experience. Developmental Disabilities Bulletin, 29, 132-151.

Frazier, M. R., \& Merrell, K.W. (1997). Issues in behavioral treatment of attentiondeficit/hyperactivity disorder. Education and Treatment of Children, 20(4), 441461.

Frick, P.J., Kamphaus, R.W., Lahey, B.B., Loeber, R., Christ, M.A.G., Hart, E.L., \& Tannenbaum, L.E. (1991). Academic underachievement and the disruptive behavior disorders. Journal of Consulting and Clinical Psychology, 59(2), 289294.

Frisch, L., Moser, S.E., Hawley, F., Johnston, J., \& Romereim, M. (2003). Kansas school nurses' knowledge and opinions about ADHD stimulant medication therapy. Journal of School Health, 73, 127-128.

Furukawa, C. T., \& Mahan, L. K. (1994). Effects of diets high in sucrose or aspartame on the behavior and cognitive performance of children: Comment. New England Journal of Medicine, 330(26), 1902-1903.

George, D., \& Mallery, P. (2006). SPSS for windows step by step: A simple guide and reference 13.0 update $\left(6^{\text {th }}\right.$ ed.). Boston: Allyn and Bacon.

Germayne, K. (1994). A study to determine the effects of the distribution of informational facts concerning attention deficit/hyperactivity disordered (ADHD) children on teachers' knowledge and attitudes towards these students. Dissertation Abstracts International, 55(04), 930. (UMI No. 9423711)

Ghanizadeh, A. (2007). Educating and counseling of parents of children with attention-deficit hyperactivity disorder. Patient Education and Counseling, 68, 23-28.

Ghanizadeh, A., Bahredar, M.J., \& Moeini, S.R. (2006). Knowledge and attitudes towards attention deficit hyperactivity disorder among elementary school teachers. Patient Education and Counseling, 63, 84-88. 
Gilbert, P. (2005).Attention-Deficit/Hyperactivity Disorder in Community College Students: A Seldom Considered Factor in Academic Success. In J.W. Murphy (Ed.), \& J.T. Pardeck (Ed.), Disability issues for social workers and human services professionals in the twenty-first century. Binghamton, NY: Haworth Social Work Practice Press

Gillis, J.J., Gilger, J.W., Pennington, B.F., \& DeFries, J.C. (1992). Attention deficit disorder in reading-disabled twins: Evidence for a genetic etiology. Journal of Abnormal Child Psychology, 20(3), 303-315.

Glass, C.S., \& Wegar, K. (2001). Teacher perceptions of the incidence and management of attention deficit hyperactivity disorder. Education, 12(2), 412420.

Goodman, R., \& Stevenson, J. (1989a). A twin study of hyperactivity-I. An examination of hyperactivity scores and categories derived from Rutter teacher and parent questionnaires. Journal of Child Psychology \& Psychiatry, 30(5), 671689.

Goodman, R., \& Stevenson, J. (1989b). A twin study of hyperactivity - II. The aetiological role of genes, family relationship and perinatal adversity. Journal of Child Psychology \& Psychiatry, 30(5), 691-709.

Gregory, R.J. (2004). Psychological testing: history, principles, and applications ( $^{\text {th }}$ ed.). Needham Heights, MA: Allyn \& Bacon.

Gross, M.D. (1984). Effect of sucrose on hyperkinetic children. Pediatrics, 74(5), 1984.

Gross-Tsur, V., Joseph, A., \& Shaley, R.S. (2004). Hallucination during Methylphenidate therapy. Neurology, 63, 753-754.

Gunderson, H.M. (1994). A study to assess elementary and secondary general education teachers' attitudes and knowledge of attention deficit hyperactivity disorder. Dissertations Abstracts International, 55(04), 850. (UMI No.9423713)

Gustafsson, P., Thernlund, G., Besjakov, J., Karlsson, M.K., Ericsson, I. \& Svedin, C.G. (2008). ADHD symptoms and maturity-A study in primary school children. Acta Paediatrica, 97(2), 233-238.

Hann, D.M., \& Borek, N., (Eds.). (2001). Taking stock of risk factors for child/youth externalizing behavior problems. Bethesda: Department of Health and Human Services, Public Health Service, National Institute of Mental Health/NIH. 
Harley, J.P., Ray, R.S., Tomasi, L., Eichman, P.L., Matthews, C.G., Chun, R., et al. (1978). Hyperkinesis and food additives: Testing the Feingold hypothesis. Pediatrics, 61(6), 818-828.

Harley, J.P., Matthews, C.G., \& Eichman, P. (1978). Synthetic food colors and hyperactivity in children: A double-blind challenge experiment. Pediatrics, 62(6), 975-983.

Heiser, P., Heinzel-Gutenbrunner, M., Frey, J., Smidt, J., Grabarkiewicz, J., Friedel, S., et al. (2006). Twin study on heritability of activity, attention, and impulsivity as assessed by objective measures. Journal of Attention Disorders, 9(4), 575-581.

Hinshaw, S. P., Owens, E. B., Wells, K. C., Kraemer, H. C., Abikoff, H. B., Arnold, L.E., et al. (2000). Family processes and treatment outcome in the MTA: Negative/ineffective parenting practices in relation to multimodal treatment. Journal of Abnormal Child Psychology, 28(6), 555-568.

Hoagwood, K., Kelleher, K.J., \& Feil, M. (2000). Treatment services for children with ADHD: A national perspective. Journal of the American Academy of Child and Adolescent Psychiatry, 39, 198-206.

Hohman, L.B. (1922). Post-encephalitic behavior disorders in children. John Hopkins Hospital Bulletin, 380, 372-375.

Holst, J. (2008). Danish teachers' conception of challenging behavior and DAMP/ADHD. Early Child Development and Care, 178(4), 363-374.

Hook, C. L., \& DuPaul, G. J. (1999). Parent tutoring for students with attentiondeficit/hyperactivity disorder: Effects on reading performance at home and school. School Psychology Review, 28(1), 60-75.

Houghton, S., Milner, N., West, J., Douglas, G., Lawrence, V., Whiting, K., et al. (2004). Motor control and sequencing of boys with attention-deficit/hyperactivity disorder (ADHD) during computer game play. British Journal of Educational Technology, 35(1), 21-34.

Hurt, E. A., Hoza, B., \& Pelham, W. E., Jr. (2007). Parenting, family loneliness, and peer functioning in boys with attention-deficit/hyperactivity disorder. Journal of Abnormal Child Psychology, 35(4), 543-555.

Janseen-Cilag. (2009, May 26). Psychiatry 24X7. Retrieved April 2, 2009, from http://www.psychiatry24x7.com 
Jerome, L., Gordon, M., \& Hustler, P. (1994). A comparison of American and Canadian teachers' knowledge and attitudes towards attention deficit hyperactivity disorder (ADHD). The Canadian Journal of Psychiatry, 39, 563567.

Jerome, L., Washington, P., Laine, C.J., \& Segal, A. (1999). Graduating teachers' knowledge and attitudes about attention-deficit hyperactivity disorder: A comparison with practicing teachers. The Canadian Journal of Psychiatry, 44(2), 192.

Jitendra, A.K., DuPaul, G.J., Volpe, R.J., Tresco, K.E., Vile Junod, R.E., Lutz, G., et al. (2007). Consultation-based academic interventions for children with attention deficit hyperactivity disorder: School functioning outcomes. The School Psychology Review, 36, 217-236.

Joseph, J. (2000). Not in their genes: A critical view of the genetics of attentiondeficit hyperactivity disorder. Developmental Review, 20, 539-567.

Joseph, J. (2002). Adoption study of ADHD. Journal of the Academy of Child and Adolescent Psychiatry, 41(12), 1389-1390.

Kaplan, H.K., Wamboldt, F.S., \& Barnhart, M. (1986). Behavioral effects of dietary sucrose in disturbed children. American Journal of Psychiatry, 14(7), 944-945.

Kasten, E.F., Coury, D.L., \& Heron, T.E. (1992). Educators' knowledge and attitudes regarding stimulants in the treatment of attention deficit hyperactivity disorder. Developmental and Behavioral Pediatrics, 13(3), 215 -219.

Kavale, K.A., \& Forness, S.R. (2001). Hyperactivity and diet treatment: A metaanalysis of the Feingold Hypothesis. Journal of Learning Disabilities, 16, 324330.

Kepley, H. O., \& Ostrander, R. (2007). Family characteristics of anxious ADHD children: Preliminary results. Journal of Attention Disorders, 10(3), 317-323.

Khan, S.A., \& Faraone, S.V. (2005). The genetics of ADHD: A literature review of 2005. Current Psychiatry Reports, 8, 393-397.

Kiffer, C.H. (1996). A study to assess Orange County elementary school teachers' attitudes toward and knowledge of attention deficit hyperactivity disorder and section 504 of the rehabilitation act of 1973. Dissertation Abstracts International, 57(10), 4267. (UMI No. 9709829)

Kinsbourne, M. (1994). "Effects of diets high in sucrose or aspartame on the behavior and cognitive performance of children": Comment. New England Journal of Medicine, 330(26), 1903-1904. 
Klorman, R., Hazel-Fernandez, L. A., Shaywitz, S. E., Fletcher, J. M., Marchione, K. et al. (1999). Executive functioning deficits in attention-deficit/hyperactivity disorder are independent of oppositional defiant or reading disorder. Journal of the American Academy of Child \& Adolescent Psychiatry, 38(9), 1148-1155.

Knight, G. (1997). Philosophy \& education: An introduction in Christian perspective $\left(2^{\text {nd }}\right.$ ed.). Berrien Springs, MI: Andrews University Press.

Kollins, S.H., Barkley, R.A., \& DuPaul, G.J. (2001). Use and management of medications for children diagnosed with attention deficit hyperactivity disorder (ADHD). Focus on Exceptional Children, 33(5), 1-24.

Kos, J.M., Richdale, A.L., \& Jackson, M.S. (2004). Knowledge about attentiondeficit/hyperactivity disorder: A comparison of in-service and preservice teachers. Psychology in the Schools, 41, 517-526.

Kos, J. M., Richdale, A. L., \& Hay, D. A. (2006). Children with attention deficit hyperactivity disorder and their teachers: A review of the literature. International Journal of Disability, Development and Education, 53(2), 147-160.

Kotrlik, J.W., \& Williams, H.A. (2003). The incorporation of effect sizes in information technology, learning, and performance research. Information Technology, Learning and Performance Journal, 21(1), 1-7.

LaHoste, G.J., Swanson, J.M., Wigal, S.B., Glabe, C., Wigal, T., King, N., et al. (1996). Dopamine D4 receptor gene polymorphism is associated with attention deficit hyperactivity disorder. Molecular Psychiatry, 1(2), 121-124.

Lange, G., Sheerin, D., Carr, A., Dooley, B., Barton, V., Marshall, D., et al. (2005). Family factors associated with attention deficit hyperactivity disorder and emotional disorders in children. The Association for Family Therapy and Systemic Practice, 27, 76-96.

Laufer, M.W., Denhoff, E., \& Solomons, G. (1957). Hyperkinetic impulse disorder in children's behavior problems. Psychosomatic Medicine, 19, 38-49.

Learning Disabilities Association of Kentucky. (2005). Myths and realities of attention deficit hyperactive disorder (ADHD). Retrieved April 2, 2009, from http://literacynetwork.verizon.org/fileadmin/popups/myths_realities_adhd.htm

Lee, S. S., \& Hinshaw, S. P. (2004). Severity of adolescent delinquency among boys with and without attention deficit hyperactivity disorder: Predictions from early antisocial behavior and peer status. Journal of Clinical Child and Adolescent Psychology, 33(4), 705-716. 
Levy, F., Hay, D. A., \& Bennett, K. S. (2006). Genetics of attention deficit hyperactivity disorder: A current review and future prospects. International Journal of Disability, Development and Education, 53(1), 5-20.

Levy, F., Hay. D.A., McStephen, M., Wood, C., \& Waldman, I. (1997). Attentiondeficit hyperactivity disorder: A category or a continuum? Genetic analysis of a large-scale twin study. Journal of the American Academy of Child and Adolescence Psychiatry, 3(6), 737-744.

Lewis, R.W. (2000). General education teachers' knowledge of and attitudes toward identified students with attention deficit/hyperactivity disorder in the general education classroom. Retrieved from ProQuest Digital Dissertations. (AAT 9989230)

Liesveld, J. (2007). Teachers' knowledge, beliefs, and values about children with $A D H D$. Retrieved from ProQuest Digital Dissertations. (Publication No. AAT 3268847)

Love, A., \& Kruger, A.C. (2005). Teacher beliefs and student achievement in urban schools serving African American students. The Journal of Educational Research, 99(2), 87-98.

Majewicz-Hefley, A., \& Carlson, J. S. (2007). A meta-analysis of combined treatments for children diagnosed with ADHD. Journal of Attention Disorders, 10(3), 239-250.

Mahomedy, Z., van de Westhuizen, D., van der Linde, M.J., \& Coetsee, J. (2007). Persistence of attention deficit/hyperactivity disorder into adulthood: A study conducted on parents of children diagnosed with attention deficit/hyperactivity disorder. South African Psychiatry Review, 10, 93-98.

Mannuzza, S., Klein, R. G., Bessler, A., Malloy, P., \& LaPadula, M. (1998). Adult psychiatric status of hyperactive boys grown up. American Journal of Psychiatry, 155(4), 493-498.

Mannuzza, S., Klein, R. G., \& Moulton, J. L., III. (2003). Persistence of attentiondeficit/hyperactivity disorder into adulthood: What have we learned from the prospective follow-up studies? Journal of Attention Disorders, 7(2), 93-100.

Martin, N.C., Levy, F., Pieka, J., \& Hay, D.A. (2006). A genetic study of attention deficit hyperactivity disorder, conduct disorder, oppositional defiant disorder and reading disability: Aetiological overlaps and implications. International Journal of Disability, Development and Education, 53(1), 21-34. 
McLoughlin, G., Ronald, A., Kuntsi, J., Asherson, P., \& Plomin, R. (2007). Genetic support for the dual nature of attention deficit hyperactivity disorder: Substantial genetic overlap between the inattentive and hyperactive-impulsive components. Journal of Abnormal Child Psychology, 35(6), 999-1008.

Milich, R., Wolraich, M.L., \& Lindgren, S. (1986). Sugar and hyperactivity: A critical review of empirical findings. Clinical Psychology Review, 6, 493-513.

Molina, B. S. G., Flory, K., Hinshaw, S. P., Greiner, A. R., Arnold, L. E., Swanson, J. M., et al. (2007). Delinquent behavior and emerging substance use in the MTA at 36 months: Prevalence, course, and treatment effects. Journal of the American Academy of Child \& Adolescent Psychiatry, 46(8), 1028-1040.

Momference: A Meeting Place of the Moms. (2008, April 15). Special needs children: ADHD myths and facts. Retrieved April 2, 2009 from http://momference.wordpress.com/2008/04/15/special-needs-children-adhdmyths-and-facts

Morelli, F. (2009). ChangeYourThinking.com. ADHD myths and facts, para. 5. Retrieved April 2, 2009 from http://www.changeyourthinking.com/index.php?page=17\&nd=1

Morrison, J.R., \& Stewart, M.A. (1973). The psychiatric status of the legal families of adopted hyperactive children. Archives of General Psychiatry, 28(6), 888-891.

Multimodal Treatment Study of Children with ADHD (MTA) Cooperative Group. (1999). A 14-month randomized clinical trial of treatment strategies for attentiondeficit/hyperactivity disorder. Archives of General Psychiatry, 56(12), 1073-1086.

National Resource Center on AD/HD: A Program of CHADD. (2009). Myth and misunderstandings. Retrieved February 8, 2008, from www.help4adhd.org/en/about/myths

Nespor, J. (1987). The role of beliefs in the practice of teaching. Journal of Curriculum Studies, 19, 317-328.

Neuman, R.J., Todd, R.D., Heath, A.C., Reich, W., Hudziak, J.J., Bucholz, K.K., et al. (1999). Evaluation of ADHD typology in three contrasting samples: A latent class approach. Journal of the American Academy of Child and Adolescent Psychiatry, $38(1), 25-33$.

New Ideas.net. (1996-2008). The ADHD Information Library: ADHD myths. Retrieved April 2, 2009, from http://newideas.net/adhd/adhd-information/adhd-myths.

Nigg, J.T. (2006). What causes ADHD? Understanding what goes wrong and why. New York: Guilford Press. 
Nigg, J.T., Blaskey, L.G., Huang-Pollock, C.L., \& Rappley, M.D. (2002). Neuropsychological executive functions and DSM-IV ADHD subtypes. Journal of the American Academy of Child and Adolescent Psychiatry, 41, 59-66.

Novartis. (2009). ADHDinfo.com. Myths and facts. Retrieved March 6, 2009, from http://www.adhdinfo.com/info/faqs/myths.jsp

Ohan, J.L., Cormier, N., Hepp, S.L., Visser, T.A.W., \& Strain, M.C. (2008). Does knowledge about attention-deficit/hyperactivity disorder impact teachers' reported behaviors and perceptions? School Psychology Quarterley, 23(3), 436-449.

Õim, A. (2004). Teachers' knowledge and misconceptions concerning attentiondeficit/hyperactivity disorder, learning disabilities and childhood depression: A comparative study between Estonia and Norway. Unpublished master's thesis, University of Tartu, Estonia.

Olfson, M. (1992). Diagnosing mental disorders in office-based pediatric practice. Journal of Developmental Behavior Pediatrics, 13, 363-365.

Pajares, F. (1992). Teachers' beliefs and educational research: Cleaning up a messy construct. Review of Educational Research, 62(3), 307-332.

Papalia, D.E., Olds, S.W., \& Feldman, R.D. (2003). Human development (9 ${ }^{\text {th }}$ ed.). Boston: McGraw Hill.

Patten, M. L. (2001). Questionnaire research: A practical guide ( $2^{\text {nd }}$ ed.). Los Angeles: Pyrczak Publishing.

Pentecost, D., \& Wood, N. (2002). Knowledge and perceptions of child-care social workers about ADHD. British Journal of Social Work, 32, 931-943.

Pfiffner, L.J., \& Barkley, R.A. (1998). Treatment of ADHD in school settings. In R.A. Barkley (Ed.), Attention deficit hyperactivity disorder: A handbook of diagnosis and treatment. New York: Guilford Press.

Pisecco, S., Huzinec, C., \& Curtis, D. (2001). The effect of child characteristics on teachers' acceptability of classroom-based behavioral strategies and psychostimulant medication for the treatment of ADHD. Journal of Clinical Child Psychology, 30, 413-421.

Plumer, P. J., \& Stoner, G. (2005). The relative effects of classwide peer tutoring and peer coaching on the positive social behaviors of children with ADHD. Journal of Attention Disorders, 9(1), 290-300. 
Power, T. J., Costigan, T. E., Leff, S. S., Eiraldi, R. B., \& Landau, S. (2001). Assessing ADHD across settings: Contributions of behavioral assessment to categorical decision making. Journal of Clinical Child Psychology, 30(3), 399-412.

Pressman, L. J., Loo, S. K., Carpenter, E. M., Asarnow, J. R., Lynn, D., McCracken, J. T., et al. (2006). Relationship of family environment and parental psychiatric diagnosis to impairment in ADHD. Journal of the American Academy of Child \& Adolescent Psychiatry, 45(3), 346-354.

Pugh, D.L. (2002). Parental perspectives of causes of attention deficit hyperactivity disorder. Retrieved from ProQuest Digital Dissertations. (AAT 1409470)

Purdie, N., Hattie, J., \& Carroll, A. (2002). A review of the research on interventions for attention deficit hyperactivity disorder: What works best? Review of Educational Research, 72(1), 61-99.

Reeve, W. V., \& Schandler, S.L. (2001). Frontal lobe functioning in adolescence with attention deficit hyperactivity disorder. Adolescence, 36, 749-763.

Reid, R., Vasa, S.F., Maag, J.W., \& Wright, G. (1994). An analysis of teachers' perceptions of attention deficit-hyperactivity disorder. The Journal of Research and Development in Education, 27(3), 195-202.

Resnick, R.J. (2005). Attention deficit hyperactivity disorder in teen and adults: They don't all outgrow it. Wiley InterScience, 61, 529-533.

Richardson, A.J., \& Puri, B.K. (2002). A randomized double-blind, placebo-controlled study of the effects of supplementation with highly unsaturated fatty acids on ADHD-related symptoms in children with specific learning difficulties. Progress in Neuro-Psychopharmacology \& Biological Psychiatry, 26, 233-239.

Rief, S.F. (2003). Educating the child with attention-deficit/hyperactivity disorder. Primary Psychiatry, 10(4), 61-66.

Rielly, N.E., Craig, W.M., \& Parker, K.C.H. (2006). Peer and parenting characteristics of boys and girls with subclinical attention problems. Journal of Attention Disorders, 9(4), 598-606.

Robin, S. (1998). Preservice teachers' knowledge and opinions concerning students with attention deficit hyperactivity disorder (ADHD). Retrieved from ProQuest Digital Dissertations. (AAT MQ30547)

Robin, A.L. (1998). Training families with ADHD adolescents. In R.A. Barkley (Ed.) Attention deficit hyperactivity disorder: A handbook of diagnosis and treatment. New York: Guilford Press. 
Rokeach, M. (1968). Beliefs, attitudes, and values: A theory of organization and change. San Francisco: Jossey-Bass.

Rostain, A.L., Power, T.J., \& Atkins, M.S. (1992). Assessing parents' willingness to pursue treatment for children with attention-deficit hyperactivity disorder. Journal of the American Academy of Child and Adolescent Psychiatry, 32, 175-181.

Samuel, V.J., George, P., Thornell, A., Curtis, S., Taylor, A., Brome, D., Mick et al. (1999). A pilot controlled family study of DSM-III and DSM-IV ADHD in African-American children. Journal of the American Academy of Child and Adolescent Psychiatry, 38(1), 34-39.

Schab, D.W., \& Trinh, N.T. (2004). Do artificial colors promote hyperactivity in children with hyperactive syndromes? A meta-analysis of double-blind placebocontrolled trials. Developmental and Behavioral Pediatrics, 25(6), 423-434.

Schnoll, R., Burshteyn, D., \& Cea-Aravena, J. (2003). Nutrition in the treatment of attention-deficit hyperactivity disorder: A neglected but important aspect. Applied Psychophysiology and Biofeedback, 28, 63-75.

Schoun, C.J. (1993a). Understanding the student with attention deficit disorder, part 1. The Journal of Adventist Education, 55(3), 8-11.

Schoun, C.J. (1993b). Helping the attention-deficit student, part 2. The Journal of Adventist Education, 55(4), 25-30.

Schuck, S.E.B., \& Crinella, F.M. (2005). Why children with ADHD do not have low IQs. Journal of Learning Disabilities, 38(3), 252-280.

Sciutto, M.J., Teriesen, M.D., \& Frank, A.S.B. (2000). Teachers' knowledge and misperceptions of attention-deficit /hyperactivity disorder. Psychology in the Schools, 37, 115-122.

Sciutto, M.J., Nolfi, C.J., \& Bluhm, C. (2004). Effects of child gender and symptom type on referrals for ADHD by elementary school teachers. Journal of Emotional and Behavioral Disorders, 12(4), 247-253.

Shapiro, E. S., DuPaul, G. J., Bradley, K. L., \& Bailey, L. T. (1996). A school-based consultation program for service delivery to middle school students with attention-deficit/hyperactivity disorder. Journal of Emotional and Behavioral Disorders, 4(2), 73-81.

Shaw, P., Eckstrand K., Sharp, W., Blumenthal, J., Lerch, J.P., Greenstein, D., et al. (2007). Attention-deficit/hyperactivity disorder is characterized by a delay in cortical maturation. PNAS Proceedings of the National Academy of Sciences of the United States of America, 104(49), 19649-19654. 
Shaw, R., Grayson, A., \& Lewis, V. (2005). Inhibition, ADHD, and computer games: The inhibitory performance of children with ADHD on computerized tasks and games. Journal of Attention Disorders, 8(4), 160-168.

Sinha, D., \& Efron, D. (2005). Complementary and alternative medicine use in children with attention deficit hyperactivity disorder. Journal of Paediatric Child Health, 41, 23-26.

Smith, A. L. (1999). School psychologists and attention-deficit/hyperactivity disorder: A survey of training, knowledge, practice, and attitude.Retrieved from ProQuest Digital Dissertations. (AAT 9950369)

Snider, V., Busch, T., \& Arrowood, L. (2003). Teacher knowledge of stimulant Medication and ADHD. Remedial and Special Education, 24, 47-57.

Spencer, T. J., Biederman, J., \& Mick, E. (2007). Attention-deficit/hyperactivity disorder: Diagnosis, lifespan, comorbidities, and neurobiology. Journal of Pediatric Psychology, 32(6), 631-642.

Sprich, S., Biederman, J., Crawford, M.H., Mundy, E., \& Farone, S.V. (2000). Adoptive and biological families of children and adolescents with ADHD. Journal of the American Academy of Child and Adolescent Psychiatry, 39(11), 1432-1437.

Stief, Elizabeth Anne (2003). Parental perceptions of attention-deficit/hyperactivity disorder: Etiology, diagnosis, and treatment. Retrieved from ProQuest Digital Dissertations. (AAT 3107846)

Still, G.F. (1902). Some abnormal psychical conditions in children. The Lancet, 1, 1008-1012.

Stormont, M., \& Stebbins, M.S. (2005). Preschool teachers' knowledge, opinions, and educational experiences with attention deficit/hyperactivity disorder. Teacher Education and Special Education, 28, 52-61.

Strecker, E. A., \& Ebaugh, F. G. (1924). Neuropsychiatric sequelae of cerebral trauma in children. Archives of Neurology \& Psychiatry (Chicago), 4, 443-453.

Swanson, J.M., McBurnett, K., Wigal, T., Pfiffner, L.J., Lerner, M.A., Williams, L., et al. (1993). Effect of stimulant medication on children with attention deficit disorder: A "review of reviews.” Exceptional Children, 60(2), 154-159.

Tabachnick, B.G., \& Fidell, L.S. (2001). Using multivariate statistics $\left(4^{\text {th }}\right.$ ed.). Needham Heights, MA: Allyn \& Bacon. 
Thapar, A., Holmes, J., Poulton, K., \& Harrington, R. (1999). Genetic basis of attention deficit and hyperactivity. British Journal of Psychiatry, 174, 105-111.

The Play Attention Solution. (2009). ADHD myths. Retrieved April 2, 2009, from http://www.playattention.com/adhd/adhd-myths/

Tsai, C. (2003). Teachers' perceptions and knowledge of students with attentiondeficit hyperactivity disorder in public elementary schools in Taiwan. Dissertation Abstracts International, 65(01), 117. (UMI No. 3119674)

Tucker, J.A. (2001). Pedagogical application of the Seventh-day Adventist philosophy of education. Journal of Research on Christian Education, 10, 309325 .

van den Oord, E.J.C.G., Boomsma, D.I., \& Verhulst, F.C. (1994). A study of problem behaviors in 10- to 15-year-old- biologically related and unrelated international adoptees. Behavior Genetics, 24(3), 193-205.

Venter, A., Van der Linde, G., du Plessis, J., \& Joubert, G. (2004). A comparison between South African psychiatrists' and paediatricians' knowledge, attitudes and current practices regarding the management of children with attention deficit/hyperactivity disorder. Journal of Child and Adolescent Mental Health, 16, $11-18$.

Vereb, R.L. \& DiPerna, J.C. (2004). Teachers' knowledge of ADHD, treatments of ADHD, and treatment acceptability: An initial investigation. School Psychology Review, 33, 421-428.

Waschbusch, D. A., King, S., \& Gregus, A. (2007). Age of onset of ADHD in a sample of elementary school students. Journal of Psychopathology and Behavioral Assessment, 29(1), 9-16.

Webb, L. D., \& Myrick, R. D. (2003). A group counseling intervention for children with Attention Deficit Hyperactivity Disorder. Professional School Counseling, $7(2), 108-115$.

Weiler, M.D., Bellinger, D., Marmor, J., Rancier, S., \& Weber, D. (1999). Mother and teacher reports of ADHD symptoms: DSM-IV questionnaire data. Journal of the American Academy of Child and Adolescent Psychiatry, 38(9), 1139-1147.

Weiss, B., Williams, J.H., Margen, S., Abrams, B., Caan, B., Citron, L.J., et al. (1980). Behavioral responses to artificial food colors. Science, 207, 1487-1488. 
Wells, K. C., Epstein, J. N., Hinshaw, S. P., Conners, C. K., Klaric, J., Abikoff, H. B., et al. (2000). Parenting and family stress treatment outcomes in attention deficit hyperactivity disorder (ADHD): An empirical analysis in the MTA study. Journal of Abnormal Child Psychology, 28(6), 543-553.

West, J., Taylor, M., Houghton, S., \& Hudyma, S. (2005). A comparison of teachers' and parents' knowledge and beliefs about attention-deficit/hyperactivity disorder (ADHD). School Psychology International, 26, 192-208.

Wilens, T.E., Hahesy, A.L., Biederman, J., Bredin, E., Tanguay, S., Kwon, A. et al. (2005). Influence of parental SUD and ADHD on ADHD in their offspring: Preliminary results from a pilot-controlled study. The American Journal on Addiction, 14, 179-187.

Williams, K. G. (1996). An analysis of Illinois elementary principals' knowledge and perceptions of children with attention deficit disorders and effective instructional practices. Retrieved from ProQuest Digital Disserations. (AAT 9716565)

Williams, P. E., Weiss, L. G., \& Rolfhus, E. G. (2003). WISC-IV: Wechsler intelligence scale for children: Clinical validity (Technical Report No. 3). San Antonio, TX: The Psychological Corporation.

Wolraich, M.L., Lindgren, S.D., Stumbo, P.J., Stegink, L.D., Appelbaun, M.I. \& Kiritsy, M.C. (1994). Effects of diets high in sucrose or aspartame on the behavior and cognitive performance of children. The New England Journal of Medicine, 330(5), 301-307.

Wolraich, M.L., Wilson, D.B., \& White, J.W. (1995). The effect of sugar or behavior or cognition in children. A meta-analysis. The Journal of the American Medical Association, 274(20), 1617-1621.

Woodward, L., Taylor, E., \& Dowdney, L. (1998). The parenting and family functioning of children with hyperactivity. Journal of Child Psychology and Psychiatry, 39(2), 161-169.

Woodward, L. J., \& Fergusson, D. M. (1999). Childhood peer relationship problems and psychosocial adjustment in late adolescence. Journal of Abnormal Child Psychology, 27(1), 87-104.

Young, S., \& Gudjonsson, G.H. (2006). ADHD symptomology and its relationship with emotional, social and delinquent problems. Psychology, Crime \& Law, 12(5), 463-471. 
CURRICULUM VITAE 


\section{Kendra-Lee Pearman, Ph.D.}

52 Wellington Slip Rd.

St. Georges GE02, Bermuda

Office: 292-4752 ext. 4163; Home: 297-8195; Cell: 505-8195

Email: kendraleep@northrock.bm

\section{EDUCATION}

- Andrews University, Berrien Springs, MI, 2009, Doctor of Philosophy, Educational

Psychology.

- Wheelock College, Boston, MA, 2001, Master of Science, Teaching Students with Special Needs.

- Atlantic Union College, South Lancaster, MA, 2000, Bachelor of Science, Elementary Education and Psychology.

- Berkeley College, W. Patterson, NJ, 1985, Associate of Science, Fashion Marketing and Management.

ACADEMIC/TEACHING EXPERIENCE

The Berkeley Institute, Pembroke, Bermuda.

Day Release/Exam Coordinator, 9/2007 to present.

Alternative Education Head, Student Services, 11/ 2007 to 9/2007.

The Bermuda College, Paget, Bermuda. Adjunct Lecturer, Liberal Arts Department, 4/2009 to present.

Atlantic Union College, South Lancaster, MA.

Assistant Professor, Center for Academic Success and Education/Psychology Department, 6/2002 to 5/2007.

Director, Freshmen Development Core (FDC), 6/2002 to 5/2007.

Seminar Director, Adult Degree Program (ADP), 1/2005 to 7/2005.

Assistant Seminar Director, Adult Degree Program (ADP), 12/2004 to 1/2005.

Director, Center for Academic Success, 6/2002 to 6/2004.

Wachusett Hills Christian School, Gardner, MA. Multi-grade Teacher, 6/2001 to 6/2002.

Germaine Lawrence School, Arlington, MA. Graduate Intern, 9/2000 to 6/2001.

\section{WORK EXPERIENCE}

Ministry of Education, Sports and Recreation, Hamilton, Bermuda. Acting Human Resources Manager, 6/2007 to 11/ 2007.

\section{PROFESSIONAL SERVICE}

- $\quad$ Presenter, "Planning for Success Workshop" \& "Writing for Success Workshop", Senior Seminar, The Berkeley Institute, Pembroke, Bermuda, 1/2008/2009.

- $\quad$ Presenter, "Children with Special Needs Workshop", Atlantic Union Conference, S. Lancaster, MA, 4/2007; Bermuda Conference, Hamilton, Bermuda, 5/2009.

- $\quad$ Presenter, ADHD Workshop, Ruth Murdock Elementary School, Berrien Springs, MI, 8/2004; Atlantic Union College, Education Department, South Lancaster, MA, 1/2006; The Berkeley Institute, Pembroke, Bermuda; 2/2008; The Bermuda Institute, Southampton, Bermuda, 3/2008.

- $\quad$ Presenter, ADHD Forum, Learning Disabilities Association of Bermuda, Devonshire, Bermuda, 5/2009. 